\title{
The economic and social effects of remittances and return migration in conflict-affected areas : the case of Burundi
}

Citation for published version (APA):

Fransen, S. (2015). The economic and social effects of remittances and return migration in conflictaffected areas : the case of Burundi. [Doctoral Thesis, Maastricht University]. Boekenplan. https://doi.org/10.26481/dis.20150616sf

Document status and date:

Published: 01/01/2015

DOI:

10.26481/dis.20150616sf

Document Version:

Publisher's PDF, also known as Version of record

Please check the document version of this publication:

- A submitted manuscript is the version of the article upon submission and before peer-review. There can be important differences between the submitted version and the official published version of record.

People interested in the research are advised to contact the author for the final version of the publication, or visit the DOI to the publisher's website.

- The final author version and the galley proof are versions of the publication after peer review.

- The final published version features the final layout of the paper including the volume, issue and page numbers.

Link to publication

\footnotetext{
General rights rights.

- You may freely distribute the URL identifying the publication in the public portal. please follow below link for the End User Agreement:

www.umlib.nl/taverne-license

Take down policy

If you believe that this document breaches copyright please contact us at:

repository@maastrichtuniversity.nl

providing details and we will investigate your claim.
}

Copyright and moral rights for the publications made accessible in the public portal are retained by the authors and/or other copyright owners and it is a condition of accessing publications that users recognise and abide by the legal requirements associated with these

- Users may download and print one copy of any publication from the public portal for the purpose of private study or research.

- You may not further distribute the material or use it for any profit-making activity or commercial gain

If the publication is distributed under the terms of Article $25 \mathrm{fa}$ of the Dutch Copyright Act, indicated by the "Taverne" license above, 


\section{THE ECONOMIC AND SOCIAL EFFECTS OF REMITTANCES AND RETURN MIGRATION IN CONFLICT-AFFECTED AREAS:}

THE CASE OF BURUNDI

Sonja Fransen 
(C) 2015, Sonja Fransen

ISBN: 9789086663682

Publisher: Boekenplan, Maastricht www.boekenplan.nl

All rights reserved. No part of this publication may be reproduced, stored in a retrieval system, or transmitted in any form, or by any means, electronic, mechanical, photocopying, recording or otherwise without the prior permission in writing, from the author. 


\title{
The Economic and Social Effects of Remittances and Return Migration in Conflict-Affected Areas: The Case of Burundi
}

\author{
DISSERTATION \\ to obtain the degree of Doctor at Maastricht University, \\ on the authority of the Rector Magnificus, \\ Prof. Dr. L.L.G. Soete \\ in accordance with the decision of the Board of Deans, \\ to be defended in public \\ on Tuesday 16 June, 2015, at 12:00 hours \\ by \\ Sonja Fransen
}




\section{Supervisor:}

Prof. Dr. Valentina Mazzucato

\section{Co-supervisors:}

Prof. Dr. Khalid Koser, Maastricht University/Geneva Centre for Security Policy

Dr. Carlos Vargas-Silva, University of Oxford

\section{Assessment Committee:}

Prof. Dr. R. Skeldon (Chair), Maastricht University/ University of Sussex

Prof. Dr. Hein de Haas, Maastricht University/University of Oxford

Dr. Nicholas van Hear, University of Oxford

Dr. Lidewyde Berckmoes, University of Amsterdam (UvA) 
This study is part of the IS-Academy Migration and Development: A World in Motion project, funded by the Dutch Ministry of Foreign Affairs. The content of this publication is the sole responsibility of the author and it does not represent the views of the Dutch Ministry of Foreign Affairs or its services in any way. 


\section{Acknowledgements}

This research would have not been possible without the trust and cooperation of the people in Burundi, who sometimes sat with us for hours to share their story, invited us in their homes and whose honesty was highly moving. I will never be able to justice to your stories and histories by means of this book, but your words form its foundation. Thank you.

I would like to express my sincerest gratitude to my thesis supervisors Valentina Mazzucato, Khalid Koser and Carlos-Vargas Silva, for their invaluable support and guidance in writing this dissertation. Valentina, your detailed feedback and the in-depth discussions we had during our meetings have helped me to finalize the thesis like I did. Thank you for being a great teacher - I have learned so much from you. Khalid, you always stressed the bigger picture and helped me with the policy relevance of my research. Thank you for your feedback and support. Carlos, thank you for being available on a daily basis. You helped me with all aspects of academic life, ranging from econometrics, to writing skills, to replying to reviewers. Thanks for all your help and I am happy to have the opportunity to continue working with you.

I am also grateful for the feedback of the members of the assessment committee: Ronald Skeldon, Hein de Haas, Nicholas van Hear, and Lidewyde Berckmoes, and the corona members who will be present during the degree ceremony. Your work has inspired me throughout the years and it is has been an honour to receive your comments and questions.

I thank Melissa Siegel and my great colleagues at Maastricht Graduate School of Governance (MGSoG). Dear Melissa, you enthusiasm, devotion and endless energy have been an inspiration for me. Thank you for always being there for us. It has been a true pleasure working with you during the past years. I remember our trip to Burundi as one of the highlights of our cooperation. I am also grateful to all other 'migration' colleagues at MGSoG and I particularly want to thank my office mates - Michaella, Katie, Ozge, Katrin, Marieke, Jenny, Craig, Biljana, Silja, and Ayla - for the continuous inflow of chocolate, the candy from all over the world, the (recently) good coffee, and all our conversations. Having great colleagues is something that has helped me through the good and bad days. Special thanks also go to Elaine, Vivianne and all others colleagues of the migration research group. 
The research for this dissertation was funded by the Dutch Ministry of Foreign Affairs, as part of the IS Academy program. I therefore want to thank the Dutch Ministry of Foreign Affairs for providing this funding and for their collaboration on this research project. Melissa, Katie, Ozge, Silja, Natasja, and Katharina, it has been pleasure working with you on this project. I would like to thank all organizations and institutes that have supported the research activities in Burundi, including Universite Sagesse d'Afrique, ZOA Refugee Care, UNHCR Burundi, IOM Burundi, DevEC, and many others.

I thank Maastricht Graduate School of Governance for giving me the opportunity to work in this inspirational, multicultural institute. Working with colleagues from all over the world has been an invaluable experience. I am grateful for the help and support of all MGSoG staff, including Eveline, Mindel, Susan, Mieke, Herman, Howard, Sueli, Franziska, Janneke, Floortje, and many others. I also want to thank my cohort members (Ilire, Irina, Luciana, Silja, Katie, Ozge, Guney, Manoj, Anthony, Carlos, Kristine) for making the first years of my PhD so very memorable.

My academic interests started in Nijmegen, where I studied Development Studies and later during the Research Master of Social Cultural Sciences. I thank all my fellow master students, and Rik, Anja, Marijn, Kim, Marieke, Michael, Rense, and Thomas de Hoop in particular. I warmly remember our evenings together, the late-nights at Odessa, the picnics in the park (more about this later), and the discussions we had about science and life in general. To this day, we have kept close links and I highly value our friendships, some of which now take place over great distances. I also want to thank Prof. Ruerd Ruben, for motivating me to pursue an academic career and for supporting me during my studies.

Over the past years I was fortunate to travel to different parts of the world to do research. These experiences have shaped my views of the world and have taught me important life lessons. Most of all, these travels have brought me friends. Highlights include the trip to South Africa with Mario and Gabriella, and the research in Ghana with fellow students from Development Studies. Kim and Marieke, our friendship started in Ghana, during our road trips. Amazing times. Another highlight is the research in Butare, Rwanda. Kim, I am so grateful that I spent this time with you. During my trips to Burundi I was fortunate to work with Lisa Andersson and Charlotte Feitscher. Thank you both for your support and 
friendship. Gordien Nahimana, thank you for your endless support for our research in Burundi.

Moving to Maastricht has also been a great adventure. However, the people made it home. I therefore thank my Maastricht partners in crime of the past years: Kim (and Tom), Marieke (and Orcun), Ozge (and Koen), and Karlijn. The time that I spent in Maastricht would not have been the same without you. The friday-afternoon drinks, the late evenings in Tribunal, the after parties, the picnics in the park, the walks at St Pieter, the (often failed) visits to the gym, the coffees and lunches. And let's not forget our Barcelona trip as one of the highlights. However, what happens in Barcelona... I feel so grateful that I spent it all with you. Thank you for your continuous support and friendship throughout the years and in the years to come.

All these adventures would not have been possible without a strong basis of (other) friends and family. First, Lieke, Ratna en Tsambika, you have been my friends since high school. We live in separate places, live separate lives, but our friendship has proven that the road to a friend's house is never long. Dear family, lieve paps, mams, Jasja, Henk, Levi en Niek. Bedankt voor jullie steun en vertrouwen door de jaren heen. Wat ben ik blij dat ik atlijd weer thuis kon komen bij jullie. Finally, Rik and Tomas, my family. Something that started with a picnic at a park has grown into a friendship and love that has given us a precious gift: our little boy. I can't wait to see where life takes us next. You are my home. 


\section{Table of Contents}

Chapter 1: Introduction to this dissertation..................................13

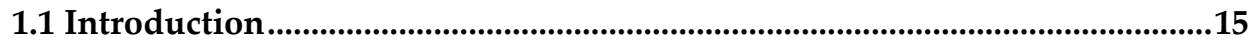

1.2 Research aims and research questions ........................................................19

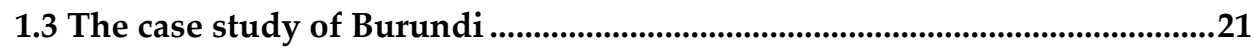

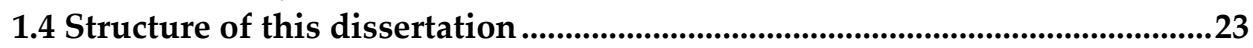

Chapter 2: Remittances, return migration and development in conflict-affected

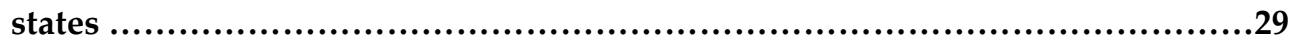

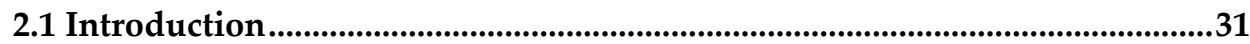

2.2 Remittances and development......................................................................32

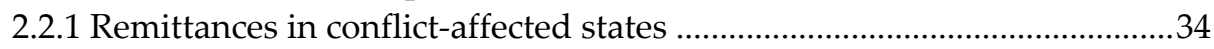

2.3 Return migration and development...........................................................37

2.3.1 Return migration in conflict-affected states ..........................................38

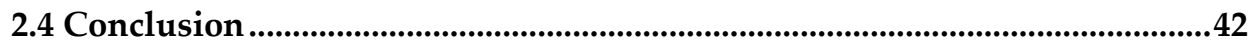

Chapter 3: Burundi: conflict, migration and development........................45

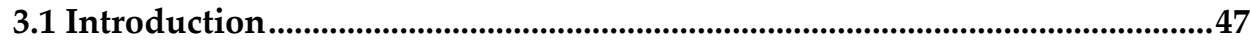

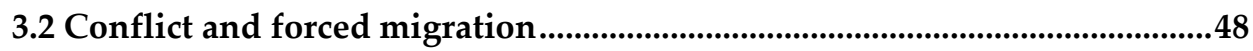

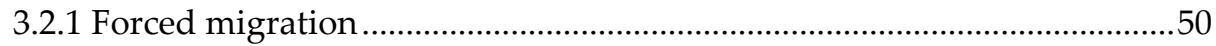

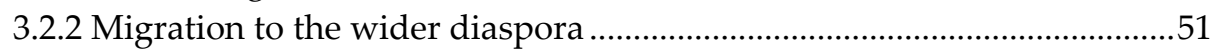

3.3 Migration in the transition from war to peace .............................................52

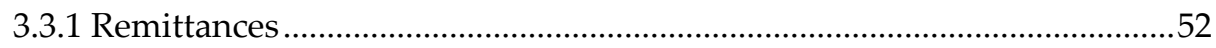

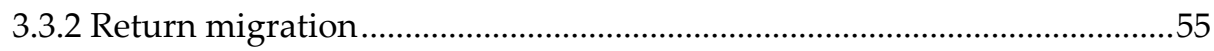

Chapter 4: Data and methods .................................................61

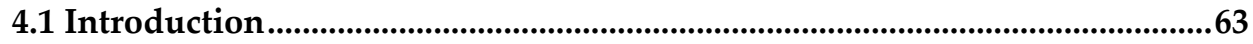

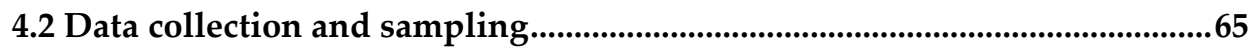

4.2.1 Sampling and main respondents ..........................................................67

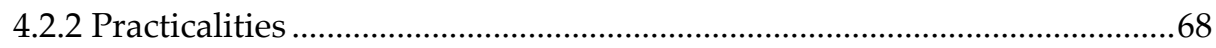

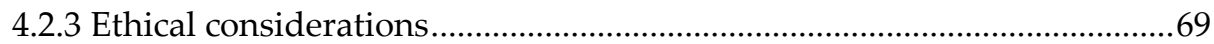

4.3 Remittances and return migration: descriptive statistics .............................70

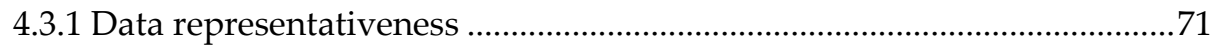

4.4 Challenges of data collection, biases \& sensitivities ......................................72

4.4.1 Challenges during data collection ............................................................72

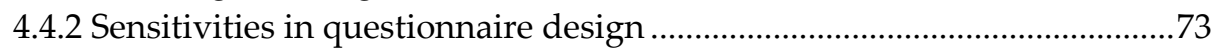

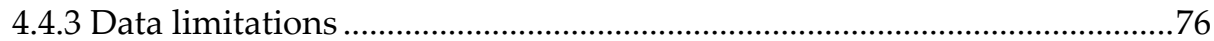

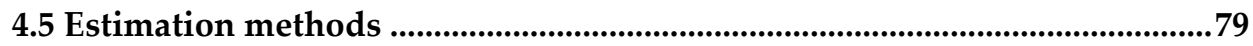




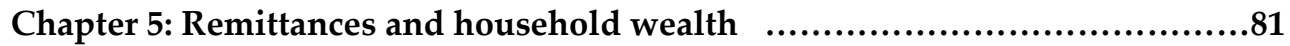

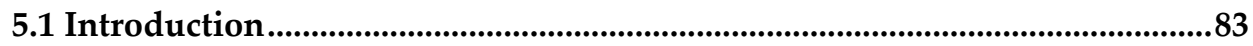

5.2 Theoretical perspectives on remittances after conflict ......................................84

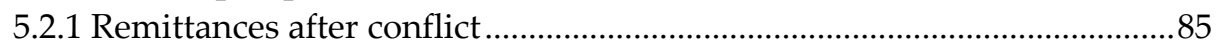

5.3 Burundi: a history of migration and remittances .............................................87

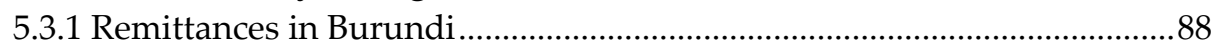

5.4 Data and empirical strategy ...........................................................................90

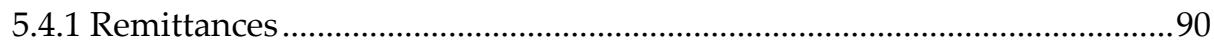

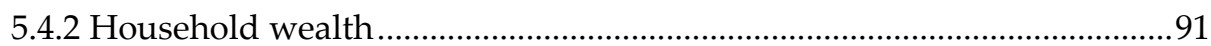

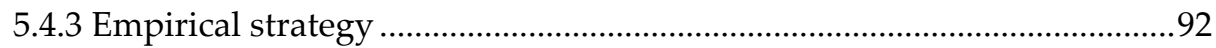

5.5 Results: remittances and household wealth ..................................................94

5.5.1 Remittance flows and channels: descriptive statistics ...............................94

5.5.2 Do remittances reach the poorest of the poor?............................................96

5.5.3 Remittances and household wealth - investment versus insurance........99

5.6 Discussion and conclusion ......................................................................106

Chapter 6: Remittances, bonds and bridges: investing remittances in social

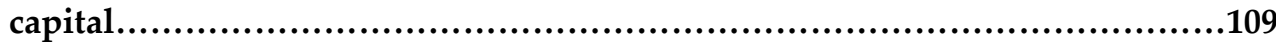

6.1 Introduction .....................................................................................................111

6.2 Theoretical perspectives on social capital and remittances............................113

6.2.1 Social capital and development ..........................................................113

6.2.2 Social capital and remittances ................................................................113

6.2.3 Social capital as a multifaceted concept .................................................116

6.3 Conflict, migration and social ties in Burundi.................................................117

6.4 Data and empirical approach ............................................................................119

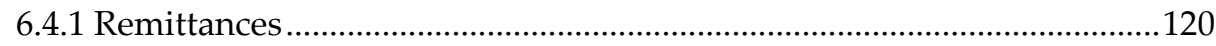

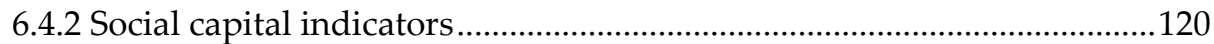

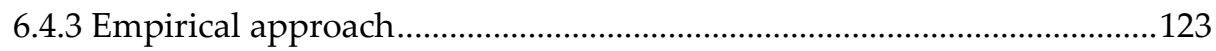

6.5 Results: remittances and social capital in urban Burundi ............................125

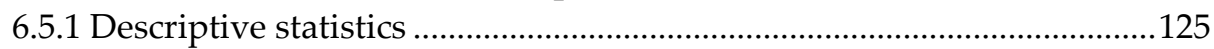

6.5.2 Remittances and social capital: addressing selection effects...................127

6.6 Discussion and conclusion ..............................................................................131

Chapter 7: The socio-economic sustainability of refugee return ..................135

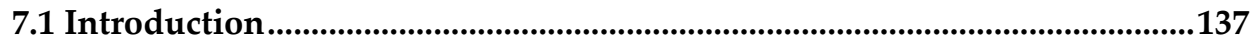

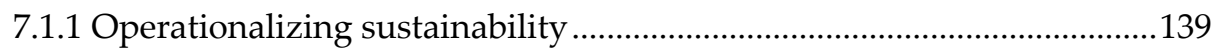

7.2 Burundi: a decade of refugee return ..................................................................141

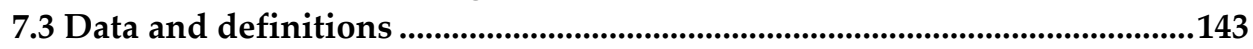

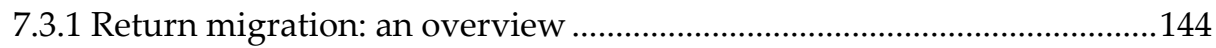

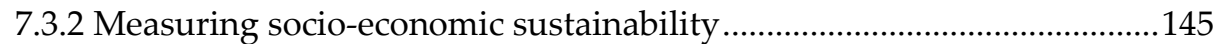

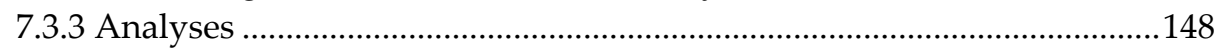

7.4 Results: The socio-economic sustainability of return in Burundi...............149 
7.4.1 Descriptive statistics: comparing households and communities 149

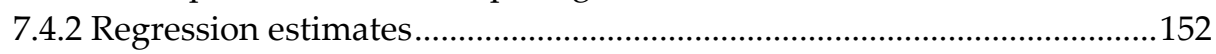

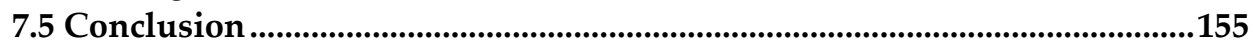

Chapter 8: A return-related crisis? Refugee return and low-intensity conflict ..159

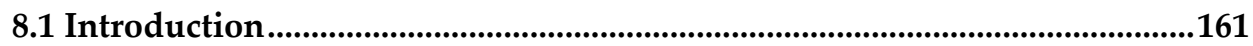

8.2 Migration, land scarcity and conflict ...........................................................163

8.3 Conflict and refugee return in Burundi ..................................................165

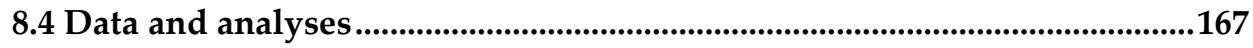

8.4.1 Measuring land disputes, thefts and security ........................................169

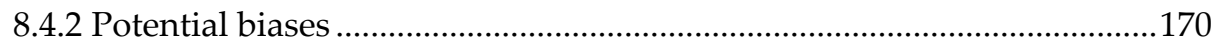

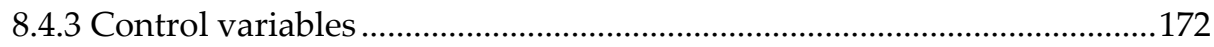

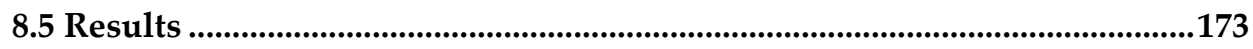

8.5.1 Return migration, land disputes and security .........................................173

8.5.2 Return migration and households' theft experiences .............................176

8.5.3 Return cohorts and time spent abroad .................................................. 178

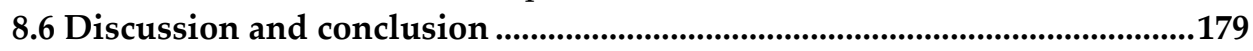

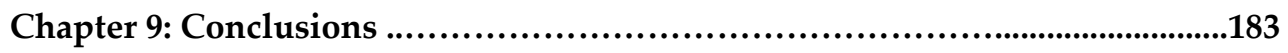

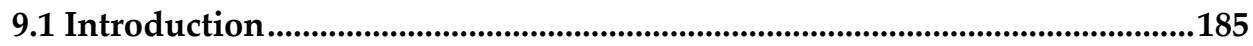

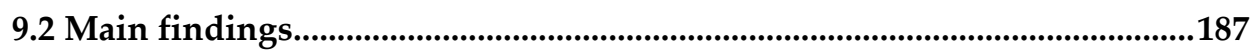

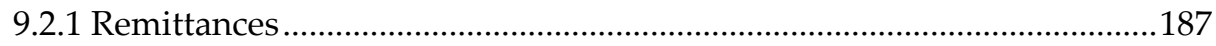

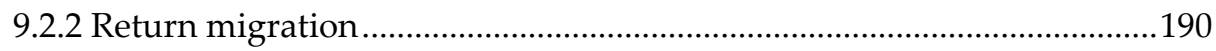

9.3 Implications and directions for future research ...........................................193

9.3.1 Are remittances essential for development in conflict-affected states?.193

9.3.2 Do remittances help to restore social relations in remittance-receiving

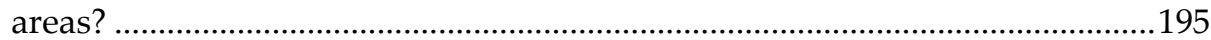

9.3.3 Does return migration lead to development in conflict-affected states?197

9.3.4 Is large-scale refugee return a threat to sustainable peace? .....................199

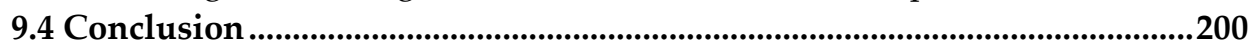

References..................................................................203

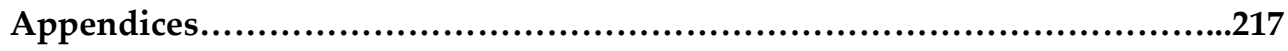



Chapter 1: Introduction to this dissertation 



\subsection{Introduction}

One in four people in the world-more than 1.5 billion people-lived in fragile and conflict-affected states (FCSs) in 2011 (World Bank, 2011a). ${ }^{1}$ This number has likely grown due to recent crises in countries such as Syria and Iraq. Most of these conflict-affected states are among the poorest in the world. People who reside in conflict-affected states are more likely to live in extreme poverty and receive less education and healthcare than people who reside in countries that are not affected by conflict. Many FCSs experience recurrent cycles of conflict and lag behind in their development. Despite these challenges, official development aid (ODA) to conflict-affected states has steadily decreased over the past few years (OECD, 2014). In addition, foreign direct investment (FDI) remains low, especially in lowincome, conflict-affected states, and is, like ODA, a volatile capital flow. For example, since the start of the economic crisis, FDI to conflict-affected states has dropped considerably.

In light of these challenges, hope lies in other forms of resource mobilization for the development of conflict-affected states. One of these forms of resource mobilization involves tapping into the positive effects of migration. Conflict-affected countries often have large diasporas that are scattered across the globe. In 2013, more than 51 million people were forcibly displaced worldwide, which was the highest spike since WWII (UNHCR, 2014a). Although most diaspora members are refugees, diasporas from conflict-affected states are highly heterogeneous, consisting of people who have migrated at different times and for different reasons and who have different intentions to stay in their host country. Diaspora members can contribute to their home countries by sending remittances, setting up community projects or sharing the skills that they have learned abroad through, for example, (temporary) return programs (Amassari \& Black, 2001). This interest in migration as a contributor to development in conflict-affected states has been inspired by a general trend concerning the positive effects of migration on development (see, e.g., Skeldon, 2008, for an overview).

The view that migration could contribute positively to development in migrant-sending countries has spurred a significant increase in academic studies

\footnotetext{
${ }^{1}$ Fragile and conflict-affected states are defined by the World Bank (2011a) as countries with '(1) homicide rates greater than 10 per 100,000 population per year; (2) major civil conflict (battle deaths greater than 1,000 per year (as defined in the from 2006 to 2009), (3) UN or regionally mandated peacebuilding or peacekeeping missions; and (4) low-income countries with institutional levels in 2006-09, correlated with high risks of violence and conflict'.
} 
that investigate migration's potential contributions to development. In the academic literature, remittances and return migration have surfaced as being among the most important migration-related phenomena that may contribute to development in migrant-sending countries (Nyberg-Sørensen, Van Hear, \& Engberg-Pedersen, 2002). Remittances, the money or goods that migrants send to family members or friends living abroad, have increased significantly over the past few decades. Developing countries received more than 404 billion US dollars in remittances in 2013, which was almost 70 per cent of global remittances and three times greater than the value of Official Development Aid (ODA) (World Bank, 2014). Given these statistics, it is not surprising that remittances are seen as important contributors to development in receiving countries.

More recently, return migration has been acknowledged as an interesting policy 'tool' to stimulate development in home countries. Return migrants, who learned new skills and generated funds abroad, would contribute to the development of their home countries by transferring these skills, bringing money home upon return or starting up businesses in their country of origin. The expectation that return migration would contribute to development inspired host country governments to invest in policies that would stimulate or facilitate return, often as part of their development policies (see, e.g., ECDPM \& ICMPD, 2013). Migrant-sending countries have also increasingly recognized the potential of their citizens residing abroad and have, depending on their institutional capacity, implemented policies to engage them in the development of their home countries (see, e.g., Newland \& Patrick, 2004).

In the emerging academic and policy literature on migration and development in conflict-affected states, migration is also generally regarded as a positive force for development. Migration may contribute positively to economic development and thereby reconstruction and peace building in conflict-affected states. The Task Force on Remittance Flows to Post-Conflict States (2013) stated, for example, that remittances 'are of central importance for restoring stability and enhancing human security in post-conflict countries' (p. 1). Remittances to fragile states grew from approximately 25 billion in 2000 to almost 80 billion US dollars in 2011, which accounted for 56 per cent of all financial inflows to fragile states 
(OECD, 2014). ${ }^{2}$ This remittance total was nearly double the share of ODA and almost four times the share of FDI. In middle-income fragile sates, remittances have now overtaken ODA and FDI as the largest capital inflow (ibid.). Lowerincome fragile states are still more dependent on aid; remittances in these states accounted for 42 per cent of the financial inflow in 2011, while ODA accounted for 45 per cent.

However, remittances in lower-income fragile states may be larger than formal statistics indicate. An estimated 35 to 75 per cent of remittances worldwide are sent through informal channels (Freund \& Spatafore, 2005), which are not represented in official statistics. Information on remittances in fragile states is limited, but it is likely that a large share passes through informal channels (Task Force on Remittance Flows to Post-Conflict States, 2013). Remittance senders are incentivized to use informal channels to transfer funds because formal financial infrastructures are often damaged during conflict (Freund \& Spatafore, 2005; Weiss Fagen \& Bump, 2006). In addition, remittances in lower-income fragile states may be more stable resources than ODA or FDI, which are more volatile (OECD, 2014).

Similarly, return migration has been described as a potential important source for development in origin countries, as returning refugees and other former migrants may bring with them the skills, assets and money, and social capital that they have acquired abroad (Nyberg-Sørensen et al., 2002). Return migration flows generally present one of the largest migration flows in conflict-affected countries. During periods of relative stability, conflict-affected countries frequently experience large population inflows when former refugees return home. For example, more than 5.7 million Afghans, a quarter of Afghanistan's population, have returned to Afghanistan since 2002 (UNHCR, 2014b). Likewise, Bosnia welcomed 1 million returnees after the 1992-1995 war, and more than 700,000 former refugees returned to Rwanda after the 1994 genocide. The return of former refugees to conflict-affected contexts is often associated with a positive change towards 'normality, peace and stability' (Chimni, 2002, p. 163). Return migration represents a transition from a conflict state to a post-conflict state, after which the reconstruction and development phase begins. The successful return of populations residing abroad also legitimizes post-conflict states and enhances

\footnotetext{
${ }^{2}$ OECD defines fragile states as 'Those failing to provide basic services to poor people because they are unwilling or unable to do so' (OECD, 2006, p. 147). This definition is wider than the definition of fragile and conflict-affected states that the World Bank employs.
} 
donor confidence (Black \& Gent, 2006; Black \& Koser, 1999). It is generally acknowledged that return can have a positive effect on development under certain conditions (Black \& Gent, 2006; Crisp, 2000).

However, research on the effects of migration on development in recent years has mainly focused on the effects of labour migration. This focus is mainly related to data availability; although the availability of data from developing countries has increased considerably over the past few decades, data from conflictaffected countries are still scarce and more likely to be of poor quality. Migration research has therefore yielded limited insights into the effects of remittances and return migration on development in conflict-affected states.

Conflict-affected states differ significantly from other developing country contexts that have not been affected by conflict, which can make us question the extent to which remittances and return migration have the potential to contribute to development in these contexts. First, the causes and characteristics of migration flows are significantly different in conflict-affected contexts. People who migrate due to conflict mainly do so because they seek security. Although studies have shown that refugees frequently support family or friends living back home (Ahmed, 2000; Carling, Erdal, \& Horst, 2012; Horst, 2004, 2008; Lindley, 2009), their motivations for migration violate the assumptions of rational choice that underlie most migration theories and are likely to affect the possibilities for remittance sending (Lindley, 2008). In addition, many refugees reside in neighbouring countries where they often reside in camps or temporary shelters (NybergSørensen et al., 2002). Refugees' living conditions during exile affect the resources that they can send home and the skills that they can acquire while abroad (Van Hear, 2004). Refugees who reside in neighbouring countries often have few employment opportunities and consequently few possibilities to send remittances or to obtain skills that can be brought back upon return.

Second, civil conflict has both direct and indirect effects on the lives of the people affected, which creates a situation of insecurity and instability that often persists long after the conflict has ended (Justino, 2009). These direct and indirect effects most likely affect the extent to which migration can contribute to development. The direct effects of conflict include the death or injury of household members, the recruitment of household members into armed groups, the demolition or looting of assets (e.g., livestock, housing and other valuables), and the forced displacement of household members. Indirect effects include reduced 
access to employment, insurance, legal aid, health or schooling. Moreover, civil conflicts often affect social ties (Colletta \& Cullen, 2000). An erosion of social ties decreases the support that households can rely on in times of need and creates higher vulnerability for those who are excluded from social ties. Households residing in conflict-affected states are thus more likely than households residing in countries that have not been affected by conflict to live in extreme poverty, often face more insecurity and have fewer opportunities to invest or find employment.

The recent decades of migration and development research have shown that migration's impact on development varies significantly across contexts. The extent to which remittances have a positive effect on development depends on characteristics in both migrant-sending and migrant-receiving countries. The context in migrant-receiving countries affects opportunities for remittance sending, whereas the economic, social and political climate in migrant-sending countries affects the development potential of remittances. In underdeveloped areas where economic opportunities are limited, remittances are unlikely to have large positive development potential (De Haas, 2005). Likewise, the impact of return migration on development highly depends on, for example, the size of the return flow, the period in which return takes place, the characteristics of returnees, their living conditions during exile, and the situation they find upon return to their country of origin (Amassari \& Black, 2001). Refugees often return in large numbers to areas that are damaged by the conflict and may encounter limited opportunities to reestablish their livelihoods (Chimni, 2002; Macrae, 1999). In these instances, return may be seen as a security threat instead of as a boost to development (Crisp, 2000).

Given the specific challenges that conflict-affected countries face, it is unclear whether the expectations that migration will play a role in the development of conflict-affected states, particularly lower-income states, are realistic. The extent to which migration may contribute to development in conflictaffected states has not been researched in detail and therefore warrants further research attention.

\subsection{Research aims and research questions}

This dissertation aims to contribute to the literature on migration and development in three ways. First, this dissertation aims to provide insights into the lives of households and communities that are recovering from civil conflict and the role that migration plays in their lives. As described above, data from conflict-affected 
contexts are scarce, and there is little knowledge on migration as a livelihood or the coping strategies of households in these contexts. The data that are used in this dissertation, which are described in detail in Chapter 4, were collected around five years after the official end of conflict in the country studied and therefore offer a unique insight into the role of migration in households residing in a conflictaffected context.

Second, the aim of this dissertation is to apply specific tenets of theoretical approaches that have often been used to study labour migration to a conflictaffected setting. The New Economics of Labour Migration (NELM) (Stark, 1980; Stark \& Bloom, 1985) approach, for example, has been specifically designed to study labour migration and the remittances that originate from it. However, people who are forced to migrate due to conflict primarily do so to seek safety and security, not to diversify their income, which violates the economic incentive assumption of the NELM (Lindley, 2008, 2010). The question remains as to what extent the conflict-affected context leads to different remittance usage when compared with the context in which migration is primarily a means of income diversification, as posited by the NELM literature.

Third, this dissertation aims to study how migration affects both economic and social aspects of a conflict-affected society. In this dissertation, development is therefore treated as a multidimensional concept that incorporates not only economic factors but also social aspects of society. This multidimensionality is especially relevant in a conflict-affected context, in which economic structures have to be rebuilt and social relations are often damaged (Colletta \& Cullen, 2000). Because of the importance of social relations for development (see, e.g., Woolcock \& Narayan, 2000, for an overview), this dissertation draws from economic approaches to the study of migration, such as NELM (Stark, 1980; Stark \& Bloom, 1985), and combines these with concepts, such as social capital (Bourdieu, 1986; Coleman, 1988; Putnam, 2002) and social cohesion (see, e.g., Jenson, 2010, for a historical overview of the concept of social cohesion). The concepts of social capital, social cohesion and civil conflict are closely related (Colletta \& Cullen, 2000). Strong social capital is seen as a prerequisite for a cohesive society, together with the absence of latent conflict 'whether in the form of income/wealth inequality; racial/ethnic tensions; disparities in political participation; or other forms of polarization' (Berkman \& Kawachi, 2000, p. 175). In turn, cohesive societies are less likely to be affected by conflict because a high level of social 
cohesion can serve as a buffer to violence (Colletta \& Cullen, 2000). In this dissertation, social capital is operationalized as a household-level resource, following Bourdieu (1986), whereas social cohesion is measured at the community level by focusing on the presence of thefts, disputes and security. Using this multidimensional view on development, this dissertation aims to provide a more holistic view on the concept of development and how it is affected by migration.

The central research question of this dissertation is: What are the economic and social effects of remittances and return migration on households and communities in a conflict-affected context? This research question is split into the following subquestions that are addressed in the four empirical papers that form the body of this dissertation (see Section 1.4, Structure of this dissertation, for more details). The first two sub-questions focus on remittances, and sub-questions 3 and 4 address the effects of return migration.

1. What are the economic effects of international monetary remittances on remittance-receiving households?

2. How do international monetary remittances affect the social capital of remittance-receiving households?

3. What is the economic impact of return migration on households and communities in a conflict-affected context?

4. What is the impact of return migration on security in return communities?

\subsection{The case study of Burundi}

The country case study for this dissertation is Burundi, a small, conflict-affected country in the African Great Lakes region. Burundi has experienced various episodes of civil conflict since it gained independence in 1962. These conflicts generated massive migration flows and left their marks on both economic and social aspects of Burundi society. Nearly all households were affected, either directly or indirectly, by the war, which, combined with increasing poverty levels, deeply divided community members.

Migration has played a large role in Burundi's transition from war to peace, which started in the early 2000s. The wider Burundi diaspora, located mainly in North America and Europe, which played an oppositional political role during the conflict period, became increasingly invested in development activities (Turner \& Bronden, 2011). Remittances, which are mainly sent by the wider diaspora, grew substantially after the war. Hundreds of thousands of internally 
displaced people (IDPs) and refugees also returned home, some on their own, and others with the help of international organizations, NGOs and the governments of Burundi and/or their host countries. Whereas remittances are considered beneficial for Burundi's development, return migration has been a topic of concern for Burundi's policymakers. Due to the size of the return flow, the time that former refugees spent in exile, and the unstable economic and political conditions in Burundi, return is feared to increase competition for the country's scarce resources, thereby re-instigating social tensions.

This situation is not unique to Burundi. As described above, many conflictaffected countries experience large return migrations during periods of relative stability and receive vast amounts of remittances that are considered beneficial to reconstruction and economic development. In that sense, Burundi provides an interesting case study to draw lessons from for other low-income, conflict-affected states that have experienced large refugee flows and are attempting to draw from their diaspora to stimulate development. At the same time, Burundi is a unique case because it is one of the poorest countries in the world and struggles with increasing population density and the scarcity of agricultural land. Burundi is also one of the least urbanized countries in the world-more than 90 per cent of its population relies on agriculture. The country offers very limited economic opportunities and struggles with low institutional capacity. This dissertation explores how remittances and return migration have affected Burundian households and communities that are recovering from decades of civil conflict in a context that is characterized by poverty, large inequalities, and, yet again, growing insecurity in the lead up to the 2015 elections.

The empirical chapters in this dissertation rely on nationally representative household and community survey data that were collected in Burundi for the IS Academy Migration and Development: A World in Motion project. The Migration and Development project, funded by the Dutch Ministry of Foreign Affairs under the heading of the IS Academy, was a five-year research project that studied the consequences of migration for four migrant-sending countries (Afghanistan, Burundi, Ethiopia and Morocco) and one migrant-receiving country (the Netherlands). The objective of the project was to provide empirical evidence on the linkages between migration and development to guide policymaking in the area of development cooperation. Burundi was chosen as a country of interest because of its position on the list of countries that receive development aid from the 
Netherlands and because little research had been conducted on migration and/or development in Burundi. Data were collected in Burundi in 2011, a little over five years after the official end of conflict there, and therefore offer a unique perspective into the livelihoods of Burundian households and communities and the impacts that migration has on these livelihoods. The research for this dissertation was conducted independently from the views or interests of the Dutch Ministry of Foreign Affairs. The views in this dissertation therefore represent the author's views only.

\subsection{Structure of this dissertation}

The rest of this thesis is organized as follows. Chapter 2 gives an overview of the research that has been conducted on the linkages between migration and development, and the theoretical views that underlie the research in this area. The chapter then addresses the relationship between migration and development in conflict-affected states and discusses the extent to which current theoretical views apply to conflict-affected states. This chapter also discusses the extent to which migration's effects on development may differ in conflict-affected countries.

Chapter 3 and Chapter 4 are background chapters that introduce the country case study of Burundi and the data that were used for this dissertation, respectively. Chapter 3 briefly discusses Burundi's history of conflict, the consequences of conflict for development, and the forced migrations that resulted from conflict. This chapter then focuses on the two migration-related phenomena that are central to this dissertation: remittances and return migration. Chapter 3 will show how remittances are seen as potential contributors to development in Burundi, while return migration is mostly seen as a threat to its fragile peace in the literature. Chapter 4 introduces the data that are used in this dissertation, as well as their limitations. It also shortly describes the methods that were used to analyse the data in the following chapters.

Chapter 5 to Chapter 8 comprise four (published or submitted) academic articles that investigate the linkages between migration and development in Burundi. Chapter 5 and Chapter 6 examine the effects of remittances on urban households, while Chapter 7 and Chapter 8 focus on the relationship between refugee return and development in rural areas. One of the remittance-related findings was that remittances are largely absent in Burundi's rural areas. The analyses in Chapter 5 and 6 are therefore based on urban survey data, while the 
analyses in Chapter 7 and 8 are based on national survey data. The differences between these two datasets will be described in detail in Chapter 4.

Each of the empirical chapters can be read independently. The status of each article (published, submitted, or revised and re-submitted) will be clearly indicated at the beginning of each chapter. Because Chapter 5 to Chapter 8 are stand-alone papers, there is some overlap between the chapters, especially in the sections that describe the country case study of Burundi (Section 5.3, Section 6.3, Section 7.2, and Section 8.3). Readers that have read Chapter 3 (Burundi: Conflict, migration and development) can skip these sections. The references that were used for the empirical chapters are presented at the end of the dissertation to ease the reading process.

Chapter 5, 'Remittances and household wealth after conflict', is a study of the effects of international monetary remittances on the wealth of receiving households in Bujumbura, Burundi's capital. This chapter analyses the extent to which relatively poorer and wealthier households rely on international remittances and the way that households allocate these funds. A distinction is made between investments in productive versus non-productive assets to investigate whether remittances are used for long-term investments or short-term income smoothing. This multidimensional view on the effects of remittances on household wealth offers a broad perspective into the role of remittances for conflict-affected households. This chapter also applies NELM theory to a conflict-affected context. Three NELM-derived hypotheses were tested to explore how remittances are used in a conflict-affected setting and to determine whether the results differ from those in other development contexts. The findings in Chapter 5 show that remittances mostly reach wealthier and higher-educated households in Bujumbura. These findings reject one of the NELM-derived hypotheses, which anticipates that rural households, being the most deprived, will be more likely to migrate and therefore receive remittances. Households primarily used remittances to enhance living conditions and establish food security, which verifies the expectation that remittances are mostly used to sustain households, especially poorer households, after conflict. The finding that remittances reach relatively better-off households matches findings from development contexts, but the finding that remittances are not invested in assets and education contradicts studies from development contexts that were not affected by conflict, where remittances were often found to be invested in schooling and assets, such as housing and agricultural land. 
Chapter 6, entitled 'Remittances, bonds and bridges', examines the social capital investments of remittance-receiving households. This paper hypothesizes that remittance-receiving households invest remittances in their social capital for insurance purposes. In unstable settings, such as those affected by conflict, other investment opportunities may be limited due to economic and political instability. By investing in social capital, remittance-receiving households create a financial safety net for difficult times. To test this hypothesis, the social capital investments of remittance-receiving and non-remittance-receiving households are compared to explore how remittances affect the structural, both bonding and bridging, social capital (networks) of remittance-receiving households. This paper extends the NELM investment assumption beyond investments that concern economic or human capital and focuses on the social capital investments of remittancereceiving households. The expectation that remittances are invested in networks for insurance purposes could only partly be confirmed. The results demonstrate that remittance-receiving households invest more in bridging social capital by participating in organizations (donating time), but these households make fewer monetary contributions compared with non-receiving households. Remittances have mixed effects on bonding social capital: compared with non-receiving households, receiving households give significantly fewer gifts to family members and friends, but they are more likely to send internal remittances. Overall, these findings seem to suggest that remittance-related financial investments have mainly strengthened the bonding social capital of remittance-receiving households, particularly family networks.

Chapter 7, 'The socio-economic sustainability of refugee return', explores the sustainability of return in Burundi using a wider view that compares return households to non-return households and focuses on the effects of return on entire communities. Socio-economic sustainability is operationalized as a multidimensional concept, including indicators such as land ownership, living conditions and subjective wealth. By exploring the relationship between refugee return and the socio-economic conditions of both households and communities, this study aims to provide a nationwide, in-depth understanding of the sustainability of refugee return in Burundi. This paper also makes a distinction between first- and second-generation returnees - the children of former refugees who were born abroad-to explore whether there are key differences in the sustainability of return in relation to both groups. This chapter shows that from a 
household perspective and from a community perspective, the sustainability of return in Burundi is questionable. Although most returnees have been successfully repatriated in their home country, many live in poor socio-economic conditions and are worse off than households that did not experience forced international migration. Non-return households were also affected by return migration to their communities. Food insecurity was higher in communities with more firstgeneration returnees, and in communities with more second-generation returnees, all households (return and non-return) reported lower living conditions, lower subjective wealth and experienced more negative changes in wealth in recent years. These findings provide support for studying sustainability from a wider view that incorporates both household and community perspectives, together with a multidimensional approach that includes multiple indicators.

Chapter 8 builds on Chapter 7 and investigates how return migration and the accompanying challenges have affected the number of thefts and disputes and security levels in rural communities. This research is based on the presumption that refugee return in large numbers may lower social cohesion and pose a threat to peace in conflict-affected societies. As described in Section 1.2, the presence of disputes and insecurity is considered an indication of weak social cohesion (Berkman \& Kawachi, 2000), which, in turn, is a conflict hazard (Colletta \& Cullen, 2000). To study the relationship between return migration, thefts, disputes, and security, this chapter draws from neo-Malthusian views that a rapid population increase will lead to a scarcity of renewable natural resources, such as agricultural land and natural water sources, which, in turn, may instigate violence (HomerDixon, 2010). Various studies have been conducted on the linkages between population pressure, land scarcity and conflict, but few have addressed population increases as a result of large-scale migration. This chapter tests the neo-Malthusian hypothesis in the context of refugee return in Burundi and studies the effects of return migration across communities that have received different numbers of returnees. This study focuses on land disputes, thefts and overall security levels in areas of return, as these variables have been identified as underlying factors in Burundi's past conflicts and are therefore considered risk factors for future conflict. The findings show that communities with more returnees did not experience more violence or less security than did communities with fewer returnees. Likewise, households in communities with more returnees did not experience more thefts or destruction of agricultural tools and livestock. Instead, structural factors, such as 
the availability of employment and the presence of infrastructure, were found to be significantly related to violence and security. These findings suggest that the direct effects of return migration on land scarcity and insecurity in Burundi are overestimated and that structural problems play a more important role in determining sustainable peace in Burundi.

The dissertation ends with the conclusions in Chapter 9. This chapter summarizes the research findings and links these back to the theory and research questions that were described in Chapter 1 and Chapter 2. This chapter also discusses this dissertation's limitations and provides suggestions for future research in the area of migration and development. 

Chapter 2: Remittances, return migration and development in conflict-affected states 



\subsection{Introduction}

As described in the introduction of this dissertation (Chapter 1), the majority of studies that have addressed the linkages between migration and development have focused on labour migration. The theoretical approaches that have been formulated to investigate migration and its consequences for development have also focused on labour migration. However, migration is considered to be an important contributor to development in conflict-affected states. This dissertation suggests that the impact of migration on development may differ in conflictaffected states, because a) the causes and characteristics of forced migration flows that originate from conflict-affected contexts differ from the causes and characteristics of forced migration flows in contexts that were not affected by conflict and b) the direct and indirect effects of conflict on development create a situation of instability and insecurity that may alter the effect of migration on development. The following questions are addressed: Are the theories discussed in the migration and development literature applicable to conflict-affected contexts? And, to what extent are the expectations that migration contributes to development transferrable to a conflict-affected context and how do the specific characteristics of conflict-affected contexts affect the impact of migration on development?

This chapter provides an overview of the linkages between migration and development and the theoretical perspectives that have guided research in this area for decades. As described in the introduction of this dissertation (Chapter 1), two thematic areas comprise the focus of this chapter: remittances and return migration. These thematic areas were selected due to their prominence in the migration and development literature as important channels via which migration may affect development in the regions of origin (Nyberg-Sørensen et al., 2002) and their relevance to the country case study of Burundi (see Chapter 3).

State of the art knowledge regarding the linkages between remittances and development will be discussed in Section 2.2. Section 2.2.1 discusses the relationship between remittances and development in conflict-affected contexts. Section 2.3 provides an overview of the literature on return migration and development, and Section 2.3.1 focuses on the relationship between return migration and development in conflict-affected states. Section 2.4 describes the theoretical contributions of this dissertation, based on previous studies. 


\subsection{Remittances and development}

Remittances served a minor role in the early migration theories, such as the push and pull models, neo-classical migration theories and historical-structural approaches to the study of migration (see, e.g., Castles, De Haas, \& Miller, 2013, for an overview). These theories primarily focused on the causes and drivers of migration (Taylor, 1999). The New Economics of Labour Migration (NELM) approach (Stark, 1980; Stark \& Bloom, 1985) that was developed in the 1980s placed particular emphasis on remittances. NELM considers migration as a household-level strategy to minimize risks by generating income via remittances. The expectation of receiving remittances is an integral aspect and driver of migration: households attempt to diversify their income and thereby reduce risks or improve their economic position via migration. With the introduction of the NELM approach, the focus also shifted from the individual migrant to households as principal actors in decision-making regarding migration.

According to the NELM approach, households can use migration to insure themselves against financial risks, such as food insecurity, failing crops, or unemployment. Remittances can smooth consumption for receiving households (Lucas \& Stark, 1985). Remittances can reduce also household liquidity constraints, enable households to invest in income-generating activities, such as businesses or agriculture, and stimulate economic development in remittance-receiving areas (Taylor, 1999). The majority of micro-level studies on remittances were based on the NELM approach.

The assumptions of the NELM approach yield three hypotheses regarding migration motivations: (1) the relative deprivation hypothesis, (2) the investment hypothesis, and (3) the insurance hypothesis. The relative deprivation hypothesis posits that households attempt to improve their economic position in their community or country via migration. Households that are relatively deprived are more likely to use migration as a household strategy (Stark \& Taylor, 1989). The investment hypothesis posits that remittances are invested in income-generating activities, such as businesses and agriculture. Remittances can stimulate development in poor countries by relaxing the liquidity constraints of households in failing markets (Taylor, 1999). The insurance or smoothing hypothesis states that households use migration to insure themselves against financial risks, such as food insecurity, failing crops, or unemployment. Remittances can smooth consumption 
by providing a form of insurance during difficult times (see, e.g., Lucas \& Stark, 1985).

Previous studies on remittances have demonstrated varying levels of support for these hypotheses. With regard to the relative deprivation hypothesis, research has shown that remittances are generally not received by people who 'need' them the most or people who are most deprived in the context of developing countries (Ratha et al., 2011). This result is due to the 'selection effect' of migration; because costs are associated with migration, wealthier households generally have more means to send someone abroad and are consequently more likely to receive remittances (Adams Jr, 2011). In Ghana, for example, international remittances were received by the richest two per cent of households (Mazzucato, Van Den Boom, \& Nsowah-Nuamah, 2008). However, another study indicated that poorer households received a greater benefit from international remittances than richer households (Adams Jr, Cuecuecha, \& Page, 2008). In Pakistan, households with more income were also more likely to receive remittances (Adams Jr, 1998). Whether the higher income of remittance-receiving households was due to remittances was not clear.

Although the literature has shown that remittances are frequently used for daily needs, the investment hypothesis has been supported by meta-analyses that showed that remittances spur development and reduce poverty in developing countries (Adams Jr, 2011; Page \& Plaza, 2006; Ratha et al., 2011). Remittances are frequently invested in human capital and physical capital, such as large assets (land or housing), businesses, or agricultural investments. Other studies have highlighted the insurance or consumption smoothing function of remittances by showing that remittances are sent for, or invested in, daily needs (Kabki, Mazzucato, \& Appiah, 2004; Mazzucato, 2009).

The investment and insurance hypothesis are not mutually exclusive. Remittances can be sent, or employed, for both investment and insurance. The literature review reveals that remittances are employed for both investment and insurance in most contexts. The development effect of remittances also seems to vary across time and place. The economic, social and political climate in migrantsending countries affects the development potential of remittances. In underdeveloped areas with limited economic opportunities, remittances are unlikely to have a large positive development potential (De Haas, 2005). 


\subsubsection{Remittances in conflict-affected states}

The extent to which theoretical perspectives on remittances are applicable to conflict-affected contexts remains ambiguous. As its name implies, the NELM approach was designed to explain labour migration and the remittances that originate from migration. It assumes that migration is a household strategy to generate income through remittances. However, people forced to migrate due to conflict primarily do so to seek safety and security; they do not migrate to diversify income, which violates the economic incentive assumption of the NELM approach (Lindley, 2008, 2010). Numerous studies have shown that refugees frequently support family or friends living back home (Ahmed, 2000; Carling, Erdal, \& Horst, 2012; Horst, 2004, 2008; Lindley, 2009). Some authors have argued that motivations to remit do not substantially differ between refugees and economic migrants (see, e.g., Horst, 2004). However, to what extent does the conflict-affected context cause different remittance usage compared with the case in which migration is primarily a means of income diversification, as posited by the NELM literature? What is the effect of remittances on development in a conflict-affected context where economic opportunities are limited?

As previously described, the majority of refugees move within the borders of their own country or to neighbouring countries where they have few resources to remit (Nyberg-Sørensen et al., 2002). Only some people have the means to travel a considerable distance to generate income that is sufficient to engage in remittance sending (Van Hear, 2004). This situation is also valid for labour migrants from conflict-affected contexts (Ahmed, 2000). Thus, remittances are most likely only received by a few households in conflict-affected settings. These households are most likely not the most disadvantaged households as the most disadvantaged households generally have fewer resources to send an individual abroad. The relative deprivation hypothesis of NELM is therefore not likely to be valid for a conflict-affected setting.

With respect to remittance usage, the limited available evidence suggests that remittances are more likely to 'sustain' livelihoods after conflict through income smoothing rather than 'transform' them through investments (Van Hear, 2002). Conflict-affected settings frequently offer limited investment possibilities due to political and economic instability, which may affect remittance allocation and the development effect of remittances. Qualitative studies have shown that refugees frequently remit to support daily needs instead of business investments 
(Van Hear, 2002; Weiss Fagen \& Bump, 2006). For example, Ahmed (2000) discovered that 15 per cent of households in Somaliland used remittances for business or asset investments. Especially in rural areas, remittances were used to smooth consumption and cope with shocks. Similarly, Horst and Van Hear (Horst \& Van Hear, 2002) describe how Somali refugees in Kenyan refugee camps smooth consumption by relying on remittances during difficult times. This evidence provides support for the insurance hypothesis instead of the investment hypothesis of the NELM approach in conflict-affected settings.

Van Hear has argued that households may also allocate (part of) their remittances to their social capital instead of to more tangible investments, such as education or business investments, in unstable settings where investment opportunities are limited (Van Hear, 2002, 2004). Social capital is commonly defined as 'features of social organization such as networks, norms, and social trust that facilitate coordination and cooperation for mutual benefit' (Putnam, 1995, p. 67). Social capital is a concept that was introduced by Bourdieu (1986) and subsequently elaborated by Coleman (1988) and Putnam (Putnam, 1995, 2000, 2002). From an economic point of view, social capital is an asset that can be addressed in times of financial difficulties (Woolcock \& Narayan, 2000). In the absence of formal insurance mechanisms, such as provided by the state, households frequently rely on informal networks and social relations for support. These networks are used to share risks and function as reciprocal insurance mechanisms during times of hardship (see, e.g., Fafchamps, 2006; Fafchamps \& Lund, 2003).

Social capital enhances the well-being of households by informationsharing among group members, cost reduction for shared initiatives, the possibility and efficiency of collective action, and by reducing deviant behaviours that are not in the interest of the group (Grootaert \& Van Bastelaer, 2002). Research has shown that households with more social capital have better socio-economic states than households with less social capital (see, e.g., Grootaert, 1999; Grootaert, Oh, \& Swamy, 2002; Narayan \& Pritchett, 1999). Based on a study in Indonesia, Grootaert (1999) noted that social capital in the form of organization membership positively affected the expenditures, savings, and assets ownership of households and their access to credit. Similarly, Narayan and Pritchett (1999) discovered that social capital at the village level positively affected household incomes of the village members in rural Tanzania. Especially for poorer households in unstable 
environments, which offer minimal institutional protection, social capital investments are an insurance strategy that reduces vulnerability to shocks (Woolcock \& Narayan, 2000).

Some studies addressed the social capital investments of remittancereceiving households by examining the church donations (James, 1997; Kabki et al., 2004), funeral participation (Kabki et al., 2004; Mazzucato, Kabki, \& Smith, 2006), or gift-giving practices (Gerber \& Torosyan, 2010) of remittance-receiving households in non-conflict affected contexts. These studies provided insights on the effect of remittances on social relations in remittance-receiving areas by showing that remittances were invested in social capital or social capital-enhancing activities. The majority of studies, however, were small-scale studies that employed single indicators of social capital.

A study conducted in Rwanda, however, has examined the previously observed and positive relationship between remittances and social capital. Caarls, Fransen and Ruben (2013) adopted a multidimensional perspective on social capital and explored the effect of migratory contacts and remittances on behaviour (memberships of civil society organizations) and attitudes (feelings of reconciliation) in Southern Rwanda. The authors revealed that migratory contacts enhanced cooperative behaviour and reconciliation, whereas remittance receivers participated less in community organizations and reported lower levels of reconciliation than non-receivers. The authors argued that remittances enabled individuals to become more financially independent and 'crowded out' their incentives to participate in social activities, especially those social activities that crossed social divides. This, in turn, led to reduced feelings of reconciliation. These findings suggested that remittance-receiving households tend to invest less in bridging social capital.

The distinction between 'bonding' and 'bridging' social capital was presented by (Putnam, 2000, 2002). Bonding social capital refers to connections between homogeneous groups or individuals, whereas bridging social capital unites individuals or groups that are dissimilar in terms of background characteristics or beliefs and bridges social divides. Putnam argued that bridging social capital benefits not only the members of these networks but also society as a whole, whereas bonding social capital creates subsets of networks that are isolated and behave according to their own interests, which potentially decreases social cohesion of society as a whole. 
If remittances are invested in social capital in remittance-receiving areas, these investments may have an important effect on social ties in remittancereceiving areas by reinforcing networks and restoring social ties (Van Hear, 2002, 2004). However, if remittance-receiving households withdraw from their social relations and exclusively invest remittances exclusively in in-group social capital, as Caarls et al. (2013) suggested, remittances may intensify social divides instead of contribute to social development. The extent to which remittance-receiving households invest in different facets of their social capital has yet to be examined in depth, leaving room for further exploration of the complex relationship between remittances and social capital.

\subsection{Return migration and development}

Neoclassical migration theories and the NELM approach shed light on the motivations for return. Neoclassical migration theory attributes migration to wage or income differences among regions. Migrants move as they expect to earn more in other places. In neoclassical migration theory, return migration is considered to be a failed attempt to increase income abroad (Cassarino, 2004). Migrants return when their expectations are not satisfied or they fail to maximize their income abroad. Conversely, the NELM approach considers return migration to be a positive move-after a successful migration episode, during which a migrant earned income that was remitted to the household back home, he or she returns to the origin country (ibid.). Following NELM, the decision to return is thus a natural outcome of the migration episode. Neoclassical migration theories and the NELM approach only provided insight into the motivations for return migration and did not address the potential impact of return migration on home societies.

The structural approach to return migration posits that the extent to which return migration affects development in home countries is dependent on the time that a migrant spent abroad and where a migrant resided while abroad (Cassarino, 2004). If a migrant spent a very long time abroad, readjustment in the country of origin and the ability to make a positive contribution will be challenging. Similarly, if the period spent abroad was very short, it is unlikely that a migrant gained any skills or resources that will positively affect the home country (King, 1986). The place that the migrant returns to determines whether the migrant is able to transfer the skills or resources that may be beneficial upon return. Whereas neoclassical 
migration theories and NELM focused on the skills that were obtained abroad, structural theorists thus emphasized the context to which former migrants return.

Cassarino (2004) identified two additional factors that affect the potential of return migrants to contribute to development in their origin countries. First, the extent to which returnees are able to mobilize financial, social and human capital before and during migration has a large effect on the development impact of return. Second, the level of preparedness of a returnee, which is determined by access to information about return, conditions in the origin country and the access to resources upon return, impact the way in which a return can contribute to development. These two factors-resource mobilization and the level of preparedness - differ for different types of migrants (e.g., low-skilled versus highskilled and refugees versus labour migrants) and are affected by the context in the host country and the home country.

The literature on return migration and development revealed mixed findings regarding the linkages between return and development and confirmed that the extent to which return migration can contribute to development is dependent on a range of factors (Amassari \& Black, 2001). The most important factors include the number of migrants returning, the type of migration flow (forced versus labour) and the timing of a return. These factors affect the development impact of return migration on the origin country. In addition, the context of the origin country serves an important role in the relationship between return migration and development (Amassari \& Black, 2001; Ghosh, 2000). In areas with limited resources, return migration is not likely to have a large positive effect on development. This argument was illustrated by Thomas (2008) who noted that returning migrants to Uganda were more likely to economically re-integrate in areas with higher employment rates. Another factor that affects the impact of a return on development are the skills and level of preparation of the returnee (Ghosh, 2000). Low-skilled returnees who are not well prepared are more likely to experience difficulties upon returning. The majority of studies focused on the return of labour migrants (see, e.g., Black, King, \& Tiemoko, 2003; King, 1978; King, 1986).

\subsubsection{Return migration in conflict-affected states}

The extent to which return migration in a forced migration context fits current theoretical approaches to the study of migration is debatable as well. The main 
assumption underlying the NELM approach and neoclassical migration theories is that migrants make rational decisions on their migration trajectories - decisions that are mainly based on economic considerations. This assumption implies that migrants, including return migrants, have the freedom to make their own, rational decisions about whether or not migrate. This may be the case for returning refugees. Voluntary repatriation has, as opposed to local integration or resettlement, been the preferred durable solution of UNHCR since the early 1990s. The return of refugees is an important part of the peace process that signifies change and restores confidence of donors (Black \& Gent, 2006; Crisp, 2000). Repatriation is a voluntary process that ought to occur in safety and dignity. However, in many forced migration contexts the return of former refugees has not been voluntary but forced (see, e.g., Chimni, 1999). In these cases, the economic incentive assumption of the NELM approach and neoclassical migration theories does not hold. Moreover, motivations for return after conflict are often related to emotional attachments to the homeland instead of to rational (economic) considerations. To what extent do these motivations for, and drivers of, return migration in a conflict-affected context affect the impact that return migration has on development?

As previously described, the extent to which return migration has the potential to contribute to development is dependent on a range of factors, including the situation in the home and host countries, the resources that migrants are able to mobilize, the time spent abroad, and the level of preparedness for a return. In conflict-affected contexts, the pre-requisites for return migration to contribute to development are minimal.

First, most returnees have resided in the region of their origin country and have frequently resided in camps or temporary shelters (Nyberg-Sørensen et al., 2002). These living conditions of refugees during exile affected the resources and skills that they acquired while abroad (Van Hear, 2004). Refugees who reside in neighbouring countries often have few employment opportunities and possibilities to obtain skills that can be brought back and applied upon their return. Second, in cases where return was forced, the resources that can be brought back upon return may be even more limited. Third, returnees frequently lack (access to) important assets, such as land and housing, upon their return, which are a necessity for (re-) building a sustainable livelihood. Different studies have highlighted the difficulties of property restitution for returning refugees (see, e.g., Ozerdem \& Sofizada, 2006; 
Pantuliano, 2009; Unruh, 1998, 2009).

Fourth, conflict-affected return areas frequently offer few opportunities for returnees to re-establish their livelihoods (Chimni, 2002). Areas affected by conflict are frequently poor with limited infrastructure. Returnees frequently return in large numbers as part of repatriation exercises. A rapid population increase due to an influx of returnees may create increased competition over resources, such as land (see, e.g., Huggins, 2007; Musahara \& Huggins, 2005; Özerdem \& Sofizada, 2006), and decrease living conditions for all households (Hammond, 1999). In areas where households are struggling to maintain their livelihoods, scarce resources, such as land, have to be shared with a large number of people, which causes poverty. The relationship between a large number of returnees and land scarcity has been observed in various contexts, such as Rwanda (Musahara \& Huggins, 2005), Sudan (Unruh, 1998)) and Mozambique (Unruh, 1998). In these instances, return migration is feared to unsettle community relations, which may contribute to a vicious cycle of conflict and forced migration (Crisp, 2000).

When return migration leads to a deterioration of living conditions or renewed conflict in return areas, return migration is considered 'unsustainable' for the countries that migrants return to. The concept of sustainability in conflictaffected states appeared high on the policy agenda in the 1990s when large return movements, especially within and to the African continent, demanded the attention of local governments and international organizations (Black \& Gent, 2006; UNHCR, 2008b). The question regarding the extent that refugee repatriation or general returns were successful or 'sustainable' for the countries of origin was posed. It was increasingly acknowledged that return not only affects individual returnees, but also the communities and countries of return (Black \& Gent, 2006). Moreover, return can pose security challenges if returnees do not sufficiently reintegrate. Refugee reintegration, therefore, became one of the focus areas in preventing future conflict and ensuring the sustainability of return.

The concept of sustainable return is now extensively incorporated in policy circles to refer to the successful reintegration of returnees in conflict-affected societies. Sustainable return is frequently considered to be the outcome of reintegration. When reintegration is successful, a return is considered to be sustainable and does not pose a security threat. Macrae (1999) argues that reintegration 'is equated with the achievement of a sustainable return' (p. 3). Similarly, a UNHCR report from 1997 indicated that sustainable return is the 
equivalent of 'effective reintegration' (UNHCR, 1997, p. 2). When returnees are similar to the local population in terms of socio-economic conditions and security, return is sustainable. However, return migration may affect not only returning individuals or households but also other households in return areas. Accordingly, scholars have argued for a comprehensive definition of sustainability that includes reintegration outcomes for individual returnees and the effect of return at the community or country level (Black \& Gent, 2006). This more extensive viewpoint of sustainability remains an underexplored topic, primarily due to a lack of reliable and large-scale data from conflict-affected settings.

The viewpoint that return migration can create social tensions by increasing resource scarcity align with neo-Malthusian ideas that a rapid population increase will cause a scarcity of renewable natural resources, such as agricultural land and natural water sources, and instigate violence (Homer-Dixon, 2010). Large-scale return migration may generate demand-induced scarcity of natural resources, which originates from a rapid population increase while resources remain fairly constant. In this case, resources have to be shared with a greater number of people, competition over resources will increase, and social tensions may form. Large-scale return may also cause structural natural resource scarcity. This case is evident when returnees have less access to resources than other households. As previously described, research has shown that returnees frequently lack (access to) important assets, such as land and housing. This is especially the case when former refugees spent long periods abroad and lost property rights.

Both demand-induced and structural scarcity may instigate tensions and violence. Neo-Malthusians predicted that this situation is more likely to occur in countries that are more dependent on natural resources and have a lower capacity to address natural resource scarcity (Homer-Dixon, 2010). Conflict-affected states that experience a rapid population increase are more likely to be affected by conflict. Various studies on the linkages among population pressure, resource scarcity and conflict have been conducted (Andre \& Platteau, 1998; Urdal, 2005; Verpoorten, 2012) but few studies have addressed population increases due to migration (an exception is: Urdal, 2005). Yet, disputes over assets, such as land, between former displaced and non-displaced populations have been argued to lie at the heart of renewed social tensions in many conflict-affected societies (Unruh, 2003). Population movements that are large, relative to local populations, are 
concentrated in certain areas, and that rapidly occur are more likely to enhance resource scarcity and creating conflict (Urdal, 2005).

The effect of return migration on households and communities remains understudied due to a lack of reliable data from conflict-affected settings. In addition to the challenges that accompany data collection in conflict-affected settings, such as continuing insecurity, problems related to infrastructure, and vulnerability of local populations (Fransen, Kuschminder, \& Siegel, 2012), other factors that are specific to returnees complicate the collection of data on refugee return in conflict-affected contexts. Returnees may be a difficult group to research as they are frequently scattered across the country instead of residing in one specific location, which hinders an accurate assessment of their locations (Allen \& Morsink, 1994). Some returnees return unregistered and others do not wish to be recognized due to fears of stigmatization (Rogge, 1994). The extent to which and the conditions under which return is a hazard to renewed conflict remains underexplored.

\subsection{Conclusion}

This chapter reviewed the available evidence regarding the linkages among remittances, return migration and development and described the theoretical approaches that are generally employed to evaluate the linkages between migration and development.

The prevailing viewpoint in the literature on remittances in conflictaffected contexts is that remittances are a crucial source of income for survival, especially due to the volatile nature of development aid (see, e.g., Weiss Fagen \& Bump, 2006). These studies argue that remittances provide a safety net for poorer households, insure them against shocks, and reduce poverty during unstable times. The majority of the studies that were conducted on remittances in conflictaffected countries were conducted on a small scale, which yielded limited knowledge about the role of remittances for development in conflict-affected contexts. The following questions remain: Are remittances a common resource for households that are recovering from conflict? Who are the main beneficiaries of remittances after conflict? And, how are remittances allocated by receiving households?

This dissertation aims to make two theoretical contributions to the literature on remittances and development. First, this dissertation applies the 
NELM theory and the hypotheses that can be derived from it to the conflictaffected context of Burundi. Three hypotheses (relative deprivation, investment and insurance) are tested to examine whether the effect of remittances in a conflictaffected context differ from the effect in other development contexts. Are remittances used to sustain households in a conflict-affected context or are they also used to invest in education, health care, or businesses? By testing the NELM hypotheses in the conflict-affected context of Burundi, this dissertation offers insight into the role of remittances for receiving households and examines the characteristics of receiving households, the extent to which they rely on remittances, and how they allocate the financial resources they receive from family members or friends who reside abroad.

Second, this dissertation will extend the NELM investment assumption beyond the most commonly studied investments that concern economic or human capital by exploring the effect of remittances on the social capital of remittancereceiving households. To what extent are remittances invested in social capital or social capital-enhancing activities in conflict-affected Burundi? Based on social capital theories, a distinction between bonding social capital and bridging social capital is made (Putnam, 2000, 2002) to determine the extent to which remittancereceiving households invest in social capital that benefits their in-group compared with social capital that crosses social divides. Social capital is treated as a multifaceted concept to investigate the link between remittances and social capital.

The prevailing viewpoint in the literature on return migration and development is that return migration may serve a positive role in the development of migrant-sending countries. However, when return flows are large, returnees have few resources and the context to which they return offers few opportunities, the results may be less positive. In conflict-affected states that receive large return movements, return is therefore frequently considered to be a security threat instead of a boost to development.

Two main gaps emerge from the literature on large-scale refugee return and its consequences for development. First, the definition of sustainability of return and its measurement remains ambiguous. A lack of consensus on the term sustainable return has created a diffused conceptual landscape that hampers the formation of a strong theoretical base underlying research on sustainable return. This 'poverty of epistemology' (Chimni, 2002, p. 164) obstructs the design of policy measures to enhance the sustainability of refugee return. Second, whether 
migration generates scarcity and conflict and represents a conflict hazard has not been sufficiently explored and warrants additional scrutiny.

This dissertation aims to make two theoretical contributions to the literature on return migration and development in conflict-affected states. First, the socio-sustainability of return migration in Burundi is evaluated using a wider viewpoint that not only compares return households to non-return households but also focuses on the effect of return on entire communities. Socio-economic sustainability is operationalized as a multidimensional concept that includes multiple indicators to provide a detailed understanding of sustainability in the Burundi context. This dissertation highlights the various challenges experienced by return and non-return households using different levels of analysis and different socio-economic indicators. The distinction between different groups of returnees, particularly first- and second-generation returnees, is made. Second-generation returnees include the children of former refugees that were born in exile. Few studies have addressed the return of second-generation returnees (exceptions are: Christou, 2006; King \& Christou, 2010; Wessendorf, 2007). Second-generation returnees are however a relevant group in the Burundi context as they represent a significant percentage of the return population in Burundi. As described in Chapter 3, second-generation returnees experience specific challenges, especially regarding property restitution (Fransen \& Kuschminder, 2012); however, minimal information about this group is available. This dissertation aims to contribute to the literature on second-generation return and investigate whether differences exist in the sustainability of return regarding both groups in Burundi.

Second, the potential destabilizing effect of return migration is examined by estimating the effect of return migration on theft and/or the destruction of crops, livestock and agricultural tools, land disputes, and security levels in communities of returnees. This dissertation employs neo-Malthusian viewpoints regarding the linkages among rapid population increase, scarcity of renewable natural resources, and conflict (Homer-Dixon, 2010) and applies these viewpoints to a case of large-scale return migration. Did large- scale return migration in Burundi cause demand-induced or structural scarcity of agricultural land? Did large-scale return migration cause thefts and disputes and diminish security in communities of returnees? These questions will be addressed 
Chapter 3: Burundi: conflict, migration and development 
Section 3.2.1 (Forced migration) and Section 3.3.2 (Return migration) in this chapter draw heavily from the following working paper: Fransen, S. and Kuschminder, K. (2012). Reintegration after repatriation: The long-term challenges of return migration in Burundi. New Issues in Refugee Research, Research Paper No. 242. Geneva:

UNHCR.

Our Burundi, gentle country, Take your place in the concert of nations, Acceding to independence with honourable intentions. Wounded and bruised, you have remained master of yourself

Our Burundi, worthy of our tenderest love, We vow to your noble service our hands and hearts and lives. May God, who gave you to us, keep you for us to venerate, Under the shield of unity, In peace, joy and prosperity.

(Burundi national anthem, 1962) 


\subsection{Introduction}

When Burundi gained independence in 1962, after 46 years of Belgian colonial rule preceded by 17 years of German suzerainty, the Burundi people had high hopes for a peaceful and prosperous future. This milestone in Burundi's history, however, marked the onset of unprecedented, recurrent waves of violence that lasted almost 40 years. Between 1962 and 2000, nearly 600,000 people lost their lives; more than a million people were uprooted from their homes; and nearly all Burundians experienced losses in terms of housing, land, livestock, other valuables, education and health, and the deaths of family members and friends (Uvin, 1999, 2009). The Arusha Peace and Reconciliation Agreements were signed in August 2000, and a new constitution was established in 2005, followed by democratic elections in that same year. These events paved the way towards stability and development, and Burundi was officially declared a post-conflict society.

During Burundi's transition from war to peace, migration played a large role in economic and social life. Hundreds of thousands of internally displaced people (IDPs) and refugees returned home, some on their own and others with the help of international organizations, NGOs and the Burundi and/or host country governments. The Burundi wider diaspora, located primarily in North America and Europa, had played an oppositional political role during the conflict period and became increasingly invested in development activities (Turner \& Bronden, 2011). Remittances, which are typically sent by the wider diaspora, grew substantially after the war (see Chapter 5 of this dissertation, or Fransen \& Mazzucato, 2014) and are regarded as important potential contributors to development. Migration has therefore been intrinsically linked to development in Burundi's post-conflict period.

Throughout this dissertation, Burundi is referred to as a conflict-affected society, although it is officially classified as a post-conflict state. The term 'postconflict' highlights the wish of the country to move forward in the pursuit of stability and economic development. The use of this term is ambiguous, however, because conflict-affected countries often experience unstable political transitions that are accompanied by incidents of violence, and such countries have a high probability of relapsing back into conflict (World Bank, 2011a). Burundi is no exception in this regard: several human right abuses have been reported since 2005, and tensions are rising again in the run-up to the early 2015 elections. The 
term 'conflict-affected' is therefore adopted here to highlight the continuity of insecurity and instability that accompanies the transition from war to peace in Burundi.

The rest of this chapter describes Burundi's transition from war to peace, beginning with a brief account of Burundi's history of conflict (Section 3.2), followed by a description of the forced migration flows that originated from this conflict in Section 3.2.1 and migration to the wider diaspora in Section 3.2.2. Then, Burundi's transition period is described in Section 3.3, including the role of migration in this transition period, with a focus on remittances (Section 3.3.1) and return migration (3.3.2). A map of Burundi is provided in the Appendix of this dissertation (Map A.1).

\subsection{Conflict and forced migration}

Burundi has experienced waves of civil conflict since it gained independence from Belgium in 1962 (see, e.g., Lemarchand, 1996, for an overview). The major conflict episodes occurred in 1965, 1972, 1988, 1991 and 1993 (Ngaruko \& Nkurunziza, 2000, 2005). These conflict episodes did not generate much media attention or scholarly debate, especially compared with Burundi's neighbouring country Rwanda, but they nevertheless had disastrous effects on economic and social life in Burundi. To quote Lemarchand (1996): 'Nowhere else in Africa has so much violence killed so many people on so many occasions in so small space as in Burundi during the years following independence' (p. xxv). Table 3.1 provides a summary of the major conflict episodes that occurred in Burundi after independence and their consequences.

The conflict episodes in 1972 and 1993 were the most prominent. In 1972, the Tutsi-dominated army repressed a violent insurgency of Hutu groups in southern Burundi (see, Lemarchand, 2008, for a detailed account). The army killed approximately 200,000 Burundians, primarily of Hutu origin (Watt, 2008). In 1993, the most recent war erupted in Burundi when extremist groups in the Tutsi army assassinated Melchior Ndadaye, the first democratically elected Hutu president. This event led to retaliations from Hutu society members against the Tutsi population, followed by a violent response from the Tutsi army against Hutus. The 1993 war lasted for more than a decade, led to approximately 300,000 casualties and essentially affected the entire country. 
Table 3.1. Burundi's conflict episodes

\begin{tabular}{|c|c|c|c|c|c|}
\hline & 1965 & 1972 & 1988 & 1991 & 1993 \\
\hline Duration (months) & 2 & 4 & 2 & 1 & 108 \\
\hline Casualties (thousands) & 5 & 200 & 15 & $1-3$ & 300 \\
\hline Refugees (thousands) & 0 & 300 & 50 & 38 & 687 \\
\hline $\begin{array}{l}\text { Casualties and refugees } \\
\text { over the total population }\end{array}$ & 0.2 & 14.0 & 1.3 & 0.7 & 17.1 \\
\hline Provinces affected & Muramvya & $\begin{array}{l}\text { Whole } \\
\text { country }\end{array}$ & $\begin{array}{l}\text { Ngozi, } \\
\text { Kirundo }\end{array}$ & $\begin{array}{l}\text { Cibitoke, } \\
\text { Bubanza, } \\
\text { Bujumbura }\end{array}$ & $\begin{array}{l}\text { Whole } \\
\text { country }\end{array}$ \\
\hline
\end{tabular}

Source: Ngaruko \& Nkurunziza, 2005.

Four decades of civil war left its marks on both economic and social aspects of Burundi society. Per capita income had decreased by nearly 40 per cent in the 1993-2007 period (World Bank, 2009), and this decrease, in combination with a substantial decrease in international aid (Bundervoet \& Verwimp, 2005), drove the percentage of individuals living below the poverty line of 1 dollar per day from 35 per cent in 1993 to 67 per cent in 2006 (World Bank, 2009). The conflict in Burundi also affected social ties, reportedly leading to low levels of interpersonal trust, solidarity, and reciprocity (Brachet \& Wolpe, 2005; Uvin, 2009; Vervisch, Vlassenroot, \& Braeckman, 2013). Horizontal networks of close friends and family members based on solidarity expressed through gift-giving and mutual support have historically formed an important part of social life in Burundi (Trouwborst, 1973; Uvin, 2009). However, as described by Vervisch et al. (2013), the insurance function of this bonding social capital weakened during the war period as a result of the conflict and economic hardship that gave rise to disputes over valuables and sometimes led to violence. The conflict, which affected nearly all households, in addition to increasing poverty levels, deeply divided community members. Burundian society has consequently been described as being characterized by 'weak bridges, strong bonds' (Brachet \& Wolpe, 2005, p. 6). This description refers to a highly fragmented society as a result of inter-ethnic tensions as well as socioeconomic inequity between social classes (principally the urban elite versus the rural population), divisions between clans within ethnic groups, and regional inequalities (especially between urban and rural areas). Post-conflict reconstruction programmes and policies in Burundi have consequently involved both the delivery 
of economic assistance and peace-building elements that focused on restoring social ties (Brachet \& Wolpe, 2005; Vervisch, Titeca, Vlassenroot, \& Braeckman, 2013).

\subsubsection{Forced migration}

Because of Burundi's history of conflict, the country experienced large forced migrations of both IDPs and refugees. Most refugees fled the country in 1972 and 1993. These refugees are therefore now referred to as '1972' and '1993 caseload' refugees. Detailed statistics on forced migration within and from Burundi are not available, but it has been estimated that approximately 300,000 people, primarily of Hutu origin, fled the country in 1972. The 1993 conflict resulted in more than 300,000 casualties and the displacement of an estimated 1.2 million people (Ngaruko \& Nkurunziza, 2005). According to Watt (2008), approximately 700,000 Hutus fled - the majority to Tanzania, whereas most Tutsi who were displaced took residence in IDP camps in Burundi and often stayed for many years.

Most 1972 and 1993 caseload refugees fled to Tanzania (Fransen \& Kuschminder, 2012). Other 1972 and 1993 refugees fled to Rwanda or the Democratic Republic of the Congo (DRC), and a small number reached European countries, the United States and Canada. An unknown number of refugees moved to communities in border areas and to Tanzania's capital, Dar Es Salaam (see, e.g., Sommers, 2001). Table 3.2 provides an overview of the refugees and asylum seekers from Burundi in the 1993-2002 period. The table indicates that in 1993, nearly 880,000 Burundians resided in other countries. Most of them resided in Tanzania, Rwanda and DRC. By the end of 2002, more than 570,000 Burundians resided in exile, the majority of them in Tanzania and a smaller group in DRC (UNHCR, 2002).

Table 3.2. Refugees and asylum seekers from Burundi by country of exile: 1993-2002

\begin{tabular}{lrrrrrrrrrr}
\hline Country of exile $^{1}$ & 1993 & 1994 & 1995 & 1996 & 1997 & 1998 & 1999 & 2000 & 2001 & 2002 \\
\hline Tanzania & & & & & & & & & & \\
DRC & 444,867 & 202,738 & 227,216 & 385,452 & 459,420 & 473,768 & 498,982 & 538,448 & 521,180 & 540,861 \\
South Africa & 176,351 & 180,098 & 117,902 & 30,226 & 47,004 & 20,000 & 19,200 & 19,760 & 19,485 & 19,374 \\
Zambia & - & - & - & - & 389 & 601 & 604 & 632 & 1,439 & 1,715 \\
Rwanda & - & - & 260 & 330 & 1,746 & 1,474 & 1,629 & 1,796 & 2,417 & 1,583 \\
Other & 250,000 & 6,000 & 3,228 & 9,611 & 6,933 & 1,408 & 1,371 & 957 & 1,670 & 1,554 \\
& 164 & 870 & 1,976 & 3,061 & 3,631 & 5,317 & 5,663 & 6,491 & 7,808 & 9,384 \\
Total & & & & & & & & & & \\
& 871,382 & \multirow{2}{*}{389,706} & 350,582 & 428,680 & 519,123 & 502,568 & 527,449 & 568,084 & 553,999 & 574,471
\end{tabular}

Note. ${ }^{1}$ UNHCR estimates for most industrialized countries. Source: UNHCR, 2002. 
Burundian refugees residing in Tanzania could be roughly divided into three groups: 1) 1972 caseload refugees residing in settlements that were eventually named the 'Old Settlements', 2) 1993 caseload refugees residing in one of the nine refugee camps in north-western Tanzania, and 3) refugees from both the 1972 and 1993 cohorts who did not settle in designated refugee areas but integrated into villages in north-western Tanzania or urban areas (Hovil, 2009). Most 1972 refugees, who were agriculturalists from Burundi's middle and southern provinces, resided in one of the three Old Settlements of Ulyankulu, Katumba, and Mishamo, located in western Tanzania in the Urambo District of the Tabora Region and the Mpanda District of the Rukwa Region. In 1987, the Old Settlements of Mishamo and Katumba together reportedly hosted approximately 110,000 Burundians (Daley, 1991). The regions in which the Old Settlements were created had low population densities and much land available for agriculture. This setting stimulated local integration and provided a boost to the local economy (Fielden, 2008). Refugees received five hectares of arable land per household upon arrival (Thomson, 2009). Most refugee households in the Old Settlements became self-sufficient. As a result, donor support for the Old Settlements was withdrawn in the 1980 s.

Burundians who fled the country in the early 1990s were largely hosted in refugee camps in Kigoma and Ngara regions in north-western Tanzania. These Burundians were spread over nine refugee camps managed by UNHCR and the Tanzanian Ministry of Home Affairs, close to the Burundi-Tanzania border. In the early 2000s, eight international and national NGOs worked as implementing partners for UNHCR, providing refugees with food aid, health care, education, and legal advice (Human Rights Watch, 2000). Although the 1993 refugees began to return to Burundi after 2000 (see Section 3.3.3 below), there were still eight refugee camps operating in 2007 (Haver, Hatungimana, \& Tennant, 2009). Between 2006 and 2008, six refugee camps in Tanzania were closed. As opposed to the Old Settlements, the camps received vast amounts of financial and material support for the full duration of their existence.

\subsubsection{Migration to the wider diaspora}

As a result of the civil conflicts, Burundi has a large and heterogeneous diaspora scattered around the globe. In total, more than 350,000 Burundians, or 4.2 per cent of the population, were living abroad in 2010 (World Bank, 2011c). Although the 
largest share of the diaspora resides in the neighbouring countries of Tanzania, Rwanda, and the DRC, a small minority migrated to Europe and North America, where they established a small but active diaspora. Migration to the wider diaspora occurred in roughly four phases and resulted in the creation of a heterogeneous group in terms of skills, migration motives and political views (Turner, 2008a, 2008b; Turner \& Bronden, 2011). The first wave of emigrants consisted of a few wealthier Burundians who temporarily moved to Belgium for study purposes before Burundi gained independence from Belgium in 1962. Most were part of the political elite or the Burundi monarchy (De Bruyn \& Wets, 2006), primarily consisting of Tutsi whose positions were strengthened through these privileges while supported by colonizers (Turner, 2008b). Despite being small, this migration trend persisted after the 1960s (De Bruyn \& Wets, 2006). The second wave consisted primarily of Hutu asylum seekers who fled the 1972 genocide (De Bruyn \& Wets, 2006; Lemarchand, 1996). Many, however, also had scholarships and either were already living in Belgium or had been living there previously (Turner, 2008a, 2008b). Over time, this diaspora formed networks that attracted more students and people seeking business opportunities, which generated the third wave of emigration between 1972 and 1993 (ibid.). The re-ignition of conflict in 1993 and the economic downturn that followed generated the fourth wave of emigrants to the wider diaspora (De Bruyn \& Wets, 2006). These emigrants were asylum seekers as well as 'young Tutsi and a similar group of young, urban, elite Hutu' who were seeking better economic opportunities (Turner, 2008b, p. 751). Anecdotal evidence suggests that highly skilled Burundians largely migrated from Bujumbura, Burundi's capital (De Bruyn \& Wets, 2006).

\subsection{Migration in the transition from war to peace}

As described in Chapter 1, this dissertation focuses on two migration-related phenomena in Burundi: remittances and return migration. Remittances and return migration are regarded as important factors influencing development in Burundi's transitional period from war to peace. This section describes the current knowledge on remittances and return migration in Burundi.

\subsubsection{Remittances}

Remittances are believed to be a low but increasing financial inflow in Burundi. Remittances were estimated at between three million USD (World Bank, 2011c) 
and 28 million USD (Banque de la Republique Burundi (BRB), 2010) in 2010.3 Compared with other countries in the region, such as Rwanda, Kenya, Uganda and Tanzania, Burundi received few remittances in 2010, despite having the highest stocks of emigrants as a percentage of its population (see Table 3.3). For example, Kenya, one of Africa's most successful countries with regard to tapping its diaspora potential, received 1,758 million USD in 2010. Bordering Burundi in the north, Rwanda received 91 million USD in 2010. It is unclear whether these numbers underestimate remittances because they represent formal flows only. De Bruyn and Wets (2006) reported that most remittances to Burundi were sent informally, whereas Fransen and Andersson (2011) argued that the remittance market has become increasingly formalized as a result of innovations and increasing competition.

Table 3.3. Stocks of emigrants and remittances in the Great Lakes region (2010)

\begin{tabular}{lccc}
\hline & $\begin{array}{c}\text { Stock of emigrants } \\
\text { in 2010 }\end{array}$ & $\begin{array}{c}\text { Stock of emigrants as a } \\
\text { percentage of the population in } \\
2010\end{array}$ & $\begin{array}{c}\text { Remittances } \\
\text { (Million USD) in 2010 }\end{array}$ \\
\hline Rwanda & 263,400 & 2.6 & 91 \\
Burundi & 356,000 & 4.2 & 3 \\
Kenya & 457,100 & 1.1 & 1.758 \\
Uganda & 757,500 & 2.2 & 773 \\
Tanzania & 316,900 & 0.7 & 17 \\
\end{tabular}

Source: World Bank, 2011c.

Apart from these formal statistics, little is known about remittances in Burundi. Small-scale studies have suggested that most remittances are sent from Europe and North America (De Bruyn \& Wets, 2006; Fransen \& Andersson, 2011). Remittance-receiving households would primarily reside in urban areas and would generally be wealthier than non-receiving households. In contrast, regional remittances are believed to be negligible despite the large regional migration flows (Fransen \& Andersson, 2011). As described, the top three destination countries for Burundi's emigrants were Tanzania, Uganda, and Rwanda in 2010 (World Bank, 2011c). However, most of these regional migrants reside in temporary settlements

\footnotetext{
${ }^{3}$ Statistics on remittances from the BRB were derived during an interview that I conducted with the BRB in Bujumbura in October 2011.
} 
or refugee camps, and their living conditions and the absence of financial infrastructure likely do not permit them to send remittances (Fransen \& Andersson, 2011).

Nevertheless, remittances are a potential resource for development in Burundi (Fransen \& Andersson, 2011; Fransen \& Siegel, 2010). In the period from 2005 to 2008, remittance inflows into Burundi were negligible relative to FDI and ODA. From 2008 onwards, however, remittances increased and surpassed FDI based on World Bank and BRB measurements. There are several potential reasons for this rise in remittances after 2008. First, the measurement of remittances improved considerably in Burundi after 2005. Since 2005, BRB includes transfers through money transfer operators such as Western Union in its statistics, and in 2007, foreign exchange bureaus were legalized, also reporting to BRB (Fransen \& Andersson, 2011). Second, the official end of conflict in Burundi and the beginning of the reconstruction of the financial sector may have eased remittance sending to Burundi. Third, the end of conflict may have also increased the confidence of diaspora members and the ease of travelling to Burundi, which may have boosted remittance sending.

The rise in the relative importance of remittances, combined with successful examples of other countries in the region to attract remittances, has inspired the Burundi government to begin designing policies to harness and increase this financial resource from abroad (Fransen \& Andersson, 2011). The first draft of Burundi's first national migration policy was designed in 2011 with the aim to enhance remittance flows into the country that would be invested in development programmes and hereby contribute to the economic reconstruction of the country (Republic of Burundi, 2011). At the time of writing this dissertation, the policy has however not been implemented yet. Although the Burundi diaspora residing in Europe and North America is relatively small, its members are well organized, highly active, and highly engaged in their home country (Fransen \& Siegel, 2010). However, the effects of remittances on development in Burundi remain underexplored. It is unclear, for example, who exactly the main beneficiaries of remittances in Burundi are and how they allocate the money that they receive from abroad. These questions warrant exploration to assess the development potential of remittances in Burundi. 


\subsubsection{Return migration}

Return migration has by far constituted the largest and most significant migration flow after the conflict in Burundi. Already during the war, conflict episodes were interspersed with periods of relative stability in which many refugees returned home again. Graph 3.1 shows the return migration to Burundi between 1993 and 2014 based on UNHCR data (UNHCR, 2002, 2014a). Before 2002, no official records of migration movements in and out of Burundi were maintained. All numbers for return migration before 2002 are therefore estimates. The data show a peak in return in 1994, which represents an estimated 250,000 to 300,000 returnees who fled to Tanzania following the 1993 violence and returned shortly thereafter. This return continued, albeit at a slower pace, in subsequent years. After 2000, the return to Burundi increased again.

Graph 3.1. Return to Burundi: 1993 - 2014 (in thousands)

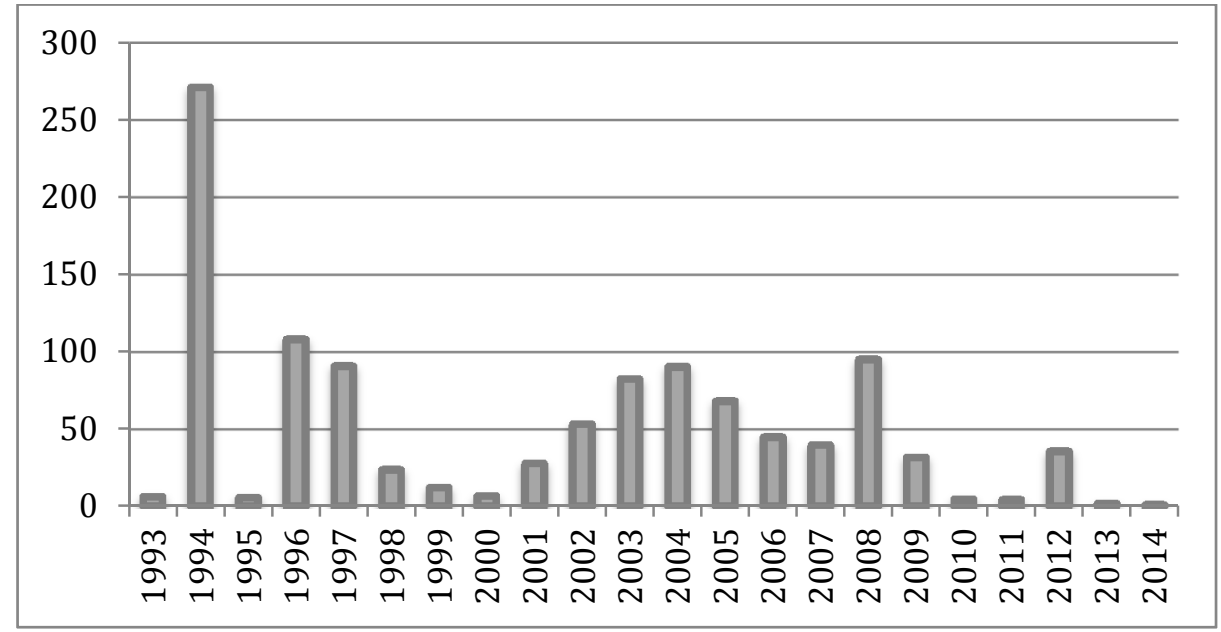

Source: UNHCR, 2002, 2014a.

Following the signing of the Arusha Peace and Reconciliation Agreements in August 2000, many Burundians began to return from exile voluntarily. Official repatriation from Tanzania, facilitated by UNHCR in a joint initiative with the Burundian and Tanzanian government, was initiated in 2002. Most early returnees were former 1993 caseload refugees who returned to their origin communities in the Northern provinces of Kirundo, Ngozi and Cibitoke, where the situation was relatively stable at the time. In 2002, the first year of the repatriation exercise, more 
than 50,000 Burundians returned from Tanzania, and more than 45,000 of them were assisted by UNHCR (UNHCR, 2002).

In 2008, UNHCR initiated the repatriation of former 1972 caseload refugees from the Old Settlements, who had thus far been reluctant to return because they had spent a long time in exile and had lived in relatively good conditions. Low rates of return from the Old Settlements had led to increased pressure from the Tanzanian government (Haver et al., 2009). The efforts of UNHCR increased the return of mainly, but not solely, 1972 refugees in 2008 (UNHCR, 2011), who primarily settled in the Southern provinces Makamba, Rutana and Bururi (see Map A.2 in the appendix of this dissertation). In October 2008, a total of 23,740 1972 refugees had been repatriated from Tanzania to Burundi, of whom 87.12 per cent (20,683 individuals) returned to these three provinces.

In 2008, Tanzania established a naturalization option for 1972 refugees from Burundi. More than 160,000 people chose this option, while approximately 50,000 1972 refugees returned to Burundi, and a small group opted for resettlement in a third country. There are no official data on the characteristics of those who returned versus those who opted for naturalization, but a study conducted in 2008 showed that access to agricultural land and education in Tanzania played a major role for many 1972 refugees in their choice of naturalization (Hovil \& Kweka, 2008). Likewise, 1972 refugees who expected to regain their land upon return in Burundi showed a preference for return. However, information on the naturalization and return options and their implications was reportedly poorly distributed among the 1972 refugee population, many of whom lacked clarity in the long-term implications of their choices.

UNHCR began repatriation from Rwanda in 2009 and initiated repatriation from DRC in October 2010. After 2009, returns to Burundi decreased, and it was estimated that in 2011, Tanzania still hosted a 'residual' of 37,000 out of more than 84,000 Burundian refugees (UNHCR, 2011). Graph 3.1 shows another peak in returns in 2012 resulting from the closing of the last refugee camp in Tanzania, Mtabila, at the end of 2012. The closing of the camp forced another 30,000 to 35,000 former 1993 refugees to return to Burundi.

Between 2002 and September 2014, more than 550,000 formally registered former refugees returned to Burundi (UNHCR, 2014c). The majority of them (approximately 490,000 refugees) were repatriated from Tanzania, slightly fewer 
than 15,000 came from DRC, and nearly 8,000 came from Rwanda (see Table 3.4). These numbers only represent the returnees who were registered by UNHCR and are likely to be underestimates of the actual return flow. In January 2014, more than 72,000 Burundian refugees were still residing abroad, and nearly 80,000 were internally displaced (UNHCR, 2014c).

Because of the protracted Burundian refugee settlement in Tanzania, some who returned to Burundi were second-generation returnees, the children of (primarily 1972) refugees who were born abroad (Fransen and Kuschminder, 2012). Bunte and Monnier (2011) cited a 2010 UNHCR report that stated that 82 per cent of the returnees in 2008 were born in Tanzania. However, there is little information on this group, including their motivations to 'return'. At the time of repatriation, many second-generation returnees were likely under-age and travelled to Burundi with their parents.

Most refugees who returned after 2002 settled in their origin provinces in Southern and Northern Burundi. Bururi province, which is located on the fertile shores of Lake Tanganyika and is close to Tanzania, also received a substantial number of returnees after 2002 (UNHCR, 2014c). Returnees who had been born abroad and/or did not have family to return to were referred to as 'des personnes sans terre ni référence' - people with no land or reference - and were housed in rural integrated villages (VRIs). These returnees were largely 1972 refugees and second-generation returnees (Fransen \& Kuschminder, 2012). The VRI approach has been evaluated by Fransen and Kuschminder, who argued that the VRIs had not provided sufficient services to the residents. However, the long-term sustainability of the VRIs remains to be explored.

Official returnees were supported by UNHCR and other international organizations to return to their origin communities. The 1993 and 1972 refugees were allowed to take $50 \mathrm{~kg}$ and $100 \mathrm{~kg}$ of personal belongings with them, respectively (Fransen and Kuschminder, 2012). Many Burundians strongly desired to return to their origins as a result of their emotional attachments to their family land (Fransen \& Kuschminder, 2012; Hovil, 2009; Rema Ministries, 2012). Hovil (2009, p. 30) stated as follows: 'Those who are returning from exile, after decades of alienation, are searching for continuity with their past, which is most tangible through physically returning to the land from which they fled, and on which their ancestors lived'. 
Table 3.4. Repatriation to Burundi by country of exile: $2002-2011$

\begin{tabular}{|c|c|c|c|c|c|c|c|c|c|c|c|}
\hline & 2002 & 2003 & 2004 & 2005 & 2006 & 2007 & 2008 & 2009 & 2010 & $2011^{a}$ & Total $^{\mathrm{a}}$ \\
\hline Tanzania & 50,899 & 79,925 & 89,039 & 62,338 & 42,765 & 39,506 & 94,891 & 29,115 & 1,011 & 281 & 489,770 \\
\hline Rwanda & 113 & 106 & 151 & 4,489 & 615 & 111 & 36 & 2,342 & 1 & 4 & 7,968 \\
\hline RDC & 2,142 & 2,142 & 879 & 1,002 & 1,284 & 45 & 6 & 95 & 3,640 & 3,408 & 14,643 \\
\hline Kenya & 78 & 50 & 62 & 23 & 78 & 16 & 6 & 1 & - & 12 & 326 \\
\hline Mozambique & - & 2 & 16 & 17 & 4 & - & 32 & 13 & - & - & 84 \\
\hline South Africa & 16 & 13 & 22 & 58 & 25 & 29 & 47 & 21 & 9 & 13 & 253 \\
\hline Benin & 3 & 8 & 10 & 10 & 7 & 11 & 2 & 3 & 7 & 3 & 64 \\
\hline China & - & - & - & - & - & - & - & 1 & - & - & 1 \\
\hline Cameroun & - & 12 & 37 & 33 & 13 & 7 & 6 & 8 & - & 6 & 122 \\
\hline Malawi & - & 1 & 1 & 35 & 34 & - & 25 & 154 & 64 & 15 & 329 \\
\hline Uganda & 4 & 1 & 12 & 17 & 18 & - & - & - & 4 & - & 56 \\
\hline Namibia & 9 & 1 & 16 & 1 & - & - & - & - & 3 & 17 & 47 \\
\hline Zambia & 9 & 67 & 29 & 32 & 28 & 59 & 16 & 17 & 12 & 10 & 279 \\
\hline Zimbabwe & - & - & - & - & - & - & - & 4 & - & - & 4 \\
\hline $\begin{array}{l}\text { East African } \\
\text { Republic }\end{array}$ & - & - & - & - & - & - & - & 3 & - & - & 3 \\
\hline Congo Braz. & - & 18 & 8 & 20 & 16 & - & - & 2 & - & - & 64 \\
\hline Ivory Coast & 6 & 3 & 8 & 11 & 5 & 4 & 1 & - & - & - & 38 \\
\hline Madagascar & - & - & - & - & - & - & - & - & 1 & - & 1 \\
\hline Other & 4 & 17 & 37 & 22 & 23 & 10 & - & - & - & 1 & 114 \\
\hline Total & 53,283 & 82,366 & 90,327 & 68,108 & 44,915 & 39,798 & 95,068 & 31,779 & 4,752 & 3,770 & 514,166 \\
\hline
\end{tabular}

Note. ${ }^{a}$ Numbers as of September 2011. Source: UNHCR, 2011.

The Burundi repatriation became internationally known as a major success because most returnees were repatriated in 'safety and with dignity' (Rema Ministries, 2012). Small-scale studies that were conducted after the conflict found that return households did not differ from non-return households in terms of housing, land and other observables (see, e.g., Terra-P Group, 2008). Others, however, have highlighted challenges that returnees still face. Especially the 1972 cohort and second-generation returnees reportedly experience language barriers, cultural differences, low access to legal services, discrimination, and difficulties in finding employment (Fransen \& Kuschminder, 2012; Rema Ministries, 2012).

Property restitution, however, emerged as the main challenge regarding the repatriation process in Burundi. Many returnees found their agricultural land occupied by others or sold by family members (Hovil, 2009). The 1986 Land Code of Burundi states that people who have been abroad for more than 30 years can no longer claim the rights to their ancestral land (Bunte \& Monnier, 2011). Consequently, returnees who had spent long periods abroad and secondgeneration returnees were not entitled to receive their land back, despite the promises of property restitution made in the Arusha Peace and Reconciliation 
Agreements. In some cases, land that was abandoned by refugees was allocated to other households by the government, sometimes to former IDPs. This land issue has led to difficult situations in which both groups feel entitled to the land.

A new land code is currently being developed, and it is likely that 1972 returnees will be exempted from the 30 -year rule in the near future. The most commonly adopted solution that has been implemented thus far is land sharing, but it frequently leads to resentment and is often viewed as a temporary solution (Hovil, 2009). Moreover, the agricultural production of a single plot is often insufficient to feed multiple families (Fransen \& Kuschminder, 2012). Given these challenges, some have argued that return migration to Burundi has increased pressure on agricultural land and other resources, thereby enhancing poverty levels in areas of high return and creating a breeding ground for conflict (Uvin, 2009; Watt, 2008).

Many programmes and projects were implemented to support the return and reintegration of former refugees in Burundi. Returnees received food ratios, educational items, non-food items such as mosquito nets, cooking materials, and other resources, and from 2007 onwards, they also received a cash grant (see, Fransen \& Kuschminder, 2012, for a detailed overview of the assistance that was offered to returnees). UNHCR also implemented a shelter programme that provided house-building materials for one-third of the most vulnerable returnees each year. Between 2002 and 2010, more than 100,000 houses were built under the UNHCR shelter programme in Burundi (Fransen \& Kuschminder, 2012). A socalled community-based approach was adopted for the majority of other programmes and projects regarding reintegration implemented by local and international NGOs. The VRIs, for example, contained not only returnees but also a small percentage of vulnerable populations from neighbouring villages to stimulate the integration of the VRIs into surrounding communities. In general, the restoration of community cohesion has been a focus of many post-conflict reconstruction programmes in Burundi.

Although the effects of return migration on development in Burundi are expected to be significant, scarcely any research has investigated the linkages between return migration and development in Burundi. This lack of research is largely caused by a lack of available data. The studies on return migration in Burundi that have been conducted provided important insights, but most were conducted in specific localities and focused on specific groups of returnees. 
Fransen and Kuschminder (2012), for example, conducted ethnographic fieldwork in two villages in southern Burundi that primarily received 1972 caseload returnees. The effects of return migration on development on a national level therefore remain to be explored. The same holds true for the effects of remittances on development. There are no micro-level data on remittances to estimate the significance and effects of remittances for remittance-receiving households. The data that were used in this dissertation therefore provide a unique opportunity to explore the effects of remittances and return migration on development in Burundi. These data will be discussed in detail in the next chapter. 
Chapter 4: Data and methods 
Section 4.2 (Data collection and sampling) of this chapter draws heavily from the following report: Fransen, S. (2011). Migration and Development, A world in Motion. Fieldwork report Burundi: Methodology and Sampling. Maastricht: Maastricht Graduate School of Governance.

Section 4.4.1 (Challenges during data collection: infrastructure, electricity and safety) of this chapter draws heavily from the following working paper: Fransen, S., Kuschminder, K., \& Siegel, S. (2012). Implementation of cross-country migration surveys in conflict-affected settings: Lessons from the IS Academy survey in Burundi and Ethiopia. UNU-MERIT Working Papers, ISSN 1871-9872. Maastricht: UNU-MERIT. 


\subsection{Introduction}

Survey data are increasingly used to study migration and its consequences for development. Survey data offer various advantages vis-a-vis aggregated statistics on migration, such as those derived from census data or cross-border statistics (see, e.g., Fawcett \& Arnold, 1987, for an overview). Important advantages include the opportunities to adapt the survey to the goal of the research and to include retrospective questions to reconstruct migration trajectories. Most importantly, micro-level data enable an investigation of the drivers and consequences of migration - the latter being the purpose of this dissertation. When studying remittances, for example, micro-level survey data can collect information on several other household characteristics, such as income, education or health, to facilitate a study of the effects of remittances on these variables (see, e.g., Brown, Carling, Fransen, \& Siegel, 2014).

As described in Chapter 1, the data that were used for this dissertation were collected for the Migration and Development: A World in Motion project, hereafter referred to as the Migration and Development project. The Migration and Development project, funded by the Dutch Ministry of Foreign Affairs under the heading of the IS Academy, was a five-year research project that studied the consequences of migration for four migrant-sending countries (Afghanistan, Burundi, Ethiopia and Morocco) and one migrant-receiving country (the Netherlands). The main methodology in each country consisted of large-scale household surveys to study the effects of migration on development using a quantitative approach. The same standardized questionnaire was used in each country, albeit in a slightly modified form to make it suitable for the context. ${ }^{4}$

In the questionnaire that was used for the Migration and Development project, questions on migration and remittances were embedded in a so-called multi-topic household survey that gathered information on various household characteristics, such as income, expenditures, asset ownership, and social capital, and individual characteristics of the household members, such as their age, level of education and employment status. ${ }^{5}$ Because of the conflict-affected context of Burundi, the questionnaire also contained a module on household conflict experiences. The household survey was combined with a community survey that

\footnotetext{
${ }^{4}$ More information on the Migration and Development project is provided on: http://www.merit.unu.edu/themes/6-migration-and-development/is-academy/

${ }^{5}$ The questionnaire that was used in Burundi can be found here: http://www.merit.unu.edu/themes/6-migrationand-development/is-academy/is-academy-research-methodology-and-fieldwork-materials/
} 
collected information on the communities in which the households resided, including the availability of infrastructure (e.g., roads, electricity), the availability of services (e.g., schools, hospitals) and the history of conflict and migration. Taken together, these data enable detailed research on the linkages between the migration experiences of household members and how these experiences have affected both households and the communities in which households reside.

The Migration and Development data from Burundi are unique in the sense that they offer a detailed view of the livelihoods of households and communities following the conflict. Large-scale survey data from conflict-affected settings are scarce because of the challenges that accompany data collection in these settings (see, e.g., Fransen et al., 2012, for an overview of these challenges). Continuing insecurity and damaged infrastructure, including roads and electricity, and limited communication networks, may all impede large-scale data collection efforts. Several of these challenges were encountered during the Migration and Development survey data collection process, and they will be discussed in detail below. Another feature that makes the Migration and Development data from Burundi unique is that the data collection occurred nation-wide. Burundi is a relatively small country, which offered an opportunity to establish a survey that covered all provinces, thus yielding results that are nationally representative.

As a $\mathrm{PhD}$ researcher, I was fortunate to work on the Migration and Development project within an interdisciplinary team of researchers. Together, we designed the questionnaires, established the sampling strategies for each country, and faced the variety of challenges that are encountered when conducting largescale survey data collection. My primary role in the project was to manage the data collection in Burundi. I was given the opportunity to travel to Burundi several times and to supervise the data collection on location. After training the team of interviewers, I travelled with them from village to village to conduct the 1,500 household interviews and later in the city to conduct the 810 household interviews there. Throughout the rest of this chapter, I will reflect on my experiences during each stage of the data collection process.

The rest of this chapter first details the data collection process, the sampling strategy that was employed in Burundi, the selection of the main respondents, the practicalities concerning data collection, and ethical considerations in Section 4.2. Then, Section 4.3 presents descriptive statistics on the main variables of interest in this dissertation - remittances and return migration - 
to provide preliminary insights into the data. This section also checks the representativeness of the data by comparing the distributions of age, gender and education in the data with the distributions of these variables in census data that were collected in Burundi in 2008. Section 4.4 describes the challenges of data collection, potential biases, sensitivities in questionnaire design, and data limitations. Finally, Section 4.5 briefly introduces the estimation methods that were used in the empirical chapters (Chapter 5 to Chapter 8) of this dissertation.

\subsection{Data collection and sampling}

The data collection occurred over a three-month period between January and March 2011, during which we worked in close cooperation with a local research company, a local university, and several NGOs, international organizations, and government officials. Several months before the start of the data collection, the project manager, Dr. Melissa Siegel, and I had travelled to Burundi for a so-called 'scoping visit', during which we had established contacts with these local institutions and organizations and had involved them in our research. This visit to Burundi also enabled us to gain detailed knowledge of the current migration and development patterns in Burundi and provided input for the design of the questionnaire and the sampling strategy. Permission for data collection was granted by the Burundian Ministry of Internal Affairs.

Although the day-to-day situation in Burundi was relatively calm when we conducted the survey in 2011, incidents of violence were frequently reported. This violence was mainly politically motivated and resulted from the 2010 elections (Human Rights Watch, 2011). The political situation was therefore tense and there was widespread fear among the population that conflict would erupt again. In early 2012, after the fieldwork, the security situation improved. This context needs to be taken into account when interpreting the results. The data collection was not affected by the political situation in 2011. The extent to which safety and security affected the data collection will be explained in more detail in Section 4.4.1.

The data collection consisted of two parts. First, a nationally representative household survey was conducted in all provinces of Burundi (including urban areas). The national household survey gathered information on 1,500 households that resided in 100 different communities across the country (see Table 4.1). Second, an urban household survey was conducted in Burundi's capital, 
Bujumbura. For the urban household survey, 810 households were interviewed in 54 different blocks in the capital. As described, the household interviews were combined with a community survey: in each community or block, a community representative was interviewed to gather contextual data on the communities. The urban survey was not part of the original fieldwork plan. However, during the national survey, we found that remittances were largely absent in rural areas and were more common in urban areas. Because the effect of remittances on development was one of the main foci of the Migration and Development project, we decided to add a separate urban survey that was conducted in the capital only.

Table 4.1. National household survey: households interviewed per province

\begin{tabular}{|c|c|c|c|c|}
\hline Province & $\begin{array}{l}\text { No. of } \\
\text { households } \\
\text { interviewed } \\
\text { per province }\end{array}$ & $\begin{array}{c}\% \text { of } \\
\text { households } \\
\text { interviewed per } \\
\text { province }\end{array}$ & $\begin{array}{c}\text { No. of } \\
\text { community } \\
\text { representatives } \\
\text { interviewed per } \\
\text { province }\end{array}$ & $\begin{array}{c}\% \text { of } \\
\text { community } \\
\text { representatives } \\
\text { interviewed per } \\
\text { province }\end{array}$ \\
\hline Bubanza & 60 & 4.00 & 4 & 4.00 \\
\hline Bujumbura Rural & 105 & 7.00 & 7 & 7.00 \\
\hline Bururi & 105 & 7.00 & 7 & 7.00 \\
\hline Cankuzo & 45 & 3.00 & 3 & 3.00 \\
\hline Cibitoke & 90 & 6.00 & 6 & 6.00 \\
\hline Gitega & 121 & 8.07 & 8 & 8.00 \\
\hline Karuzi & 75 & 5.00 & 5 & 5.00 \\
\hline Kayanza & 119 & 7.93 & 8 & 8.00 \\
\hline Kirundo & 120 & 8.00 & 8 & 8.00 \\
\hline Makamba & 75 & 5.00 & 5 & 5.00 \\
\hline Muramvya & 60 & 4.00 & 4 & 4.00 \\
\hline Muyinga & 120 & 8.00 & 8 & 8.00 \\
\hline Mwaro & 60 & 4.00 & 4 & 4.00 \\
\hline Ngozi & 120 & 8.00 & 8 & 8.00 \\
\hline Rutana & 60 & 4.00 & 4 & 4.00 \\
\hline Ruyigi & 75 & 5.00 & 5 & 5.00 \\
\hline Bujumbura Mairie (urban) & 90 & 6.00 & 6 & 6.00 \\
\hline Total & 1,500 & 100.00 & 100 & 100.00 \\
\hline
\end{tabular}

Source: Migration and Development national survey data. 


\subsubsection{Sampling and main respondents}

Burundi is divided into 17 provinces, 117 communes (similar to a district or municipality) and 2,639 collines (literally: hills). Each colline consists of several sous-collines (literally: sub-hills), which represent the smallest administrative unit in Burundi. These sous-collines are small agglomerations of houses and typically consist of between 150 and 300 households.

Sampling was based on the Burundi census data from 2008 provided by our local research partner. For the national household survey, we followed a twostep self-weighting design. The primary sampling unit (PSU) was the sous-colline, of which 100 were selected based on budget and time constraints. The sous-collines were distributed throughout the 17 provinces in Burundi according to the demographic weight of these provinces (step 1), after which the sous-collines within the provinces were sampled proportionally to the population size (step 2). Within each sous-colline, 15 household interviews were conducted. A similar sampling strategy was applied for the urban household survey. The PSUs in Bujumbura were quartiers (literally: neighbourhoods). In each quartier, one block, consisting of 2 to 4 streets, was randomly chosen for conducting the interviews. In total, 810 interviews were conducted in 54 blocks.

Households were randomly selected to be interviewed based on the lists of households residing in the community or neighbourhood that were provided by the community leaders or neighbourhood representatives. In some urban neighbourhoods, a random walk method was applied to select households. This method was used in relatively new neighbourhoods where no household lists were available or in neighbourhoods where the neighbourhood representative was not present when the survey occurred. In the rural areas, lists were available in all cases.

The main respondent within each household was interviewed. This person was over 18 years of age and was the most knowledgeable person on household financial and social affairs. Preferably, the main respondent was the head of the household or a senior household member, such as a mother/father or grandmother/grandfather. The respondent for the community questionnaire was a senior person in the community and preferably the community leader. The final module of the household questionnaire contained questions specifically designed for return migrants in the household. One return migrant per household (if there 
was one) was interviewed. If there were multiple return migrants in the household, one return migrant was randomly selected to be interviewed.

The main respondent provided information on all household members, with a household defined as 'all individuals who are living together and have communal arrangements concerning subsistence and other necessities of life and inclusive of all individuals presently residing elsewhere (in the country or abroad) whose principal commitments and obligations are to this household'. Following this definition, household members who had migrated were thus included in the sample as well. The average size of the households that were interviewed during the national survey was 5.32, yielding a total sample of 7,983 individuals in the national survey data. In urban areas, households were slightly smaller, with an average household size of 5.14. The urban survey yielded information on 4,163 individuals.

\subsubsection{Practicalities}

The enumerator team consisted of 15 enumerators divided into three teams, each with its own supervisor. The three teams with their supervisors were also supervised by an overall field supervisor who arranged the logistics and were responsible for the detailed planning of each day (which community to visit and when). Each team went to a different community each day to interview households. Each enumerator conducted three interviews per day; hence, 45 household interviews were conducted per day. In each community, one community questionnaire was administered. In total, 3 community questionnaires were therefore administered each day. The enumerator teams were visited in their fieldwork locations each day by the field supervisor and me. These visits were conducted to enhance data quality and to ensure the safety of the enumerators. Each evening, we held debriefings with the enumerators to determine whether any problems had arisen.

Data were collected electronically using personal digital assistants (PDAs). This method of data collection, also called computer-assisted personal interviewing (CAPI), offers various advantages relative to the use of, for example, paper and pencil interviewing (PAPI). CAPI enhances data quality, facilitates data management and data control, and eliminates the need for data entry, which eliminates the possibility of data entry mistakes and reduces the time between data collection and data analysis. Each evening after data collection, we obtained the 
data from the PDAs and uploaded the data to a computer. The data were checked for inconsistencies or errors each evening - provided that we had access to electricity that day.

\subsubsection{Ethical considerations}

There are several ethical issues that researchers working in conflict-affected contexts should be aware off (see, e.g., Goodhand, 2000). Ethical issues that should be considered by researchers include ensuring the safety of the research team and the respondents and confidentiality of potential sensitive information that the respondents provide. Furthermore, certain questions that are asked during research may re-open wounds for people that are traumatized. As will be described in Section 4.4.2 (Sensitivities in questionnaire design), the Migration and Development questionnaire contained several, potentially sensitive subjects.

During the Migration and Development survey, several measures were taken to adhere to international ethical standards. First, before each interview, the respondents were informed that the information that they provided would be treated confidentially and that we would respect the anonymity of the respondents. We emphasized that we were not related to any government, NGO or international organization and that the information that we received would not be used for any purpose other than research. Second, to avoid to 'do harm' when asking sensitive questions, the potentially sensitive questionnaire items were embedded in other modules in the questionnaire and therefore followed 'logically' from other questions. All questions were introduced while emphasizing to the respondent that he or she had the option to decline to reply to these questions. Third, all interviewers were trained to be aware of the potential sensitivity of the questions on remittances and return migration and were given tools to either ask for more information ('probing') or to stop asking questions if the interviewer did not want to reply. More information on potentially sensitive questions and the measures that were taken to avoid 'doing harm' are described in Section 4.4.2. Fourth, to ensure the safety of our interviewer teams and the respondents, we designed detailed safety protocols and worked in close collaboration with our local research partner who provided us with up-to-date information on our working locations. More information on safety issues that were encountered during data collection can be found in Section 4.4.1. 


\subsection{Remittances and return migration: descriptive statistics}

This section presents descriptive statistics on the main variables of interest remittances and return migration - to provide some preliminary insights into the data. Remittances were defined in the questionnaire as international monetary transfers that were received by a household from a migrant in the 12 months prior to the interview. The national survey data revealed that remittances are most common in Burundi's urban areas. The national survey that preceded the urban survey showed that 2.40 per cent $(n=36)$ of the 1,500 sampled households had received remittances in the past year and that most of these receiving households (38.89 per cent) lived in Bujumbura. This result is illustrated in Map 4.1. The finding that remittances were more common in the capital was confirmed by the urban data: of the 810 households, 15.93 per cent $(n=129)$ were remittancereceiving households. The empirical chapters on remittances in this dissertation are therefore based on the urban data.

An individual was defined as a first-generation return migrant if he or she had returned to Burundi either voluntarily or had been forced to live there full time after having lived abroad for a consecutive period of at least three months. The three-month period was chosen to ensure that the migrant had spent a period abroad that was long enough to affect his or her livelihood upon return. If someone returned to Burundi after spending two weeks abroad, for example, it is likely that this migration episode only had minimal effects on the reintegration of this person. Using the three-month period also ensured that we excluded most of the cross-border seasonal migration that takes place between Burundi and Tanzania.

A total of 491 individuals in the national survey data were first-generation return migrants, representing 6.17 per cent of the total sample of 7,983 individuals. Another 206 individuals ( 2.59 per cent of the total sample) were identified as socalled second-generation return migrants - the children of return migrants who were born abroad. Hence, 8.73 per cent $(n=697)$ of the individuals in the national sample were either first- or second-generation returnees. Map 4.1 shows the proportion of return migrants for each province in Burundi. Nearly 9 per cent of the first-generation return migrants resided in the capital city of Bujumbura. Because of the high prevalence of return migration across the country, the empirical chapters on return migration in this dissertation rely on the national survey data. 
Map 4.1. Prevalence of remittances and return migration in Burundi
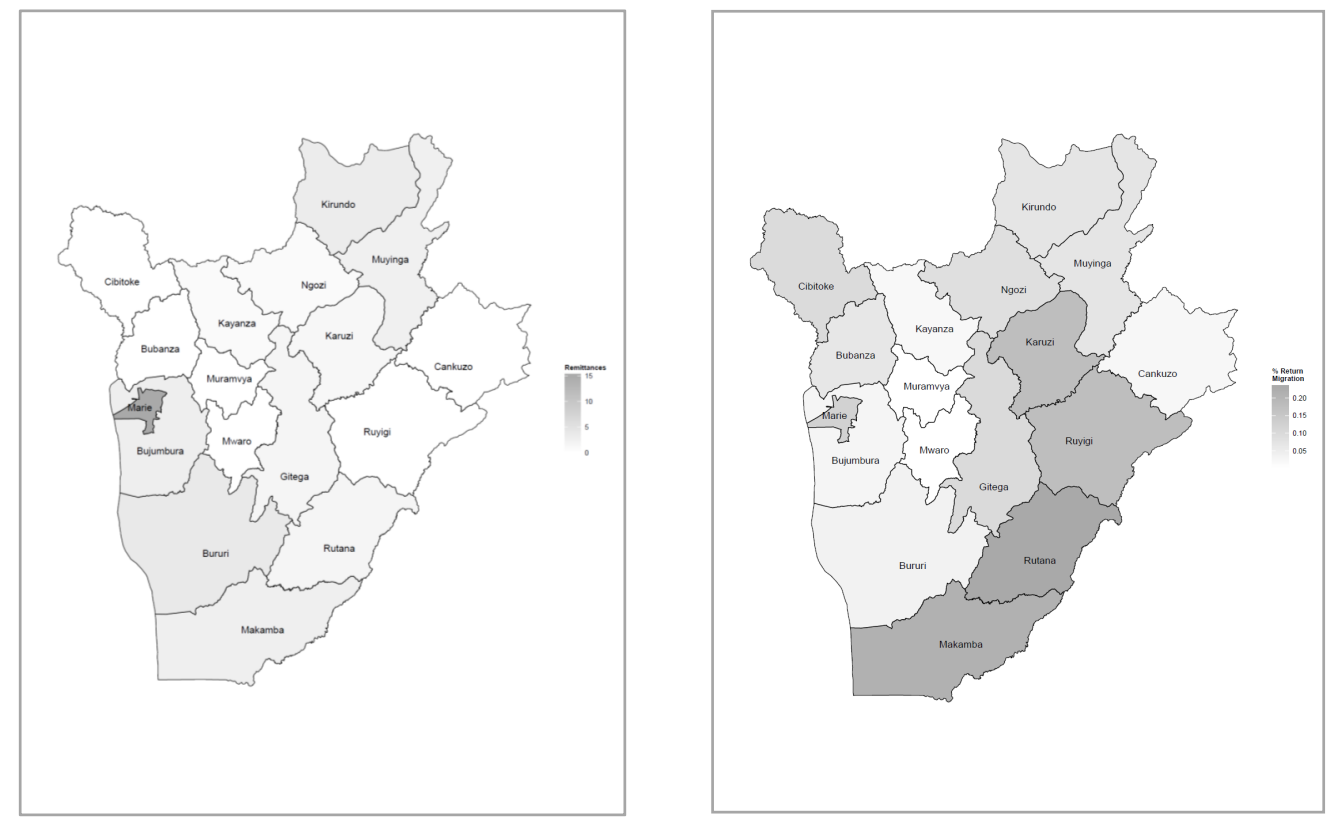

Source. Migration and Development national survey data.

\subsubsection{Data representativeness}

To examine whether the Migration and Development data are indeed representative of the country as a whole, this section compares the distribution of certain characteristics in the sample data with 2008 census data from Burundi. Table 4.2 shows that in terms of age, gender, household size, and marital status, the Migration and Development sample does not deviate much from the 2008 census data. However, individuals in the Migration and Development sample are considerably better educated. For example, more than 70 per cent of respondents aged 9 and older reported being able to read and write, whereas the 2008 census data reported a literacy rate of 43 per cent. Likewise, the proportion of people (aged 3 and older) without any education was nearly 13 per cent lower in the sample than in the census data. These differences, albeit large for a three-year period, may result from the increases in government expenditures on education after the war and the launch of free primary education in 2005, which has led to a sharp increase in primary school enrolment and a 20 per cent increase in literacy rates after the war (UNESCO, 2011). Apart from the differences, the distribution of characteristics in the sample seems comparable to that of the Burundi population. 
Table 4.2. Comparing census data with the Migration and Development data

\begin{tabular}{|c|c|c|c|}
\hline & $\begin{array}{c}\text { Burundi census } \\
\text { data } 2008\end{array}$ & $\begin{array}{c}\text { Migration and } \\
\text { Development } \\
\text { national survey data } \\
2011\end{array}$ & Difference \\
\hline \multicolumn{4}{|l|}{ Age distribution } \\
\hline Age group <14 (\%) & 44.10 & 42.60 & -1.50 \\
\hline Age group $15-59(\%)$ & 50.90 & 50.01 & -0.08 \\
\hline Age group $60>(\%)$ & 2.10 & 4.56 & 2.46 \\
\hline \multicolumn{4}{|l|}{ Gender } \\
\hline Male (\%) & 49.20 & 48.50 & -0.70 \\
\hline Female (\%) & 50.80 & 51.50 & 0.70 \\
\hline Average household size rural & 4.7 & 5.3 & +0.6 \\
\hline Average household size urban & 4.9 & 5.1 & +0.2 \\
\hline Literacy $(\%)^{1}$ & 43.20 & 70.50 & 27.30 \\
\hline No education $(\%)^{2}$ & 50.30 & 37.46 & -12.84 \\
\hline Primary education $(\%)^{2}$ & 39.10 & 18.80 & -20.30 \\
\hline Married (\%) & 46.70 & 43.86 & -2.84 \\
\hline
\end{tabular}

Note. ${ }^{1}$ includes individuals aged 10 and older, ${ }^{2}$ includes individuals aged 3 and older.

\subsection{Challenges of data collection, biases \& sensitivities}

This section first describes the challenges that were encountered during data collection, which include the lack of physical infrastructure, access to electricity and safety in Section 4.4.1. Second, I reflect on potential biases that may arise from the research design in Section 4.4.2. Third, the limitations of the data that resulted from unforeseen errors and the implications of these errors for the analyses and research findings are described in Section 4.4.3.

\subsubsection{Challenges during data collection}

Several challenges were encountered during the data collection in Burundi. ${ }^{6}$ Some of these challenges are commonly encountered when conducting survey research in a developing country context, and others were specific to the conflict-affected

\footnotetext{
${ }^{6}$ See Fransen, Kuschminder and Siegel (2012) for a detailed comparison of the data collection challenges encountered during the Migration and Development project in Burundi and Ethiopia.
} 
context in which this study occurred. First, the lack of physical infrastructure, especially in rural areas, posed challenges for data collection. Some parts of the country were difficult to reach, and interviewers often had to travel large distances to reach, first, the fieldwork locations and, second, the households to be interviewed. Fieldwork locations were reached by vehicle, often with an additional walk. In the end, all sampled locations were reached, but travel times significantly increased working hours and limited the number of interviews that could be conducted per day.

Second, access to electricity was a critical issue. As described, the data collection was performed using PDAs, which need to be recharged regularly. This issue was resolved by recharging the PDAs in the cars in which the interviewer teams travelled and by carrying paper questionnaires in case the PDAs could not be recharged. Because of these precautions, access to electricity did not affect the number of interviews that were conducted or the data quality.

Third, safety posed a key concern in the data collection process in Burundi. During the data collection period, there were incidental reports of violence, human rights violations and rumours of new rebel group formations. The security situation at each fieldwork location was evaluated daily, and decisions regarding safety measures were taken in close collaboration with the research partner and the interviewer teams. All interviewers carried a safety protocol that detailed how to act in an emergency situation. The security situation limited travel times for the interviewer teams, which also limited the number of interviews that could be conducted per day. Travelling during evening, nights and early mornings was not possible. In the end, all sampled communities were considered safe at the times that they were visited for data collection; therefore, the sampling strategy did not need to be adjusted due to safety concerns.

\subsubsection{Sensitivities in questionnaire design}

Several parts of the questionnaire contained questions that were potentially sensitive for the respondents. These parts included questions on our two main variables of interest - remittances and return migration - and conflict experiences. The issue of ethnicity was also sensitive in Burundi and was therefore not addressed in the questionnaire. This section details the reasons for the sensitivity of these subjects and the effects on the research design and the findings. 
First, our two main variables of interest, remittances and return migration, are known to represent sensitive issues for respondents in some contexts. Whether someone financially supports family members or friends, for example, often has a moral dimension and may lead to over- or under-reporting (see Brown, Carling, Fransen \& Siegel, 2014, for an overview). A household that has a migrant abroad but does not receive remittances may feel ashamed and decide to report remittances that are not received. These issues are closely linked to social norms in receiving areas regarding migrants and remittances. Under-reporting of remittances may also occur, for example, when households believe that correctly reporting their income may jeopardize their potential support from NGOs or from the state. Households may also under-report remittances if they receive remittances via informal channels and fear that this activity is illegal.

Return migration may also be sensitive topic for respondents. Migration experiences in Burundi were often the result of conflicts that people had experienced. Discussing their migration experiences could therefore prompt bad memories. In addition, social reintegration is a current problem in Burundi and there are many social tensions between returnees and non-returnees (Fransen and Kuschminder, 2012). It was therefore a possibility that returnees did not want to be identified as former refugees because they feared stigmatization. This problem has been described in the literature as one of the challenges that researchers may encounter when conducting research with returnees or former refugees (Rogge, 1994).

Because we were aware of the potential sensitivity of the survey questions on remittances and return migration, we took several measures to reduce over- or under-reporting. As described, we stressed issues of anonymity and confidentially before each interview. The questionnaire items on remittances were also embedded in a module on the migration of household members and therefore followed 'logically' from the questions on migration. The questions were introduced while emphasizing to the respondent that he or she had the option to decline to reply to these questions. In addition, all interviewers were trained to be aware of the potential sensitivity of the questions on remittances and return migration and were given tools to either ask for more information ('probing') or to stop asking questions if the interviewer did not want to reply.

Second, the questionnaire contained a module that asked about the conflict experiences of the household during the last war in Burundi. For example, the 
module asked about the experiences of crime that resulted in the death or disablement of an adult household member, imprisonment of household members and persecution. These questions may be difficult for respondents to answer and may also reduce a respondent's willingness to answer the questions. When integrating questions on conflict experiences in multi-topic household surveys, such as the Migration and Development survey, it is critical to keep the conflict module as short as possible (Bruck, Justino, Verwimp, \& Avdeenko, 2010). We therefore chose to use only a few and simple items to measure conflict experiences. This limited the interview time, enhanced data quality and response rates and reduced the stress that the respondent experienced when answering these questions as much as possible. The questions on conflict experiences in the Migration and Development questionnaire were reduced to 7 questions. At the beginning of the module, we also emphasized again that the questions did not need to be answered if the respondent chose not to do so.

Third, ethnicity was one of the most sensitive topics that we encountered in Burundi. From a research perspective, it would have made sense to incorporate the concept of ethnicity into the research design. There are significant historic differences between ethnic groups in terms of livelihood activities, wealth and social class (Uvin, 2009). Adding a measurement of ethnicity would have allowed us to control for these differences. Second, ethnicity played a large role in the Burundi conflicts. People from both groups were targeted because of their ethnicity at different points in time. Ethnicity is consequently linked to migration as well. Members of both the Hutu and Tutsi populations were forced to flee their homes to seek refuge elsewhere, either abroad or within the country, at a certain point in history. As described in Chapter 3, the Burundi refugee population in Tanzania largely consisted of Hutus, whereas the residents of IDP camps were primarily Tutsi.

Despite the importance of ethnicity in the Burundi context, the concept is not further addressed in this dissertation for two reasons. First, because ethnicity was used to target violence during Burundi's conflicts, asking about ethnicity during the research may have prompted bad memories or raised fear among the respondents. People frequently do not wish to share their ethnic background, and asking about it directly could have created suspicion or even fear amongst the respondents. Our interviewer teams also expressed that they did not feel comfortable asking about ethnicity, and we therefore decided to omit the ethnicity 
questions from the questionnaire. Second, Uvin (2009) found that 'Burundians genuinely desire to move beyond ethnocentricity' (Uvin, 2009, p. 188). Ethnicity is an extremely sensitive issue, and referring to ethnicity is generally not accepted. Both Hutus and Tutsis were and feel that they were victims of the long-lasting conflict (Lemarchand, 1996; Uvin, 2009). As a researcher, I chose to respect this wish to avoid the concept of ethnicity altogether.

Although controlling for ethnicity is not possible with these data, the data contain some proxies for ethnicity that were used as control variables in the analyses in Chapter 7 and Chapter 8. These proxies include the IDP camp experiences of households versus the international refugee experiences of households. As described above, these variables were strongly linked to ethnicity. Moreover, community-level information on ethnic homogeneity (only one ethnic group in a community) versus ethnic heterogeneity (two or more ethnic groups in a community) was collected using the community questionnaire. This information was also used as a control variable in Chapter 7 and Chapter 8. In Chapter 5 and Chapter 6, other variables that controlled for wealth differences were included as control variables. These included asset ownership (e.g., housing, land), expenditures and education. Although the proxies do not completely capture differences between households related to ethnicity, they do eliminate most of the variation in terms of wealth that may exist between ethnic groups.

\subsubsection{Data limitations}

Data collection is a complex and lengthy process that is rarely completed without errors. Some limitations regarding the data should therefore be mentioned. These limitations relate to the information that was not collected and unforeseen errors that the data contained. The implications of these data limitations for the analyses in the empirical chapters of this dissertation (Chapter 5 to Chapter 8 ) are discussed.

First, the questionnaire did not collect detailed information on previous experiences of forced internal displacement of households. This decision was a consequence of the thematic focus of the Migration and Development project, which concentrated on the effects of international migration on development. As described in Chapter 3, internal displacement was common in Burundi during the war, and it is likely that internal displacement, or the return of IDPs, had significant consequences for development. One item in the questionnaire referred to the IDP camp experiences of household members. Household heads were asked 
whether at least one household member had ever resided in an IDP camp. This measurement provides a broad and rather crude measurement of the internal displacement experiences of households. First, the item does not capture experiences of internal displacement that occurred outside camps. Second, the item does not identify the exact household members who had been displaced. Third, the item does not provide information on when, where and for how long individuals had been displaced.

Nevertheless, the indicator on IDP camp residence provides important information on the wartime experiences of households. First, IDPs who ended up in camps usually resided in these camps for a long time. Scarce humanitarian aid was provided in the camps, especially compared with the humanitarian aid that was given to refugees who resided in the camps in Tanzania. IDP camp experiences are thus likely to have had a significant effect on households' welfare, and controlling for the IDP camp residence of at least one household member allowed me to capture, or at least control for, these effects. Second, as described in the previous section, IDP camp residence can be used as a proxy for ethnicity in the Burundi context. Third, in the face of conflict, families often migrated together to IDP camps. Information on the IDP camp residence of 'at least one of the household members' can therefore be used as a proxy for the IDP experiences of all household members. For these reasons, the item provided an important control variable in many of the analyses that were conducted for the empirical chapters (Chapter 5 to Chapter 8). However, because of its crude measurement, the results regarding this variable should be treated with caution, and the effect of IDP experiences on development in Burundi remain to be explored in future research.

Second, although the goal of the research was to study the consequences of international migration, we were unable to collect reliable information on the emigrant connections of households. The questionnaire posed the following question: 'Are there any household members who currently reside abroad and have been residing abroad for at least three months?' In the Burundi context, however, a household member who moves abroad is no longer considered part of the household. This consideration was not anticipated, and we therefore had very few observations on emigrant connections in the data. In the urban survey data, for example, only 22 of the 810 households ( 2.7 per cent) indicated that they had a household member residing abroad, while 129 households (15.93 per cent) reported having received remittances in the 12 months prior to the interview. 
Households who receive remittances have an emigrant connection by definition, but this emigrant connection was not captured because of the definitions of migrants and households that we used.

The incomplete information on emigrant connections may have affected the results of the analyses in Chapter 6 (Remittances, Bonds and Bridges), where I study the effects of remittances on the social capital of remittance-receiving households. I argue that one of the mechanisms through which remittances may affect social capital investments is through the norms and values that are transmitted to receiving households by emigrants abroad. Thus, enhanced participation in community organizations, for example, may be a result of emigrant connections rather than a result of remittances per se. Because of the incomplete information on emigrant connections, I am unable to make a distinction between the effects of emigrant connections and remittances. This chapter does make a valuable contribution to the literature by showing that there are linkages between remittances and social capital. Although the exact mechanism through which remittances affect social capital cannot be disentangled, this chapter makes a valuable contribution to the literature by showing that there are linkages between remittances and social capital that warrant further research attention.

Third, because of a programming error in the PDAs, we did not have information on the remittance usage of remittance-receiving households. A specific module in the questionnaire asked about how remittances are usually spent by the household, with answer categories including items such as education, health care, food and drinks, and business investments. This information proved to be unreliable and unusable. Although this information would have provided interesting insight with descriptive information on the remittance usage of remittance-receiving households, the appropriateness of asking about remittance usage is also debated in the literature (see Brown, Carling, Fransen, Siegel, 2014; McKenzie and Sasin, 2007). Money is considered fungible, meaning that remittances are treated as income and are probably not spent differently than any other income source. Thus, a question on remittance usage would be difficult to answer for the respondents. The best way to determine the effect of remittances on other household indicators, such as education or assets, is therefore to use econometric methods such as those used in Chapter 5 and Chapter 6. These econometric methods will be described in the next section. 


\subsection{Estimation methods}

When studying the effect of migration or migration-related phenomena such as remittances, one of the key challenges is to demonstrate causal relationships between the variables of interest. Potential endogeneity issues may arise as a result of reversed causality, selection biases or omitted variable bias (see MckKenzie \& Sasin, 2007). Especially when using cross-sectional data, as in the present study, it is important to account for potential endogeneity by means of statistical techniques. The estimation methods in the empirical chapters consisted of propensity score matching (PSM) (Chapters 5 and 6), regression analyses (Chapter 7) and regression analyses in combination with an instrumental variable (IV) approach (Chapter 8). The statistical techniques that were used in this dissertation are introduced in this section and are described in more detail in the empirical chapters (Chapter 5 to Chapter 8 ). In each of the chapters, several post-estimation test results are presented to validate the use of the techniques. The estimation methods are also complemented with descriptive statistics that provide preliminary insights into the data.

PSM was used to estimate the effects of remittances on the household wealth (Chapter 5) and social capital investments (Chapter 6) of remittancereceiving households. The PSM technique is often used in the absence of experimental or longitudinal data. This estimation procedure allows us to control for a possible selection effect of migration in which households who receive remittances may be wealthier or have more social capital initially and may therefore be more likely to migrate. Using PSM, a researcher can match remittancereceiving households with similar non-remittance receiving households (Rosenbaum and Rubin, 1983) to calculate an 'average treatment effect for the treated' (ATT). The ATT signifies the situation of a household if it had not received remittances. Using PSM, we are able to 'filter out' the effect of remittances on household wealth and social capital by controlling for a possible migration selection effect.

Chapter 7, which studies the sustainability of refugee return in Burundi, relies on regression analyses. The purpose of this chapter is to show relationships between refugee return and the socio-economic conditions of households. In addition, this paper aims to contribute to the literature on the sustainability of return by operationalizing the concept at different levels of analysis and by comparing different groups (first- versus second-generation returnees). Because I 
did not take any measures to address potential endogeneity, no causal inferences can be drawn from the analyses. However, as will be described in this chapter, the relationships that I identify are likely to run in the expected direction. In addition, even if the relationships are not causal, this chapter shows the existence of significant relationships between return migration and socio-economic conditions in areas of return. This finding is important because it emphasizes that return migration and socio-economic development are related.

In Chapter 8, I use regression analyses complemented with an IV approach to study the effect of refugee return on thefts, disputes and security in communities. The aim of this chapter is to examine causal effects of the return of refugees on communities. The relationship between return and security may, however, be confounded by a selection bias concerning the communities of return. Returnees may have chosen to settle in areas based on area characteristics such as the availability of land, the availability of employment or the security levels in those areas. If this is the case, any findings on the relationship between return and the dependent variables may result from this selection effect. The IV approach is a quasi-experimental method in which the independent variable of interest - return migration - is instrumented for by another variable that is relevant (correlated with the main independent variable) and exogenous (only related to the dependent variable via the dependent variable). In this study, the proportion of return migrants in the community was instrumented for by the distance of the community to the closest border (in $\mathrm{km}$ ). Because it is not possible to eliminate the possibility of endogeneity between return migration and the dependent variables, an IV approach using the two-stage least-squares (2SLS) technique was used as a robustness check. 
Chapter 5: Remittances and household wealth 
This chapter has been published as: Fransen, S. \& Mazzucato, V. (2014).

Remittances and Household Wealth after Conflict: A Case Study on Urban Burundi. World Development, 60, 57-68. 


\subsection{Introduction}

Conflict-affected settings have received scant attention in the literature on remittances, mainly due to limitations related to data availability and quality in unstable settings (Ahmed, 2000; Weiss Fagen \& Bump, 2006). Although some studies have been conducted on remittances after conflict (Van Hear, 2002; Weiss Fagen \& Bump, 2006), most were small scale and based on qualitative research, yielding limited knowledge on the role of remittances for households after conflict. In addition, the extent to which current theoretical perspectives on remittances are applicable to conflict-affected settings remains unclear. People forced to migrate due to conflict primarily do so to seek safety and security, not to diversify income (Lindley, 2008, 2010). To what extent do these objectives of safety and security lead to different remittance usage, than when migration is primarily a means of income diversification, as posited by the NELM literature?

Existing studies on remittances in conflict-affected contexts focus on how remittances support households that are 'recovering from' violent conflict (see, e.g., Weiss Fagen \& Bump, 2006). These studies argue that remittances provide a safety net for poorer households, insure them against shocks, and reduce poverty. In the face of failing states that are unable to provide members of society with basic needs, households are salvaged by family or friends who live abroad. Yet quantitative evidence for these claims is missing and consequently several unanswered questions remain concerning remittances after conflict. First, it is unclear whether remittances are a common resource for households recovering from conflict. Second, there is a lack of information regarding who the main beneficiaries of remittances after conflict are, and third, the effects of remittances on households' living conditions after conflict remain underexplored.

This paper analyses the extent and effects of remittances for households in a conflict-affected setting using data from Burundi, a small country in the African Great Lakes region. The data include a nationally representative dataset of 1,500 households and an urban dataset of 810 households living in Burundi's capital, Bujumbura. The analyses for this study are based on the latter dataset. The data were collected in 2011, slightly more than 5 years after the official end of conflict in the country, and contained information on each household's economic situation in 2011 and 5 years prior to the survey. Additional information was collected on households' international migration and remittance-receiving histories. The data thus offer a unique insight into the role of remittances for receiving households 
and allow a quantitative study of the characteristics of receiving households, the extent to which they rely on remittances, and the way they allocate this financial resource from abroad.

The study of remittances in a conflict-affected context provides insights into the livelihood strategies of households after conflict. It also provides an opportunity to test specific tenets of NELM studies of labor migration, to a conflictaffected setting. This study therefore adopts an explorative approach guided by the three hypotheses about the destination and use of remittances derived from NELM studies: relative deprivation, insurance, and investment, to research the extent to which these hold for remittances to households in Burundi. A multidimensional perspective on household wealth is taken to analyze the effects of remittances on several indicators, such as asset ownership, living conditions, and education. In doing so, we explore the various ways households might allocate remittances in this setting. Remittance allocation is also compared among poorer and wealthier households to analyze how remittances affect different household types, shedding light on the impacts of remittances on different household types after conflict.

\subsection{Theoretical perspectives on remittances after conflict}

The majority of micro-level studies on remittances of the past decades are based on the NELM approach (Stark, 1980; Stark \& Bloom, 1985). In NELM studies, migration is conceptualized as a household-level strategy to generate income through remittances with which a household can invest, diversify income, and insure itself against financial shocks.

The assumptions of NELM yield three hypotheses regarding migration motivations: (1) the relative deprivation hypothesis, (2) the investment hypothesis, and (3) the insurance hypothesis. The relative deprivation hypothesis posits that households attempt to better their economic position in their community or country through migration. Households that are relatively deprived are more likely to use migration as a household strategy (Stark \& Taylor, 1989). The investment hypothesis posits that remittances are invested in income-generating activities, such as businesses and agriculture. Remittances thus stimulate development in poor countries by relaxing households' liquidity constraints in failing markets (Taylor, 1999). Following this reasoning, the marginal effect of remittances is highest for remittance receiving households that face the largest financial constraints (Taylor, 1999; Taylor \& Wyatt, 1996). The insurance or 
smoothing hypothesis states that households use migration to insure themselves against financial risks, such as food insecurity, failing crops, or unemployment. Remittances thus smooth consumption by providing a form of insurance during difficult times (see, e.g., Lucas \& Stark, 1985).

The past decades of remittance research have provided varying levels of support for these hypotheses. With regard to the relative deprivation hypothesis, research has shown that remittances generally do not reach those who 'need' them the most or those who are most deprived in the context of developing countries (Ratha et al., 2011). This result is due to the 'selection effect' of migration; because costs are associated with migration, wealthier households generally have more means to send someone abroad and are consequently more likely to receive remittances (Adams Jr, 2011). In Ghana, for example, international remittances were found to be received by the richest two per cent of households (Mazzucato et al., 2008) although another study showed that poorer households benefited more from international remittances than richer households (Adams Jr et al., 2008). In Pakistan, households with more income were also more likely to receive remittances (Adams Jr, 1998). Whether the higher income of remittance-receiving households was due to remittances was not clear.

The investment hypothesis has been supported by meta-analyses that showed that remittances spur development and reduce poverty in developing countries (Adams Jr, 2011; Page \& Plaza, 2006; Ratha et al., 2011). Ratha et al. (2011), for example, conclude that remittances are generally invested in human capital, physical capital such as large assets (land or housing), businesses, or agricultural investments. Other studies have highlighted the insurance or consumption smoothing function of remittances by showing that remittances are invested in daily needs (Kabki et al., 2004; Mazzucato, 2009).

\subsubsection{Remittances after conflict}

Each of the three hypotheses may be applicable to explaining remittances in conflict-affected settings. There are however reasons why the applicability of NELM to these settings is debated. Many emigrants from conflict-affected settings moved because of security reasons, which are different from the economic reasons posited in NELM studies (Lindley, 2008). Yet a growing body of literature has shown that refugees often support family or friends living back home (Ahmed, 2000; Carling et al., 2012; Diaz-Briquets \& Perez-Lopez, 1997; Horst, 2004, 2008; 
Lindley, 2009), and authors have argued that motivations to remit do not differ substantially between refugees and economic migrants (see, e.g., Horst, 2004). Remittance sending may be more of a 'post hoc strategy' (Lindley, 2009, p. 1331), but migration motives are often multidimensional, and priorities may change over time depending on the circumstances of the migrant or the household in the home country (Lindley, 2008). In addition, not all emigrants from a conflict-affected context are necessarily refugees (see, e.g., Ahmed, 2000). The NELM hypotheses of relative deprivation, investment, and insurance can therefore be tested in a conflict-affected context.

Based on the existing literature, we can generate some expectations for remittances in a conflict-affected context. First, the relative deprivation hypothesis is not likely to hold. Most people flee within the borders of their own country or to neighboring countries, where there are few resources to remit (Nyberg-Sørensen et al., 2002). Only some people have the means to travel far and to generate income that is sufficient to engage in remittance sending (Van Hear, 2004). This situation also holds for labor migrants from conflict-affected contexts (Ahmed, 2000). These studies, in combination with remittance literature that finds that remittances do not accrue to the poorest of the poor (Adams Jr, 2011; Adams Jr et al., 2008; Mazzucato et al., 2008) make us expect that remittances will not reach the most disadvantaged households because they generally do not have the resources to send an individual abroad.

Second, the limited available evidence suggests that remittances are more likely to 'sustain' livelihoods after conflict through income smoothing rather than to 'transform' them through investments (Van Hear, 2002). This evidence provides support for the insurance hypothesis rather than the investment hypothesis. Households in conflict-affected settings might have limited investment opportunities due to damaged economic infrastructures and political and economic instability. In addition, remittances may function as insurance in areas where formal insurance mechanisms are deficient. Qualitative studies have shown that refugees most often remit to support daily needs rather than business investments (Van Hear, 2002; Weiss Fagen \& Bump, 2006). For example, Ahmed (2000) found that only 15 per cent of households in Somaliland used remittances for business or asset investments. Especially in rural areas, remittances were used to smooth consumption and to cope with shocks. Similarly, Horst and Van Hear 
(2002) describe how Somali refugees in Kenyan refugee camps smooth consumption by relying on remittances during difficult times.

In the following sections, the relative deprivation, investment, and insurance hypothesis are tested for the Burundi case. The relative deprivation hypothesis is tested by examining the prevalence of remittance receiving across relatively poorer and wealthier households. The investment and insurance hypotheses are tested by analyzing the effect of remittances on different household indicators. The hypotheses are not necessarily mutually exclusive; households might use remittances both for smoothing and investment purposes, and the uses might differ for households with different levels of deprivation. A multidimensional view of household wealth is therefore adopted to explore how households allocate remittances. Most previous studies have explored remittance effects on one or a few economic indicators, such as income or expenditures. Because this is one of the few quantitative studies in a conflict-affected context, we take a broad, exploratory perspective.

\subsection{Burundi: a history of migration and remittances}

Burundi has suffered from civil conflict and population displacements over the past four decades. Massive migration flows arose in the African Great Lakes region in the early 1960s, which also marked the end of Burundi's colonial period. These migrations were the result of violent conflict that was mostly organized along ethnic lines (De Bruyn \& Wets, 2006; Fransen \& Andersson, 2011). Burundi experienced several periods of conflict, notably in 1965, 1972, 1988, 1991, and between 1993 and 2005, and became one of the largest migrant-sending countries in the world between 1960 and 1980 (Spaan \& Van Moppes, 2006). In 1999, more than 800,000 were residing in Internally Displaced Persons (IDPs) camps, mostly in Southern Burundi (UNOCHA, 2000). Also during the late 1990s, another estimated 800,000 were forcedly relocated in regroupment camps as a result of a government policy that aimed to facilitate military operations (Martin, 2003; USCRI, 2000). ${ }^{7}$ Many other Burundians sought shelter in the neighboring countries of Tanzania, Rwanda, and the DRC. A small minority migrated to Europe and North America.

\footnotetext{
${ }^{7}$ Households were officially relocated for security reasons, to protect citizens against actions of the Hutu rebel group FNL (Forces Nationales pour la Liberation). The international community, however, condemned the forced relocation activities and accused the government, which consisted of Tutsi (minority) rule, of attempting to isolate FNL forces among the rural Hutu population.
} 
More than 350,000 Burundians, or 4.2 per cent of the population, were living abroad in 2010 (World Bank, 2011c). In January 2012, UNHCR estimated Burundian refugees and asylum seekers to approximate 110,000 (UNHCR, 2012).

Migration to Europe and North America was not only induced by conflict but was also due to economic incentives. The Burundian diaspora was created during four migration waves and consists of a heterogeneous group in terms of skills, migration motives, and political views (Turner, 2008a, 2008b). The first wave consisted of a few better-off Burundians who were mostly part of the Tutsi political elite or monarchy that moved to Belgium to study before Burundi's independence from Belgium in 1962. This trend persisted after the 1960s (De Bruyn \& Wets, 2006; Turner, 2008a, 2008b). The second wave comprised mainly Hutu asylum seekers who fled the 1972 genocide (De Bruyn \& Wets, 2006; Lemarchand, 1996, 2008). Many had scholarships and were either already living in Belgium or had been living there previously (Turner, 2008a, 2008b). Over time they formed networks that attracted students and entrepreneurs, creating the third wave during 1972-93. The re-ignition of conflict in Burundi in 1993 and the economic downturn that followed generated the fourth wave (De Bruyn \& Wets, 2006). These were asylum seekers as well as young, urban Burundians of both Tutsi and Hutu origin who were in search of better economic opportunities. The first wave thus consisted mostly of wealthier emigrants, whereas the subsequent waves were more diverse. Anecdotal evidence suggests that highly skilled Burundians mostly migrated from Bujumbura, Burundi's capital.

\subsubsection{Remittances in Burundi}

The long-lasting conflict in Burundi left its people traumatized and impoverished (Lemarchand, 1996; Uvin, 2009). In 2006, 67 per cent of the population lived below the national poverty line (World Bank, 2011b), and in 2011, Burundi ranked 185 on the Human Development Index, the lowest ranking in the world after DRC and Niger (UNDP, 2011). Significant differences exist in poverty levels between urban and rural areas, with rural areas being more deprived than urban areas (Bundervoet, 2006). Remittances are considered an important potential resource for development, and policies are now being designed to harness and increase this financial resource from abroad (Fransen and Andersson, 2011 and Fransen and Siegel, 2010). 
Remittances to Burundi were estimated at three million USD in 2010 (World Bank, 2011c). The Burundian Central Bank, Banque de la Republique Burundi (BRB), estimated remittances at 27.74 million USD between January and October 2010, a sharp increase from the 0.06 million USD that they reported in 2005 (personal communication with BRB, January 2011). The difference between these statistics is most likely due to measurement differences and variations in data quality. Compared to other countries in the region, remittances to Burundi are low. For example, Kenya, one of Africa's emblematic countries with regard to tapping its diaspora potential, received 1,758 million USD in 2010. When comparing Burundi's remittance inflows to FDI and ODA during 2005-10, remittance and FDI inflows were negligible (see Figure 5.1). It is unclear whether these numbers underestimate remittances because they represent only formal flows. De Bruyn and Wets (2006) report that most remittances to Burundi were sent informally, but Fransen and Andersson (2011) argue that due to innovations and increasing competition, the remittance market is increasingly formalizing. From 2008 onward, remittances increased and surpassed FDI using both World Bank and BRB measurements.

Figure 5.1. Remittances, FDI, and ODA in Burundi: 2005 - 2010

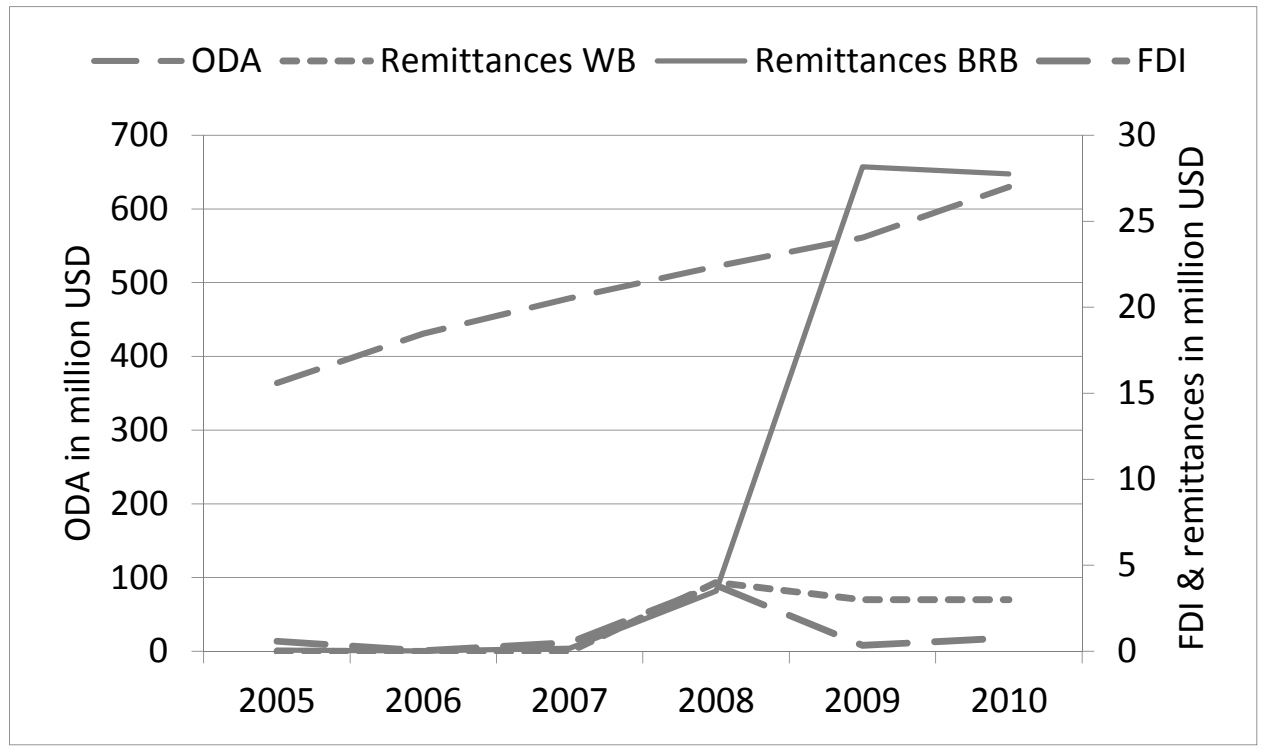

Sources: World Bank, 2011c; Banque de la Republique du Burundi, 2011. 
A few small-scale studies have been conducted on remittances in Burundi. These studies found that regional remittances are negligible despite the large regional migration flows (Fransen \& Andersson, 2011). Most regional migrants reside in temporary settlements or refugee camps, and their living conditions, combined with the absence of financial infrastructure, likely do not permit them to send remittances. Remittance sending is more common among the Burundian wider diaspora, and it is generally assumed that most remittances are sent from Europe and North America (De Bruyn \& Wets, 2006; Fransen \& Andersson, 2011). These studies were based on a small number of qualitative interviews with key stakeholders. The data collected for the present study, provide a first, larger-scale analysis of remittances in Burundi and will show that, indeed, regional remittances are small.

\subsection{Data and empirical strategy}

Two datasets were used for this paper based on a national and an urban household survey conducted in Burundi in 2011. For the national survey, 1,500 households were interviewed in all 17 provinces of Burundi (including Bujumbura) based on a two-step self-weighting sampling design between January and February 2011. ${ }^{8}$ The national survey was followed by an urban survey that took place in March 2011 and collected information on 810 households in Bujumbura, Burundi's capital. Data collection took place in 54 randomly selected blocks within the 17 zones or quartiers (neighborhoods) in the city. On each block, 15 randomly selected households were interviewed. In this paper, the national data are used to provide general statistics on remittances in Burundi, and the urban data are employed to quantitatively explore the effects of remittances on household wealth.

\subsubsection{Remittances}

Remittances were defined in the survey as international monetary transfers that were received by a household from a migrant in the 12 months previous to the interview. Information was collected on the frequency of the financial transfers, their value, and the characteristics of the remittance senders. The national survey that preceded the urban survey revealed that 2.40 per cent $(n=36)$ of the sampled

\footnotetext{
${ }^{8}$ See the Burundi fieldwork report of the Migration and Development: A World in Motion project for a detailed account of the sampling strategy of the survey, available at: http://mgsog.merit.unu.edu/ISacademie/publications.php.
} 
households had received remittances in the past year, and that most receiving households (38.89 per cent) lived in Bujumbura. The finding that remittances were more common in the capital was confirmed by the urban data: of the 810 households, 15.93 per cent $(n=129)$ were remittance-receiving households. Further analyses were therefore based on the urban household data.

\subsubsection{Household wealth}

Six indicators were constructed to measure household wealth. All items for the survey questionnaire in Burundi were derived from standard questions in multitopic household surveys that are often applied in developing countries, such as the Living Standards Measurement Survey (LSMS), the Demographic Health Survey (DHS), and the World Values Survey (WVS). ${ }^{9}$ First, an asset index was created with Principal Component Analysis (PCA), following Filmer and Pritchett (2001). This index included whether the household owned a house, land, livestock, and other assets, such as a radio, a television, a car, or a motorbike. Asset data represent a household's long-term wealth (Filmer \& Pritchett, 2001) and are generally more reliable than income or expenditure data (Sahn \& Stifel, 2003). Especially in a poor country such as Burundi, where many households do not have a regular income source, asset ownership is a good indicator of household wealth.

The second indicator was the average educational attainment of all adult household members, ranging from one (no education) to four (bachelor's degree or higher). This indicator was chosen because primary education (up to 13 years old) is freely available in Burundi and because a substantial number of households in the sample did not have children aged 14 to 18 . Third, a financial access index measured the household's access to financial services, including the use of a bank account, the ability to generate money in case of an emergency, and savings. This index ran from zero, for households that answered 'no' to all questions, to three, for households that answered 'yes' to all. Financial access is increasingly covered in household surveys in developing countries because it is considered important for poverty alleviation. ${ }^{10}$

\footnotetext{
${ }_{9}$ See http://http://econ.worldbank.org/ for more information on the Living Standard Measurement Survey, http://www.measuredhs.com/ for the Demographic Health Survey, and http://www.worldvaluessurvey.org/ for the World Values Survey.

${ }^{10}$ An example of data collection on financial inclusion is the World Bank's Global Findex Questionnaire. For more information, visit http://http://econ.worldbank.org/.
} 
The fourth indicator, a living conditions index, was also constructed with PCA and was composed of the type of water, toilet, and cooking fuel the household used as well as housing characteristics. Details on the PCA results are available upon request. Fifth, food security measured the frequency with which the household had difficulties meeting food needs, ranging from one (every day) to five (never). Finally, for subjective wealth, the household head was asked to rate the household's economic situation on a scale from one (we are finding it very difficult) to five (we are living very comfortably). These items were based on standard measurements in surveys such as the DHS and WVS. Table 5.1 shows the summary statistics of the wealth variables. Correlations between variables ranged from 0.24 ( $p<0.01)$ (between the asset index and food security) to 0.60 ( $p<0.01$ ) (between the living conditions index and average educational attainment).

Table 5.1. Summary statistics of the wealth indicators

\begin{tabular}{lccccc}
\hline Variable & $\mathrm{n}$ & $\mathrm{M}$ & $\mathrm{SD}$ & Min & Max \\
\hline & & & & & \\
Assets (index) & 810 & 0.00 & 1.58 & -2.45 & 5.67 \\
Educational attainment & 809 & 2.02 & 0.75 & 1 & 4 \\
Financial access (index) & 761 & 1.12 & 1.26 & 0 & 3 \\
& & & & & \\
Living conditions (index) & 808 & 0.00 & 2.37 & -4.04 & 4.44 \\
Food security & 808 & 3.66 & 1.66 & 1 & 5 \\
Subjective wealth & 807 & 2.85 & 0.91 & 1 & 5 \\
& & & & & \\
\hline
\end{tabular}

\subsubsection{Empirical strategy}

The analyses in this paper were based on descriptive statistics, logistic regression analysis, and propensity score matching (PSM). Descriptive statistics provide insight into remittance flows in Burundi. We use logistic regression analysis to explore which households are more likely to receive remittances. Because this technique does not take into account the selectivity of migration, PSM was employed. PSM matches remittance-receiving households with similar nonremittance-receiving households (Rosenbaum \& Rubin, 1983) to calculate an 'average treatment effect for the treated' (ATT). The ATT signifies what a household would have looked like had it not received remittances. This estimation procedure allows us to control for a possible selection effect of migration in which it may be that households who receive remittances may be wealthier to begin with and therefore more likely to migrate. Using PSM we are able to 'filter out' the effect 
of remittances on household wealth, controlling for possible migration selection effect.

The matching variables for PSM include age, gender, educational attainment, employment, and marital status of the household head and household characteristics such as the dependency ratio and the number of economic shocks that the household experienced in the past 5 years. These variables cover the most important migration determinants identified in the literature (McKenzie \& Sasin, 2007) and play a role in Burundi's emigration. The displacement camp and regroupment camp experiences of households were included to control for internal, forced displacement experiences. Regroupment camps (camps de regroupement) were part of a forced relocation scheme in Burundi that occurred in the late 1990s and mainly affected the Hutu majority in Burundi, whereas displacement camps were mostly inhabited by Tutsi Internally Displaced Persons (IDPs) who fled violent conflict. Almost 37 per cent of households in the sample had either displacement camp experiences or had at least one household member that had been placed in a regroupment camp. Households were also matched on whether they had a current or return migrant. Retrospective data on house and land ownership were used to match households on characteristics from the period before they started receiving remittances. These indicators refer to the household's situation 5 years earlier. The five-year period was used because it marks the official transition from the pre-conflict to the post-conflict situation in Burundi and was therefore the most reliable reference point for interviewees to provide retrospective information. Descriptive statistics of the matching variables are available upon request.

Sensitivity analyses were conducted after matching using the bounding approach (Rosenbaum, 2002) to explore the extent to which unobserved heterogeneity, or 'hidden bias,' between remittance-receiving households and nonremittance-receiving households would affect the estimates. To verify the robustness of the results, three estimation methods were used to calculate the ATT: Nearest Neighbor (5), Kernel (Gaussian), and Radius matching (Caliper 0.01) (see, Caliendo \& Kopeinig, 2008). For the final part of the analyses, Kernel matching was used, in which weighted averages of all individuals in the control group were calculated to produce the counterfactual. Balancing tests, which check whether systematic differences between groups are eliminated through matching, were performed by comparing mean absolute standardized biases (Rosenbaum \& Rubin, 
1985), pseudo R2, and p-values of the likelihood ratio tests before and after matching (Sianesi, 2004).

\subsection{Results: remittances and household wealth}

The results are presented in three steps. First, descriptive statistics are presented on remittance flows and channels in Section 5.5.1. These descriptive statistics will provide a general insight into remittance inflows in Burundi. Second, the characteristics of remittance-receiving households are explored in Section 5.5.2. These findings are used to test the relative deprivation hypothesis. Finally, the effects of remittances on different household types are analyzed to test the insurance versus investment hypothesis in Section 5.5.3.

\subsubsection{Remittance flows and channels: descriptive statistics}

The urban data revealed that in the capital, almost 16 per cent of all households received remittances in the previous year. Some remittance-receiving households in Bujumbura received remittances from more than one sender: for the 129 receiving households, the average number of senders was 1.26 , for a total of 162 senders. Descriptive statistics on the financial transfers of these 162 senders yield some interesting insights (see Table 5.2). First, remittances were an irregular or infrequent source of income for most households. Most remittances were sent to the households irregularly, once, or twice in the previous 12 months. A smaller percentage of senders sent the money either every month or every 3 months. Second, the vast majority of senders were family members of the receiving household. This finding indicates that remittance flows are mostly a family affair. Third, regional remittances were small compared to 'North-South' flows. The majority of senders were located in Europe and North America, which is in line with anecdotal evidence on Burundi (Weiss Fagen \& Bump, 2006) and with findings of studies conducted both in non-conflict settings (see, e.g., Mazzucato et al., 2008) and forced migration contexts (see, e.g., Horst, 2004). 


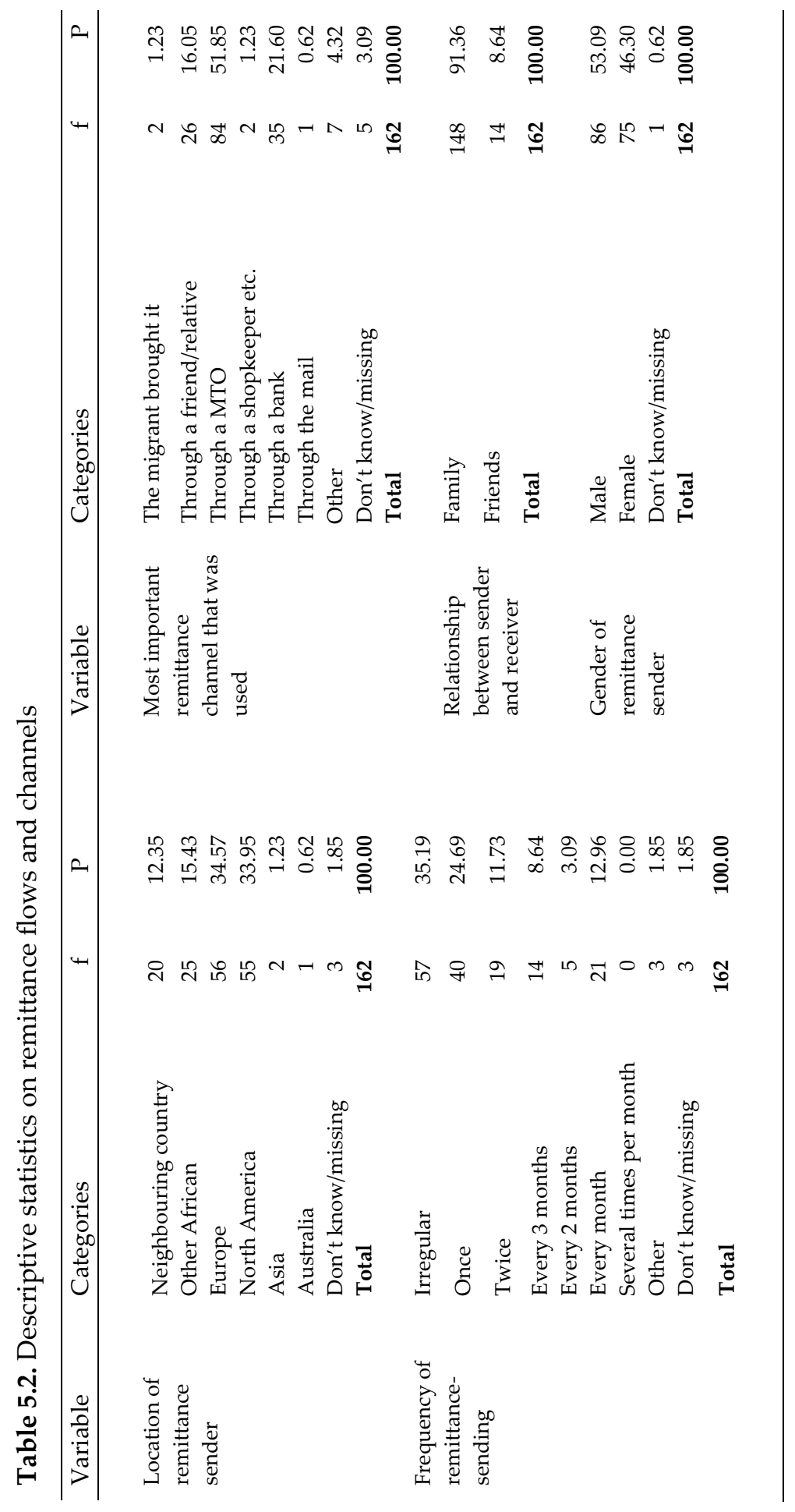

ลำ 
Table 5.3. Remittance-receiving households per wealth quartile/category

\begin{tabular}{lcccccc}
\hline & \multicolumn{5}{c}{ Quartiles/Categories } & \\
& 1 & 2 & 3 & 4 & 5 & Total \\
\hline \multirow{4}{*}{ Assets } & 16 & 16 & 36 & 61 & - & 129 \\
& $(7.69)$ & $(8.00)$ & $(17.91)$ & $(30.35)$ & & $(15.93)$ \\
Educational attainment & 8 & 29 & 26 & 65 & - & 128 \\
& $(2.97)$ & $(12.39)$ & $(22.03)$ & $(34.57)$ & & $(15.82)$ \\
Financial access & 20 & 9 & 32 & 61 & - & 122 \\
& $(5.22)$ & $(10.59)$ & $(28.83)$ & $(33.52)$ & & $(16.03)$ \\
& & & & & & \\
Living conditions & 6 & 12 & 43 & 68 & - & 129 \\
& $(2.96)$ & $(5.94)$ & $(21.08)$ & $(33.83)$ & & $(15.93)$ \\
Food security & 3 & 5 & 3 & 6 & 111 & 128 \\
& $(1.81)$ & $(6.10)$ & $(6.12)$ & $(8.22)$ & $(25.34)$ & $(15.84)$ \\
Subjective wealth & 0 & 13 & 54 & 51 & 10 & 128 \\
& $(0.00)$ & $(6.34)$ & $(14.63)$ & $(33.77)$ & $(41.67)$ & $(15.86)$ \\
& & & & & & \\
\hline
\end{tabular}

This finding also confirms expectations that regional remittances are relatively small, likely because of the dire living conditions of migrants in neighboring countries. Fourth, most senders used formal channels, the most popular of which were Money Transfer Operators (MTOs) and banks. This finding suggests that formal remittance statistics on Burundi such as those provided by the World Bank and BRB provide good estimates because they capture the majority of transfers. On average, households received 1827 USD (SD = 4780), with a minimum of less than one USD and a maximum of 25,530 USD per household in the previous twelve months. The median was 400 USD per household. Given that GNI per capita in PPP was 250 USD in Burundi in 2011 (World Bank, 2011b), it is safe to say that remittances are an important resource for receiving households in Bujumbura.

\subsubsection{Do remittances reach the poorest of the poor?}

Table 5.3 above presents the number and percentage of remittance-receiving households per quartile (for the indexes) and categories of the Likert scale (for food security and subjective wealth). It is clear that there are more remittance-receiving households in the higher quartiles or categories of the indicators. For example, 8 per cent of the households that are in quartile one of the asset index were remittance-receiving households, whereas in quartile four, more than 30 per cent 
were remittance receivers. These findings indicate that the urban remittancereceiving households in our sample generally had more assets, higher educational attainment, more financial access, and better living conditions, food security and subjective wealth than non-remittance-receiving households. T-tests show that remittance-receiving households scored significantly $(\mathrm{p}<0.01)$ higher on all outcome variables than non-receiving households.Logistic regression analysis shows comparable results (Table 5.4). Households with higher average educational attainment had higher odds of receiving remittances, as did households that scored higher on the asset index, keeping all other variables constant.8 At this point, no causal inferences can be made because there may be a migration selection effect at play. It is not yet clear whether wealthier households had more migration opportunities and were therefore more likely to receive remittances or whether households became wealthier because of remittances.

The analysis shows that employment of the household head decreased the odds of receiving remittances. A likely explanation is that households in which the household head was unemployed had a greater need for financial support. Surprisingly, households that experienced more economic shocks had lower odds of receiving remittances. This may be because wealthier households experienced less economic shocks or were less affected by them and therefore underreported them in the survey. There is a small but significant correlation between the asset index and the number of economic shocks that households experienced $(r=-0.15$, $\mathrm{p}<0.01)$. Households in which members had ever been in a regroupment camp had lower odds of receiving remittances, which yields two possible explanations: (1) the Hutu majority that mainly inhabited these camps and that was marginalized during the war period (Lemarchand, 1996; Uvin, 2009) had lower opportunity for mobility and therefore for receiving remittances, or (2) households with regroupment camp experiences were more vulnerable due to their resettlement. A t-test reveals that households with regroupment camp experiences scored significantly lower on the asset index $(t=5.08, p<0.01)$, but it is not clear whether this was due to their relocation. Internal displacement and return migration experiences were not related to receiving remittances. 
Table 5.4. Logistic regression: the odds of receiving remittances $(n=793)$

\begin{tabular}{|c|c|c|c|c|}
\hline & B & SE & $\mathrm{Z}$ & OR \\
\hline \multicolumn{5}{|l|}{ Household. head characteristics } \\
\hline Age & 0.01 & 0.01 & 0.49 & 1.03 \\
\hline Gender ( $1=$ female) & -0.19 & 0.45 & -0.44 & 1.97 \\
\hline Educational attainment & $0.89^{* * *}$ & 0.18 & 4.89 & 3.49 \\
\hline \multicolumn{5}{|l|}{ Marital status } \\
\hline \multicolumn{5}{|l|}{ Single (= ref.) } \\
\hline Married & -0.09 & 0.42 & -0.22 & 2.07 \\
\hline Divorced & 0.79 & 0.62 & 1.28 & 7.36 \\
\hline Widowed & 0.14 & 0.51 & 0.27 & 3.15 \\
\hline Employed (1=yes) & $-0.47^{*}$ & 0.25 & -1.90 & 1.01 \\
\hline \multicolumn{5}{|l|}{ Household characteristics } \\
\hline \multicolumn{5}{|l|}{ Asset index } \\
\hline \multicolumn{5}{|l|}{ Quartile1 (= ref.) } \\
\hline Quartile2 & -0.07 & 0.40 & -0.18 & 2.03 \\
\hline Quartile3 & 0.59 & 0.37 & 1.59 & 3.75 \\
\hline Quartile4 & $0.83^{* *}$ & 0.39 & 2.11 & 4.97 \\
\hline Dependency ratioa & -0.02 & 0.07 & -0.26 & 1.13 \\
\hline Economic shocks in the past 5 years & $-0.14^{* *}$ & 0.07 & -1.99 & 1.00 \\
\hline Migrant abroad (1 = yes) & $1.74^{* * *}$ & 0.49 & 3.54 & 14.94 \\
\hline Return migrant $(1=$ yes $)$ & 0.14 & 0.31 & 0.44 & 2.11 \\
\hline Displacement camp experiences $(1=$ yes $)$ & 0.49 & 0.31 & 1.57 & 3.02 \\
\hline Regroupment camp experiences $(1=$ yes $)$ & $-0.85^{* *}$ & 0.38 & -2.22 & 0.91 \\
\hline Constant & -3.80 & 0.68 & -5.58 & - \\
\hline \multicolumn{5}{|l|}{ Model evaluation } \\
\hline Likelihood ratio test & $119.74^{* * *}$ & & & \\
\hline Pseudo R squared & 0.1733 & & & \\
\hline
\end{tabular}

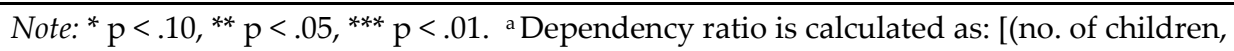
younger than 18$)+($ no. of elderly, 65 and older)]/ (number of adults, 18-65)*100.

While better off households were more likely to receive remittances (Table 5.3), here we investigate how significant remittances were to those households receiving them. Table 5.5 shows that wealthier households, on average, received higher values of remittances. The table also shows the importance of remittances relative to the households' yearly expenditures. On average, remittances constituted 61 per cent of household expenditures, with a minimum of 0.01 per cent and a maximum of 934.12 per cent (median $=9.81$ per cent). Generally, for 
wealthier households remittances constituted a higher average percentage of total household expenditures. Specifically, the asset index and the education variable followed a clear upward trend, meaning that households with more assets and higher educational attainment received more remittances, which constituted larger percentages of their total household expenditures. For the other household indicators, the relative importance of remittances is non-linear. This is likely due to the small sample sizes in the lower categories of some of the indicators, which yield statistics sensitive to outliers.

Table 5.5. Remittance-values and percentages of yearly expenditures (in USD)

\begin{tabular}{|c|c|c|c|c|c|c|c|c|c|}
\hline \multirow{2}{*}{$\begin{array}{l}\text { Quartile/ } \\
\text { Category }\end{array}$} & \multicolumn{3}{|c|}{ Assets } & \multicolumn{3}{|c|}{ Education } & \multicolumn{3}{|c|}{ Financial access } \\
\hline & M & $\mathrm{P}$ & $\mathrm{n}$ & M & $\mathrm{P}$ & $\mathrm{n}$ & M & $\mathrm{P}$ & $\mathrm{n}$ \\
\hline 1 & 341.09 & 28.97 & 13 & 114.90 & 6.95 & 8 & 263.21 & 26.67 & 18 \\
\hline 2 & 589.75 & 44.09 & 14 & 235.88 & 16.82 & 24 & 438.90 & 20.07 & 9 \\
\hline 3 & 1112.02 & 50.15 & 31 & 1359.92 & 55.34 & 24 & 1088.88 & 53.02 & 27 \\
\hline 4 & 2936.95 & 78.92 & 53 & 3027.84 & 91.51 & 54 & 3069.00 & 86.38 & 51 \\
\hline 5 & - & - & - & - & - & - & - & - & - \\
\hline Total & 1827.23 & 60.64 & 111 & 1842.93 & 61.17 & 110 & 1827.23 & 60.64 & 111 \\
\hline Quartile/ & \multicolumn{3}{|c|}{ Living conditions } & \multicolumn{3}{|c|}{ Food security } & \multicolumn{3}{|c|}{ Subjective wealth } \\
\hline Category & M & $\mathrm{P}$ & $\mathrm{n}$ & M & $\mathrm{P}$ & $\mathrm{n}$ & M & $\mathrm{P}$ & $\mathrm{n}$ \\
\hline 1 & 160.75 & 7.50 & 5 & 111.02 & 5.67 & 3 & - & - & - \\
\hline 2 & 663.08 & 57.42 & 9 & 365.42 & 43.18 & 5 & 333.37 & 40.36 & 11 \\
\hline 3 & 852.55 & 32.09 & 41 & 140.83 & 5.78 & 3 & 1191.69 & 43.14 & 45 \\
\hline 4 & 2876.71 & 86.88 & 56 & 637.75 & 89.21 & 4 & 2454.36 & 76.28 & 45 \\
\hline 5 & - & - & - & 2079.88 & 64.44 & 95 & 3346.06 & 32.26 & 9 \\
\hline Total & 1827.23 & 60.64 & 111 & 1827.23 & 60.64 & 111 & 1827.23 & 60.64 & 111 \\
\hline
\end{tabular}

Note: 18 observations on remittance values were missing.

\subsubsection{Remittances and household wealth - investment versus insurance}

In this section, we analyze the extent to which remittances affect the wealth of remittance-receiving households. The previous analyses may have been confounded by the selection effect of migration. As described in Section 5.4, we make a distinction between productive and non-productive assets to test to what extent remittances are used for investments and insurance purposes. The first PSM 
logit estimates are shown in Table 5.6. The table shows the mean values for the treated (remittance receivers) and untreated (non-remittance receivers), the ATT, and the results of the sensitivity analyses. The analyses reveal that remittancereceiving households scored higher on non-productive assets, such as living conditions, food security, and subjective wealth, compared to non-remittancereceiving households. Remittances did not have a significant effect on productive assets, such as asset ownership and the household's average educational attainment. An exception is the financial access indicator; households invested part of their remittances in savings and a bank account. Based on these results, we are unable to reject either the insurance or investment hypothesis, although it seems that remittances were used for insurance purposes to a larger extent.

The results are robust across the different matching estimations. The asset index analyses show lower robustness, but the differences between the results are small. The critical levels of sensitivity to hidden bias are presented in Table 5.6. Values of gamma $(\Gamma)$ that are close to 1.0 indicate that the estimates are sensitive to potential hidden bias, whereas larger values mean that the estimates are insensitive (Rosenbaum, 2002). $\Gamma$ values range from 1.0 to 4.3 , showing higher sensitivity for the asset index and education and lower sensitivity for the other outcome variables. The value 1.5, for example, indicates that in the case of an unobserved covariate, this variable should affect the odds of receiving remittances by a factor of 50 per cent to alter the estimates. It is unlikely that the estimates suffer from hidden bias because we matched households on all theoretically relevant variables.

Table 5.7 shows a comparison of the pseudo R2, p-values of the likelihood ratio tests, and the mean absolute standard biases before and after matching. These balancing tests were based on the asset index outcome variable. The table shows lower pseudo R2 and insignificant p-values of the likelihood ratio tests after matching. This result indicates that there were no systematic differences in the covariates between remittance-receiving and non-remittance-receiving households, meaning that the non-remittance-receiving households can be considered a good control group. The mean standardized bias reduction after matching ranged from 79 per cent to 90 per cent. Rosenbaum and Rubin (1985) proposed that when the mean standardized bias after matching is larger than 20 per cent, there is residual bias. In our case, the mean standardized biases after matching ranged from 2.0 to 4.9 across the different matching algorithms, meaning that bias was significantly reduced by matching. 
Table 5.6. PSM: remittances and household wealth

\begin{tabular}{|c|c|c|c|c|c|c|c|}
\hline $\begin{array}{l}\text { Outcome } \\
\text { variable per } \\
\text { matching } \\
\text { algorithm }\end{array}$ & $\begin{array}{c}\mathrm{M} \\
\text { Treated }\end{array}$ & $\begin{array}{c}\mathrm{M} \\
\text { Untreated }\end{array}$ & ATT & $t$ & $\begin{array}{l}\text { Critical } \\
\text { level of } \\
\text { hidden } \\
\text { bias }(\Gamma)\end{array}$ & $\begin{array}{l}\text { No. of } \\
\text { treated }\end{array}$ & $\begin{array}{c}\text { No. of } \\
\text { untreated }\end{array}$ \\
\hline \multicolumn{8}{|l|}{ Assets } \\
\hline $\mathrm{NN}(5)$ & 0.99 & 0.79 & 0.20 & 0.97 & 1.1 & 123 & 642 \\
\hline Kernel & 1.00 & 0.71 & 0.28 & 1.49 & 1.1 & 123 & 642 \\
\hline Radius $^{1}$ & 0.95 & 0.47 & $0.48^{* *}$ & 2.49 & 1.5 & 123 & 642 \\
\hline \multicolumn{8}{|l|}{ Education } \\
\hline $\mathrm{NN}(5)$ & 2.56 & 2.49 & 0.07 & 0.87 & 1.0 & 123 & 642 \\
\hline Kernel & 2.55 & 2.48 & 0.07 & 0.95 & 1.0 & 123 & 642 \\
\hline Radius $^{1}$ & 2.53 & 2.42 & 0.11 & 1.38 & 1.2 & 123 & 642 \\
\hline \multicolumn{8}{|l|}{ Financial access } \\
\hline $\mathrm{NN}(5)$ & 2.10 & 1.74 & $0.37^{* *}$ & 2.50 & 1.7 & 118 & 604 \\
\hline Kernel & 2.09 & 1.64 & $0.45^{* * *}$ & 3.31 & 2.2 & 118 & 604 \\
\hline Radius $^{1}$ & 2.09 & 1.56 & $0.54^{* * *}$ & 3.88 & 2.4 & 118 & 604 \\
\hline \multicolumn{8}{|c|}{ Living conditions } \\
\hline $\mathrm{NN}(5)$ & 1.66 & 1.06 & $0.60^{* *}$ & 2.55 & 1.7 & 123 & 642 \\
\hline Kernel & 1.67 & 1.01 & $0.67^{* * *}$ & 3.25 & 2.1 & 123 & 642 \\
\hline Radius $^{1}$ & 1.62 & 0.88 & $0.74^{* * *}$ & 3.43 & 2.3 & 123 & 642 \\
\hline \multicolumn{8}{|l|}{ Food security } \\
\hline $\mathrm{NN}(5)$ & 4.69 & 4.08 & $0.61^{* * *}$ & 3.99 & 3.6 & 123 & 641 \\
\hline Kernel & 4.69 & 4.10 & $0.59^{* * *}$ & 4.37 & 4.1 & 123 & 641 \\
\hline Radius $^{1}$ & 4.68 & 4.04 & $0.63^{* * *}$ & 4.49 & 4.3 & 123 & 641 \\
\hline \multicolumn{8}{|c|}{ Subjective wealth } \\
\hline NN (5) & 3.45 & 3.10 & $0.35^{* * *}$ & 3.62 & 2.0 & 112 & 640 \\
\hline Kernel & 3.44 & 3.12 & $0.33^{* * *}$ & 3.81 & 2.1 & 122 & 640 \\
\hline Radius $^{1}$ & 3.41 & 3.03 & $0.38^{* * *}$ & 4.25 & 2.2 & 122 & 640 \\
\hline
\end{tabular}

Note: ${ }^{*} \mathrm{p}<.10,{ }^{* *} \mathrm{p}<.05,{ }^{* * *} \mathrm{p}<.01 .{ }^{1}$ Caliper 0.01 . 


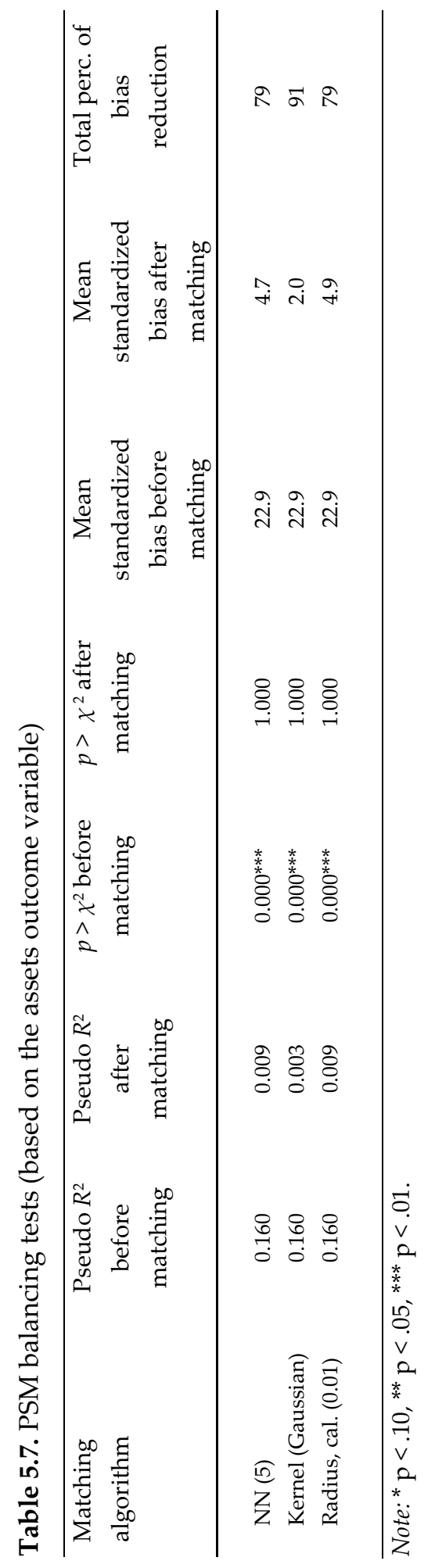

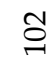


Table 5.8. PSM (Kernel, Gaussian) per quartile of the asset index

\begin{tabular}{|c|c|c|c|c|c|c|c|}
\hline $\begin{array}{l}\text { Outcome } \\
\text { variable }\end{array}$ & $\begin{array}{c}\text { M } \\
\text { Treated }\end{array}$ & $\begin{array}{c}\mathrm{M} \\
\text { Un- } \\
\text { treated }\end{array}$ & ATT & $t$ & $\begin{array}{l}\text { Critical } \\
\text { level of } \\
\text { hidden } \\
\text { bias }(\Gamma)\end{array}$ & $\begin{array}{l}\text { No. of } \\
\text { treated }\end{array}$ & $\begin{array}{c}\text { No. of } \\
\text { untreated }\end{array}$ \\
\hline \multicolumn{8}{|l|}{ Assets } \\
\hline Index q. 1\&2 & -1.10 & -1.01 & -0.09 & -0.65 & 1.4 & 31 & 348 \\
\hline Index q. 3 & 0.44 & 0.39 & 0.05 & 0.80 & 1.0 & 35 & 159 \\
\hline Index q. 4 & 2.47 & 2.11 & 0.36 & 1.54 & 1.1 & 57 & 135 \\
\hline \multicolumn{8}{|l|}{ Education } \\
\hline Index q. 1\&2 & 2.14 & 1.98 & 0.16 & 1.22 & 1.1 & 31 & 348 \\
\hline Index q. 3 & 2.49 & 2.54 & -0.05 & -0.37 & 1.7 & 35 & 159 \\
\hline Index q. 4 & 2.83 & 2.74 & 0.09 & 0.82 & 1.0 & 57 & 135 \\
\hline \multicolumn{8}{|l|}{ Financial access } \\
\hline Index q. $1 \& 2$ & 1.18 & 0.89 & 0.29 & 1.04 & 1.0 & 30 & 340 \\
\hline Index q. 3 & 2.25 & 1.56 & $0.69^{* * *}$ & 3.06 & 2.2 & 34 & 143 \\
\hline Index q. 4 & 2.51 & 2.29 & 0.22 & 1.17 & 1.5 & 54 & 121 \\
\hline \multicolumn{8}{|l|}{ Living conditions } \\
\hline Index q. $1 \& 2$ & 0.07 & -0.60 & $0.67^{*}$ & 1.70 & 1.2 & 31 & 348 \\
\hline Index q. 3 & 1.32 & 0.95 & 0.38 & 1.04 & 1.1 & 35 & 159 \\
\hline Index q. 4 & 2.92 & 2.64 & 0.29 & 1.30 & 1.4 & 57 & 134 \\
\hline \multicolumn{8}{|l|}{ Food security } \\
\hline Index q. $1 \& 2$ & 4.00 & 3.10 & $0.90^{* * *}$ & 2.62 & 1.8 & 31 & 348 \\
\hline Index q. 3 & 4.79 & 4.24 & $0.55^{* *}$ & 2.48 & 4.0 & 35 & 159 \\
\hline Index q. 4 & 4.94 & 4.85 & 0.09 & 0.78 & 3.7 & 57 & 134 \\
\hline \multicolumn{8}{|l|}{ Subjective wealth } \\
\hline Index q. $1 \& 2$ & 2.79 & 2.62 & 0.17 & 1.13 & 1.1 & 31 & 347 \\
\hline Index q. 3 & 3.52 & 2.95 & $0.57^{* * *}$ & 4.27 & 4.3 & 34 & 158 \\
\hline Index q. 4 & 3.74 & 3.59 & 0.15 & 1.08 & 1.0 & 57 & 135 \\
\hline
\end{tabular}

Note: ${ }^{*} \mathrm{p}<.10,{ }^{* *} \mathrm{p}<.05,{ }^{* * *} \mathrm{p}<.01$. 


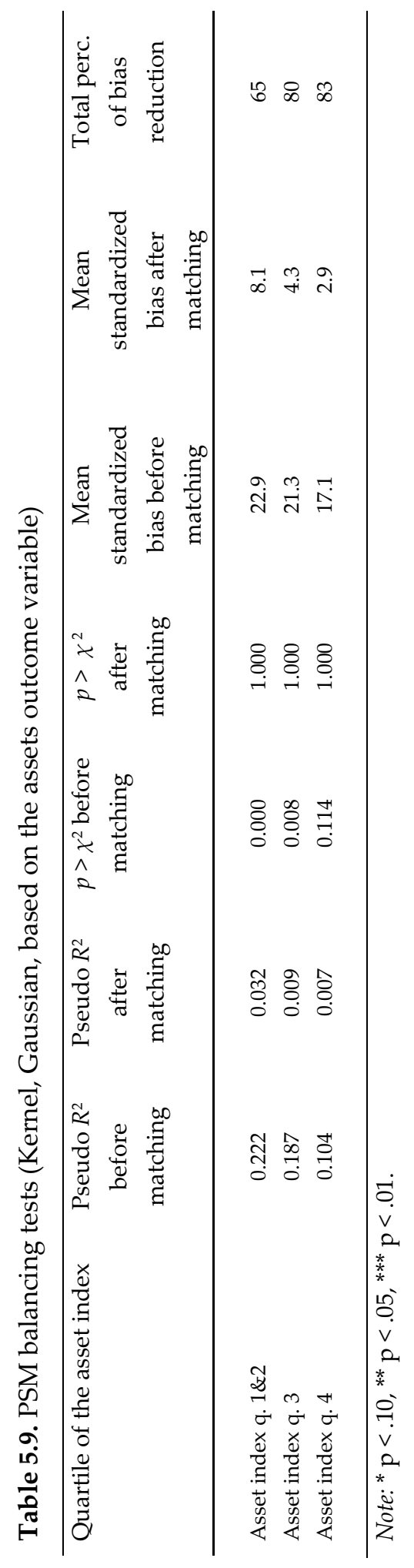


The previous analyses were based on the complete sample of households. However, it may be that poorer and wealthier households allocated remittances differently and were therefore affected by remittances in different ways. As described, the marginal effects of remittance investments are generally highest for households with larger capital constraints (Taylor, 1999; Taylor \& Wyatt, 1996). To explore whether this was the case, the households were split into four equally sized groups depending on their score on the asset ownership index. Matching (Kernel, Gaussian) was performed for the households in each quartile separately (see Table 5.8). Because remittances are less common among relatively less wealthy households, quartiles one and two were merged to ensure a sufficient sample size for these categories.

The results show that poorer and wealthier households allocated remittances differently. For households that were in the lowest quartiles of the asset index, remittances significantly improved their living conditions and food security. The poorest households in our sample seem to have allocated remittances mostly to non-productive assets, which rejects the investment hypothesis for this group. For households that were in the third quartile, the results are more mixed: remittances increased access to finances and subjective wealth for these households and improved their food security. These households therefore invested in both productive and non-productive assets.

None of the ATTs were significant for households that were in the fourth asset index quartile, meaning that these remittance-receiving households did not score significantly differently on the indicators compared to non-remittancereceiving households that were in the same quartile. Wealthier households thus seemed unaffected by remittances despite the fact that they were more likely to receive remittances and received higher values of remittances. As in the previous analyses (Table 5.6), the ATTs for the productive assets of asset ownership and education are not significant in Table 5.8. The critical levels of sensitivity to hidden bias $(\Gamma)$ are higher than in the previous analyses, meaning that the estimates are more sensitive to potential hidden bias.

Table 5.9 shows the balancing tests results for the PSM estimates from Table 5.8. The results again show that the non-remittance-receiving group of households was a good matching group for the non-remittance-receiving households. After matching, the pseudo R2 values were significantly lower, and the p-values of the likelihood ratio test became insignificant, suggesting little 
systematic difference in the covariates between both groups. The mean standardized bias was significantly reduced by matching, showing reductions ranging from 65 per cent to 83 per cent.

\subsection{Discussion and conclusion}

This paper explored the role of remittances for households recovering from conflict in Burundi, slightly more than 5 years after the official end of conflict in the country. Three hypotheses (relative deprivation, investment, and insurance) proposed by NELM were tested. The analyses showed that remittances are largely absent in rural areas. This rejects the relative deprivation hypothesis, which would anticipate that rural households, being the most deprived, would be more likely to migrate and therefore to receive remittances. In Bujumbura, remittance receiving is more frequent, particularly among wealthier and higher-educated households. This seems to be the result of a (historical and current) selection of migration to the wider diaspora (Europe, North America). The data therefore corroborate anecdotal evidence that few remittances are sent from the region and that remittance receivers in a conflict-affected setting are primarily the better-off households (Nyberg-Sørensen et al., 2002; Van Hear, 2004). These findings are similar to those in other development contexts (Adams Jr et al., 2008; Mazzucato et al., 2008) and corroborate with a general trend found in the remittance literature that most remittance receivers are relatively well-off (Adams Jr, 2011). The contribution of remittances to the household budgets of receiving households in Bujumbura was substantial in the previous year, totaling an average of 61 per cent of household expenditures. Wealthier households were found to receive higher values of remittances, both in absolute terms and relative to their yearly expenditures.

We hypothesized that remittances would mostly serve as insurance and would be used for investment purposes to a more limited extent as a result of the conflict-affected setting. The analyses partly confirmed these expectations. Remittances were found to be mostly allocated to non-productive assets. Remittances significantly affected the living conditions and food security of the remittance-receiving households in urban Burundi. Subjective wealth also increased due to remittances. These findings verify qualitative studies that argued that remittances are mostly used to sustain households during or immediately after crises (see, e.g., Van Hear, 2002) and confirm those from non-conflict-affected settings where remittances are often spent on daily needs (Kabki et al., 2004; 
Mazzucato, 2009). Productive assets, including asset ownership and education, were not affected by remittances in Burundi. This corroborates with other studies from conflict-affected settings (Ahmed, 2000), but contradicts studies from 'normal' development contexts, where remittances are often found to be invested in schooling and assets such as housing and agricultural land (Ratha et al., 2011). It is likely that the unstable nature of a conflict-affected context lowers households' opportunities and incentives to invest their remittances. Future research should address these issues in more detail.

Poorer households were less likely to receive remittances and received less. These findings highlight that remittances cannot replace official state and international aid initiatives on development and poverty alleviation programs, as is sometimes suggested by 'co-development' initiatives in which migrants are seen as a way to channel development aid more directly to the 'grass roots' (see, e.g., Nyberg-Sørensen et al., 2002, for a discussion on co-development). At the same time though, migration can help poor households. In our study, remittances did make a difference to those poor households that received them, especially in improving their living conditions and food security. This finding confirms expectations that the effects of remittances are stronger for households with higher capital constraints (Taylor, 1999; Taylor \& Wyatt, 1996) yet rejects the investment hypothesis for this group. Similar findings were found in other non-conflict development contexts (Adams Jr et al., 2008).

This study offered a unique perspective into the role of remittances for households after conflict. The multidimensional view of household wealth allowed us to research the various ways that households allocate remittances in this context. The fact that remittance allocation differs for poorer and wealthier households is an important finding. This paper has limitations with regard to estimating the long-term effects of remittances on development in Burundi due to the cross-sectional nature of the data. Further research should analyze the longterm effects of the remittance-allocation decisions of receiving households in conflict and conflict-affected settings. Although collecting data in unstable settings will continue to pose a challenge for scholars, efforts should be made to sustain data collection after conflict in order to gain a better understanding of the longterm effects of remittances in conflict-affected settings.

Future research is needed to determine whether this support from remittances during and after crises results in longer-term benefits for receiving 
households. It could be that remittances improve wealth prospects for poorer households, because having better food security, living conditions, and subjective wealth may contribute to increased productivity. For example, households with better food security due to remittances are probably more fit to work than households without such support. Wealthier households in our sample were largely unaffected by remittances. This finding hints at a 'ceiling effect' of remittances, meaning that their wealth reaches a point beyond which it does not improve in this context. Yet wealthier households may invest in other incomegenerating activities, such as businesses, or spend remittances on leisure or luxury goods. These investment possibilities were not addressed in this research and should be explored by further research. 
Chapter 6: Remittances, bonds and bridges: investing remittances in social capital 
This chapter has been accepted for publication as: Fransen, S. Remittances, bonds and bridges: investing remittances in social capital in Burundi. Journal of Development Studies. 


\subsection{Introduction}

Recent decades have witnessed a rise in micro-level studies examining the impact of remittances on development. Most studies have employed the NELM approach, in which migration is considered a household strategy to generate income through remittances that a household uses to diversify its income and insure against financial shocks (Stark, 1980; Stark \& Bloom, 1985). Remittances would also reduce household liquidity constraints, enabling households to invest, thereby stimulating economic development in remittance-receiving areas (Taylor, 1999). When exploring the effects of remittances on development, most studies have examined economic outcomes such as increased income or expenditures (Adams, 2006), assets and agricultural outputs (Azam \& Gubert, 2006), or human capital investments such as schooling (Adams \& Cuecuecha, 2010; Amuedo-Dorantes \& Pozo, 2010). While prior studies provided important insights, few studies have focused on the relationship between remittances and social development in receiving countries.

In the absence of formal insurance mechanisms, such as those provided by the state, households often rely on informal networks for support. These networks are used to share risks and function as reciprocal insurance mechanisms during periods of hardship (Fafchamps, 2006; Fafchamps \& Lund, 2003). From an economic perspective, this so-called social capital is an asset based on the assumption that it is fungible, meaning that it can be turned into other forms of capital if needed (Bourdieu, 1986; Woolcock \& Narayan, 2000). In unstable settings where economic investment opportunities are limited, households may allocate (part of) their remittances to their social capital (Van Hear, 2002, 2004). By investing in social capital by, for example, participating in community organisations or financially supporting family members or friends, remittancereceiving households insure themselves against future risks.

Some studies have touched upon the relationship between remittances and social capital by examining the organisational participation (Caarls et al., 2013), church donations (James, 1997; Kabki et al., 2004), funeral participation (Kabki et al., 2004; Mazzucato et al., 2006), or gift-giving practices (Gerber \& Torosyan, 2010) of remittance-receiving households. These studies provided interesting preliminary insights into the effects of remittances on social relations in remittancereceiving areas. Most studies, however, were small-scale and used single indicators of social capital. Therefore, this paper contributes to the literature on remittances 
and social development by treating social capital as a multifaceted concept to investigate the link between remittances and social capital in greater detail.

The case study selected for this study is Burundi, a small country in the African Great Lakes Region. Data were collected from 810 households in Burundi's capital, Bujumbura, in 2011, just over five years after the official end of conflict in the country. The data contain information on the households' migration and remittance-receiving histories, as well as their economic well-being and social capital investments, such as participation in organizations, expenditures on religious organizations and gifts to family members and friends. This information allows us to investigate the extent to which remittance-receiving households allocate remittances to their social capital. A distinction is made between bonding and bridging social capital (Putnam, 2000, 2002), which allows an exploration of the extent to which remittance-receiving households invest in social capital that benefits their in-group, as opposed to social capital that crosses social divides. This is especially relevant in a conflict-affected setting, such as Burundi, where decades of conflict have led to social tensions that are considered a risk for renewed conflict. In this paper, the bonding versus bridging social capital distinction is based on networks of family members and friends. These networks have an important insurance function for households in Burundi (Uvin, 2009; Vervisch, Vlassenroot, et al., 2013).

By exploring the link between remittances and social capital in Burundi, this paper contributes to the remittances and development debate by analysing the effects of remittances on social development in remittance-receiving areas. Remittances used for social capital investments may have spill-over effects, strengthening networks and social relations. Such investments may restore social ties and foster reconciliation, especially in conflict-affected settings where social ties have been damaged (Van Hear, 2002, 2004). Investing remittances in social capital may also have economic implications. There is growing evidence that social capital is associated with economic development (Fafchamps, 2006; Fukuyama, 2001; Grootaert \& Van Bastelaer, 2002; Woolcock \& Narayan, 2000). In conflictaffected states, social capital is considered a prerequisite for reconstruction and economic development (Colletta \& Cullen, 2000). This paper examines the relationship between remittances and social capital using a unique dataset, which provides an opportunity to explore how households allocate remittances in a conflict-affected context. 


\subsection{Theoretical perspectives on social capital and remittances}

\subsubsection{Social capital and development}

The importance of networks and social relations for development gained increasing recognition in the 1990s (Woolcock \& Narayan, 2000). These networks and social relations are conceptualised as social capital, a concept introduced by Bourdieu (1986) and subsequently elaborated on by Coleman (Coleman, 1988, 1994) and Putnam (Putnam, 1995, 2000, 2002). Since its introduction, numerous scholars have attempted to define and operationalise social capital (Portes, 2000a, $2000 \mathrm{~b})$. Social capital is most commonly defined as the 'features of social organisation such as networks, norms, and social trust that facilitate coordination and cooperation for mutual benefit' (Putnam, 1995, p. 67). Another commonly used definition is 'the norms and networks that enable people to act collectively' (Woolcock \& Narayan, 2000, p. 226). These definitions treat social capital as a communal or societal resource that contributes to the development of these communities or societies.

In this study, social capital is treated as an economic, micro-level concept. This resembles the views of Bourdieu (1986), who regarded social capital as an individual- or household-level resource that can be created and maintained through investments. Social capital provides individuals or households with access to the economic resources of members of their network, enhances their access to information and cultural capital, and increases their access to institutional credit (Portes, 2000a). Research has demonstrated that households with higher levels of social capital occupy better socio-economic positions within their communities (Grootaert, 1999; Grootaert et al., 2002; Narayan \& Pritchett, 1999). Social capital investments are an insurance strategy that reduces vulnerability to shocks, particularly for poorer households that live in unstable environments that offer little institutional protection (Woolcock \& Narayan, 2000). Poorer households generally have fewer resources to make social capital investments (Cleaver, 2005; Fafchamps, 2006), but they tend to receive higher returns from social capital than wealthier households (Grootaert, 1999; Grootaert \& Van Bastelaer, 2002).

\subsubsection{Social capital and remittances}

In the migration literature, social capital has been identified as an important enabler of migration and, consequently, remittances. Households may, for 
example, facilitate the migration of a household member by relying on finances, information, or physical help derived from their social networks (see, e.g., Haug, 2008, for an overview). This paper argues that social capital in remittance-receiving areas may also be affected by remittances, through the social capital investments of remittance-receiving households.

Remittances may affect social capital through three main mechanisms. First, remittances relax the liquidity constraints of receiving households, enabling them to invest the resource from abroad (Taylor, 1999). In unstable settings, such as those affected by conflict, other investment opportunities may be limited or involve high risk, incentivizing remittance-receiving households to invest in their social capital (Van Hear, 2002, 2004). Second, remittances increase the income of remittance-receiving households, which may increase their civic engagement. Investing in social capital involves contributions of both resources and time - two goods that are generally more available to wealthier households. The remittance literature has shown that remittance-receiving households generally have higher consumption levels and more leisure time than non-receiving households, because of the income-smoothing function of remittances (Adams Jr, 2011). As described, social capital studies have shown that wealthier households participate more in networks (Fafchamps, 2006; Fafchamps \& Lund, 2003). Remittances may thus increase social capital investments, both in terms of resources and time, by increasing wealth.

Third, households that have migrants abroad may be exposed to different values and norms, which incentivize them to be more civically engaged. Research has shown that so-called 'conflict-generated diasporas' (Lyons, 2007, p. 530) are often highly organized and engaged in their home country (see, e.g., Lyons, 2007; Mohamoud, 2006; Orjuela, 2008) through lobbying, protesting, participating in development activities, and remittance sending. These norms to be civically engaged may be transferred to relatives and friends residing in the migrant sending country, through social remittances, or 'the ideas, behaviors, identities, and social capital that flow from receiving- to sending-country communities' (Levitt, 1998, p. 926), enhancing participation in organizations and other forms of civic engagement among households in the migrant-sending country.

The limited evidence available on the effects of remittances on social capital has shown mixed results. Kabki et al. (2004) demonstrated that remittances in rural Ghana were used for, among other things, church donations. These 
donations function as investments because churches in Ghana often provide financial support for their members during periods of hardship. Similarly, remittance-receivers in Tonga were found to donate part of their remittances to churches (Brown \& Conneil, 1993; James, 1997). Putnam (1995) used church membership or affiliation as an example of civic engagement, and such behaviour is frequently used as a social capital indicator (Lochner, Kawachi, \& Kennedy, 1999). Research has also revealed remittances being spent on funerals in Ghana (Mazzucato et al., 2006). Funerals are important social gatherings in Ghana through which attendees create and maintain networks. Migrants residing abroad were found to finance funerals through remittances to reinforce their position in the family and broader networks. Gerber and Torosyan (2010) found that remittance-receiving households in Georgia gave more financial gifts to other households than non-receiving households.

Research on Rwanda, however, has called the previously observed, positive relationship between remittances and social capital into question. In a study by Caarls et al. (2013), remittance receivers were found to participate less in community organisations and reported lower levels of reconciliation than nonreceivers. According to the authors, household reliance on remittances reduced motivations to invest in bridging social capital in particular and led to cooperative behaviour that only benefitted their own group. Remittances allowed individuals to behave more financially independent and therefore 'crowded out' their incentives to participate in activities that crossed social divides. This, in turn, led to reduced feelings of reconciliation. This finding shares similarities with a moral hazard effect that has been linked remittance reception. Research has shown that remittance-receivers may become less productive, because remittances provide them with insurance from abroad (see, e.g., Azam \& Gubert, 2006, for an overview).

Gerber and Torosyan (2010) argued that gift-giving practices in Georgia sustained social relations and fostered networks of reciprocity and mutual help in remittance-receiving areas in the post-conflict period. In conflict-affected contexts in which social ties are damaged, investing remittances in social capital may thus be particularly important. However, if remittance-receiving households withdraw from their social relations and invest remittances exclusively in in-group, or bonding, social capital, as Caarls et al. (2013) suggested, this may intensify social divides. The extent to which remittance-receiving households invest in bonding 
versus bridging social capital has yet to be examined in depth, leaving room for further exploration of the complex relationship between remittances and social capital.

\subsubsection{Social capital as a multifaceted concept}

Social capital can be divided into a structural and cognitive component (Uphoff, 2000). Structural social capital refers to organisational forms of social capital such as the 'roles, rules, precedents and procedures as well as networks that contribute to cooperation' (Uphoff, 2000, p. 218), whereas cognitive social capital comprises the shared norms, values and attitudes that underlie structural social capital. Examples of structural social capital include all types of formal or informal organisations, associations, or cooperatives. Cognitive social capital is often operationalised as trust, norms of reciprocity, or cooperation (see, e.g., Knack \& Keefer, 1997). Structural social capital provides the structure through which group members cooperate, while cognitive social capital is the set of attitudes that encourages group members to employ structural capital (Uphoff, 2000). ${ }^{11}$

This study focuses specifically on structural social capital, which is captured by people's participation and financial investments in networks. Within structural social capital, a distinction is made between bonding and bridging social capital (Putnam, 2000, 2002). Bonding social capital refers to connections between homogeneous groups or individuals, while bridging social capital unites individuals or groups that are dissimilar in terms of characteristics or beliefs, thereby bridging social divides. The concepts of bonding and bridging social capital are relevant in a conflict-affected setting, such as Burundi, because bridging social capital in particular is believed to prevent conflict and foster reconciliation in the wake of a conflict. Colletta and Cullen (2000), for example, concluded that low stocks of bridging social capital led to low social cohesion and therefore impeded reconstruction efforts in Cambodia, Rwanda, Guatemala, and Somalia. Similarly, Varshney studied the relationship between civic engagement and ethnic conflict in India, calling inter-ethnic networks 'agents of peace' (Varshney, 2001, p. 363) and intra-ethnic networks a conflict hazard. Formal forms of engagement, such as clubs

\footnotetext{
11 The distinction between structural and cognitive social capital stems from Putnam's definition, described above, and that of Coleman, who referred to social capital as 'a variety of different entities having two characteristics in common: they all consist of some aspect of social structure and they facilitate certain actions of individuals who are within the structure' (1990, p. 302).
} 
and associations, are argued to be particularly important conflict buffers, as they make society more resilient to political polarisation.

Treating social capital as a multifaceted concept, comprising networks of bonding and bridging social capital, acknowledges that households may invest remittances differently in different types of social capital. This information sheds light on the various channels through which remittances affect households' social capital and, consequently, social relations in remittance-receiving areas.

\subsection{Conflict, migration and social ties in Burundi}

Burundi has experienced waves of civil conflict since it gained independence from Belgium in 1962 (Lemarchand, 1996). These conflict episodes spurred large population movements and had harmful effects on both economic and social aspects of Burundian society. Per capita income decreased by nearly 40 per cent in the period 1993-2007 (World Bank, 2009), which in combination with a substantial decrease in international aid (Bundervoet, 2006), drove the percentage of individuals living below the poverty line of 1 dollar per day from 35 per cent in 1993 to 67 per cent in 2006 (World Bank, 2009). The signing of the Arusha Peace and Reconciliation Agreements in August 2000 and the election of a new government in 2005 signified the beginning of the peace and reconstruction phase in Burundi. Poverty, however, remains one of Burundi's main challenges, despite recent economic improvements. In 2011 Burundi still ranked 185 on the Human Development Index, which is the lowest in the world after the Democratic Republic of the Congo (DRC) and Niger (UNDP, 2011).

As a result of this civil conflict, Burundi has a large and heterogeneous diaspora scattered around the globe. The largest share of the diaspora resides in the neighbouring countries of Tanzania, Rwanda, and the DRC. A small minority migrated to Europe and North America. In total, more than 350,000 Burundians, or 4.2 per cent of the population, were living abroad in 2010 (World Bank, 2011c). Recently, new migration patterns from Burundi have arisen, primarily comprising skilled migrants moving to Western Africa, South Africa, and Europe to seek employment and education opportunities (Fransen \& Siegel, 2010).

The Burundian government is currently exploring strategies to access the resources of the Burundian diaspora for reconstruction purposes. The first draft of the national migration policy aims to enhance remittance flows into the country and invest them in development programmes (Republic of Burundi, 2011). The aim 
is to create social stability through economic development. Although the Burundi diaspora residing in Europe and North America is relatively small, its members are well organized, highly active, and engaged in their home country (Fransen \& Siegel, 2010).

International remittances are believed to be a small, but growing, financial inflow into Burundi. Remittances were estimated at between three million USD (World Bank, 2011c) and 28 million USD (Banque de la Republique Burundi (BRB), 2010) in 2010.12 Most remittances are sent from Europe and North America (De Bruyn \& Wets, 2006; Fransen \& Andersson, 2011). Remittance-receiving households primarily reside in urban areas and a recent study has shown that they are generally wealthier than non-receiving households (Fransen \& Mazzucato, 2014, or Chapter 5 of this dissertation). Urban-rural financial transactions have also increased due to increasing rural-urban migration flows, primarily consisting of young, rural men seeking better job opportunities in the capital. These remittances typically pass through informal channels; they are sent either through hand delivery or couriering and are transferred within family networks that are based on trust and reciprocity (Fransen \& Andersson, 2011; Uvin, 2009).

The conflict in Burundi also affected social ties within society, reportedly leading to low levels of interpersonal trust, solidarity, and reciprocity (Brachet \& Wolpe, 2005; Uvin, 2009; Vervisch, Vlassenroot, et al., 2013). The conflict, in which nearly all households were affected, combined with increasing poverty levels, deeply divided community members. This led scholars to describe Burundian society as characterised by 'weak bridges, strong bonds' (Brachet \& Wolpe, 2005, p. 6). They refer to a highly fragmented society, due to inter-ethnic tensions, but also socio-economic inequity between social classes (principally the urban elite versus the rural population), divisions between clans within ethnic groups, and regional inequalities (especially between urban and rural areas). Tensions between former refugees and other community members have also been reported, due to disputes regarding land and other assets (Fransen \& Kuschminder, 2012).

Social relations with friends and relatives are an important form of insurance and support for Burundian households (see, e.g., Trouwborst, 1973; Uvin, 2009). Horizontal networks of close friends and family members, based on

\footnotetext{
12 The difference between these statistics is due to measurement differences. The BRB estimate refers to the period from January to October 2010 and was provided by BRB during a personal interview with the author.
} 
solidarity expressed through gift-giving and mutual support, have historically formed an important part of social life in Burundi (Trouwborst, 1973). Financial transactions are an important manifestation of these social ties. Many households engage in gift giving for (religious) celebrations, educational support or other necessities (Uvin, 2009). Vervisch et al. (2013) described how the insurance function of this bonding social capital weakened during the war period, due to conflict and economic hardship that gave rise to disputes over valuables, and sometimes led to violence. Uvin (2009) however argues that poverty and limited economic opportunities have increased households' dependency on social capital:

There seems no doubt that this results from Burundian's profound vulnerability: they need to maintain relations at all cost, for, apart from their bodies, the little bit of social capital they have is the only thing that may make the difference between total destitution and simple poverty, especially in the context of complete absence of law. The capacity to maintain relations with people who crossed you, whom you distrust, is crucial, for one never knows - they may be necessary one day (Uvin, 2009, p. 167).

The restoration of social relations has been a focus of many post-conflict reconstruction programmes in Burundi (Brachet \& Wolpe, 2005; Vervisch, Titeca, et al., 2013). Since the end of the conflict, the number of civil society organisations and community associations has increased in Burundi and civil society has become more active in areas such as women and youth issues, development and reconciliation, human rights, and religion (Brachet \& Wolpe, 2005; Vervisch, Titeca, et al., 2013). Given these unique social dynamics, characterised by low trust but high inter-household dependency because of economic hardship, and increasing civic engagement, Burundi provides an interesting case study to explore the effects of international remittances on bonding and bridging social capital.

\subsection{Data and empirical approach}

The dataset includes information on 810 households residing in Bujumbura, Burundi's capital. The data were collected in March 2011 in 54 randomly selected blocks within the 17 zones or quartiers (neighbourhoods) of the city. The distribution of blocks across the different neighbourhoods was based on a 
neighbourhood's population size, meaning that more blocks were visited in more densely populated neighbourhoods. In each block, consisting of two to four streets, 15 randomly selected households were interviewed. The household interviews were conducted with a main respondent, who was at least 18 years of age and knowledgeable on household financial and social affairs. In 82 per cent of the cases the main respondent was the household head or his/her spouse. In 11 per cent of the cases the main respondent was a child of the household head. The main respondents were, on average, 34 years old.

\subsubsection{Remittances}

Remittances were defined as international monetary transfers that were received by a household in the 12 months preceding the interview. Remittance receipt was common in Bujumbura: of the 810 households in the sample, 15.93 per cent $(\mathrm{n}=$ 129) had received remittances. For these 129 receiving households, the average number of senders was 1.26, yielding a total of 162 remittance senders in the data. Most remittance senders lived in Europe or North America: 34.57 per cent $(n=56)$ and 33.95 per cent $(n=55)$, respectively. Other senders lived in non-neighbouring African countries (15.43 per cent, $\mathrm{n}=25)$, neighbouring countries (12.35 per cent, $\mathrm{n}$ $=20$ ), Asia (1.23 per cent, $n=2)$, or Australia (0.62 per cent, $n=1) .{ }^{13}$ These findings confirm anecdotal evidence that most remittances to Burundi are sent from Europe and North America (Weiss Fagen \& Bump, 2006). The majority of senders (93.83 per cent, $\mathrm{n}=152$ ) were not considered household members, but most of them (90.79 per cent, $\mathrm{n}=138$ ) were family members. ${ }^{14}$ International remittances are thus primarily a family affair in Burundi.

\subsubsection{Social capital indicators}

As described, this study focused on structural social capital, which was divided into bonding and bridging social capital. Bonding social capital was defined in this paper as networks of close friends and family members, acknowledging the importance of these horizontal social networks in Burundi (see, e.g., Trouwborst,

\footnotetext{
${ }^{13}$ Three households (1.85 per cent) indicated that they were unaware of the location of their remittance sender(s).

${ }^{14}$ A household was defined as 'all individuals living together with communal arrangements concerning subsistence and other necessities of life and including all individuals presently residing elsewhere (in the country or abroad) whose principal commitments and obligations are to this household' (Fransen, 2011).
} 
1973; Uvin, 2009; Vervisch, Vlassenroot, et al., 2013). Networks of close friends and family members are frequently, but not necessarily, aligned with ethnic ties in Burundi, and should therefore not be treated as a proxy for ethnicity. Bridging social capital is defined as social capital that transcends these networks of close friends and family members. Because of the ethnic character of the conflict in Burundi, it would have been interesting to link remittances with inter- or intraethnic social capital. However, the survey data contain no references to the households' ethnicity, due to the sensitivity associated with the concept of ethnicity in Burundi.

Four indicators were used to measure households' structural social capital: 1) membership in organisations, 2) monthly expenditures on religious organisations, 3) monthly expenditures on gifts to family members and friends, and 4) internal remittance sending. These indicators thus included social capital investments in the form of both investing time (organisation membership) and money (religious organisations, gifts to family members and friends, and internal remittances). First, the number of organisation memberships per household, measuring households' associational involvement, is often used to study social capital (see, e.g., Grootaert, 1999; Narayan \& Pritchett, 1999). As described, formal forms of engagement, such as clubs and associations, are also particularly important in conflict-affected settings (Varshney, 2001). In this study, organisations included credit or savings associations, agricultural associations, religious organisations, political organisations, and sports clubs. ${ }^{15}$ The indicator refers to membership only and does not include monetary contributions. Organization membership is therefore perceived as a social capital investment that is made by donating time.

The second indicator, monthly expenditures on religious organisations, was considered separately from organisation memberships, as it specifically relates to financial contributions. This indicator was selected because previous studies have linked remittances to church donations (Brown \& Conneil, 1993; James, 1997; Kabki et al., 2004) and churches may offer financial safety nets for their members.

\footnotetext{
15 The data also contained information on donations to community projects, agricultural cooperatives, and saving and credit groups. These donations were, however, not common, which made it impossible to run separate analyses for these indicators due to small sample sizes. Analyses performed with averaged scores of all donations did not yield significantly different results (results available upon request).
} 
Churches are important meeting places in Burundi and the data showed that church donations were frequent among both remittance and non-remittance receiving households. The third indicator referred to gifts to family members and close friends that were not part of the household that the household had given in the month previous to the interview. The second and third indicator were derived from the expenditure section of the questionnaire, where the households were asked about their average, monthly spending on several items.

The fourth indicator measured households' financial transfers to family or friends residing in other provinces in Burundi over the past 12 months. These final two indicators were selected due to the importance of gift-giving in maintaining social relations in Burundi (see Section 6.3). Practices of gift giving have been studied extensively by anthropologists, pioneered by the work of Mauss (2005), and are considered an important part of building reciprocity, trust and social ties terms that are highly linked to current notions of social capital. Although the fourth indicator specifically refers to monetary support to households that live in other provinces in Burundi, there may be some overlap between the third (average monthly expenditures on gifts to family and friends) and fourth indicator. Nevertheless, both indicators are used because they refer to different support networks. Whereas indicator number three makes reference to both family members and close friends, urban-rural remittances primarily represent intrafamily financial transactions. The data used in this paper show that over 99 per cent of the rural recipients were family members of the sending households in the capital. The indicators were therefore used separately in the analyses.

Of the four structural social capital indicators, organisational membership and expenditures on religious organisations were treated as bridging social capital indicators. Brachet and Wolpe (2005) have described that civil society organizations, including religious organizations, have become increasingly (ethnically) mixed in Burundi after the war. In addition, the development community has focused on so-called community-based development, using an inclusive approach to strengthen social cohesion (Vervisch, Titeca, et al., 2013). The assumption is therefore made in this study that organisations, such as saving associations, sport clubs, political organisations, and agricultural associations are larger social structures that cross social networks of close friends and family members. Gift giving to family and friends was considered a bonding social capital investment, based on the ethnographic work of Trouwborst (1973) and Vervisch et 
al. (2013) described in Section 6.3. Finally, urban-rural remittance sending was also used as an indicator of bonding social capital.

As described, the information on social capital investments was derived from the main respondent. Just like information on, for example, income may not be shared with all household members (see, e.g., Fisher, Reimer, \& Carr, 2010), household information on social capital investments may also not be pooled. In the absence of individual data on social capital investments, the data derived from the main respondent is therefore used as a proxy for the households' total social capital investments.

\subsubsection{Empirical approach}

The empirical approach consisted of descriptive statistics and propensity score matching (PSM). Although descriptive statistics provide interesting insights, PSM addresses the possibility that households differ in their social capital investments due to household characteristics other than remittances. For example, remittancereceiving households in Burundi are generally wealthier than non-remittance receiving households, which might affect their social capital. Studies have shown that wealthier households are more able to make social capital investments (see, e.g., Cleaver, 2005; Fafchamps, 2006). Using PSM, remittance-receiving households were matched to non-remittance receiving households that are similar, following Rosenbaum and Rubin (1983). This yielded an average treatment effect for the treated (ATT), which approximates a household's circumstances with respect to social capital under the counterfactual that it had not been treated, meaning that it had not received remittances.

For the analyses in this paper, households were matched based on the characteristics of the main respondent, including his or her age, gender, educational attainment, employment, and marital status. Matching variables also included household characteristics including asset ownership, the number of economic shocks the household experienced over the past five years, and the number of adults in the household (see Table 6.1). These variables have been identified as important migration determinants and are therefore closely related to remittance receipt (McKenzie \& Sasin, 2007). Households were also matched based on the past migration experiences of their household members, including international return migration and internal displacement, and the current migration status of a household member. 
Table 6.1. Variables used for matching

\begin{tabular}{|c|c|c|c|c|c|}
\hline Variable & $\mathrm{n}$ & M & SD & Min. & Max. \\
\hline \multicolumn{6}{|l|}{ Main respondent characteristics } \\
\hline Age & 810 & 33.53 & 12.66 & 17 & 80 \\
\hline Gender $(1=$ male $)$ & 810 & 0.28 & 0.45 & 0 & 1 \\
\hline Years of education & 810 & 7.68 & 5.38 & 0 & 19 \\
\hline Employment status $(1=$ employed $)$ & 810 & 0.41 & 0.49 & 0 & 1 \\
\hline \multicolumn{6}{|l|}{ Marital status } \\
\hline Single (ref.) & 810 & 0.25 & 0.43 & 0 & 1 \\
\hline Married & 810 & 0.59 & 0.49 & 0 & 1 \\
\hline Divorced & 810 & 0.05 & 0.21 & 0 & 1 \\
\hline Widowed & 810 & 0.11 & 0.31 & 0 & 1 \\
\hline \multicolumn{6}{|l|}{ Household characteristics } \\
\hline House ownership (1 = yes) & 810 & 0.45 & 0.49 & 0 & 1 \\
\hline Land ownership $(1=$ yes $)$ & 807 & 0.21 & 0.41 & 0 & 1 \\
\hline Other assets (index) & 810 & 0.00 & 1.55 & -2.42 & 4.84 \\
\hline House ownership five years ago ( $1=$ yes) & 810 & 0.44 & 0.50 & 0 & 1 \\
\hline Land ownership five years ago (1=yes) & 810 & 0.30 & 0.46 & 0 & 1 \\
\hline Number of economic shocks in the past 5 years & 810 & 1.07 & 1.91 & 0 & 7 \\
\hline Number of adults in the household & 810 & 2.99 & 1.58 & 1 & 11 \\
\hline Migrant abroad in the household $(1=$ yes $)$ & 810 & 0.03 & 0.17 & 0 & 1 \\
\hline Return migrant $(1=$ yes $)$ & 809 & 0.13 & 0.34 & 0 & 1 \\
\hline Displacement camp experiences ( $1=y e s)$ & 809 & 0.20 & 0.40 & 0 & 1 \\
\hline
\end{tabular}

The questionnaire that was used for this study contained questions on retrospective home and land ownership. This information was used in the analyses to match households based on their status from before they began receiving remittances. A previous study on remittances in Burundi showed that wealthier and higher educated households were more likely to receive remittances; a finding that the authors ascribed to a selection into migration - wealthier households have more means to send a household member abroad, and are therefore more likely to receive remittances (Fransen \& Mazzucato, 2014, or Chapter 5 of this dissertation). By including retrospective information on wealth (assets), the aim is to control for this selection. The indicators refer to five years in the past and are therefore not necessarily linked to the pre-remittance period for all households. The data reveal that 44 of the 162 senders (27.16 per cent) began sending remittances prior to 2005. However, this five-year period was used in the survey, as it was linked to the pre- 
to post-conflict transition in Burundi. This was considered the most reliable reference point for interviewees to provide retrospective information.

Three estimation methods were used to calculate the ATT: Nearest Neighbour (5), Kernel (Gaussian) and Radius matching (calliper 0.01), to verify the robustness of the results. The assumption required for PSM is that all relevant differences between groups are captured by observable characteristics in the data. Balancing tests, which calculate the reduction of systematic differences between groups through matching, were performed by comparing mean absolute standardised biases (Rosenbaum \& Rubin, 1985), pseudo R2 and p-values of the likelihood ratio tests before and after matching (Sianesi, 2004). In addition, common support graphs were constructed to determine whether there were remittance and non-remittance receivers in the data for all values of the dependent variables.

\subsection{Results: remittances and social capital in urban Burundi}

\subsubsection{Descriptive statistics}

Table 6.2 presents the descriptive statistics on the households' social capital. The table indicates that nearly half of the households had at least one organisation membership and, on average, households spent nearly 0.70 US dollars on religious organisations per month. Almost 4.70 US dollars were spent, on average, on gifts to family members and friends. Urban-rural remittances were relatively common as well: 30 per cent of the households in the sample had sent money to family members living in rural areas in the 12 months preceding the interview. The values of these remittances differed significantly. The mean value across all 810 households was nearly 40 US dollars, with a minimum of zero, for households that had sent no remittances, and a maximum of 2760 US dollars for households that had sent remittances. The average amount sent per transaction was just over 22 US dollars. 


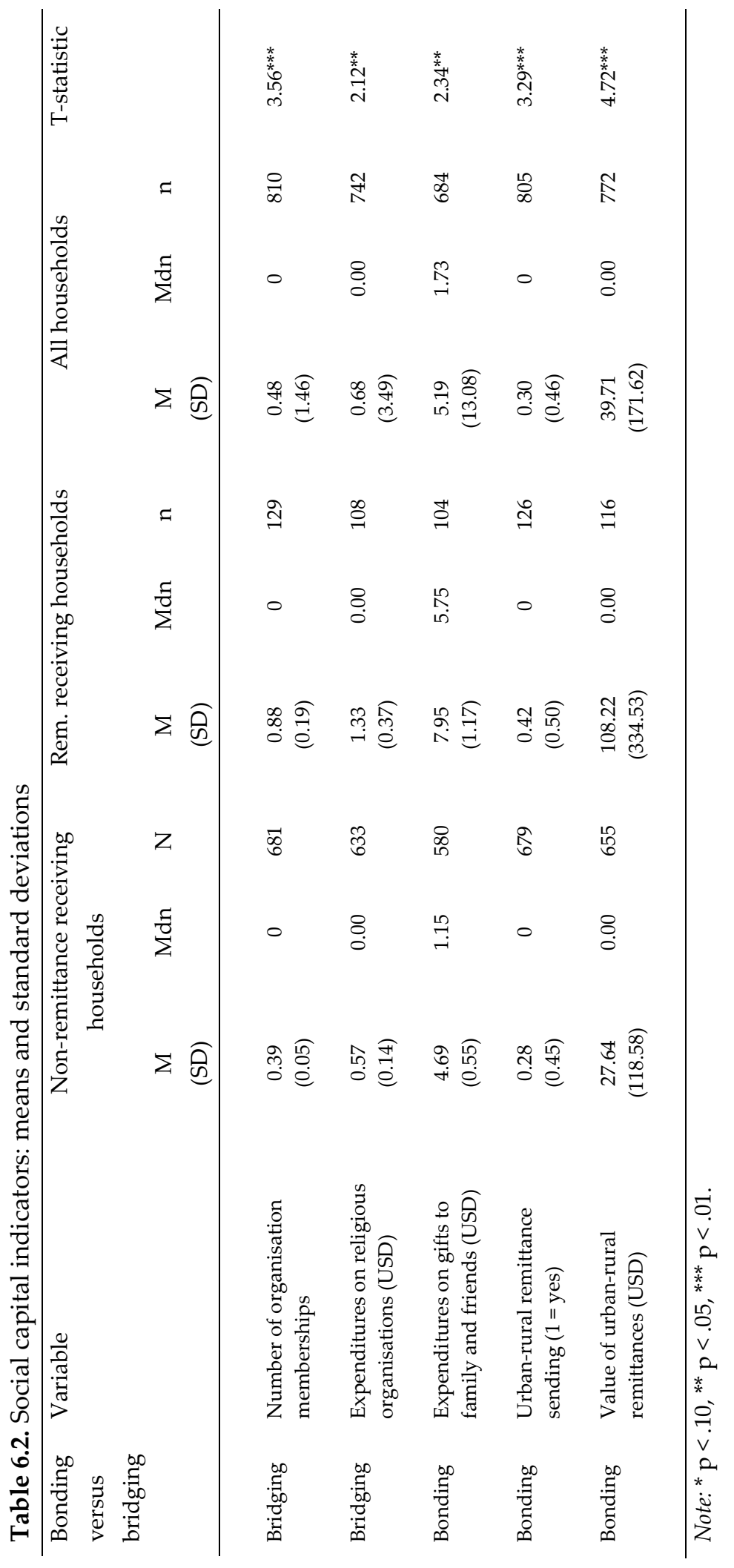


The descriptive statistics reveal that remittance-receiving households invested significantly more in their structural social capital, both bonding and bridging, than non-receiving households. Receiving households had on average 0.88 organisation memberships, versus 0.39 for non-receiving households. Receiving households also spent more on religious organisations: 1.33 US dollars versus 0.57 US dollars in the past month, for remittance-receiving and nonremittance receiving households, respectively. Receiving households also gave significantly more financial gifts to family and friends, with almost 8 US dollars per month, versus 4.69 US dollars for non-receiving households. Finally, receiving households were more likely to send urban-rural remittances and sent higher values. Forty-two per cent of households that had received international remittances in the past 12 months had sent internal remittances. Of the households that had not received international remittances, 28 per cent had sent internal remittances. As described earlier, remittance-receiving households may differ in their social capital investments due to household characteristics other than remittances, which may explain why remittance-receiving households score higher on social capital in Table 6.2. The following section therefore presents the PSM estimates, for which remittance-receiving households were matched to similar, non-remittance receiving households.

\subsubsection{Remittances and social capital: addressing selection effects}

The PSM estimates are presented in Table 6.3, which shows the mean values for remittance-receiving households (the treated) and non-remittance receiving households (the untreated), and the ATT, which signifies the average difference between the treated and untreated.16 The assumption is that the analyses are controlled for all theoretically relevant variables, so that the ATT signifies the difference in social capital between remittance-receiving and non-remittance receiving households, due to remittances.

\footnotetext{
${ }^{16}$ Logit regression analyses were used for the estimates, to predict the probability of receiving remittances (results are available upon request).
} 
Table 6.3. Remittances and structural social capital: PSM results

\begin{tabular}{|c|c|c|c|c|c|c|c|}
\hline $\begin{array}{l}\text { Bonding } \\
\text { versus } \\
\text { bridging }\end{array}$ & $\begin{array}{l}\text { Matching } \\
\text { algorithm }\end{array}$ & $\begin{array}{c}\mathrm{M} \\
\text { Treated }\end{array}$ & $\begin{array}{c}\mathrm{M} \\
\text { Untreated }\end{array}$ & ATT & $t$ & $\begin{array}{l}\text { No. of } \\
\text { treated }\end{array}$ & $\begin{array}{c}\text { No. of } \\
\text { untreated }\end{array}$ \\
\hline \multirow[t]{4}{*}{ Bridging } & $\begin{array}{l}\text { Number of } \\
\text { organisation } \\
\text { memberships }\end{array}$ & & & & & & \\
\hline & NN (5) & 0.93 & 0.36 & $0.57^{* *}$ & 2.54 & 124 & 663 \\
\hline & Kernel (Gaussian) & 0.93 & 0.44 & $0.49^{* *}$ & 2.21 & 124 & 663 \\
\hline & Radius, cal. (0.1) & 0.93 & 0.44 & $0.48^{* *}$ & 2.23 & 124 & 663 \\
\hline \multirow[t]{4}{*}{ Bridging } & $\begin{array}{l}\text { Expenditures on } \\
\text { religious } \\
\text { organisations (USD) }\end{array}$ & & & & & & \\
\hline & NN (5) & 1.31 & 2.09 & -0.78 & -1.42 & 107 & 617 \\
\hline & Kernel (Gaussian) & 1.31 & 1.50 & -0.20 & -0.43 & 107 & 617 \\
\hline & Radius, cal. (0.01) & 1.31 & 1.37 & -0.07 & -0.16 & 107 & 617 \\
\hline \multirow[t]{4}{*}{ Bonding } & $\begin{array}{l}\text { Expenditures on gifts } \\
\text { to family and friends } \\
\text { (USD) }\end{array}$ & & & & & & \\
\hline & NN (5) & 8.02 & 12.81 & $-4.79^{* *}$ & -2.43 & 103 & 566 \\
\hline & Kernel (Gaussian) & 8.02 & 13.46 & $-5.44^{* * *}$ & -3.30 & 103 & 566 \\
\hline & Radius, cal. (0.1) & 8.02 & 11.97 & $-3.95^{* *}$ & -2.58 & 103 & 566 \\
\hline \multirow[t]{4}{*}{ Bonding } & $\begin{array}{l}\text { Urban-rural } \\
\text { remittance sending ( } 1 \\
=\text { yes })\end{array}$ & & & & & & \\
\hline & NN (5) & 0.43 & 0.30 & $0.13^{* *}$ & 2.21 & 122 & 661 \\
\hline & Kernel (Gaussian) & 0.43 & 0.28 & $0.15^{* * *}$ & 2.62 & 122 & 661 \\
\hline & Radius, cal. (0.1) & 0.43 & 0.29 & $0.14^{* *}$ & 2.51 & 122 & 661 \\
\hline \multirow[t]{4}{*}{ Bonding } & $\begin{array}{l}\text { Value of urban-rural } \\
\text { remittances (USD) }\end{array}$ & & & & & & \\
\hline & $\mathrm{NN}(5)$ & 111.97 & 32.30 & $79.67^{* *}$ & 2.30 & 113 & 641 \\
\hline & Kernel (Gaussian) & 115.08 & 36.57 & $78.51^{* *}$ & 2.29 & 113 & 641 \\
\hline & Radius, cal. (0.1) & 112.99 & 38.32 & $74.68^{* *}$ & 2.22 & 113 & 641 \\
\hline
\end{tabular}

Note: ${ }^{*} \mathrm{p}<.10,{ }^{* *} \mathrm{p}<.05,{ }^{* * *} \mathrm{p}<.01$. 


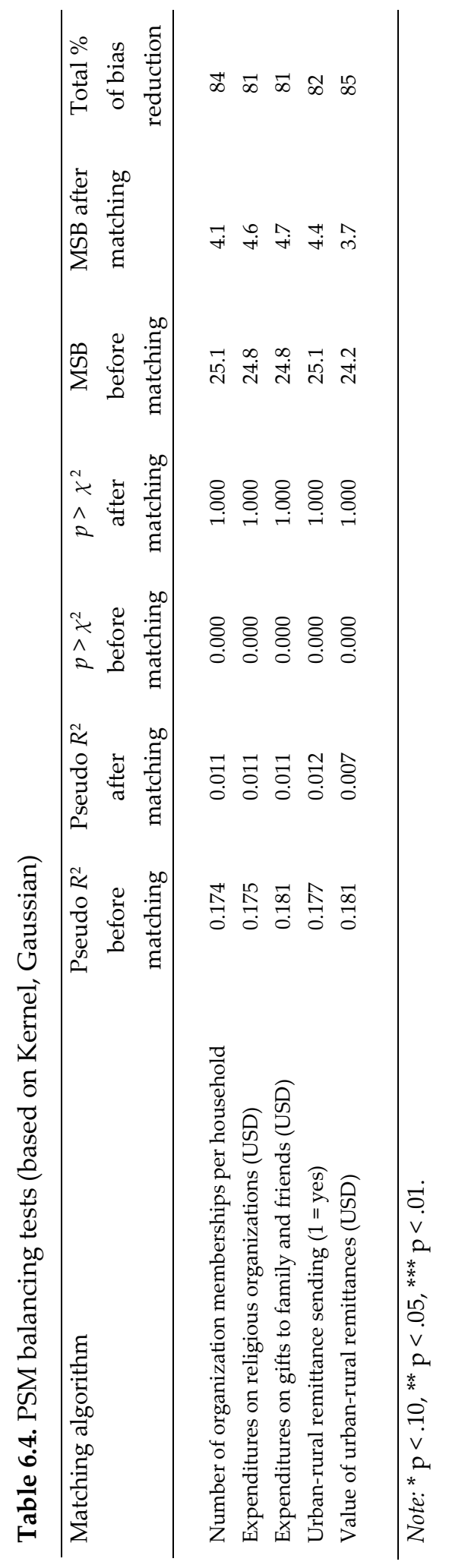

ปิ 
Table 6.3 shows mixed results for the effects of remittances on bridging social capital. Remittance-receiving households had significantly more organisation memberships per household, compared to similar, non-remittance receiving households. The effect of remittances on the second bridging indicator, expenditures on religious organisations, however, became insignificant after matching. This signifies that remittance-receiving households do not spend significantly more or less on religious organizations than similar, non-remittance receiving households. As explained above, organisation memberships and expenditures on religious organisations refer to social capital investments that are made by donating time versus money, respectively. Remittance-receiving households thus seemed to invest more in their bridging social capital by donating time, but did not make larger monetary contributions than non-remittance receiving households.

The estimates in Table 6.3 reveal mixed effects of remittances on bonding social capital as well. Remittance-receiving households spent significantly less on gifts to family members and friends. Yet, remittance-receiving households sent more and higher values of urban-rural remittances. Sending urban-rural remittances was classified as a bonding social capital investment, because internal remittances, like international remittances, are mostly a family affair in Burundi: remittances tend to stay within close family networks. Remittances thus seemed to incentivize receiving households to spend less on their networks comprised of family members and close friends and more on family networks only.

The estimates for the indicators of social capital in Table 6.3 are robust across the different matching estimations. Common support graphs, illustrating the distribution of the propensity scores and the area of common support for the propensities of remittance-receiving households and non-remittance receiving households, are presented as Figure A.1a to Figure A.1e in the appendix of this dissertation. The graphs indicate that few observations are outside the common support area, meaning that non-remittance receiving households can be considered a good control group for the remittance-receiving households.

The balancing tests that present the pseudo $R^{2 s}$, the $p$-values of the likelihood ratio tests, and the mean absolute standard biases before and after matching, are presented in Table 6.4. Declines in mean standardised bias after matching ranged from 81 per cent to 85 per cent. The residual mean standardised bias ranged from 3.7 to 4.7 , indicating that bias was significantly reduced through 
matching (Rosenbaum \& Rubin, 1985). The pseudo $R^{2 s}$ were also significantly smaller after matching, and the $p$-values of the likelihood ratio tests became insignificant, indicating that systematic differences in the covariates between remittance-receiving and non-remittance receiving households were eliminated through matching.

\subsection{Discussion and conclusion}

This paper explored the relationship between remittances and households' social capital in Bujumbura, the capital of Burundi. Social capital is considered a prerequisite for post-conflict reconstruction and development but has largely been overlooked in the substantial literature researching the effects of remittances on development in migrant-sending areas. Remittances were hypothesized to increase social capital investments by 1) relaxing liquidity constraints, thereby facilitating investments, 2) raising the income of remittance-receiving households, incentivizing them to civically engage, and 3) the transfer of norms and values regarding civic engagement from the diaspora. Urban Burundi provided an interesting setting to study the link between remittances and social capital because of its unique social dynamics, characterised by 'weak bridges, strong bonds' (Brachet \& Wolpe, 2005, p. 6).

Two main findings emerged from this study. First, remittances seemed to incentivize households to invest in structural social capital by donating time (associational involvement), but not money (church donations). Although the exact mechanisms through which remittances affect social capital were not addressed, some possible explanations can be mentioned. The finding that remittancereceiving households participated more in organizations may be explained by the income-smoothing effect of remittances, which generates leisure time, or the fact that remittance-receiving are more likely to participate in networks because they have more to offer to other members. Remittance-receiving households may also be affected by norms and values regarding civic engagement through contacts with the diaspora. Previous studies have shown that the Burundi diaspora is highly organized and active (see, e.g., Fransen \& Siegel, 2010). These norms of civic engagement may have incentivized remittance-receiving households to participate in organizations as well.

The observation that remittance-receiving households participated more in organizations contradicts findings from Rwanda, a country neighbouring Burundi, 
where remittance-receiving households were found to participate less in community organisations (Caarls et al., 2013). It is unclear why these findings differ. The contrasting findings might be due to economic differences between the countries. Burundi is significantly poorer than Rwanda and has a more recent history of conflict. Research has demonstrated that social capital investments are especially important for poorer households (Grootaert, 1999; Grootaert et al., 2002; Woolcock \& Narayan, 2000). The finding that remittance-receiving households did not contribute more to religious organizations than non-remittance receiving households also contradicts previous research findings (Brown \& Conneil, 1993; James, 1997; Kabki et al., 2004). It is not clear why this is the case. Future research should provide further insights into the effects of context on the relationship between remittances and social capital.

The second important finding that emerged is that remittance-receiving households invested more in their bonding social capital than non-remittance receiving households, but only when the network comprised family members. Receiving households sent more and higher values of urban-rural remittances, which, as the data showed, are almost always sent within family networks. However, receiving households spent significantly less on gifts to family members and close friends, compared to similar, non-receiving households. This indicator was used to capture social networks that have historically performed an important insurance function in Burundi society (Uvin, 2009; Vervisch, Vlassenroot, et al., 2013). Remittances seem to crowd out gifts to these networks, to the extent that remittance-receiving households spend less than similar, non-remittance receiving households. This may be due to the crowding-out effect that Caarls et al. (2013) mentioned: remittance reception may reduce incentives to invest in social capital, because it creates financial independence. The crowding-out effect is similar to a moral hazard effect that predicts that remittances reduce the receiver's incentives to be productive, because remittances provide insurance (see, e.g., Azam \& Gubert, 2006). Another possible explanation is that remittance-receiving households have shifted their investment priorities to their network members residing abroad, from whom they receive financial support. Horizontal social networks have reportedly weakened in Burundi during the war (Vervisch, Vlassenroot, et al., 2013), which may have incentivized remittance-receiving households to invest more in their emigrant connections. 
Based on these results, the expectation that remittances are invested in networks for insurance purposes (Gerber \& Torosyan, 2010; James, 1997; Kabki et al., 2004; Mazzucato et al., 2006) can only partly be confirmed. Remittancereceiving households spent more time on their bridging social capital, but did not make higher monetary contributions to their bridging social capital. Remittancereceiving households spent more money on their bonding social capital, but only when the network comprised family members. Overall, these findings seem to suggest that financial investments due to remittances strengthened mainly the bonding social capital of remittance-receiving households, and family networks in particular. Despite the fact that remittance-receiving households made fewer monetary contributions to their bridging social capital, their participation in organizations may have positive, long-term effects. Participation in formal organisations such as associations is particularly important for conflict prevention, as they make society more resilient to political polarisation (Varshney, 2001). Because of small sample sizes, it was not possible to explore the types of organizations that remittance-receiving households participated in, leaving room for further exploration of the associational involvement of remittance-receiving households.

This paper studied the linkages between remittances and social capital in a conflict-affected setting. The use of a multifaceted social capital measure demonstrated that the relationship between remittances and social capital is complex and dependent on the measure of social capital considered. Some limitations should be mentioned. First, the mechanisms underlying the relationship between remittances and social capital could not be disentangled with the present data. Whether remittances increase social capital investments by relaxing households' liquidity constraints or by increasing the income of remittance-receiving households is unclear. In addition, it was not possible to distinguish between monetary remittances and the transfer of norms and values (social remittances) from the diaspora as driving forces of social capital investments. The mechanisms underlying the relationship between remittances and social capital investments therefore warrant further research attention. Second, because of the cross-sectional nature of the data, it is difficult to draw causal inferences. PSM is an empirical approach that is commonly used in the absence of longitudinal or experimental data to create a counterfactual situation. However, there may be unobservable variables that simultaneously affect the assignment of a 
household into the treatment group and the dependent variable, potentially creating a 'hidden bias' that may drive the results. Future research is therefore needed to study the long-term effects of remittances on social capital formation in conflict-affected settings. 
Chapter 7: The socio-economic sustainability of refugee return 
This chapter has been invited for revision and resubmission as: Fransen, S. The socio-economic sustainability of refugee return: Insights from Burundi. Population, Space and Place. 


\subsection{Introduction}

The concept of sustainable return has been used extensively in policy circles to refer to the successful reintegration of returnees in conflict-affected societies. Sustainability is often seen as the equivalent of 'effective reintegration' (UNHCR, 1997, p. 2); it assumes that when returnees are similar to the local population in terms of socio-economic conditions and security, return is sustainable. However, return migration may affect not only returning individuals or households but also other households in return areas (Black \& Gent, 2006). In some contexts, return has led to increased competition for resources such as land (Huggins, 2007; Kamungi, Oketch, \& Huggins, 2005; Musahara \& Huggins, 2005; Özerdem \& Sofizada, 2006), resulting in lower living standards for all households. Accordingly, scholars have argued for a wider definition of sustainability that includes reintegration outcomes for individual returnees and the effects of return at the community or country level (see, Black and Gent, 2006). This wider view of sustainability remains an underexplored topic, primarily due to a lack of reliable and large-scale data from conflict-affected settings.

Some studies have addressed the sustainability of return in conflictaffected contexts by conducting in-depth case studies. These studies have often focused on factors related to the sustainability of return, such as property restitution. Ozerdem and Sofizada (2006), for example, have studied the sustainability of refugee return in Afghanistan in the early 2000s by focusing on land-related challenges for returnees. Similarly, Williams (2006) has addressed the process of property restitution for returning refugees and Internally Displaced Persons (IDPs) in Bosnia and Herzegovina. Despite these contributions, the research field on sustainable return is small. Little is known about the lives of former refugees after their return to their countries of origin, and even less is known about the effects of their return on their communities. Moreover, few studies are based on quantitative data that allow a comparative, cross-national or sub-national perspective.

This paper aims to contribute to the emerging literature on refugee return by studying the sustainability of refugee return in Burundi, a small and densely populated country in the African Great Lakes region. More than 500,000 former refugees returned to Burundi between 2002 and 2011, mainly from neighbouring Tanzania (UNHCR, 2011). The Burundi case became internationally known as a major success because most returnees were repatriated in 'safety and with dignity' 
(Rema Ministries, 2012), which are the main principles underlying the repatriation activities of UNHCR. Some studies found no significant differences between returnees and non-returnees, suggesting that reintegration had been successful (Terra-P Group, 2008). Several humanitarian organisations consequently closed their country offices, convinced that the 'humanitarian crisis' had ended. However, the long-term sustainability of return in Burundi was questioned by others, who argued that return had put additional pressure on scarce resources such as agricultural land, intensifying poverty in areas of return (Fransen \& Kuschminder, 2012; Rema Ministries, 2012). Instead of comparing return to non-return households, these studies focused on communities and took into account changes to households over time. Whereas previous studies provided important insights, most were small-scale, conducted in specific localities, or focused on specific groups of returnees.

This study provides a nationwide study on refugee return in Burundi by analysing nationally representative household and community survey data collected in 2011, a little more than five years after the official end of conflict and after most former refugees had returned. Following Black and Gent's (2006) wider definition of sustainable return, this paper a) compares return and non-return households, and b) estimates the relationship between return migration and the socio-economic conditions of all households in communities that host returnees. A distinction is made between the return of first- and second-generation returnees, the latter of whom are the children of former refugees who were born in exile. This distinction is especially relevant in the Burundi context because, due to their time spent in exile, many former refugees had children who returned with them to Burundi. Few studies have addressed second-generation returnees (exceptions are: Christou, 2006; King \& Christou, 2010; Wessendorf, 2007) and none have been conducted in conflict-affected contexts. This paper aims to fill these gaps and investigates whether in Burundi, there are key differences between these two groups related to the sustainability of return. Because of this paper's country context, it focuses specifically on the socio-economic dimension of sustainability. Economic issues such as poverty and land scarcity have been identified as the primary factors hampering the reintegration of former refugees in Burundi (Fransen \& Kuschminder, 2012; Rema ministries, 2012). 


\subsubsection{Operationalizing sustainability}

Sustainable return is defined as a 'longer-term, contextual, and challenging understanding of return that encompasses social and economic dimensions' (Black \& Gent, 2006, p. 26). The concept of sustainable return goes beyond the livelihoods of returnees and refers to structural conditions in the country of return that enable all households to generate viable livelihoods. Sustainable return is therefore 'more than simple development' or the provision of basic needs; it also implies good structural conditions in return areas. Sustainability may be understood as comprising three dimensions: physical, socio-economic, and political sustainability (Black, 2004) (see Table 7.1). Physical sustainability refers to the perpetuity of migration, meaning that returnees are not re-displaced after return. Socioeconomic sustainability focuses on the living conditions of returnees and other households in areas of return, whereas political sustainability refers to security levels after return and access to public services.

Table 7.1. Measuring sustainable return

\begin{tabular}{|c|c|c|c|c|}
\hline \multirow{2}{*}{$\begin{array}{l}\text { Level of } \\
\text { analysis }\end{array}$} & \multirow[t]{2}{*}{ Operationalisation } & \multicolumn{3}{|c|}{ Indicators of the three dimensions } \\
\hline & & $\begin{array}{c}\text { Physical } \\
\text { sustainability }\end{array}$ & $\begin{array}{c}\text { Socio- } \\
\text { economic } \\
\text { sustainability }\end{array}$ & $\begin{array}{c}\text { Political- } \\
\text { security } \\
\text { sustainability }\end{array}$ \\
\hline \multirow[t]{2}{*}{$\begin{array}{l}\text { Micro (individual } \\
\text { or household) }\end{array}$} & $\begin{array}{l}\text { Objective conditions of } \\
\text { returnee }\end{array}$ & $\begin{array}{l}\text { Proportion of } \\
\text { returnees } \\
\text { who (do not) re- } \\
\text { emigrate }\end{array}$ & $\begin{array}{l}\text { Actual socio- } \\
\text { economic } \\
\text { status of } \\
\text { returnees }\end{array}$ & $\begin{array}{l}\text { Actual } \\
\text { persecution or } \\
\text { violence against } \\
\text { returnees }\end{array}$ \\
\hline & $\begin{array}{l}\text { Subjective perception of } \\
\text { returnee }\end{array}$ & $\begin{array}{l}\text { (Lack of) desire } \\
\text { to re-emigrate }\end{array}$ & $\begin{array}{l}\text { Perceived socio- } \\
\text { economic } \\
\text { status }\end{array}$ & $\begin{array}{l}\text { Perception of } \\
\text { safety, } \\
\text { security threats }\end{array}$ \\
\hline $\begin{array}{l}\text { Meso/Macro } \\
\text { (community or } \\
\text { country) }\end{array}$ & $\begin{array}{l}\text { Aggregate conditions of } \\
\text { home country }\end{array}$ & $\begin{array}{l}\text { Trends in levels } \\
\text { of emigration } \\
\text { and asylum } \\
\text { seeking } \\
\text { abroad }\end{array}$ & $\begin{array}{l}\text { Trends in levels } \\
\text { of poverty and } \\
\text { well-being }\end{array}$ & $\begin{array}{l}\text { Trends in levels } \\
\text { of persecution, } \\
\text { conflict and } \\
\text { violence }\end{array}$ \\
\hline
\end{tabular}

Source: Black et al. (2004), modified by author. 
Sustainability can be measured at two levels: micro (individual/household) and meso/macro (community/society). At the micro level, return is sustainable when a) it is permanent, meaning that returnees are not re-displaced again, and b) return migrants are doing well socially and economically compared to nonreturnees. At the meso or macro levels, return migration is sustainable if has no negative influences on socio-economic conditions or security levels in the areas of return and if it does not spur new emigration flows (Black et al., 2004). Defining sustainability as the permanence of return is referred to as a 'narrow' definition of sustainability, whereas focusing on the living conditions of returnees and the wider impact of return on return areas is considered the 'wider' definition of sustainable return (Black \& Gent, 2006).

The narrow definition of sustainability is hotly debated (Black \& Gent, 2006; Black \& King, 2004; Stigter, 2006). Migration theories hypothesise that migration is inspired by relative deprivation and offers economic benefits for poorer households. From a development perspective, mobility thus provides livelihood opportunities for households. Maconachie, Binns, Tengbe and Johnson (2006), for example, argued that seasonal labour migration was essential for the sustainability of return for IDPs in Sierra Leone. These views contrast with the idea that the permanence of return migration is an indicator of 'success'. Accordingly, the narrow view of sustainability is disregarded in the rest of this paper.

The individual or household measurement of sustainability is often used in research on return migration and has been applied in Burundi (see, e.g., Terra-P Group, 2008). It offers clear benchmarks to estimate the 'success' of return, is easy to operationalise for research purposes and is informative for policy makers because it highlights the areas in which returnees need support. It can also be used to study which returnees reintegrate, or the aspects that underlie successful reintegration (Black \& Gent, 2006). Sustainability at the micro level can be measured using either objective or subjective indicators (Black \& Gent, 2006). Whereas objective indicators focus on tangible aspects such as asset ownership, subjective indicators consider the perceptions of returnees or of returning households.

A further distinction involves the use of either absolute or relative standards. Black et al. (2004) use an absolute measure, arguing that when returnees have an 'adequate level of well-being' (p. 27), their return is socio-economically sustainable. In contrast, relative measures compare returnees to other society 
members. When returnees are on par with local populations in terms of, for example, employment and living conditions, their return is considered sustainable. There are disadvantages to using either absolute or relative standards to assess the sustainability of return. The absolute measurement begs the question of the definition of an 'adequate' level of well being, whereas a relative measurement overlooks the fact that living conditions may be poor in general.

The primary disadvantage of the micro-level perspective on sustainability is that it overlooks potential changes experienced by other members of society. Although from an objective viewpoint returnees and non-returnees may have equal assets and opportunities, the overall pie may have become smaller due to return, leading to (increased) poverty for all of the households in areas of return (Black \& Gent, 2006; Hammond, 1999). Given these potential effects, it is important not only to take into account the effects of displacement on individuals or households but also to explore how return migration has affected entire communities using a long-term perspective (Black \& Gent, 2006). A meso/macro level perspective on sustainable return offers the advantage of providing insight into the long-term development implications of return because it refers to all households (both return and non-return) in areas of return and incorporates changes over time that may occur due to return. The macro perspective, however, is more difficult to apply because it requires large-scale data collection, which is often a challenge in unstable settings. Consequently, the macro perspective has been largely overlooked in research on return migration.

\subsection{Burundi: a decade of refugee return}

Refugees fled from Burundi during waves of political instability and civil conflict that emerged after Burundi's independence in 1962. Most refugees left the country as a result of conflict episodes in 1972 and 1993 that generated refugee flows of approximately 300,000 and 700,000 individuals, respectively. Approximately twothirds of the 1972 refugees fled to neighbouring Tanzania, where they inhabited refugee sites that were eventually named the 'Old Settlements'. Refugees in 1993 mostly settled in refugee camps in Northwest Tanzania (Fransen \& Kuschminder, 2012). An unknown number of refugees moved to communities in border areas and Tanzania's capital, Dar es Salaam. Others, both 1972 and 1993 refugees, fled to Rwanda or the DRC, and a small number reached Europe, the United States and Canada. 
After the signing of the Arusha Peace and Reconciliation Agreements in August 2000, many Burundians began to return voluntarily from exile. The Arusha Agreements stated that everyone affected by the conflict would be compensated for their losses and would be entitled to property restitution (Republic of Burundi, 2000), which incentivised many refugees to return (Fransen \& Kuschminder, 2012). Official repatriation movements, facilitated by UNHCR in a joint initiative with the Burundian and Tanzanian governments, began in 2002. Between 2002 and September 2011, more than 500,000 formally registered Burundians crossed the border back into their home country (UNHCR, 2011). Approximately 490,000 returnees were repatriated from Tanzania, approximately 15,000 returned from DRC, and almost 8,000 returned from Rwanda. ${ }^{17}$ In 2008, UNHCR initiated the repatriation of 1972 refugees from the Old Settlements. Until then, few had returned, and the Tanzanian government increased pressure to return (Haver et al., 2009). ${ }^{18}$ The efforts of UNHCR led to an increase in the return of primarily 1972 refugees in 2008 (UNHCR, 2011). In 2009, UNHCR started the repatriation of Burundians living in Rwanda, and in October 2010, repatriation from the DRC was launched. In 2011, approximately 84,000 refugees were in exile, of which 37,000 were in Tanzania (UNHCR, 2011).

Because of the protracted Burundian refugee settlement in Tanzania, some who returned to Burundi were second-generation returnees, the children of (mostly 1972 cohort) refugees who were born in exile. Most second-generation returnees were born and raised in the Old Settlements in Tanzania and were migrating to a country unknown to them (Fransen \& Kuschminder, 2012). Bunte and Monnier (2011) cite a 2010 UNHCR report that stated that 82 per cent of the returnees in 2008 were born in Tanzania. However, there is little information on this group, including their motivations to return. It is likely that at the time of repatriation, many of the second-generation returnees were under-age and travelled to Burundi with their parents.

Most returnees settled in their provinces of origin in Southern and Northern Burundi, which border Tanzania and Rwanda (see Map A.2 in the

\footnotetext{
${ }^{17}$ These numbers represent only returnees who were registered by UNHCR and are likely to be an underestimate of the actual return flow.

18 In 2008, Tanzania also established a naturalization option for 1972 refugees from Burundi. More than 160,000 people chose this option, whereas approximately 50,000 1972 refugees decided to return to Burundi, and a small group opted for resettlement in a third country.
} 
appendix of this dissertation). However, the country offered few opportunities; Burundi is one of the poorest countries in the world, ranking 185th out of 187 countries on the Human Development Index in 2011 (UNDP, 2011). World Food Programme (WFP) estimated that approximately 1.5 million people suffered from food insecurity in October 2012, primarily because of scarcity of agricultural land. ${ }^{19}$ Agricultural land is the most important source of livelihoods in the rural areas, where the majority of households rely on subsistence farming. Land is inherited in Burundi; therefore, it is also an important identity marker (Fransen \& Kuschminder, 2012). Due to their emotional attachments to family land, most of the returnees strongly desired to return to their origin communities (Fransen \& Kuschminder, 2012; Hovil, 2009).

However, returnees frequently found their agricultural land either occupied by others or sold by family members (Hovil, 2009), leading to various land disputes. In 2006, the Burundian government established the National Commission on Land and other Properties (CNTB) to address land (and other property) disputes (Fransen \& Kuschminder, 2012). Land sharing is the most common resolution to land disputes, but it has frequently led to resentment, and most people see it as a temporary solution (Hovil, 2009). Moreover, the agricultural production of a single plot is often insufficient to feed multiple families (Fransen \& Kuschminder, 2012). Returnees who spent more than 30 years abroad (notably, the 1972 cohort), as well as second-generation returnees, often are not entitled to reclaim their land. Burundi's 1986 land law provides that those who reside on land or other property for a consecutive period of 30 years gain legal tenure (Bunte \& Monnier, 2011). This situation has led to additional challenges for the returning groups in terms of, for example, food security (Rema Ministries, 2012).

\subsection{Data and definitions}

Data were collected in all 17 provinces of Burundi and included 1,500 households residing in 100 different communities. Within each sous-colline (sub-hill), which is the smallest administrative unit in Burundi, 15 household heads and one community representative were interviewed using a standardised questionnaire. Urban households residing in the capital of Bujumbura were eliminated from the analyses to create a more homogeneous sample in terms of migration experiences.

\footnotetext{
${ }_{19}$ See http://www.wfp.org/countries/burundi/food-security for more information.
} 
Urban areas are significantly wealthier than rural areas and display different migration dynamics, including migration for educational or employment opportunities. In rural areas, migration has been mostly conflict-related. Because this study's purpose was to focus on refugee return, only rural households were included in the analyses. This approach yielded a sample of 7,477 individuals living in 1,410 households distributed over 94 communities.

\subsubsection{Return migration: an overview}

A first-generation return migrant was defined as a former international migrant who had lived abroad for a consecutive period of at least 3 months. Of the 7,477 rural household members in the sample, 447 individuals (5.99 per cent) were firstgeneration returnees. If the household contained a first-generation return migrant, he or she was interviewed in-depth about his or her migration experiences. If there were multiple first-generation return migrants, one person was randomly selected for the in-depth interview. These interviews revealed that most first-generation returnees had returned from countries in the region: Tanzania (57.79 per cent), Rwanda (22.13 per cent), the DRC (15.57 per cent), and Uganda (4.10 per cent). The reasons they had returned were mostly related to emotional attachment to Burundi and the improved political and security situation since 2005. This finding confirms that migration was mostly conflict-related in rural areas. Most returnees in the sample had returned between 1993 and 1997 and between 2001 and 2008. These peaks in return aligned with the aftermath of the 1993 conflict and the signing of the Arusha agreements in 2000 that signalled the start of the reconstruction phase, respectively.

Second-generation returnees were identified as children of former migrants who were born abroad. In this sample, 190 individuals (2.54 per cent) were second-generation returnees. Descriptive statistics show that secondgeneration returnees were generally younger than first-generation returnees (see Table 7.2). Most of them were not married, and they were more likely to be in school as opposed to being employed. Seventy-three per cent of the secondgeneration returnees lived with first-generation returnees at the time of the survey; these first-generation returnees were their parents in 97 per cent of cases.

A household was classified as a first- or second-generation return migrant household if it contained at least one first- or second-generation return migrant, respectively. Because of this classification, some households were categorized as 
both a first- and second-generation return household. This categorization was chosen because the main purpose of the analyses is to compare first- and secondgeneration return migrant households to non-migrant households. The variables indicating whether the household was a first- or second-generation return migrant household were included separately in the analyses, to avoid multicollinearity.

Individual data on return were aggregated to the community level to create proportions of community populations consisting of returnees (see Table 7.3). These proportions varied significantly, ranging from zero to 43 per cent and from zero to 33 per cent for first- and second-generation returnees, respectively. The highest proportions of return migrants were found in communities in the Southern provinces of Rutana, Makamba, and Ruyigi, and the lowest proportions were found in Mwaro and Muramvya provinces in the interior of the country.

\subsubsection{Measuring socio-economic sustainability}

Five indicators were used to measure the socio-economic sustainability of return:

1) land ownership, 2) living conditions, 3) food security, 4) subjective wealth, and 5) subjective change in wealth over the previous five years. Descriptive statistics are shown in Table 7.3. The first three indicators provided objective measurements of households' economic conditions, whereas indicators 4 and 5 measured subjective experiences. First, land ownership referred to whether the household owned land that was used for agricultural purposes, herding or other activities. Eighty-two per cent of the households in the sample reported owning land. Second, a living conditions index was constructed based on the households' primary water source, toilet type, cooking fuel, lighting type, and housing conditions. The index was constructed using Principal Component Analysis (PCA) (results available upon request) and yielded a unique score for each household, ranging from -1.23 to 12.51 . Third, food security measured the frequency with which the household experienced difficulties in meeting its food needs, ranging from one (every day) to five (never). More than 42 per cent of the sampled households reported difficulties meeting food needs on a daily basis. The average score on the five-point food security scale was 2.80 . 


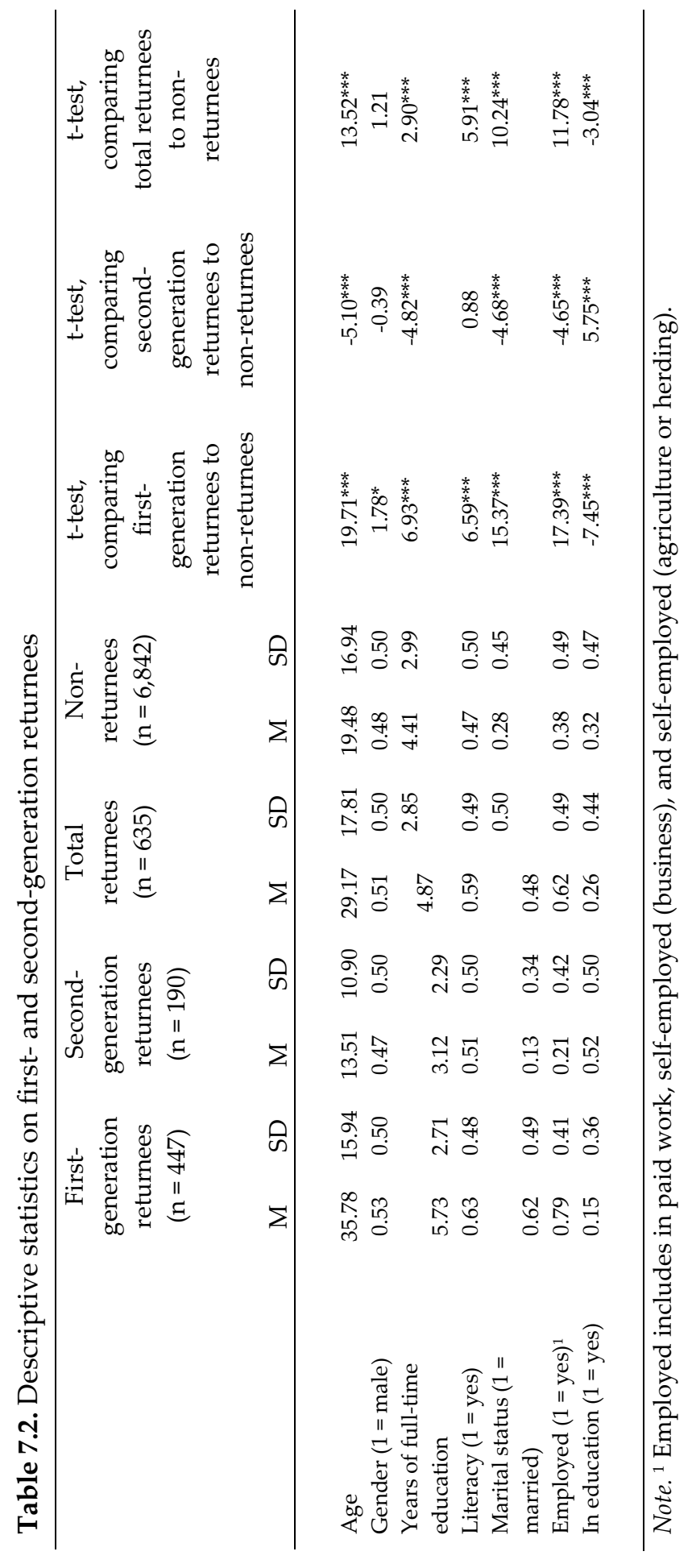

암 
Table 7.3. Descriptive statistics of the main variables

\begin{tabular}{|c|c|c|c|c|c|}
\hline & $\mathrm{M}$ & SD & Min. & Max. & $\mathrm{n}$ \\
\hline \multicolumn{6}{|l|}{ Community return migration } \\
\hline First-generation returnees (prop.) & 0.06 & 0.08 & 0 & 0.43 & 94 \\
\hline Second-generation returnees (prop.) & 0.03 & 0.06 & 0 & 0.33 & 94 \\
\hline \multicolumn{6}{|l|}{ Socio-economic sustainability variables } \\
\hline Land ownership ( 1 = yes) & 0.82 & 0.38 & 0 & 1 & 1,410 \\
\hline Living conditions (index) & 0.00 & 1.94 & -1.23 & 12.51 & 1,409 \\
\hline Food security ${ }^{1}$ & 2.80 & 1.76 & 1 & 5 & 1,405 \\
\hline Subjective wealth ${ }^{2}$ & 2.43 & 0.90 & 1 & 5 & 1,409 \\
\hline Subjective change in wealth ${ }^{3}$ & 2.64 & 0.99 & 1 & 5 & 1,359 \\
\hline \multicolumn{6}{|l|}{ Community control variables } \\
\hline Population size (ln) & 6.70 & 0.76 & 5.21 & 8.93 & 91 \\
\hline Infrastructure (index) & 0.00 & 1.39 & -0.61 & 3.94 & 94 \\
\hline Households that own land (prop.) & 0.82 & 0.19 & 0.20 & 1.00 & 94 \\
\hline No. of environmental shocks in the past five years & 4.55 & 2.78 & 0 & 14 & 94 \\
\hline No. of conflict experiences & 12.48 & 23.64 & 0 & 180 & 94 \\
\hline Households with IDP camp experiences (prop.) & 5.31 & 4.41 & 0 & 19.35 & 94 \\
\hline Ethnic heterogeneity ( 1 = yes) & 0.85 & 0.36 & 0 & 1 & 94 \\
\hline Hum. org./NGO presence ( 1 = yes $)$ & 0.26 & 0.44 & 0 & 1 & 94 \\
\hline \multicolumn{6}{|l|}{ Household control variables } \\
\hline Age of the household head & 39.17 & 14.47 & 18 & 98 & 1,401 \\
\hline Gender of the household head $(1=$ male $)$ & 0.43 & 0.49 & 0 & 1 & 1,410 \\
\hline Marital status $(1=$ married $)$ & 0.77 & 0.42 & 0 & 1 & 1,410 \\
\hline Educational attainment of the household head ${ }^{4}$ & 1.71 & 0.84 & 1 & 4 & 1,408 \\
\hline Household size & 5.30 & 2.27 & 1 & 14 & 1,410 \\
\hline Internal displacement (IDP) experiences ( $1=$ yes) & 0.28 & 0.45 & 0 & 1 & 1,407 \\
\hline First-generation return household $(1=$ yes $)$ & 0.17 & 0.38 & 0 & 1 & 1,410 \\
\hline Second-generation return household $(1=$ yes $)$ & 0.05 & 0.22 & 0 & 1 & 1,410 \\
\hline
\end{tabular}

Notes. ${ }^{1} 1=$ daily, $2=$ weekly, $3=$ monthly, $4=$ once every few months, $5=$ never. ${ }^{2} 1=$ we are finding it very difficult, 2 = we are finding it difficult, 3 = we are coping, 4 = we are living comfortably, $5=$ we are living very comfortably. ${ }^{3} 1=$ (our living conditions) became much worse, 2 = became worse, $3=$ stayed the same, $4=\operatorname{improved}, 5=\operatorname{improved}$ a lot. ${ }^{4} 1=$ no formal education, 2 = pre-school, 3 = primary school, 4 = secondary school. 
Fourth, subjective wealth was measured by asking the household head to rate the household's economic situation on a scale from one (we are finding it very difficult) to five (we are living very comfortably) and yielded an average score of 2.43. Most of the respondents (36 per cent) chose the second answer category, indicating that they were having a difficult time. The fifth indicator, which referred to subjective changes in household wealth over the previous five years, was measured on a scale from 1 (became much worse) to 5 (improved a lot). The average score on this indicator was 2.64. Most of the respondents (39 per cent) indicated that their situation had worsened.

\subsubsection{Analyses}

The analyses are conducted in two phases. First, descriptive statistics are presented to explore the economic sustainability of return at the household and community levels in an absolute and relative manner using the five socio-economic indicators. Second, regression models are employed to estimate the relationship between return migration and the socio-economic conditions of all households (return and non-return) in the communities while controlling for other household and community variables. These control variables are presented in Table 7.3. The community control variables include the community's population size, the availability of land in the community, availability of employment, the number of conflicts experienced by the community during the conflict, the number of environmental shocks that the community experienced over the previous five years, and an infrastructure index that included whether the community had electricity, lighting, drinking water, and facilities such as schools and health care facilities. This index was constructed using Principal Component Analysis (PCA) (results available upon request) and yielded a unique score for each community. Other community control variables included the proportion of households with IDP camp experiences, ethnic heterogeneity and NGO presence. The household control variables include the age, gender, marital status and educational attainment of the household head along with the household size and the households' IDP camp experiences. This latter variable referred to whether at least one household member had ever resided in an IDP camp. 


\subsection{Results: The socio-economic sustainability of return in Burundi}

\subsubsection{Descriptive statistics: comparing households and communities}

Table 7.4 presents descriptive statistics for the return and non-return households in the sample. The table shows that 23 per cent and 32 per cent of the first- and second-generation return households, respectively, did not own land. These percentages are high given the importance of agricultural land in rural Burundi. First- and second-generation return households also regularly experienced food insecurity. The median score was 2 for both groups, meaning that most return households experienced food insecurity on a weekly basis. The median responses for subjective wealth and subjective change in wealth were also 2 for both groups, which corresponds to the answer categories 'we are finding it difficult' and 'our living conditions became worse'. This result indicates that most return households experienced economic difficulties and witnessed negative changes in wealth over the previous years.

Compared to non-return households, both first- and second-generation return households were significantly less likely to own land. Eighty-four per cent of non-return households owned land, versus 77 per cent and 68 per cent for firstand second-generation return households, respectively. Return households did not report lower food security. This finding may indicate that returnees continued to have access to agricultural land because of land-sharing practices, that returnees had chosen other livelihood strategies, such as business activities, herding or fishing, or that they were more likely to be food aid recipients than were nonreturn households. However, the data show no differences in livelihood activities or receipt of food aid between return and non-return migrant households (results available upon request).

For all other socio-economic indicators, first-generation return households did not differ significantly from non-return households. Second-generation return households scored lowest on all indicators. They were the least likely to own land and reported worse living conditions and lower subjective wealth compared to non-return households. In terms of food security and a perceived change in wealth over the previous years, second-generation return households did not differ significantly from non-return households. 


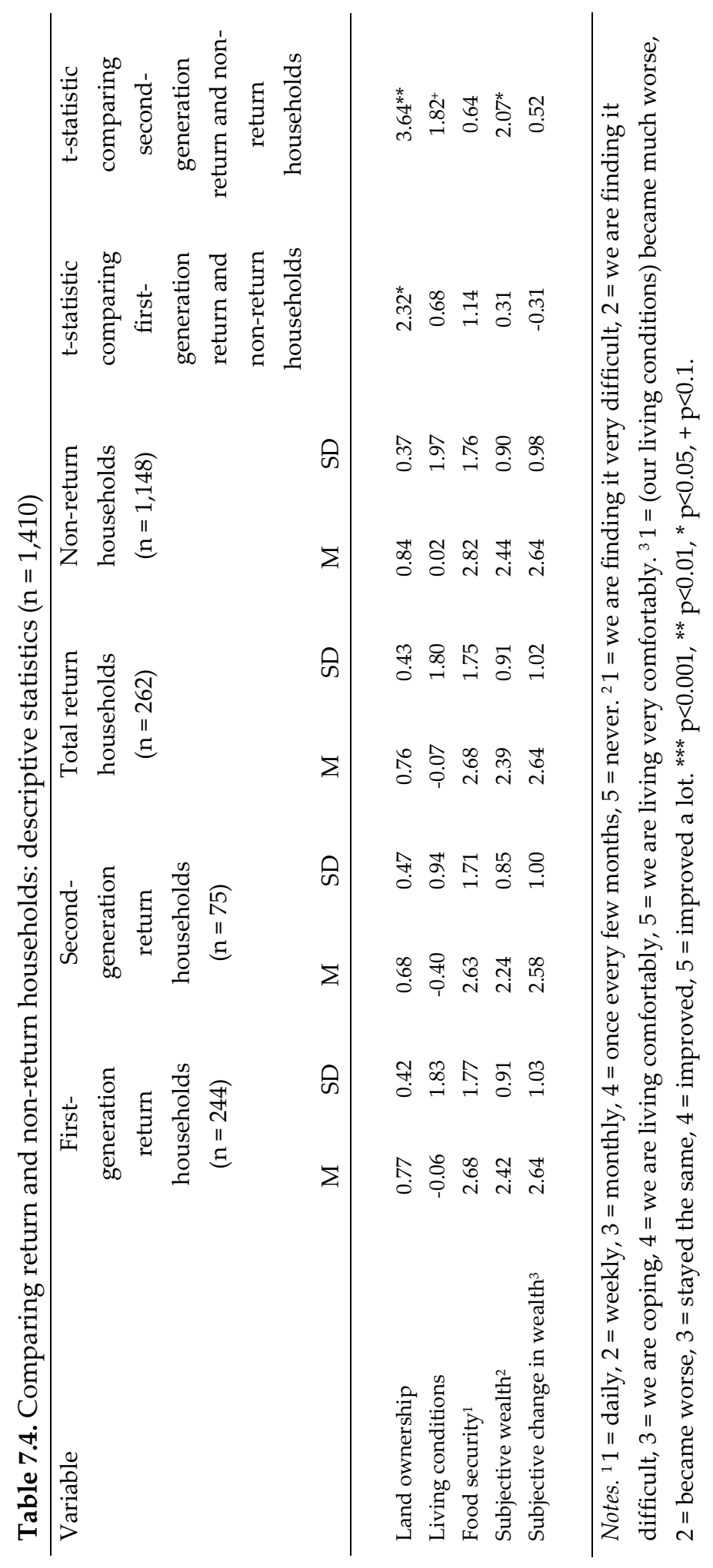

윰 


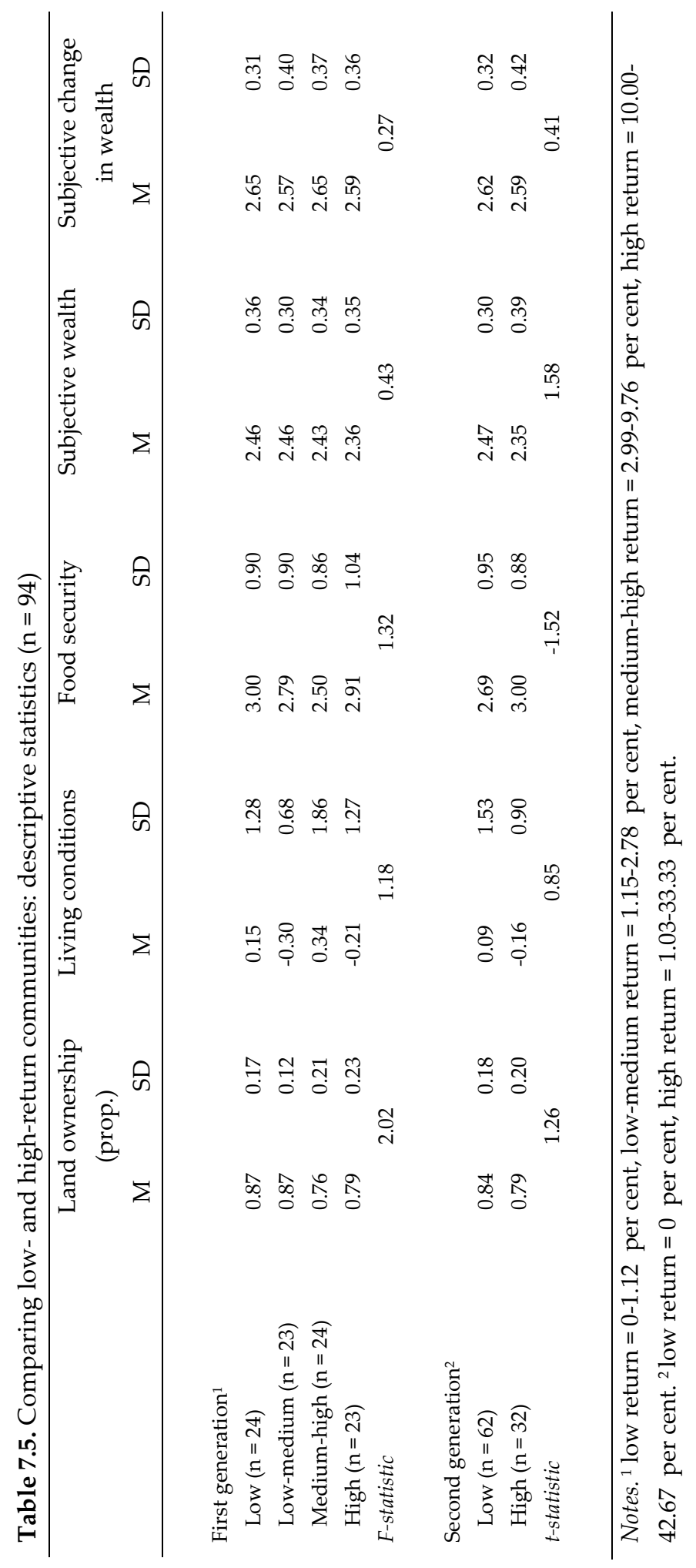

듬 
To compare the socio-economic conditions in communities with relatively low and high numbers of returnees, the communities were split into four (for firstgeneration returnees) and two (for second-generation returnees) equally sized groups. The results are presented in Table 7.5. The community comparisons show no significant differences between communities with relatively lower and higher percentages of either first- or second-generation returnees. These descriptive results suggest that in terms of socio-economic conditions, communities with higher shares of return migrants do not differ significantly from communities with lower shares of return migrants.

\subsubsection{Regression estimates}

Tables 7.6 and 7.7 present the results of the regression analyses that simultaneously estimate a) the relationship between being either a first- or second-generation return household and the household's socio-economic living conditions and b) the relationship between the proportions of first- and second-generation returnees in communities and the socio-economic conditions of all households residing in the communities. Table 7.6 presents the results for the proportion of first-generation returnees, and Table 7.7 presents the results for the proportion of secondgeneration returnees. The analyses are controlled for other household and community variables. Tobit regressions were used to estimate the effect of return on land ownership, whereas Ordinary Least Squares (OLS) regression analyses were employed for the other socio-economic indicators. Standard errors were clustered at the community level to control for intra-community correlations.

The results in Tables 7.6 and 7.7 confirm the descriptive statistics in Table 7.4 indicating that both first- and second-generation return migrant households are less likely to own land compared to non-return households. Controlling for all other household variables, such as the age and level of education of the household head and various community variables, return households score significantly lower on land ownership. In addition to being less likely to own land, the results in Table 7.6 confirm the results from Table 7.4 that first-generation return households do not differ significantly from non-return households in terms of the other socioeconomic indicators. 
Table 7.6. Regression analyses: first-generation returnees

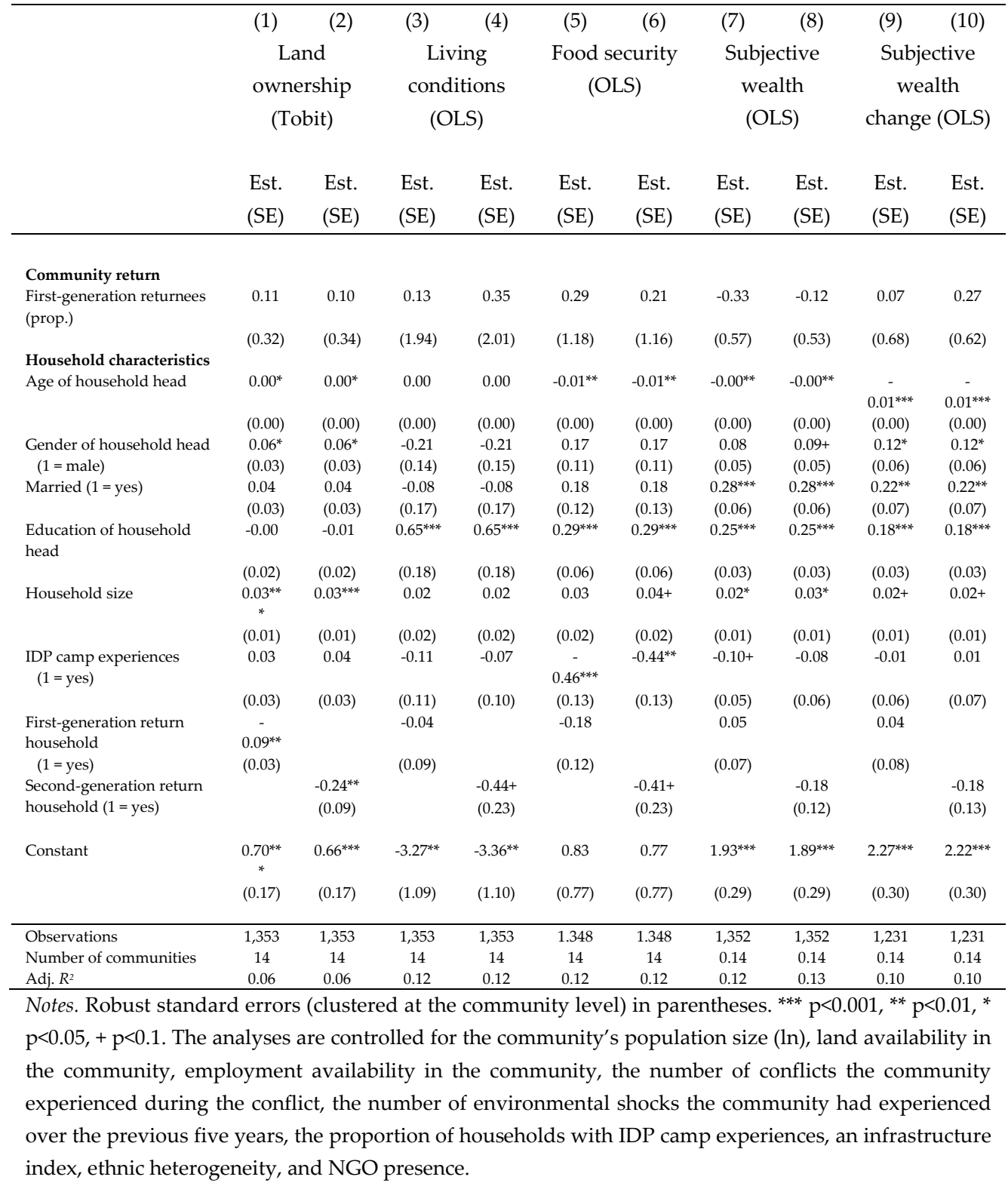


Table 7.7. Regression analyses: second-generation returnees

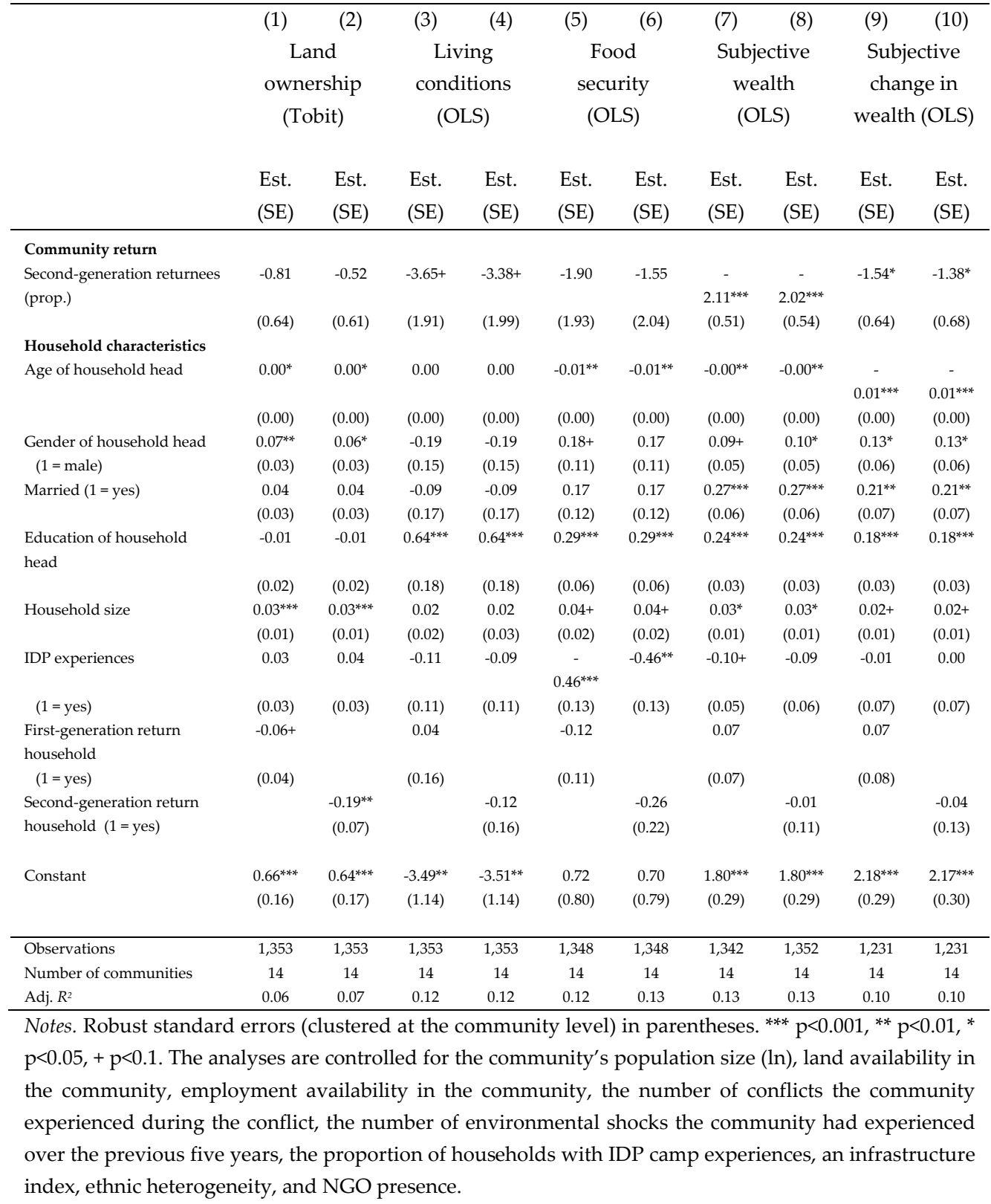


Table 7.4 suggested that second-generation return households had lower living conditions and lower subjective wealth compared to non-return households. The significant relationship between being a second-generation return household and the household's living conditions remained visible when controlling both for other household characteristics and for the community control variables. However, when the proportion of second-generation returnees in the community was added to the model, the significance of the estimate disappeared (see Table 7.7, column 4). This finding suggests that second-generation returnees did not necessarily have lower living conditions than non-return households. Instead, it seems that the proportion of second-generation returnees in the community is related to the living conditions of all households residing in the community, including those of secondgeneration return households. When controlling for household and community characteristics, second-generation returnees no longer scored significantly lower on subjective wealth, which was instead associated with other household characteristics, such as the age, gender, marital status, and education of the household head, the household size, and, to a lesser extent, IDP camp experiences of the household. Table 7.7 confirms the results from Table 7.4 that secondgeneration return migrant households did not experience different changes in wealth in previous years.

Return migration at the community level showed varying relations to the socio-economic conditions of households residing in the communities. The proportion of first-generation returnees in the community was not significantly related to any of the socio-economic indicators (see Table 7.6). The return of second-generation returnees, however, showed significant relationships with some of the socio-economic indicators. Table 7.7 shows that in communities with higher proportions of second-generation returnees, households had significantly lower living conditions (column 4) and subjective wealth (column 8) and reported a more negative change in wealth in previous years (column 10). The proportion of second-generation returnees was not significantly associated with food security and land ownership.

\subsection{Conclusion}

In the past decade, Burundi has received more than a half-million former refugees. In a context of poverty, population pressure and land scarcity, most returnees moved to their origin communities, some after spending more than 30 years 
abroad. Some were second-generation returnees, the children of former refugees who were born in exile. Although the majority of returnees were repatriated successfully, questions have been raised concerning the sustainability of their return. Due to the size of the return movement, the short time period in which it took place and the concentration of return in certain areas, it is feared that the return of former refugees will destabilise Burundi's transition to peace. This paper explored the socio-economic sustainability of return migration to Burundi based on household and community survey data collected in 2011. This paper opted for a wider view of sustainability, following Black and Gent (2006) and incorporating both household comparisons and an analysis of the relationship between return migration and the socio-economic conditions of all households in communities of return. By doing so, this paper aimed to go beyond household comparisons and one-dimensional measurements that have often been used in studies on reintegration or the sustainability of return in conflict-affected contexts.

The analyses revealed that from both a household and a community perspective, the socio-economic sustainability of return in Burundi is questionable. Using absolute standards, it is clear that return households are struggling. Land ownership among first- and particularly second-generation return households was low. Most such households experienced food security on a weekly basis and reported low subjective wealth. Most return households also reported a decline in their wealth over the previous years. Relative to non-return households, both firstand second-generation return households were less likely to own land. These findings contradict other studies in Burundi that did not find significant differences between returnees and non-returnees (see, e.g., Terra-P Group, 2008). Previous studies were small-scale and often conducted in a single location or in a few locations, which may explain these different findings.

Communities also seemed to be affected by return migration. In communities with higher proportions of second-generation returnees, food insecurity for both return and non-return households was higher, on average. This finding corroborates with the findings of Fransen and Kuschminder (2012), who found that population increases due to large-scale return led to food shortages in high return communities. In communities with higher proportions of secondgeneration returnees, all households had lower living conditions and reported both lower subjective wealth and a more negative change in wealth in previous years. From both an objective and a subjective perspective, households that resided in 
communities with more second-generation returnees were thus worse off than households residing in other communities. This finding corresponds to previous findings that second-generation returnees face more challenges upon return (Fransen \& Kuschminder, 2012; Rema Ministries, 2012).

The purpose of this paper was to show relationships between return migration in rural Burundi and the socio-economic conditions of households and communities. In estimating the relationship between return migration and the socio-economic conditions of households residing in the communities, return migration is assumed to be exogenous from these socio-economic conditions. However, there may be a selection at play: returnees may have chosen to settle in areas based on area characteristics such as land availability or living conditions. If this is the case, any positive relationship that is found between return migration and the dependent variables may be due to this selection regarding the communities of return. This is unlikely, however, due to the fact that most returnees were repatriated to their communities of origin (Hovil, 2009). The data show that approximately 85 per cent of first-generation returnees returned to their original provinces. Although this information was not available for secondgeneration returnees, most second-generation returnees resided in a household with first-generation returnees, which indicates that the majority of secondgeneration returnees also settled in communities of their families' origin.

It is not possible to rule out the possibility that a significant share of second-generation returnees chose a different community in which to settle. Second-generation returnees experienced more problems retrieving their family land (Fransen \& Kuschminder, 2012), which may have incentivised some of them to migrate further. If a bias regarding the community of return exists, one would, however, expect to find a positive relationship between return migration and the socio-economic conditions of households because return migration is expected to be higher in communities where socio-economic conditions are better. Any negative relationship between these variables is therefore likely to underestimate the true relationship.

Overall, the results indicate that although most returnees have been repatriated successfully to their home country, many of them live in poor socioeconomic conditions and are worse off than households that did not experience forced international migration. The issue of property restitution, which in this case mainly concerns agricultural land, comes forward as a central issue driving these 
poor socio-economic conditions. The Arusha Agreements stated that everyone affected by the conflict would be entitled to property restitution and would be compensated for their losses (Republic of Burundi, 2000). These objectives incentivised many refugees, including those from the 1972 cohort, to return. These objectives could not be reached. The unequal distribution of land raises concern because of the importance of land for livelihoods in rural Burundi and the emotional ties felt by many people to their ancestral land (Rema Ministries, 2012). Other studies in Burundi have shown that inequity in terms of land ownership has led to disputes (Fransen \& Kuschminder, 2012; Rema Ministries, 2012).

The findings validate the use of a wider approach to studying the sustainability of return. At different levels of analysis and across different socioeconomic indicators, different challenges were highlighted for return versus nonreturn households. Sustainability is therefore best measured at the household and community levels simultaneously using a multi-dimensional approach that incorporates both objective and subjective indicators. The finding that the return of second-generation returnees had a particularly negative effect on socio-economic conditions in communities indicates that returnees are not a homogenous group. Second-generation returnees face particular challenges upon return, but are an understudied group in the literature on return and reintegration and therefore warrant future research attention. 
Chapter 8: A return-related crisis? Refugee return and security 


\subsection{Introduction}

The return of former refugees to conflict-affected areas is often considered a threat to peace, especially when return flows are large. Countries recovering from conflict are frequently politically unstable and impoverished, offering few opportunities for returnees to re-establish their livelihoods (Chimni, 2002; Crisp, 2000). In the absence of resources and favourable conditions in areas of return, a rapid population increase resulting from return flows may lead to increased competition over scarce resources such as land and lower living standards for all households (see, e.g., Hammond, 1999). The relationship between refugee return and increasing land scarcity has been observed in various contexts, such as Sudan (Pantuliano, 2009), Rwanda (Musahara \& Huggins, 2005), and Mozambique (Unruh, 1998). When the return of refugees leads to scarcity, community relations may be unsettled, leading to a vicious cycle of conflict and forced migration (Crisp, 2000).

These ideas are consistent with neo-Malthusian views that a rapid population increase will lead to scarcity of renewable natural resources, such as agricultural land and natural water sources, which may in turn instigate violence (Homer-Dixon, 2010). Such an outcome is more likely to occur in countries that are more dependent on natural resources and that have a lower capacity to address natural resource scarcity (Homer-Dixon, 2010). With damaged institutional capacity, conflict-affected states that experience a rapid population increase are therefore more likely to be affected by conflict (again). Various studies have been conducted to examine the linkages between population pressure, land scarcity and conflict (Andre \& Platteau, 1998; Urdal, 2005; Verpoorten, 2012), but few have addressed population increases resulting from large-scale migration. An exception is Urdal (2005), who used a cross-country design to study whether armed conflict was more likely to occur in countries with large refugee populations. The author found no effect but used an absolute and crude measurement of a refugee population, defining it as large when it consisted of more than 100,000 individuals. Thus, there is little empirical evidence of a potential destabilizing effect of population increases as a result of migration, especially at sub-national level.

This paper tests the neo-Malthusian hypothesis in the context of refugee return in conflict-affected Burundi, a small and densely populated country in the African Great Lakes region. After decades of civil conflict, nearly 600,000 formally registered former refugees returned to Burundi between 2002 and 2014 (UNHCR, 
2014c). Most of them returned to their origin communities in southern and northern Burundi, increasing the population sizes of some communities by 50 per cent (Fransen \& Kuschminder, 2012). Because of the size of the return flow, its concentration in certain areas, the short time period in which it occurred, and existing problems of land shortage and population density, return is feared to destabilize Burundi's transition to peace (Hovil, 2009). Others, however, contend that land-related problems have been too strongly ascribed to return migration and that the structural nature of poverty and land scarcity are underestimated (Huggins, 2007; Van Leeuwen, 2010). Van Leeuwen (2010) concluded that a significant group of returnees did not face conflict over land and that land disputes are therefore not a direct cause of return migration.

This study investigates the extent to which refugee return to Burundi has led to more thefts and disputes and less security based on nationally representative household and community data. The data were collected in 2011, approximately five years after the official end of conflict in the country and after the bulk of refugees had returned (UNHCR, 2014c). A total of 1,500 households throughout 100 communities were interviewed on their migration history and current wellbeing in an effort to conduct a subnational comparative study on the effects of refugee return. Whereas most studies that have investigated the relationship between population growth and conflict have concentrated on the outbreaks of civil conflict as outcome variables (Koubi, Spilker, Böhmelt, \& Bernauer, 2014), this study focuses on issues such as land disputes and thefts and overall security levels in areas of return. These variables have been identified as factors underlying past conflicts in Burundi (see, e.g., Kamungi, Oketch, \& Huggins, 2005) and are therefore considered risk factors for future conflict. This study also presents preliminary findings on how the effects of return may change over time by studying the return of different cohorts of returnees. An instrumental variable (IV) approach is applied to control for potential endogeneity in the relationship between return migration and security. By investigating the effects of large-scale refugee return on thefts, disputes and security in Burundi, this study aims to contribute to the literature on the relationship between population growth and conflict using unique data from a conflict-affected setting. 


\subsection{Migration, land scarcity and conflict}

Neo-Malthusian ideas arose in the late 1960s and early 1970s (see, e.g., Urdal, 2005, for an overview). Observing rapid population increases across the world, neoMalthusianists feared that resources would deplete, leading to poverty and ultimately resulting in violence. Neo-Malthusian ideas originated from Malthus' hypothesis from the $19^{\text {th }}$ century that stated that arithmetically growing food production could not maintain pace with exponential population growth, which would result in food shortages, disease, or conflict.

Neo-Malthusians predicted that scarcity of natural resources could cause certain 'social effects', including economic downfall, out-migration and social tensions (Homer-Dixon, 2010). These social effects, either individually or combined, may generate conflict. The social effects of resource scarcity are most likely to lead to internal civil or ethnic conflicts rather than inter-state conflicts because of their local character (Homer-Dixon, 2010). Compared with Malthusians, neo-Malthusians thus focus on local dynamics in the role of population growth regarding resource scarcity and conflict (Verpoorten, 2012). Different forms of scarcity have been distinguished, including demand-induced, supply-induced, and structural scarcity (Homer-Dixon, 1994). Demand-induced scarcity is caused by population growth in combination with a constant resource base, such as the availability of agricultural land. Supply-induced scarcity is the result of resource degradation, as in the case of land degradation, and structural scarcity results from unequal access to resources within a society.

Neo-Malthusian ideas have been tested across various contexts using different research designs. Early work primarily relied on qualitative analyses, with in-depth examinations of single-country case studies (see, e.g., Andre \& Platteau, 1998; Homer-Dixon, 1994, 2010), and these studies generally found support for the neo-Malthusian hypothesis (Koubi et al., 2014). These studies were, however, criticized for their methodological shortcomings and lack of generalizability. More recent studies have applied quantitative methods using either cross-national (see, e.g., Urdal, 2005) or subnational (see, e.g., Bundervoet, 2009; Verpoorten, 2012) perspectives. Quantitative studies have largely yielded mixed results, perhaps because of the large variety in the type of scarcity that is addressed, the way that conflict is measured, the level of analysis that is adopted, and the region of focus (Koubi et al., 2014). Quantitative studies are also criticized for not properly addressing potential endogeneity problems in the relationship 
between scarcity and conflict and for not considering the role of context in the relationship between scarcity and conflict (Theisen, 2008). Empirical evidence on the linkages between resource scarcity and conflict at subnational levels is especially scarce (Koubi et al., 2014; Verpoorten, 2012).

Migration was considered a potential outcome of resource scarcity by Homer-Dixon (2010), who claimed that resource scarcity would hamper economic development and incentivize people to migrate to areas with better economic opportunities. It is argued in this study that migration can also cause resource scarcity by rapidly increasing population pressure. Countries that experience substantial conflict often generate large forced migration flows, which can lead to large population increases in receiving areas. After conflict, many of those who fled return, leading to large population increases in home countries, typically in the areas that were affected by conflict. Notorious examples are the return movement to Afghanistan after 2002, which involved approximately 5.7 million Afghans (approximately 25 per cent of Afghanistan's population) (UNHCR, 2014b), and the return of approximately 700,000 and 2 million Rwandans following the 1994 genocide and in the late 1990s, respectively (Bruce, 2007).

Large-scale return migration may lead to two types of scarcity. First, it may generate demand-induced scarcity of natural resources, which originates from a rapid population increase while resources remain fairly constant. If this scarcity arises, resources must be shared with more people, competition over resources will increase, and social tensions may arise. Second, large-scale return may lead to structural natural resource scarcity. This scarcity arises when returnees have less access to resources than other households do. Research has shown that returnees frequently lack (access to) important assets such as land and housing. That challenges faced by (primarily) rural returnees who are unable to (re-)gain land are well documented in the literature (see, e.g., Bruce, 2007; Özerdem \& Sofizada, 2006; Pantuliano, 2009; Unruh, 1998, 2009). Such challenges are especially likely when former refugees have spent long periods abroad and have therefore lost property rights. In fact, land disputes between former displaced and non-displaced populations have been argued to lie at the heart of renewed social tensions in many conflict-affected societies (Unruh, 2003).

The extent to which migration flows affect resources in destination areas depends on the scale of migration, the extent to which migration is concentrated in certain areas, and the time period over which migration occurs (Urdal, 2005). 
Population movements that are large relative to local populations, are concentrated in certain areas, and occur quickly are more likely to increase resource scarcity, potentially creating conflict. As will be described in the following sections, all of these conditions were present in the Burundi case. The time that a refugee spends in exile also has a significant effect on return experiences (Rogge, 1994). Some returnees in Burundi spent 30 or 40 years abroad and consequently experienced problems regarding property restitution. Refugee reintegration, defined by UNHCR as the disappearance of differences in legal rights and duties between returnees and their compatriots and the equal access of returnees to services, productive assets and opportunities' (UNHCR, 1997, p. 7), can take as many as 10 or 15 years, especially when former refugees have spent long periods abroad (Rogge, 1994). These time dimensions should therefore be considered when studying large-scale return migration.

\subsection{Conflict and refugee return in Burundi}

Refugees fled Burundi during waves of political instability and conflict that largely emerged after the country's independence in 1962. Most refugees fled the country in 1972 and 1993: approximately 300,000 and 700,000, respectively. These groups are now referred to as '1972 caseload' and '1993 caseload' refugees. Approximately two-thirds of the 1972 refugees fled to neighbouring Tanzania, where they inhabited refugee sites that were eventually named 'the Old Settlements'. 1993 refugees primarily settled in refugee camps in north-west Tanzania (Fransen \& Kuschminder, 2012). An unknown number of refugees moved to communities in border areas and to Tanzania's capital, Dar Es Salaam (Sommers, 2001). Other 1972 and 1993 refugees fled to Rwanda or the Democratic Republic of the Congo (DRC), and a small number reached Europe, the USA and Canada.

Voluntary return movements to Burundi began in 2000 after the signing of the Arusha Peace and Reconciliation Agreements. Official repatriation activities, facilitated by UNHCR in a joint initiative with the Burundian and Tanzanian government, commenced in 2002. In 2006, UNHCR changed its repatriation strategy from 'facilitation of return' to 'promotion of return'. The promotion of return consisted of return promotion campaigns targeted at 1972 refugees who were reluctant to return. These promotion campaigns led to a large increase in the number of returns of largely 1972 caseload returnees in 2008. In total, approximately 490,000 returnees were repatriated from Tanzania between 2002 and 
2011. Slightly fewer than 15,000 came from DRC, and nearly 8,000 came from Rwanda. ${ }^{20}$ In 2011, Tanzania still hosted a 'residual' of 37,000 out of more than 84,000 Burundian international refugees (UNHCR, 2011). Nearly 90 per cent of repatriates between 2002 and 2011 had fled the country in the 1990s. Of the 1972 caseload refugees, approximately 50,000 returned. Many of the 1972 caseload refugees that had settled in the Old Settlements opted for naturalization in Tanzania, which was finally granted to them in October 2014.

Returnees and other conflict-affected people had been promised compensation for the losses that they had suffered during the war. Restitution of land, housing and other durables was specifically mentioned in the Arusha Agreements, which incentivized many former refugees to return (Fransen \& Kuschminder, 2012). Most Burundians strongly desired to return to their family land and were reluctant to settle elsewhere (Fransen \& Kuschminder, 2012; Hovil, 2009). As Hovil (2009, p. 30) stated, 'Those who are returning from exile after decades of alienation, are searching for continuity with their past, which is most tangible through physically returning to the land from which they fled, and on which their ancestors lived'. Land is inherited from father to son in Burundi and therefore has high emotional value (Bunte \& Monnier, 2011; Rema Ministries, 2012). Agricultural land is also the most important household asset in rural areas, where households largely rely on subsistence farming to fulfil basic needs. UNHCR and other international organizations facilitated the return of former refugees to their origin communities by providing logistics.

Property restitution, however, appeared to be one of the major challenges for conflict-affected Burundi, especially concerning land. Because of the scarcity of agricultural land in rural areas, plots of land were often redistributed while refugees were abroad. Upon arrival in their origin communities, returnees frequently found their agricultural land occupied by others or sold by family members (Hovil, 2009). Restitution of land was especially a problem for the 1972 refugee cohort and second-generation returnees. Burundi's 1986 land law stated that those who reside on land or other property for a consecutive period of 30 years gain legal tenure of the property (Bunte \& Monnier, 2011). Therefore, returnees who had spent more than 30 years abroad as well as second-generation returnees -

\footnotetext{
${ }^{20}$ These numbers represent only returnees who were registered by UNHCR and are therefore likely to be an underestimate of the actual return flow.
} 
the children of former refugees who were born abroad - were no longer entitled to reclaim their land.

The government's official position with respect to land disputes is that returnees and non-returnees should share land (Fransen \& Kuschminder, 2012). If a dispute cannot be settled within a community, then the returnee can adhere to the Commission Terres et Autres Biens (CNTB), which was established in 2006 to address land and other property-related conflicts through mediation. In 2011, 70 per cent of the cases at CNTB were filed by returnees, and 80 per cent of these claims concerned land (Fransen \& Kuschminder, 2012). However, the CNTB decision is not legally binding. As a last resort, returnees can make a claim at the national court of Burundi, but this process is lengthy and expensive, and court cases can be filed only in the capital. Because of these challenges, most land disputes have not yet been resolved. In practice, land sharing is the most commonly applied solution, but it frequently leads to resentment, and most people view it as a temporary solution (Hovil, 2009). In many cases, the agricultural production from a plot of land is insufficient to feed multiple families (Fransen \& Kuschminder, 2012).

Return migration to Burundi therefore appears to have generated both structural and demand-induced scarcity of agricultural land by creating differences between returnees and non-returnees in terms of land ownership and by reducing food security in areas of high return due to a lack of land. Some studies have indicated that disputes over land have increased as a result of return migration and have led to occasional violence (see, e.g., Fransen \& Kuschminder, 2012; Rema Ministries, 2012). These studies have occurred in areas with high return rates and have been focused on specific groups of returnees. Fransen and Kuschminder (2012), for example, conducted their fieldwork in high-return communities in Southern Burundi and examined the return experiences of 1972 caseload returnees. The data that were used for this study offer a unique opportunity to study the effects of return on security on a national scale. These data will be discussed in the next section.

\subsection{Data and analyses}

Survey data were collected from 1,500 households residing in 100 communities across all 17 Burundian provinces. The data collection was part of the Migration and Development: A World in Motion project. Within each sous-colline ('sub-hill'), 
which is the smallest administrative unit in the country, 15 household heads and one community representative were interviewed using a standardized questionnaire (Fransen, 2012). Urban households $(n=90)$ were eliminated from the analyses to create a more homogeneous sample in terms of households' migration experiences. In rural areas, migration has largely been conflict related, whereas urban areas are characterized by more diverse migration dynamics, including migration to Europe and North America for educational or employment opportunities. Eliminating urban households yielded a sample of 1,410 households residing in 94 communities. The average household size in rural areas was 5.30. The total number of individuals in the rural data was 7,477.

A first-generation return migrant was defined as a former international migrant who was born in Burundi and had lived abroad for a consecutive period of at least 3 months. Of the 7,477 rural household members, 447 individuals (5.99 per cent) were first-generation returnees. Another set of 190 individuals (2.54 per cent) in the data was identified as second-generation returnees - the children of former refugees who were born abroad. This latter term was derived from the literature on this returnee type (see, e.g., Christou, 2006; King \& Christou, 2010; Wessendorf, 2007). At the time of the survey, 73 per cent of the second-generation returnees lived with first-generation returnees, who were their parents or grandparents in 97 per cent of the cases. First-generation returnees were generally older, more likely to be married, better educated, and more likely to be literate than non-returnees (see Table 7.2 in Chapter 7). Educational systems in Tanzania were generally better than those in Burundi during the conflict (Fransen \& Kuschminder, 2012), which may explain the difference in educational levels. Employment rates were also higher among first-generation returnees.

On average, communities consisted of almost 9 per cent returnees. The median was 3 per cent per community. The highest proportions of return migrants were found in communities in the southern provinces of Rutana, Makamba, and Ruyigi, bordering Tanzania. In these provinces, some communities were $40-60$ per cent returnees. The lowest proportions of return migrants were found in Mwaro and Muramvya provinces in the interior of the country, where some communities did not have any international returnees. Of all 94 rural communities, 15 communities (16 per cent) did not have any returnees. The proportions of firstand second-generation returnees in the communities were highly correlated ( $r=$ $0.54, \mathrm{p}<0.001)$. For this reason, in the analyses presented in the following sections, 
the proportion of first-generation returnees and the proportion of total returnees (first- and second-generation returnees) are the main explanatory variables.

\subsubsection{Measuring land disputes, thefts and security}

The analyses were conducted in two steps. First, the effect of return migration on thefts, disputes and security was studied by exploring whether more problems were reported in communities with higher proportions of returnees. Data on thefts, disputes and security were gathered at the community and household levels. Two indicators were derived from the community questionnaire, which was conducted with a community representative: 1) whether the community experienced problems of land disputes at the time of the survey (yes/no) and 2) a subjective assessment of the security level in the community, measured on a five-point scale ranging from 1 (very bad) to 5 (very good). Of the 94 rural communities, 40 per cent $(n=38)$ reported problems with land disputes, and the communities' average score was $3.12(\mathrm{SD}=0.67)$ on the security scale. One indicator was derived from the household questionnaire: the number of thefts or destruction of crops, livestock and agricultural tools that households had experienced in the previous five years. The average score for all households was $0.57(\mathrm{SD}=1.53)$.

Second, the analyses in step 1 were replicated by using different cohorts of first-generation returnees (those who returned before 2000, those who returned between 2000 and 2005, and those who returned between 2005 and 2011) and by controlling for the effect of the time that the returnees spent abroad. Information on the year of return and the time spent in exile were collected from one randomly selected first-generation returnee in each household who was interviewed in depth about his or her migration experience. In total, 241 first-generation returnees were interviewed in rural areas. This information therefore serves as a proxy for the effects of the return period and the time that first-generation returnees spent abroad. These analyses do not address second-generation returnees and should be treated as preliminary research because of the small sample size. However, the analyses will provide some important insights into the ways in which the effect of return migration may change over time.

Nearly 53 per cent $(n=133)$ of the returnees returned before 2000, 14 per cent $(n=36)$ returned between 2000 and 2005, and almost 33 per cent $(n=82)$ returned after 2005. Because of the small sample sizes in each of these groups, a community was assigned a value of ' 1 ' if it had received returnees in these time 
periods. ${ }^{21}$ On average, the first-generation returnees had spent 5.75 years abroad $(\mathrm{SD}=7.35)$, with a minimum of three months and a maximum of 36 years. The median time spent abroad was two years. This individual information was aggregated to the community level by calculating a mean and a median time spent abroad for all first-generation returnees in the community.

\subsubsection{Potential biases}

In estimating the effect of return migration on the dependent variables, we assume that return migration to the communities was exogenous. However, several biases may be at play. First, there may be a selection bias concerning the communities of return. Returnees may have chosen to settle in areas based on area characteristics such as the availability of agricultural land. In Burundi, however, such a choice is unlikely because most returnees were repatriated to their origin communities because of their emotional attachment to their ancestors' land (Hovil, 2009). The survey data show that approximately 85 per cent of first-generation returnees returned to their provinces of origin. This information is not available for secondgeneration returnees. The previous section has shown that 73 per cent of secondgeneration returnees resided in a household with first-generation returnees. This finding indicates that the majority of second-generation returnees also settled in communities of their families' origin. It is, however, not possible to eliminate the possibility that a significant share of second-generation returnees chose a different community to settle in or decided to migrate further after not being able to retrieve family land in the origin community.

Second, self-selection might be involved in the return decisions of returnees. For instance, of all Burundians living abroad, only those who were confident that they would be able to retrieve their house and family land returned. As described, the Arusha Agreements stated that everyone affected by the conflict would be compensated for their losses and would be entitled to property restitution (Republic of Burundi, 2000), which incentivized many refugees to return (Fransen \& Kuschminder, 2012). There are no official data on the characteristics of those who returned versus those who decided to stay in Tanzania, but a study funded by the International Refugee Rights Initiative (Hovil \& Kweka, 2008) showed that 1972 refugees who expected to reclaim their land upon return to Burundi showed a preference to return. Because the survey was

\footnotetext{
${ }^{21}$ Communities without returnees were excluded from these analyses.
} 
conducted in Burundi, we do not have information on those who did not return. If there is self-selection bias in the decision to return, significant findings with respect to return migration might be related to the specific characteristics of returnees who differ from community members in the return communities instead of a population increase.

Because it is not possible to eliminate the possibility of endogeneity between return migration and the dependent variables, an IV approach using the two-stage least-squares (2SLS) technique was used as a robustness check. The IV approach is a quasi-experimental method in which the independent variable of interest is instrumented for by another variable that is relevant (correlated with the main independent variable) and exogenous (only related to the dependent variable via the dependent variable). In this study, the proportion of return migrants in a community was instrumented for by the distance of each community to the closest border (in $\mathrm{km}$ ). As described in Section 8.3, most returnees resided in areas bordering Tanzania because individuals residing in communities that were closer to the border were more likely to cross international borders in times of conflict. Communities that generated more refugees were also more likely to receive returnees after the conflict ended. In contrast, people were more likely to become internally displaced during conflict in areas that were farther from the border. On average, communities were located 21 kilometres from the closest border, with a minimum of 3 kilometres and a maximum of 67 kilometres.

A valid instrument should have two key characteristics. First, the instrument should be relevant, meaning that it is significantly and directly related to the dependent variable. Correlations between the proportions of first-generation and total returnees in the communities and the instrument are $-0.35(p<0.001)$ and -0.26 ( $p=0.01)$, respectively. Thus, the distance to the border is lower for communities that host more returnees. The correlation between the proportion of first-generation returnees and the dependent variable is higher than the correlation between the combined sample and the dependent variable. This finding suggests that second-generation returnees may have been less likely to settle in their origin communities or may have migrated further after their return. Nevertheless, the correlations show that the distance to the closest border is significantly related to return migration. Second, the instrument should be exogenous, meaning that it is not affected by the dependent variable. Validity is clearly demonstrated, as the distance from the border cannot be affected by return migration. 


\subsubsection{Control variables}

Community control variables included the community's population size, the proportion of households that owned land, employment availability, the number of environmental shocks that the community had experienced in the past five years, the number of conflict experiences of the community during the past conflict period, the proportion of households in which at least one household member had IDP camp experiences, ethnic heterogeneity, and the presence of an NGO or humanitarian organization in the community. Finally, an infrastructure index included whether the community had electricity, lighting, drinking water, and facilities such as schools and health care facilities. This index was constructed using principal component analysis (PCA) (results are available upon request) and yielded a unique score for each community. Household control variables comprised the age, gender, marital status, and educational attainment of the household head; the household's land ownership; living conditions; and household size. The living conditions variable was constructed using PCA and was composed of the type of water, toilet, and cooking fuel that the household used, as well as housing characteristics (results are available upon request). The analyses also controlled for whether one of the household members had ever been in a displacement camp. Descriptive statistics on the control variables are presented in Table 8.1.

\subsection{Results}

The results are presented in three phases. First, the relationships between return migration on the one hand and land disputes and security in the community on the other hand are studied. All of these analyses were conducted at the community level. Second, the effects of return migration on the households' experiences of thefts are explored. Third, to study how the effects of return may have changed over time, the estimates for phases 1 and 2 are replicated using different cohorts of first-generation returnees: a) those who returned before 2000, b) those who returned between 2000 and 2005, and c) those who returned after 2005. 
Table 8.1. Main variables: descriptive statistics

M SD $\quad$ Min. $\quad$ Max. $\quad \mathrm{N}$

\section{Conflict indicators}

Number of thefts experienced in the previous five years

Problems of land disputes $(1=$ yes $)$

Security level ${ }^{1}$

$\begin{array}{rrrrr}0.23 & 0.87 & 0 & 12 & 1,401 \\ 0.61 & 0.49 & 0 & 1 & 94 \\ 3.12 & 0.67 & 1 & 5 & 94\end{array}$

\section{Community characteristics}

First-generation returnees (prop.)

Second-generation returnees (prop.)

$\begin{array}{rrrrr}0.06 & 0.08 & 0 & 0.43 & 94 \\ 0.03 & 0.06 & 0 & 0.33 & 94 \\ 0.09 & 0.12 & 0 & 0.60 & 94 \\ 6.70 & 0.76 & 5.21 & 8.93 & 91 \\ 0.00 & 1.39 & -0.61 & 3.94 & 94 \\ 0.82 & 0.19 & 0.20 & 1.00 & 94 \\ 4.55 & 2.78 & 0 & 14 & 94 \\ 12.48 & 23.64 & 0 & 180 & 94 \\ 5.31 & 4.41 & 0 & 19.35 & 94 \\ 0.85 & 0.36 & 0 & 1 & 94 \\ 0.26 & 0.44 & 0 & 1 & 94\end{array}$

Total returnees (prop.)

Population size (ln)

Infrastructure (index)

Households that own land (prop.)

No. of environmental shocks in the past five years

No. of conflict experiences

Households with IDP camp experiences (prop.)

Ethnic heterogeneity $(1=$ yes $)$

Hum. org./NGO presence ( 1 = yes $)$

\section{Household (head) characteristics}

Age

Gender (1 = male)

39.17

$\begin{array}{rr}98 & 1,401 \\ 1 & 1,410 \\ 1 & 1,410 \\ 4 & 1,408 \\ 12.51 & 1,409 \\ 1 & 1,410 \\ 1 & 1,407 \\ 1 & 1,410\end{array}$

$0.77 \quad 0.42$

$1.71 \quad 0.84$

$0.00 \quad 1.94$

$-1.23$

Living conditions (index)

$0.82 \quad 0.38$

$0.28 \quad 0.45$

$\begin{array}{ll}0.19 & 0.39\end{array}$

1,410

Notes. ${ }^{1}$ from 1 (very bad) to 5 (very good), ${ }^{2}$ from 1 (no education) to 4 (bachelor or higher).

\subsubsection{Return migration, land disputes and security}

Table 8.2 shows the results of the community analyses. First, land disputes do not appear to be related to the proportions of first-generation and total returnees in the communities. Both the logit and IV tobit estimates are insignificant, indicating that land disputes were not more common in communities with relatively more returnees. The inclusion of a squared term of return migration does not reveal any significant findings regarding return migration and land disputes, which indicates that there is no non-linear relationship (results are available upon request). 


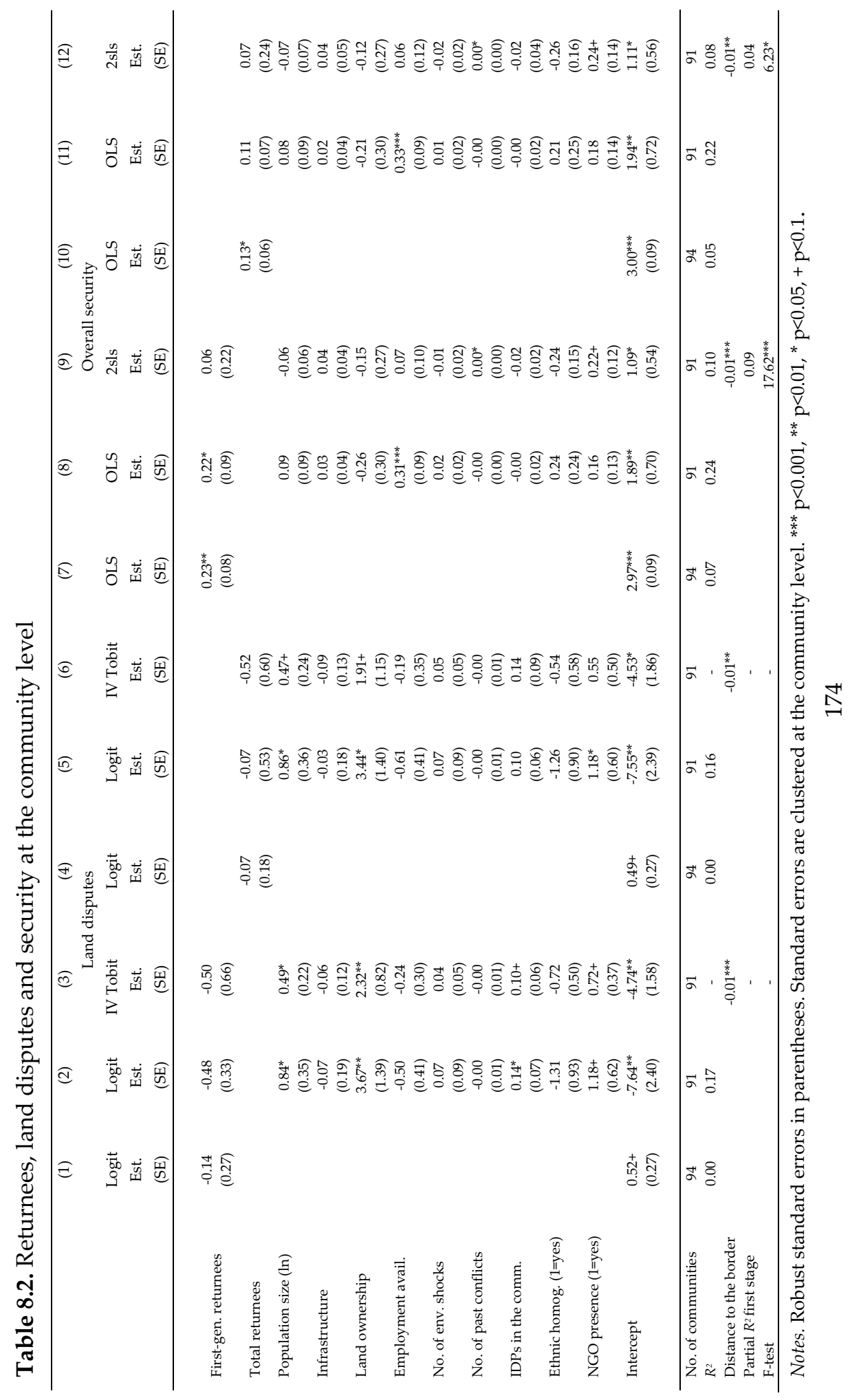


Land disputes were, however, significantly more common in communities with higher population sizes and in communities with more land-owning households. These findings provide support for the neo-Malthusian hypothesis regarding the linkages between population pressure and disputes. Land disputes were also more common in communities in which an NGO or a humanitarian organization was present. This situation is likely to be a matter of reverse causality in the sense that NGOs or humanitarian organizations are more likely to work in more problematic areas. Because the type of activities of NGOs in the communities were not analysed in this paper, it is not possible to derive conclusions from these findings. Security seemed better in communities in which an NGO or humanitarian organization was present. Whether the work of NGOs or humanitarian organizations leads to better security or whether such organizations are more likely to work in areas with better security does not become clear from these findings and should be explored by future research.

Based on the OLS estimates, return migration seems to be associated with security in the communities, although the relationship does not run in the expected direction. Security was, on average, better in communities with higher proportions of first-generation and total returnees. However, when controlling for other community variables, the relationship between the total proportion of returnees and security in the communities became insignificant. Based on the IV estimations, which control for potential endogeneity in the relationship between return migration and security, the effects became insignificant for both the firstgeneration and total returnees. The instrument seems to work well for the proportion of first-generation returnees but less well for the proportion of total returnees in the community. F statistics for the significance of the instrument in the first-stage regressions are 17.62 for the proportion of first-generation returnees and 6.23 for the proportion of total returnees in the community. The general rule is that F-statistics under 10 signify weak instruments (Staiger and Stock, 1997). The Durbin (1954) and Wu-Hausman (Wu, 1974; Hausman, 1978) tests showed insignificant results for all estimates (results are available upon request), indicating that there are no significant differences between the OLS and IV estimations. Overall, the analyses do not provide convincing evidence that return migration has led to less security in communities. Instead, security seems to be strongly, positively associated with the availability of employment in the communities. 


\subsubsection{Return migration and households' theft experiences}

Table 8.3 shows the estimates for the number of thefts or destruction of crops, livestock and agricultural tools that households experienced in the previous five years. The results show that the proportion of returnees in the community is not significantly related to the dependent variable. In both the OLS and 2SLS estimates, the proportions of first-generation returnees in the community are insignificant. The proportion of total returnees shows a significant but weak, negative effect on the number of thefts, but the effect disappears when controlling for endogeneity. $F$ statistics show that the distance to the border is a strong instrument for both the proportions of first-generation and total returnees in these analyses, with Fstatistics of 29.31 and 12.81, respectively. The Durbin (Durbin, 1954) and WuHausman (Hausman, 1978; Wu, 1974) tests again show insignificant results for all estimates (results are available upon request), indicating that there are no significant differences between the OLS and IV estimations. The inclusion of a squared term did not reveal any signs of a non-linear relationship between return migration and the dependent variable (results are available upon request).

Overall, the analyses in Table 8.3 do not yield any evidence that return migration is related to households' experiences of thefts or destruction in the previous five years. The infrastructure in the communities seems to be significantly related to the dependent variable. In communities with more infrastructure available, households experienced fewer thefts and less destruction of agriculturerelated items. As described, the infrastructure index included whether the community had electricity, lighting, drinking water, and facilities such as schools and health care facilities. The presence of employment and ethnic homogeneity in the community also showed significant relationships with the dependent variable, but the results were weak. 
Table 8.3. Return and households' thefts of crops, livestock and agricultural tools

\begin{tabular}{|c|c|c|c|c|c|c|}
\hline & $\begin{array}{c}(1) \\
(\mathrm{OLS}) \\
\text { Est. } \\
(\mathrm{SE})\end{array}$ & $\begin{array}{c}(2) \\
(\mathrm{OLS}) \\
\text { Est. } \\
\text { (SE) }\end{array}$ & $\begin{array}{c}(3) \\
(2 s l s) \\
\text { Est. } \\
(\mathrm{SE})\end{array}$ & $\begin{array}{c}(4) \\
(\mathrm{OLS}) \\
\text { Est. } \\
(\mathrm{SE})\end{array}$ & $\begin{array}{c}\text { (5) } \\
(\mathrm{OLS}) \\
\text { Est. } \\
\text { (SE) }\end{array}$ & $\begin{array}{c}(6) \\
(2 s l s) \\
\text { Est. } \\
(\mathrm{SE})\end{array}$ \\
\hline First-gen. returnees & $\begin{array}{l}-0.05 \\
(0.03)\end{array}$ & $\begin{array}{l}-0.05 \\
(0.04)\end{array}$ & $\begin{array}{c}0.01 \\
(0.05)\end{array}$ & & & \\
\hline Total returnees & & & & $\begin{array}{l}-0.04+ \\
(0.02)\end{array}$ & $\begin{array}{l}-0.05+ \\
(0.03)\end{array}$ & $\begin{array}{c}0.01 \\
(0.05)\end{array}$ \\
\hline Population size $(\ln )$ & $\begin{array}{l}-0.02 \\
(0.03)\end{array}$ & $\begin{array}{c}-0.02 \\
(0.03)\end{array}$ & $\begin{array}{c}-0.02 \\
(0.03)\end{array}$ & $\begin{array}{c}-0.02 \\
(0.03)\end{array}$ & $\begin{array}{c}-0.02 \\
(0.03)\end{array}$ & $\begin{array}{l}-0.02 \\
(0.03)\end{array}$ \\
\hline Infrastructure & $\begin{array}{c}-0.04^{* * *} \\
(0.01)\end{array}$ & $\begin{array}{l}-0.03^{*} \\
(0.01)\end{array}$ & $\begin{array}{l}-0.03^{*} \\
(0.01)\end{array}$ & $\begin{array}{c}-0.04^{* * *} \\
(0.01)\end{array}$ & $\begin{array}{l}-0.03^{* *} \\
(0.01)\end{array}$ & $\begin{array}{l}-0.03^{*} \\
(0.01)\end{array}$ \\
\hline Land ownership & $\begin{array}{l}0.19+ \\
(0.12)\end{array}$ & $\begin{array}{c}0.14 \\
(0.13)\end{array}$ & $\begin{array}{c}0.16 \\
(0.13)\end{array}$ & $\begin{array}{c}0.17 \\
(0.12)\end{array}$ & $\begin{array}{c}0.10 \\
(0.13)\end{array}$ & $\begin{array}{c}0.16 \\
(0.14)\end{array}$ \\
\hline Employment avail. & $\begin{array}{l}0.13^{*} \\
(0.05)\end{array}$ & $\begin{array}{l}0.10+ \\
(0.05)\end{array}$ & $\begin{array}{c}0.08 \\
(0.05)\end{array}$ & $\begin{array}{l}0.13^{*} \\
(0.05)\end{array}$ & $\begin{array}{l}0.10+ \\
(0.05)\end{array}$ & $\begin{array}{c}0.08 \\
(0.05)\end{array}$ \\
\hline Number of env. shocks & $\begin{array}{c}0.00 \\
(0.01)\end{array}$ & $\begin{array}{c}0.00 \\
(0.01)\end{array}$ & $\begin{array}{c}0.00 \\
(0.01)\end{array}$ & $\begin{array}{c}0.00 \\
(0.01)\end{array}$ & $\begin{array}{c}0.00 \\
(0.01)\end{array}$ & $\begin{array}{c}0.00 \\
(0.01)\end{array}$ \\
\hline Number of conflicts & $\begin{array}{l}-0.00 \\
(0.00)\end{array}$ & $\begin{array}{c}0.00 \\
(0.00)\end{array}$ & $\begin{array}{c}0.00 \\
(0.00)\end{array}$ & $\begin{array}{l}-0.00 \\
(0.00)\end{array}$ & $\begin{array}{c}0.00 \\
(0.00)\end{array}$ & $\begin{array}{l}-0.00 \\
(0.00)\end{array}$ \\
\hline IDPs in the comm. & $\begin{array}{l}-0.01 \\
(0.01)\end{array}$ & $\begin{array}{c}-0.00 \\
(0.01)\end{array}$ & $\begin{array}{c}-0.01 \\
(0.01)\end{array}$ & $\begin{array}{c}-0.01 \\
(0.01)\end{array}$ & $\begin{array}{c}-0.00 \\
(0.01)\end{array}$ & $\begin{array}{c}-0.01 \\
(0.01)\end{array}$ \\
\hline Ethnic homog. $(1=$ yes $)$ & $\begin{array}{l}0.08^{*} \\
(0.04)\end{array}$ & $\begin{array}{c}0.01 \\
(0.04)\end{array}$ & $\begin{array}{c}0.02 \\
(0.04)\end{array}$ & $\begin{array}{l}0.09^{*} \\
(0.04)\end{array}$ & $\begin{array}{c}0.01 \\
(0.04)\end{array}$ & $\begin{array}{c}0.02 \\
(0.04)\end{array}$ \\
\hline NGO presence $(1=$ yes $)$ & $\begin{array}{c}0.04 \\
(0.04)\end{array}$ & $\begin{array}{c}0.05 \\
(0.05)\end{array}$ & $\begin{array}{c}0.06 \\
(0.04)\end{array}$ & $\begin{array}{c}0.03 \\
(0.04)\end{array}$ & $\begin{array}{c}0.04 \\
(0.05)\end{array}$ & $\begin{array}{c}0.06 \\
(0.05)\end{array}$ \\
\hline Intercept & $\begin{array}{l}-0.08 \\
(0.24)\end{array}$ & $\begin{array}{l}-0.06 \\
(0.29)\end{array}$ & $\begin{array}{c}-0.07 \\
(0.28)\end{array}$ & $\begin{array}{c}-0.09 \\
(0.24)\end{array}$ & $\begin{array}{c}-0.05 \\
(0.29)\end{array}$ & $\begin{array}{l}-0.07 \\
(0.28)\end{array}$ \\
\hline Province fixed effects & No & Yes & Yes & No & Yes & Yes \\
\hline No. of hhs/comm. & $1,346 / 94$ & $1,346 / 94$ & $1,346 / 94$ & $1,346 / 94$ & $1,346 / 94$ & $1,346 / 94$ \\
\hline Adj. $R^{2}$ & 0.03 & 0.04 & 0.04 & 0.03 & 0.04 & 0.04 \\
\hline Distance to the border & & & $-0.04^{* * *}$ & & & $-0.04^{* * *}$ \\
\hline Partial $R^{2}$ first stage & & & 0.24 & & & 0.14 \\
\hline F-test & & & $29.31^{* * *}$ & & & $12.81^{* * *}$ \\
\hline
\end{tabular}

Notes. Robust standard errors in parentheses. Standard errors are clustered at the community level. ${ }^{* *} \mathrm{p}<0.001,{ }^{* *} \mathrm{p}<0.01,{ }^{*} \mathrm{p}<0.05,+\mathrm{p}<0.1$. Household control variables were included in all analyses. 


\subsubsection{Return cohorts and time spent abroad}

In the previous analyses, former refugees who had returned to Burundi were treated as a homogenous group in the analyses. However, as Section 3 has described, returnees arrived in Burundi at different times and spent different periods abroad. It can be expected that the effects of return migration on the communities differ depending on when returnees returned. In addition, studies have shown that the longer a refugee has spent in exile, the more difficult his or her reintegration will be (Rogge, 1994). The analyses of Tables 8.2 and 8.3 were therefore replicated by using different cohorts of first-generation returnees (those who returned before 2000, those who returned between 2000 and 2005, and those who returned between 2005 and 2011) and by controlling for the effect of their time spent abroad.

The results are presented in Table 8.4. In this table, each coefficient was derived from a different estimation. The effects of the period of return and the time spent abroad on the households' experiences of thefts or destruction of crops, livestock or agricultural tools community land disputes are insignificant. Communities that received returnees after 2005, however, reported significantly lower security, although this effect was weak. This finding may be an indication that return migration generated short-term problems that faded over time. More recent returns may have led to lower security in areas of return, whereas the effects of less recent returns on security are no longer visible. Another possible explanation of the negative effect of returnees after 2005 is that returnees who returned after 2005 have particular characteristics that differ from the characteristics of returnees who returned before 2005. As described in Section 3, 1972 caseload returnees were initially reluctant to return after the war and began to return primarily after 2007, when UNHCR and the Burundi and Tanzania governments began to promote return for this group. The 1972 returnees spent longer periods abroad and may have experienced more problems upon return. Property restitution was a particular problem for this group (Fransen \& Kuschminder, 2012). Nevertheless, 1972 caseload refugees constituted only a small share of the total returnees to Burundi, as many of them opted for citizenship in Tanzania. The extent to which the characteristics of the post-2005 return cohort explains the negative effect of return on security remains to be explored. 
Table 8.4. First-generation returnees: cohorts and time spent abroad

\begin{tabular}{|c|c|c|c|}
\hline & $\begin{array}{l}\text { (1) } \\
\text { Thefts/destruction } \\
\text { of crops, livestock } \\
\text { or agricultural tools }\end{array}$ & $\begin{array}{c}(2) \\
\text { Land disputes }\end{array}$ & $\begin{array}{c}(2) \\
\text { Security }\end{array}$ \\
\hline & OLS & Logit & OLS \\
\hline & $\begin{array}{l}\text { Est. } \\
\text { (SE) }\end{array}$ & $\begin{array}{l}\text { Est. } \\
\text { (SE) }\end{array}$ & $\begin{array}{l}\text { Est. } \\
\text { (SE) }\end{array}$ \\
\hline \multicolumn{4}{|l|}{ Returnees received } \\
\hline Before 2000 ( 1 = yes $)$ & $\begin{array}{l}-0.05 \\
(0.05)\end{array}$ & $\begin{array}{c}0.77 \\
(0.77)\end{array}$ & $\begin{array}{c}0.08 \\
(0.13)\end{array}$ \\
\hline Between 2000 and 2005 ( 1 = yes) & $\begin{array}{c}0.10 \\
(0.07)\end{array}$ & $\begin{array}{c}-0.82 \\
(0.90)\end{array}$ & $\begin{array}{c}-0.02 \\
(0.17)\end{array}$ \\
\hline Between 2005 and 2011 ( 1 = yes) & $\begin{array}{c}0.05 \\
(0.07)\end{array}$ & $\begin{array}{l}-1.06 \\
(0.67)\end{array}$ & $\begin{array}{l}-0.33+ \\
(0.17)\end{array}$ \\
\hline Median time spent abroad (ln) & $\begin{array}{c}0.00 \\
(0.02)\end{array}$ & $\begin{array}{l}-0.00 \\
(0.26)\end{array}$ & $\begin{array}{c}0.02 \\
(0.05)\end{array}$ \\
\hline Mean time spent abroad (ln) & $\begin{array}{c}0.00 \\
(0.03)\end{array}$ & $\begin{array}{c}0.14 \\
(0.30)\end{array}$ & $\begin{array}{c}0.04 \\
(0.06)\end{array}$ \\
\hline Household controls & Yes & - & - \\
\hline Community controls & Yes & Yes & Yes \\
\hline Province fixed effects & Yes & No & No \\
\hline No. of observations & 1,136 & 77 & 77 \\
\hline
\end{tabular}

Notes. Each coefficient was derived from a different estimation. Robust standard errors, clustered at the community level, in parentheses. $\left.{ }^{* * *} \mathrm{p}<0.001,{ }^{* *} \mathrm{p}<0.01,{ }^{*} \mathrm{p}<0.05,+\mathrm{p}<0.1 .1\right)$.

\subsection{Discussion and conclusion}

This chapter tested the neo-Malthusian hypothesis of population growth, natural resource scarcity and conflict in the context of large-scale return migration in a conflict-affected setting. Burundi, the country considered in this case study, witnessed the return of nearly 600,000 refugees between 2002 and 2014. In a context of poverty, population pressure and land scarcity, most returnees moved to their origin communities, some having spent more than 30 years abroad. Because of the size of the return movement, the short time period in which it occurred and the concentration of returns in certain areas, it has been feared that the return of former refugees would destabilize Burundi's transition to peace. Return has created both structural scarcity of agricultural land, as returnees have 
less access to land than other households, and demand-induced scarcity of agricultural land, as pressure on land has increased as a result of return migration (Fransen \& Kuschminder, 2012; Rema Ministries, 2012). This chapter examined whether return migration to Burundi has indeed led to more insecurity. Applying the neo-Malthusian hypothesis to the Burundi context, the expectation was that communities with higher proportions of returnees would experience more land disputes and lower security and that households residing in communities with higher proportions of returnees would experience more thefts and destruction of crops, livestock and agricultural tools.

Descriptive statistics showed that a substantial share of the Burundi population interviewed in 2011 had been affected by international forced migration: approximately 8.5 per cent of individuals in the sample were first- or second-generation returnees. Most international returnees were residing in Burundi's border provinces in the North and the South. In some cases, return had led to significant population increases, with some communities consisting of more than 40 to 60 per cent returnees. Most communities consisted of approximately 3 per cent returnees. Fifteen communities in the sample (16 per cent) had not received any returnees. These descriptive statistics suggest that return was highly concentrated in certain areas but that the majority of areas had received small amounts of returnees.

The findings revealed that communities with higher proportions of returnees were not more likely to experience land disputes and did not have lower security levels than communities with lower proportions of returnees. Similarly, households residing in communities with higher proportions of return migrants did not report significantly more thefts or destruction of crops, livestock and agricultural tools. These findings contrast with those of previous studies finding that return had led to disputes and insecurity as a result of differences in access to land between returnees and non-returnees and the resulting increased poverty (see, e.g., Fransen \& Kuschminder, 2012; Rema Ministries, 2012). Previous studies were often conducted in a single location or in a few locations that were chosen specifically for their experiences with return migration. Although these studies provided valuable insights into the effects of return in Burundi's high-return areas, the current study indicates that the effects of return are negligible at a national level. Although return migration after the conflict led to significant population increases in some communities, most communities received only a few returnees, 
and these returnees seem to be absorbed in the communities without decreasing security. However, even in the high-return communities that witnessed substantial population increases due to return, this study did not find any indications of higher insecurity. The analyses therefore revealed no support for the neoMalthusian hypothesis in relation to large-scale return migration in Burundi. A potential explanation for these different findings is that qualitative studies measured the perceptions of respondents with respect to returnees and the changes that they felt had occurred in the community since return, whereas the present study used more objective indicators of security. It is possible that the experiences of potential violence, or feelings of threats, that people experienced differ from actual events.

This study did find some indications that return migration created security problems in the short term. The findings showed that communities that received returnees after 2005 reported slightly lower levels of security. This result indicates that return migration may have affected security in communities of high return but that this effect diminished over time. The data for this research were collected in 2011, approximately five years after the official end of conflict and after most returnees had returned (UNHCR, 2014c). Most returnees returned in the early 2000s. It has been argued that refugee reintegration can take as many as 10 or 15 years, especially when former refugees spent long periods abroad (Rogge, 1994). It is therefore possible that the effects of return on the communities had already dissolved by the time of data collection. The analyses that addressed the time dimension provided preliminary evidence because the analyses focused on firstgeneration returnees and because a rather crude measurement of return was used as a result of data limitations. Nevertheless, the preliminary results suggest that the period of return is an important variable to consider when studying the effects of return migration on receiving communities and households, thus indicating an interesting avenue for future research.

Another possible explanation for the insignificant findings is that population increases resulting from return migration are different from natural population growth. Former refugees who return to their origin communities are often received by networks of (extended) family members and kin. Although some returnees in Burundi spent long periods abroad and some were even born abroad, it is likely that their networks or their parents' networks still existed when they returned. Research has shown that despite problems of property restitution and 
initial adaptation, most former refugees have been positively received, especially when returnees shared strong ties with their community members (Rogge, 1994). In Eritrea, for example, experiences of conflict had created a shared identity, in addition to already existing ties of kinship and ethnicity, which facilitated the reintegration of returnees (Bascom, 2005). Although return may have created problems of land access and higher poverty in Burundi, the social networks on which returnees could rely upon return may have facilitated their reintegration and served as a 'buffer' to the instigation of violence.

The instrumental variable approach that was used in this study yielded good test results for the proportion of first-generation returnees in the community, but the results were weaker for the combined sample that included both first- and second-generation returnees. This finding indicates that second-generation returnees may have been less likely to have settled in the communities of origin of their parents or may have moved on after 'return'. As described in Section 8.3, second-generation returnees have experienced more problems in regaining their family land (Fransen \& Kuschminder, 2012), which may have incentivized them to move to areas with, for example, more employment opportunities. Whether this explanation indeed applies cannot be determined based on these data and should thus be explored in future research.

This study found no significant relationships between return migration and insecurity in Burundi. However, other more structural factors, such as the availability of infrastructure and employment, were found significantly affect security in the communities. Communities with more employment opportunities were found to have significantly higher security levels. Similarly, in communities with more infrastructure, including electricity, clean drinking water, and facilities such as schools and health care facilities, households reported significantly fewer thefts or destruction of crops, livestock or agricultural tools. These findings contradict the general perception in Burundi that return migration poses a threat to long-term peace, and the results support the arguments of researchers such as Van Leeuwen (2010), who argued that current land problems in Burundi are not a direct cause of return migration but rather the result of structural problems of population density and poverty. Although return may have exacerbated these problems in the short term, the long-term implications of return migration for sustainable peace in Burundi seem negligible. 
Chapter 9: Conclusions 



\subsection{Introduction}

This dissertation explored the development effects of remittances and return migration in Burundi. By doing so, the dissertation aimed to contribute to the broad literature on the linkages between migration and development by focusing on a conflict-affected context. Conflict-affected contexts have received little attention in the migration and development debate, mainly because of a lack of large-scale, reliable data. The data that were collected for the IS Academy Migration and Development: A World in Motion project provided a unique opportunity to explore how remittances and return migration had affected households and communities that were recovering from violent conflict in a context of continuing insecurity and uncertainty. This dissertation opted for a multidimensional perspective on development, focusing on both the economic and social effects of remittances and return migration on development. This multidimensional focus is especially relevant in a conflict-affected context, in which not only economic development is hindered but social ties may be damaged as well (Colletta \& Cullen, 2000).

This dissertation had three main aims: 1) to provide insights into the lives of households and communities that were recovering from civil conflict and the role that migration played in their lives, 2) to apply tenets of theoretical approaches that have often been used to study labour migration to a specific conflict-affected setting, and 3) to study how migration affects both economic and social aspects of a conflict-affected society. The central research question that this dissertation aimed to address was: What are the economic and social effects of remittances and return migration on households and communities in a conflict-affected setting? This question was divided into the following sub-questions that are addressed in the four empirical papers that formed the body of this dissertation (see Section 1.4, Structure of this dissertation, for more details). The first two sub-questions focused on remittances, whereas sub-questions 3 and 4 addressed the effects of return migration.

1. What are the economic effects of international monetary remittances on remittance-receiving households?

2. How do international monetary remittances affect the social capital of remittance-receiving households? 
3. What is the economic impact of return migration on households and communities in a conflict-affected context?

4. What is the impact of return migration on security in return communities?

Burundi was the country case study of this dissertation. After decades of insecurity and recurrent episodes of violent conflict since its independence in 1962, Burundi entered a transition period towards peace and development in 2000 . Migration played an important role during this transition period. Remittances, the money and goods sent by Burundians living abroad, increased significantly in recent years and are now seen as potential contributors to the country's economic reconstruction (Fransen \& Andersson, 2011). At the same time, approximately 600,000 formally registered former refugees returned to the country over a period of a decade (UNHCR, 2014c). This large return flow has raised concerns because of already existing problems of poverty and land scarcity. Burundi is one of the most densely populated countries in the world, and it suffers from a shortage of agricultural land, especially in rural areas. Because of the short time period in which the returns took place, the concentrations of returnees in certain areas and the already existing problems of agricultural land scarcity, it is feared that return migration will re-instigate social tensions by exacerbating the poverty in rural areas (Hovil, 2009).

Burundi provided an interesting case for researching the linkages between migration and development in a conflict-affected setting. Many conflict-affected countries experience large return migrations during periods of relative stability and receive vast amounts of remittances that are considered beneficial to reconstruction and economic development. The findings from this study are therefore, to a certain extent, generalizable to other low-income, conflict-affected countries. At the same time, Burundi is a unique case because it is one of the poorest countries in the world and it struggles with increasing population density and scarcity of agricultural land. Burundi is also one of the least urbanized countries in the world-more than 90 per cent of its population relies on agriculture. The country offers very limited economic opportunities, and it struggles with low institutional capacity. To what extent have remittances and return migration affected Burundian households and communities that are recovering from decades of civil conflict in a context that is characterized by 
poverty, large inequalities, and, yet again, growing insecurity in the run-up to the 2015 elections?

This study provided one of the first quantitative studies on the effects of remittances on development in a conflict-affected context. The empirical chapters in this dissertation relied on nationally representative household and community data that were collected for the Migration and Development: A World in Motion project. The data were collected in 2011, approximately five years after the official end of conflict in Burundi. The household questionnaire gathered information on all household members, including basic characteristics such as age, gender and education level, and their migration histories by interviewing a main respondent. Household characteristics that were collected included the households' experiences with violence and their current well-being. Questions on migration history were therefore combined with various other household characteristics regarding economic and social well-being. These data are unique in the sense that they offer detailed insights into the livelihoods of households after conflict and the role that migration plays in these livelihoods.

This chapter discusses the main findings of this dissertation regarding the economic and social effects of remittances and return migration in Burundi in Section 9.2. Then, the implications of the findings and suggestions for future research are presented in Section 9.3, and the conclusion is presented in Section 9.4.

\subsection{Main findings}

Chapter 5 and Chapter 6 addressed the development potential of remittances in Burundi, investigating the effects of remittances on receiving households' wealth (Chapter 4) and the social capital investments of remittance-receiving households in urban areas (Chapter 5). Chapter 7 and Chapter 8 focused on return migration and studied the socio-economic sustainability of return migration in Burundi (Chapter 7) and the effects of return migration on security in receiving communities in rural areas (Chapter 8). The remainder of this section is divided into two parts: Section 9.2.1 describes the research findings on remittances, and Section 9.2.2 introduces the findings on return migration.

\subsubsection{Remittances}

Chapter 5 studied the importance and effects of remittances for households in Burundi's capital, Bujumbura, based on survey data collected from 810 
households. This chapter took an explorative approach guided by the three hypotheses derived from NELM (relative deprivation, insurance, and investment) and applied these to the conflict-affected context of Burundi. The chapter addressed questions regarding the main beneficiaries of remittances in Burundi's capital, the extent to which these beneficiaries relied on remittances, and the ways they allocated this resource from abroad. By doing so, this study explored the extent to which remittances have the potential to contribute to development in Burundi.

Chapter 5 revealed two main findings regarding the three NELM hypotheses. First, receiving remittances was more frequent among wealthier and higher-educated households, which is most likely the result of the (historical and current) selection to migration into the wider diaspora (Europe, North America). This finding rejects the relative deprivation hypothesis, which anticipates that the most deprived households are more likely to migrate and therefore to receive remittances. The expectation that remittances would provide important insurance for households affected by conflict appears to be unjustified in the Burundi context. Second, remittances were found to be mostly allocated to non-productive assets. Remittance-receiving households, for example, reported better living conditions and greater food security than similar but non-remittance-receiving households. Productive assets, including asset ownership and education, were not affected by remittances. These findings thus provided more support for the insurance than the investment hypothesis of NELM and verified the findings of the qualitative studies that argued that remittances are mostly used to sustain households during or immediately after crises (Ahmed, 2000; Van Hear, 2002).

These findings differ from those in other developing country contexts, but only to a certain extent. The finding that remittances do not reach the poorest of the poor is a common finding in other developing country contexts as well (see, e.g., Adams Jr, 1998; Mazzucato et al., 2008). Because members of relatively better-off households tend to select themselves into migration, these wealthier households are generally more likely to receive remittances. The finding that remittances are mostly spent on living conditions and food security appears to be a specific result of the conflict-affected context of Burundi. Previous studies have shown that remittances are often spent on daily needs (see, e.g., Kabki et al., 2004; Mazzucato, 2009), and others have shown that remittances are often sent for or spent on schooling and assets such as housing and agricultural land, thereby boosting 
development in remittance-receiving countries that did not experience conflict (Mazzucato et al., 2008; Ratha et al., 2011). The remittance literature has therefore shown that remittances are often spent on both productive and non-productive assets. It is likely that the unstable nature of the conflict-affected context in Burundi lowered households' opportunities and incentives to invest their remittances in items other than living conditions and food security.

Chapter 6 studied the effects of remittances on the social capital of remittance-receiving households based on the same urban survey data that were used in Chapter 5. Social capital is considered a prerequisite for reconstruction and development, but it has been largely overlooked in the literature on the effects of remittances on development in migrant-sending areas. Previous studies have argued that, especially in unstable settings in which investment opportunities are limited, households may allocate (part of) their remittances to their social capital (Van Hear, 2002, 2004), but the empirical evidence is limited. Burundi provided an interesting setting for studying the link between remittances and social capital because of its unique social dynamics, characterized by 'weak bridges, strong bonds' (Brachet \& Wolpe, 2005, p. 6).

Chapter 6 extended the NELM investment assumption beyond the most commonly studied investments that concern economic or human capital by studying the effects of remittances on the social capital of remittance-receiving households. A distinction was made between bonding and bridging social capital investments (Putnam, 2000, 2002), which allowed for exploring the extent to which remittance-receiving households invested in social capital to benefit their ingroups as opposed to social capital investments that crossed social divides. The bonding versus bridging social capital distinction was based on networks of family members and friends. These networks have an important insurance function for households in Burundi, but they were reportedly weakened during the war (Uvin, 2009; Vervisch, Vlassenroot, et al., 2013).

Chapter 6 showed that the assumption that remittances are invested in social networks for insurance purposes could only be partly confirmed for the Burundi context. The use of a multifaceted social capital measure demonstrated that the relationship between remittances and social capital is complex and dependent on the measure of social capital considered. First, the analyses showed that remittances incentivized households to invest in structural social capital by donating time but not money. Remittance-receiving households participated more 
in organizations, which may be explained by the income-smoothing effect of remittances, which generate leisure time (see, e.g., Adams Jr, 2011), or by the fact that wealthier households are more likely to participate in networks because they have more to offer to other members (Fafchamps, 2006). Remittance-receiving households may also be affected by norms and values regarding civic engagement through contacts with the diaspora that incentivize them to be civically engaged (see, e.g., Caarls et al., 2013).

Second, remittance-receiving households invested more in their bonding social capital than did non-remittance-receiving households but only when the network comprised family members. Remittance-receiving households spent more on financially supporting family members in rural areas. However, remittances appeared to reduce gifts to larger networks of family and friends in the sense that remittance-receiving households spent less on these networks than did similar but non-remittance-receiving households. This may be because of a crowding-out effect of remittances, introduced by Caarls et al. (2013), which states that receiving remittances may reduce incentives to invest in social capital because the remittances create financial independence.

\subsubsection{Return migration}

Chapter 7 contributed to the emerging literature on refugee return and development by exploring the concept of sustainable return, a concept that has been used extensively in policy circles and in the academic debate to refer to situations in which refugee returns increase poverty and negatively influence longterm peace in former refugees' home countries (Black \& Gent, 2006). This chapter applied the sustainability framework to the context of Burundi. Using nationally representative household and community data, the chapter explored the wider view on sustainability, following Black and Gent (2006) by incorporating both household comparisons and an analysis of the relationship between returns and the socio-economic conditions of all households in communities of returnees. Socio-economic sustainability was measured using a multidimensional approach that encompassed both objective and subjective indicators. In doing so, the aim of this paper was to provide detailed insights into the relationships between return migration and the socio-economic conditions of both households and communities in rural Burundi. 
Descriptive statistics in Chapter 7 showed that returnees represented a substantial share of the population in rural Burundi: nearly 8.5 per cent of the individuals were either first- or second-generation returnees. Because the data were nationally representative, this means that with an estimated population of 10 million people in 2011, the returnee population in Burundi comprised approximately 850,000 people. The returns were very concentrated, with the highest proportions of return migrants found in communities in the southern provinces of Rutana, Makamba, and Ruyigi, which border Tanzania. Here, some communities had experienced large increases in their populations because of returns and at the time consisted of 30 or 40 per cent returnees.

The analyses in Chapter 7 highlighted different challenges for return versus non-return households at different levels of analysis and across the different socio-economic indicators. The household-level analyses revealed that land ownership among first- and particularly second-generation return households was low and that most such households experienced food insecurity on a weekly basis and reported low subjective wealth. Most return households also reported declines in their wealth over the previous years. Relative to non-return households, both first- and second-generation return households were less likely to own land. The community-level analyses showed that in communities with higher proportions of second-generation returnees, all households had lower living conditions and reported both lower subjective wealth and more negative changes in wealth in previous years. Thus, from both objective and subjective perspectives, households in communities with more second-generation returnees were worse off than were households in other communities.

Because of the size of the return movement, the short time period in which it took place and the concentrations of returnees in certain areas, it has been feared that the return of former refugees will destabilize Burundi's transition to peace. Returns have created both structural scarcity of agricultural land, because returnees have less access to land than do other households, and demand-induced scarcity of agricultural land, because pressure on land has increased as a result of return migration (Fransen \& Kuschminder, 2012; Rema Ministries, 2012).

Chapter 8 studied whether return migration to Burundi has led to more insecurity. The idea that large-scale return migration would lead to competition over resources and, ultimately, violence is similar to neo-Malthusian views that a rapid population increase will lead to scarcity of renewable natural resources, such 
as agricultural land and natural water sources, which in turn may instigate violence (Homer-Dixon, 2010). This chapter tested the neo-Malthusian hypothesis of population growth, natural resource scarcity and conflict (Homer-Dixon, 2010) in the context of large-scale return migration in Burundi. The expectation was that communities with higher proportions of returnees would experience more land disputes, more thefts, and lower security.

The findings revealed that communities with higher proportions of returnees were not more likely to experience land disputes and did not have lower security levels than did communities with lower proportions of returnees. Similarly, households in communities with higher proportions of return migrants did not report significantly more thefts or destruction of crops, livestock or agricultural tools. These findings contrast with those of previous studies that found that returns had led to disputes and insecurity as a result of differences in access to land between returnees and non-returnees and the resulting increased poverty (Fransen \& Kuschminder, 2012; Rema Ministries, 2012). Previous studies were often conducted in a single location or in a few locations that were chosen specifically for their experiences with return migration. Although these studies provided valuable insights into the effects of returns in Burundi's high-return areas, the current study indicates that the effects of returns are negligible at the national level.

This study did find some indications that return migration created security problems in the short term. The findings showed that communities that received returnees after 2005 reported slightly lower levels of security. This result indicates that return migration may have affected security in communities of high return but that this effect diminished over time. The data for this research were collected in 2011, approximately five years after the official end of conflict and after most returnees had returned (UNHCR, 2014c); most returned in the early 2000s. It has been argued that refugee reintegration can take as long as 10 or 15 years, especially when former refugees spent long periods abroad (Rogge, 1994). It is therefore possible that the effects of return on the communities had already resolved by the time of data collection.

This study found no significant relationships between return migration and insecurity in Burundi. However, other, more structural factors, such as the availability of infrastructure and employment, were found to have a significant effect on security in the affected communities. Communities with more 
employment opportunities were found to have significantly higher security levels. Similarly, in communities with more infrastructure, including electricity, clean drinking water, and facilities such as schools and health care facilities, households reported significantly fewer thefts or destruction of crops, livestock or agricultural tools. These findings contradict the general perception in Burundi that return migration poses a threat to long-term peace, and the results support the arguments of researchers such as Van Leeuwen (2010), who argued that current land problems in Burundi are not a direct cause of return migration but rather the result of structural problems of population density and poverty. Although return may have exacerbated these problems in the short term, the long-term implications of return migration for sustainable peace in Burundi appear to be negligible.

\subsection{Implications and directions for future research}

The introduction and theoretical chapters of this dissertation have shown that both remittances and return migration are considered potential contributors to development in conflict-affected states. This chapter reflects on the common assumptions regarding remittances and return migration in the academic literature and relates them to the research findings in this dissertation.

\subsubsection{Are remittances essential for development in conflict-affected states?}

As described in the introduction of this dissertation, remittances are seen as important contributors to economic development and, consequently, sustainable peace in conflict-affected countries; they are seen as lifelines for poorer households that were affected by conflict. Despite the limited evidence available, remittances are believed to provide a safety net for poorer households, insure them against shocks, and reduce poverty in the context of failing states that are unable to provide members of society with basic needs.

The research in this dissertation has shown that remittances sent to Burundi are a small but growing financial resource. Compared with other countries in the region, such as neighbouring Rwanda, remittances have not yet, however, developed into a stable financial flow that has the potential to contribute to economic and social reconstruction. The findings presented in Chapter 5 suggest that the economic development potential of remittances in Burundi is currently limited. Remittances only reach a few, mostly relatively well-off households in the capital, and they are a scarce resource among the rural, more deprived 
populations. The limited access of the rural population to remittances appears to be largely attributable to a lack of financial infrastructure in rural areas in Burundi. In addition, mobility, especially international mobility, is low in rural areas, where poverty levels are high. Remittances therefore do not reach the most disadvantaged households. Thus, one of the greatest limitations for remittances to contribute to development in Burundi is the limited access of those who need them the most.

However, research has shown that when remittances are transmitted into local economies through investments, increased production or increased consumption, they may have a welfare-enhancing effect for other households (Taylor, 1999). Remittances were mostly invested in food security and living conditions in Burundi, but these investments may yield positive effects on, for example, local production and employment, which may boost development in the long term. These transmissions or spill-over effects of remittances may enhance community wealth, the availability and quality of schooling, and community public services. Although remittances mostly reach relatively wealthy households, eventually the positive effects may trickle down to poorer households as well. These potential trickle-down effects of remittances in conflict-affected contexts should be explored in future research.

In addition, remittances did have important positive effects for remittancereceiving households. First, they provided an important source of capital for those households that did receive them. The contribution of remittances to the household budgets of receiving households in Bujumbura totalled an average of 61 per cent of household expenditures. Second, of all remittance-receiving households, poorer households appeared to benefit the most. Relatively poor remittance-receiving households enjoyed better food security and living conditions because of the remittances. Although remittances were not invested as much in productive assets, their impact on the livelihoods of receiving households was significant and may have long-term beneficial effects for these households. The significant positive impacts on food security, living conditions, and subjective wealth may have positive, long-term effects on the productivity, health and education of remittancereceiving households. These long-term effects warrant the attention of future research.

In the policy arena in Burundi, the linkages between remittances and development are being increasingly recognized. Dialogues between diaspora 
organizations and the National Bank of Burundi (BRB) are ongoing, and a diaspora directorate has been created in the Ministry of External Affairs (Fransen \& Siegel, 2010). These developments have put the issue of remittances on the policy agenda, which may lead to the design and implementation of policies that stimulate remittance inflows and enhance the effectiveness of remittances for development.

\subsubsection{Do remittances help to restore social relations in remittance-receiving areas?}

Researchers have argued that in unstable settings in which investment opportunities are limited, households may also allocate (part of) their remittances to their social capital rather than to more tangible investments such as education or business (Van Hear, 2002, 2004). In the absence of formal insurance mechanisms, such as those provided by the state, households often rely on informal networks and social relations for support. If remittances are invested in social capital in remittance-receiving areas, this may have important effects on social ties in these areas, reinforcing networks and restoring social ties (Van Hear, 2002, 2004). However, if remittance-receiving households withdraw from their social relations and invest their remittances exclusively in in-group social capital, as Caarls et al. (2013) suggested, remittances may intensify social divides rather than contributing to social development.

The impact of remittances on social development in Burundi appeared to be highly complex. Remittance-receiving households spent more time on but did not make higher monetary contributions to their bridging social capital. Remittance-receiving households spent more money on their bonding social capital but only when the network comprised family members. Overall, these findings suggest that the financial investments of remittances mainly strengthened the bonding social capital of remittance-receiving households and of family networks in particular. However, despite the fact that remittance-receiving households in Burundi made fewer monetary contributions to their bridging social capital, their enhanced participation in organizations may have positive, long-term effects. Participation in formal organizations such as associations is particularly important for conflict prevention because it makes societies more resilient to political polarization (Varshney, 2001). Since the end of the conflict in Burundi, the number of civil society organisations and community associations has increased, and civil society has become more active in areas such as women's and youth issues, development and reconciliation, human rights, and religion (Brachet \& 
Wolpe, 2005; Vervisch, Titeca, et al., 2013). The finding that remittance-receiving households participated more in organizations may positively reinforce this trend of growing civic engagement in Burundi. These potential effects of remittances on civic engagement provide an interesting avenue for future research.

More research is needed on the linkages between remittances and social capital in remittance-receiving areas. The use of a multifaceted social capital measure demonstrated that the relationship between remittances and social capital is complex and dependent on the measure of social capital considered. The linkages between remittances and both bonding and bridging social capital, for example, deserve more attention by future research to determine the extent to which remittances affect relations that cross social divides versus relations between in-groups only. Further research should also address the effects of remittances on organization memberships. Insights into the types of organizations that the remittance-receiving households engage in, the types of involvement (financial versus donating time), and the intensity of households' organizational involvement will shed more detailed light on the effects of remittances on organizational involvement.

Further research should also focus on the exact mechanisms that underlie the relationship between remittances and social capital. These could not be disentangled with the present data and therefore warrant further research attention. For example, whether remittances increase social capital investments by relaxing households' liquidity constraints or by increasing the incomes of remittance-receiving households remains to be examined. In addition, it was not possible to distinguish between monetary remittances and the transfer of norms and values (social remittances) from the diaspora as driving forces of social capital investments. The mechanisms underlying the relationship between remittances and social capital investments therefore also warrant further research attention.

Finally, because of the cross-sectional nature of the data, it is difficult to draw causal inferences from the findings regarding remittances. PSM is an empirical approach that is commonly used in the absence of longitudinal or experimental data to create a counterfactual situation. However, there may be unobservable variables that simultaneously affect the assignment of a household into the treatment group and the dependent variable, potentially creating a hidden bias that may drive the results. Future research is therefore needed to study the 
long-term effects of remittances on social capital formation and, consequently, social development in conflict-affected settings.

\subsubsection{Does return migration lead to development in conflict-affected states?}

The prevailing view in the literature on return migration and development is that return migration may play a positive role in the development of migrant-sending countries because returning migrants may bring with them skills, assets (including money), and social capital that they acquired abroad. However, when return flows are large, returnees have few resources and the contexts to which they return offer few opportunities, the results may be less positive; this is often the case for conflictaffected contexts. Often, former refugees return from neighbouring countries where they had few employment opportunities and consequently few possibilities to obtain skills that could be brought back upon their returns. After they return, former refugees may find limited opportunities to re-establish their livelihoods.

The repatriation exercise of Burundian refugees after the war was one of the largest ever undertaken in the region. Many support programs were put in place for returnees, including distributing Non Food Item (NFI) kits, food rations, educational items, and, after 2007, cash grants (Fransen \& Kuschminder, 2012). UNHCR also set up a shelter program that distributed house building materials for over 100,000 households between 2002 and 2010 and participated in the Rural Integrated Villages (VRI) project, together with other international organizations, NGOs and the Burundi government, which was established for landless returnees and other vulnerable populations (Fransen \& Kuschminder, 2014). The logistics of coordinating the return process and supporting such a large group is an immense achievement.

Nevertheless, many returnees live in poor socio-economic conditions and are worse off than households that did not experience forced international migration. Moreover, whole communities were affected by returns in some cases. The issue of property restitution, which in this case mainly concerns agricultural land, came forward as a central driver of the differences between returnees and non-returnees. Return migrant households were found to be significantly less likely to own land. The Arusha Agreements stated that everyone affected by the conflict would be entitled to property restitution and would be compensated for their losses (Republic of Burundi, 2000). These objectives incentivized many refugees, including those from the 1972 cohort, to return. The objectives were, 
however, not met, leading to significant differences between returnees and nonreturnees. The unequal distribution of land raised concerns because of the importance of land for livelihoods in rural Burundi and the emotional ties felt by many people to their ancestral land (Rema Ministries, 2012). The findings of this thesis highlight the importance of property restitution after conflict and the responsibility of local governments in providing restitution and compensation for the losses that people suffered.

Return migration may be an individual or household decision, but the process of reintegration is one that also affects those households that have not returned. The findings in Chapter 7 validate the use of a wider approach to studying the sustainability of returning, using both household- and communitylevel comparisons. The finding that the effects of returning on households and communities differed suggests that sustainability is best measured at the household and community levels simultaneously, using a multidimensional approach that incorporates both objective and subjective indicators. This will lead to a detailed understanding of the relationship between returns and the socioeconomic conditions of households and communities. The broad perspective on the sustainability of returns showed that return migration affects not only the returnees and return households but their entire communities as well. This finding highlights the need for support programs that benefit not only the returnees or the returning households but their community members well.

This dissertation also made a distinction between the first- and secondgeneration returnees, the latter of whom are the children of former refugees who were born in exile. This distinction is especially relevant in the Burundi context because, owing to their time spent in exile, many former refugees had children who returned with them to Burundi. The finding that second-generation return households are particularly worse off indicates that returnees are not a homogeneous group and that reintegration assistance should be adapted to fit the needs of different types of returnees. More research is needed on the return experiences of second-generation returnees and particularly the issue of property restitution in this regard. Second-generation returnees are an understudied group in the larger migration literature (exceptions are: Christou, 2006; King \& Christou, 2010; Wessendorf, 2007). The research in this dissertation has, however, indicated that there are differences in the return experiences of first- and second-generation 
returnees that should be taken into account when studying the sustainability of returns in conflict-affected contexts.

\subsubsection{Is large-scale refugee return a threat to sustainable peace?}

The research findings in this dissertation suggested that return migration does not pose a direct threat to security in Burundi. Although return migration after the conflict led to significant population increases in some communities, most communities received only a few returnees, and these returnees appeared to have been absorbed into the communities without increasing insecurity. However, even in the high-return communities that witnessed substantial population increases from returns, this study found no indications of higher insecurity.

Another possible explanation for the insignificant findings is that population increases resulting from return migration are different from those resulting from natural population growth. Former refugees who return to their origin communities are often received by networks of (extended) family members and kin. Although some returnees in Burundi spent long periods abroad and some were even born abroad, it is likely that their networks or their parents' networks still existed when they returned. Research has shown that despite problems of property restitution and initial adaptation, most former refugees have been positively received, especially when they shared strong ties with their community members (Rogge, 1994). In Eritrea, for example, experiences of conflict had created a shared identity, in addition to already existing ties of kinship and ethnicity, which facilitated the reintegration of returnees (Bascom, 2005). Although returns may have created problems of land access and higher poverty in Burundi, the social networks on which returnees could rely may have facilitated their reintegration and served as buffers against the instigation of violence.

In addition, the findings that return migration may have lowered security in areas of return in the short term suggests that the period of return is an important variable to consider when studying the effects of return migration on receiving communities and households. It is possible that return has significant effects on security in the short term that diminish over time.

The research in this dissertation focused on former refugees only. As described in Chapter 4, this was a consequence of the project focus, which addressed mostly international migration. However, former IDPs were also a significant population in Burundi, and it is likely that the return of IDPs has had 
important effects on development as well. Refugees and IDPs differed in their experiences during migration. Whereas the refugee camps in Tanzania where most refugees resided received vast amounts of humanitarian aid and assistance, residents of IDP camps in Burundi were more deprived of assistance and frequently lacked access to basic services such as health care and education. The literature has shown that experiences during migration have an effect on the extent to which return migration can affect development. An interesting avenue for future research would therefore to be to compare the return migration of former refugees and former IDPs to study how these different migrations impact development in conflict-affected states.

Finally, future research should address secondary migrations after return, studying the extent to which former refugees migrate further after having arrived in their countries of origin. Although the research in this dissertation could not give conclusive evidence, it found some indications that second generations in particular may have migrated to other regions in Burundi after having returned to their origin communities. It is likely that a significant share of the secondgeneration returnees migrated to areas with more employment or education opportunities because of the problems they experienced regarding property restitution, employment and social reintegration (Fransen \& Kuschminder, 2012). Whether or not this is indeed the case, and the potential effects of these secondary migration flows on development, provide an interesting avenue for future research.

\subsection{Conclusion}

Migration is an important part of the daily lives of individuals and households in Burundi. Remittances that are sent by migrants abroad are a common financial resource for households in urban areas, and the return of former refugees has affected nearly all rural communities, albeit in different intensities. The multidimensional focus on development that this dissertation adopted, focusing on both the economic and the social effects of remittances and return migration, showed that migration affects not only the economic aspects of societies but also social ties between society members. However, the development implications of remittances and return migration on the economic and social lives of households and communities showed different results. 
This dissertation has shown that in a conflict-affected country such as Burundi, which is one of the poorest countries the world, migration does not have the anticipated development-boosting effect that comes forward from the policy and academic literature on migration and development. The economic development impact of remittances, for example, was limited because remittances did not reach the citizens who needed it the most. This finding highlights that remittances cannot replace official state and international aid initiatives on development and poverty alleviation programmes, as is sometimes suggested by 'co-development' initiatives in which migrants are seen as a way to channel development aid more directly to the 'grass roots' (see, e.g., Nyberg-Sørensen et al., 2002, for a discussion on co-development). The finding that remittances were not as invested in education, financial access and assets may be the result of the unstable nature of the conflict-affected context in Burundi. It is likely that the high levels of uncertainty that characterize conflict-affected contexts lower households' opportunities and incentives to invest their remittances in more productive, longterm items. Similarly, return migration led to structural inequalities between return and non-return households and was found to negatively affect the living conditions of non-return households as well.

When interpreting these results it is important to keep in mind that the political situation was tense at the time the survey data were collected in 2011. There were frequent incidents of political violence resulting from the 2010 elections and there was fear among the population that these violent incidents would result in large-scale conflict again. It is likely that this context played a role in the outcomes of this study. Households were continuously faced with uncertainty and insecurity, which most likely affected their behavior and opinions.

The findings of this research highlight the necessity of a basic level of development before migration can positively affect development. In the absence of investment opportunities for remittances or opportunities for returnees or returning households to establish their livelihoods, the development effects of remittances and return migration will be limited or, in the case of return migration, even negative. These findings highlight the need for policies that simultaneously address humanitarian needs and economic and social development. Important steps have already been taken in this direction. The activities of UNHCR, for example, shifted from pure humanitarian aid towards more long-term development practices in the 1990s (Crisp, 2001). In the early 2000s, UNHCR also 
shifted its focus from individual assistance to a so-called community-based approach (CBA) to humanitarian aid (UNHCR, 2008a). The CBA implies local cooperation for humanitarian support and a more 'bottom-up' working method. In practice, this means that operations are undertaken in cooperation with local governments and decisions are made while working with the community. This community involves not only the displaced or the people of concern but also the community's non-displaced. These initiatives can, however, only have their desired effects if issues such as property restitution and providing legal status to returnees are addressed.

Nevertheless, the impact of migration on development was in some cases promising. First, the long-term effects of remittances are likely to be positive. Remittance flows to Burundi are growing, and their positive effects are likely to trickle down to non-remittance-receiving context households. Second, despite expectations, and despite the finding that returns led to structural inequalities and lower living conditions in areas of high return, return migration did not pose a direct security threat to sustainable peace in the country. These findings suggest that migration may play a positive role in contributing to development after conflict if the other criteria of a basic level of development and property restitution are met.

Burundi provided an interesting country case for studying the linkages between remittances, return migration and development in a conflict-affected state, but more research is needed on the effects of migration on development, especially social development, in conflict-affected states. A call for more research suggests that more and better data need to be collected in conflict-affected settings. Although important strides are being made in the area of monitoring and evaluation, better data need to be collected on remittances and on the repatriation and, especially, the reintegration of former refugees in conflict-affected settings. Collecting better data will enhance the visibility of the areas in which returnees need support and therefore guide policymaking and enhance the effectiveness of returnee support programs. As emerged from this dissertation, data collection should preferably take place using a multidimensional framework that incorporates both the economic and the social aspects of societies. 
References 

Adams Jr, R. H. (1998). Remittances, investment, and rural asset accumulation in Pakistan. Economic Development and Cultural Change, 47(1), 155-173.

Adams Jr, R. H. (2011). Evaluating the economic impact of international remittances on developing countries using household surveys: A literature review. Journal of Development Studies, 47(6), 809-828.

Adams Jr, R. H., Cuecuecha, A., \& Page, J. (2008). The impact of remittances on poverty and inequality in Ghana (No. 4732). Washington D.C.: World Bank.

Adams, R. H., \& Cuecuecha, A. (2010). Remittances, household expenditure and investment in Guatemala. World Development, 38(11), 1626-1641.

Ahmed, I. I. (2000). Remittances and their economic impact in post-war Somaliland. Disasters, 24(4), 380-389.

Allen, T., \& Morsink, H. (1994). When refugees go home: African experiences. Suffolk: James Currey Publishers.

Amassari, S., \& Black, R. (2001). Harnessing the potential of migration and return migration to promote development. Geneva: International Organization for Migration (IOM).

Amuedo-Dorantes, C., \& Pozo, S. (2010). Accounting for remittance and migration effects on children's schooling. World Development, 38(12), 1747-1759.

Andre, C., \& Platteau, J.-P. (1998). Land relations under unbearable stress: Rwanda caught in the Malthusian trap. Journal of Economic Behavior \& Organization, 34(1), 1-47.

Azam, J.-P., \& Gubert, F. (2006). Migrants' remittances and the household in Africa: a review of evidence. Journal of African Economies, 15(suppl 2), 426-462.

Bascom, J. (2005). The long, "last step"? Reintegration of repatriates in Eritrea. Journal of Refugee Studies, 18(2), 165-180.

Berkman, L., \& Kawachi, I. (2000). Social epidemiology. Oxford, New York: Oxford University Press.

Black, R. (2004). Defining, measuring and influencing sustainable return: The case of the Balkans (Working Paper No. T7). Sussex: Sussex Centre for Migration Research.

Black, R., \& Gent, S. (2006). Sustainable return in post-conflict contexts. International Migration, 44(3), 15-38.

Black, R., \& King, R. (2004). Editorial introduction: migration, return and development in West Africa. Population, Space and Place, 10(2), 75-83.

Black, R., King, R., \& Tiemoko, R. (2003). Migration, return and small enterprise development in Ghana: A Route out of poverty?. Sussex: Sussex Centre for Migration Research.

Black, R., \& Koser, K. (1999). The end of the refugee cycle? Refugee repatriation and reconstruction. Oxford, New York: Berghahn Books.

Black, R., Koser, K., Munk, K., Atfield, G., D’Onofrio, L., \& Tiemoko, R. (2004). Understanding voluntary return. Sussex: Sussex Centre for Migration Research. 
Bourdieu, P. (1986). The forms of capital. In Handbook of theory and research for the sociology of education (pp. 241-258). New York: Greenwood.

Brachet, J., \& Wolpe, H. (2005). Conflict-sensitive development assistance: The case of Burundi (Social Development Papers, Conflict Prevention and Reconstruction No. 27). Washington D.C.: World Bank.

Brown, R., Carling, J., Fransen, S., \& Siegel, M. (2014). Measuring remittances through surveys: Methodological and conceptual issues for survey designers and data analysts. Demographic Research, 31(41), 1243-1274.

Brown, R., \& Conneil, J. (1993). The global flea market: migration, remittances and the informal economy in Tonga. Development and Change, 24(4), 611-647.

Bruce, J. (2007). Returnee land access: Lessons from Rwanda. HPG Background Briefing. London: ODI.

Bruck, T., Justino, P., Verwimp, P., \& Avdeenko, A. (2010). Identifying conflict and violence in micro-level surveys. IZA Discussion Paper No. 5067. Bonn: IZA.

Bundervoet, T. (2006). Estimating poverty in Burundi. Households in Conflict Network Working Paper No. 20. Brighton: University of Sussex.

Bundervoet, T. (2009). Livestock, land and political power: The 1993 killings in Burundi Journal of Peace Research, 46(3), 357-376.

Bundervoet, T., \& Verwimp, P. (2005). Civil war and economic sanctions: Analysis of anthropometric outcomes in Burundi. Households in Conflict Network Working Paper No. 11. Brighton: University of Sussex.

Bunte, T., \& Monnier, L. (2011). Mediating land conflict in Burundi: A documentation and analysis project. Bujumbura: ACCORD.

Caarls, K., Fransen, S., \& Ruben, R. (2013). Can migratory contacts and remittances contribute to reconciliation and reconstruction in Rwanda? International Migration, 51(s1), e98-e117.

Caliendo, M., \& Kopeinig, S. (2008). Some practical guidance for the implementation of propensity score matching. Journal of Economic Surveys, 22(1), 31-72.

Carling, J., Erdal, M. B., \& Horst, C. (2012). How does conflict in migrants' country of origin affect remittance-sending? Financial priorities and transnational obligations among Somalis and Pakistanis in Norway. International Migration Review, 46(2), 283-309.

Cassarino, J.-P. (2004). Theorising return migration: The conceptual approach to return migrants revisited. International Journal on Multicultural Societies, 6(2), 253-279.

Castles, S., De Haas, H., \& Miller, M. J. (2013). The age of migration: International population movements in the modern world (5th ed.). London: Palgrave Macmillan.

Chimni, B. S. (1999). From resettlement to involuntary repatriation: Towards a critical history of durable solutions to refugee problems. New Issues in Refugee Research, 2.

Chimni, B. S. (2002). Refugees, return and reconstruction of 'post-conflict' societies: A critical 
perspective. International Peacekeeping, 9(2), 163-180.

Christou, A. (2006). American dreams and European nightmares: experiences and polemics of second-generation Greek-American returning migrants. Journal of Ethnic and Migration Studies, 32(5), 831-845.

Cleaver, F. (2005). The inequality of social capital and the reproduction of chronic poverty. World Development, 33(6), 893-906.

Coleman, J. S. (1988). Social capital in the creation of human capital. American Journal of Sociology, S95-S120.

Coleman, J. S. (1994). Foundations of social theory. Harvard: Harvard university press.

Colletta, N. J., \& Cullen, M. L. (2000). Violent conflict and the transformation of social capital:

Lessons from Cambodia, Rwanda, Guatemala, and Somalia. Washington D.C.: World Bank Publications.

Crisp, J. (2000). Africa's refugees: patterns, problems and policy challenges. Journal of Contemporary African Studies, 18(2), 157-178.

Crisp, J. (2001). Mind the gap! UNHCR, humanitarian assistance and the development process. New Issues in Refugees Research, 43.

Daley, P. (1991). Gender, displacement and social reproduction: settling Burundi refugees in Western Tanzania. Journal of Refugee Studies, 4(3), 248-266.

De Bruyn, T., \& Wets, J. (2006). Remittances in the Great Lakes Region. IOM Migration Research Series, No. 25. Geneva: IOM

De Haas, H. (2005). International migration, remittances and development: Myths and facts. Third World Quarterly, 26(8), 1269-1284.

Diaz-Briquets, S., \& Perez-Lopez, J. (1997). Refugee remittances: Conceptual issues and the Cuban and Nicaraguan experiences. International Migration Review, 31(2), 411-437.

Durbin, J. (1954). Errors in variables. Review of the International Statistical Institute, 22, 23-32.

ECDPM, \& ICMPD. (2013). Migration and development policies and practices. Berne: Swiss Agency for Development and Cooperation.

Fafchamps, M. (2006). Development and social capital. The Journal of Development Studies, 42(7), 1180-1198.

Fafchamps, M., \& Lund, S. (2003). Risk-sharing networks in rural Philippines. Journal of Development Economics, 71(2), 261-287.

Fawcett, J. T., \& Arnold, F. (1987). The role of surveys in the study of international migration: an appraisal. International Migration Review, 1523-1540.

Fielden, A. (2008). Local integration: An under-reported solution to protracted refugee situations. New Issues in Refugees Research, 158.

Filmer, D., \& Pritchett, L. (2001). Estimating wealth effects without expenditure data - or tears: An application to educational enrollments in states of India. Demography, 38(1), 115-132. 
Fisher, M., Reimer, J. J., \& Carr, E. R. (2010). Who should be interviewed in surveys of household income? World Development, 38(7), 966-973.

Fransen, S. (2011). Migration and Development: A World in Motion. Fieldwork report Burundi: Methodology and sampling. Maastricht: Maastricht Graduate School of Governance.

Fransen, S., \& Andersson, L. (2011). The emerging remittances market in Burundi: Opportunities for development. Migration and Development Policy Brief No. 6. Maastricht: Maastricht Graduate School of Governance.

Fransen, S., \& Kuschminder, K. (2012). Back to the land: The long-term challenges of refugee return and reintegration in Burundi. New Issues in Refugee Research, 242.

Fransen, S., \& Kuschminder, K. (2014). Lessons learned from refugee return settlement policies: A case study on Burundi's rural integrated villages. Refugee Survey Quarterly, 33(1), 59-76.

Fransen, S., Kuschminder, K., \& Siegel, M. (2012). Implementation of cross-country migration surveys in conflict-affected settings: Lessons from the IS Academy survey in Burundi and Ethiopia. Maastricht: Maastricht Graduate School of Governance.

Fransen, S., \& Mazzucato, V. (2014). Remittances and household wealth after conflict: A case study on urban Burundi. World Development, 60(0), 57-68.

Fransen, S., \& Siegel, M. (2010). Diaspora engagement in Burundi: The emergence of a migration policy. Migration and Development Policy Brief No. 3. Maastricht: Maastricht Graduate School of Governance.

Freund, C., \& Spatafore, N. (2005). Remittances: Transaction costs, determinants, and informal flows. World Bank Policy Research Working Paper No. 3704. Washington D.C.: World Bank Publications.

Fukuyama, F. (2001). Social capital, civil society and development. Third World Quarterly, 22(1), 7-20.

Gerber, T. P., \& Torosyan, K. (2010). Remittances in Georgia: Correlates, economic impact, and social capital formation. Tbilisi: International School of Economics at Tbilisi State University (ISET), Tbilisi State University.

Ghosh, B. (2000). Return migration: Journey of hope or despair? Geneva: International Organization for Migration (IOM).

Goodhand, J. (2000). Research in conflict zones: ethics and accountability. Forced Migration Review, 8, 12-15.

Grootaert, C. (1999). Social capital, household welfare, and poverty in Indonesia. World Bank Policy Research Working Paper No. 2148. Washington D.C.: World Bank Publications.

Grootaert, C., Oh, G.-T., \& Swamy, A. (2002). Social capital, household welfare and poverty in Burkina Faso. Journal of African Economies, 11(1), 4-38.

Grootaert, C., \& Van Bastelaer, T. (2002). The role of social capital in development: An empirical 
assessment. Cambridge University Press.

Hammond, L. (1999). Examining the discourse of repatriation: towards a more proactive theory of return migration. In The end of the refugee cycle (pp. 227-244). Oxford: Berghahn Books.

Haug, S. (2008). Migration networks and migration decision-making. Journal of Ethnic and Migration Studies, 34(4), 585-605.

Hausman, J. A. (1978). Specification tests in econometrics. Econometrica, 46, 1251-1271.

Haver, K., Hatungimana, F., \& Tennant, V. (2009). Money matters: An evaluation of the use of cash grants in UNHCRs Voluntary Repatriation and Reintegration programme in Burundi. Geneva: UNHCR.

Homer-Dixon, T. F. (1994). Environmental scarcities and violent conflict: Evidence from cases. International Security, 19(1), 5-40.

Homer-Dixon, T. F. (2010). Environment, scarcity, and violence. Princeton University Press.

Horst, C. (2004). Money and mobility: Transnational livelihood strategies of the Somali diaspora. Global Migration Perspectives No. 9. Geneva: Global Commission on International Migration (GCIM).

Horst, C. (2008). The transnational political engagements of refugees: Remittance sending practices amongst Somalis in Norway: Analysis. Conflict, Security \& Development, 8(3), 317-339.

Horst, C., \& Van Hear, N. (2002). Counting the cost: Refugees, remittances and the "war against terrorism." Forced Migration Review, 14, 32-34.

Hovil, L. (2009). Two people can't share the same pair of shoes': Citizenship, land and the return of refugees to Burundi. Citizenship and Forced Migration in the Great Lakes Region: Working Paper No. 2. New York: International Refugee Rights Initiative.

Hovil, L., \& Kweka, O. (2008). Going home or staying home? Ending displacement for Burundian refugees in Tanzania. Citizenship and Forced Migration in the Great Lakes Region: Working Paper No. 2. New York: International Refugee Rights Initiative.

Huggins, C. (2007). Land in return, reintegration and recovery processes: Some lessons from the Great Lakes Region of Africa. London: Humanitarian Policy Group.

Human Rights Watch. (2000). Seeking protection: Addressing sexual and domestic violence in Tanzania's refugee camps. New York: Human Rights Watch.

Human Rights Watch. (2012). "You will not have peace while you are living". The escalation of political violence in Burundi. New York: Human Rights Watch.

James, K. (1997). Reading the leaves: The role of Tongan women's traditional wealth and other" contraflows" in the processes of modern migration and remittance. Pacific Studies, 20(1), 1-27.

Jenson, J. (2010). Defining and measuring social cohesion. Geneva: United Nations Research Institute for Social Development. 
Justino, P. (2009). Poverty and violent conflict: A micro-level perspective on the causes and duration of warfare. Journal of Peace Research, 46(3), 315-333.

Kabki, M., Mazzucato, V., \& Appiah, E. (2004). “Wo benan $\epsilon$ a $\epsilon y \epsilon$ bebree”: the economic impact of remittances of Netherlands-based Ghanaian migrants on rural Ashanti. Population, Space and Place, 10(2), 85-97.

Kamungi, P. M., Oketch, J., \& Huggins, C. (2005). Land access and the return and resettlement of IDPs and refugees in Burundi. In From the ground up: Land rights, conflict and peace in sub-Saharan Africa. Pretoria: African Centre for Technology Studies/Insitute for Security Studies:

King, R. (1978). Return migration: A neglected aspect of population geography. Area, 10(3), 175-182.

King, R. (1986). Return migration and regional economic problems. London: Croom Helm Ltd.

King, R., \& Christou, A. (2010). Cultural geographies of counter-diasporic migration: perspectives from the study of second-generation "returnees" to Greece. Population, Space and Place, 16(2), 103-119.

Knack, S., \& Keefer, P. (1997). Does social capital have an economic payoff? A cross-country investigation. The Quarterly Journal of Economics, 1251-1288.

Koubi, V., Spilker, G., Böhmelt, T., \& Bernauer, T. (2014). Do natural resources matter for interstate and intrastate armed conflict? Journal of Peace Research, 51(2), 227-243.

Lemarchand, R. (1996). Burundi: Ethnic conflict and genocide. Cambridge: Cambridge University Press.

Lemarchand, R. (2008, June 27). The Burundi killings of 1972. Online Encyclopedia of Mass Violence. Retrieved March 5, 2015.

Levitt, P. (1998). Social remittances: Migration driven local-level forms of cultural diffusion. International Migration Review, 926-948.

Lindley, A. (2008). Conflict-induced migration and remittances: Exploring conceptual frameworks. Refugee Studies Centre Working Paper Series No. 47. Oxford: Refugee Studies Centre.

Lindley, A. (2009). The early-morning phonecall: Remittances from a refugee diaspora perspective. Journal of Ethnic and Migration Studies, 35(8), 1315-1334.

Lindley, A. (2010). Leaving Mogadishu: towards a sociology of conflict-related mobility. Journal of Refugee Studies, 23(1), 2-22.

Lochner, K., Kawachi, I., \& Kennedy, B. P. (1999). Social capital: a guide to its measurement. Health \& Place, 5(4), 259-270.

Lucas, R. E., \& Stark, O. (1985). Motivations to remit: Evidence from Botswana. The Journal of Political Economy, 901-918.

Lyons, T. (2007). Conflict-generated diasporas and transnational politics in Ethiopia: Analysis. Conflict, Security \& Development, 7(4), 529-549. 
Maconachie, R., Binns, T., Tengbe, P., \& Johnson, R. (2006). Temporary labour migration and sustainable post-conflict return in Sierra Leone. GeoJournal, 67(3), 223-240.

Macrae, J. (1999). Aiding peace and war: UNHCR, returnee reintegration, and the reliefdevelopment debate. New Issues in Refugee Research, 14.

Martin, S. (2003). Burundi: out of sight, out of mind? Forced Migration Review, 17, 27-28.

Mazzucato, V. (2009). Informal insurance arrangements in Ghanaian migrants' transnational networks: The role of reverse remittances and geographic proximity. World Development, 37(6), 1105-1115.

Mazzucato, V., Kabki, M., \& Smith, L. (2006). Transnational migration and the economy of funerals: Changing practices in Ghana. Development and Change, 37(5), 1047-1072.

Mazzucato, V., Van Den Boom, B., \& Nsowah-Nuamah, N. N. (2008). Remittances in Ghana: Origin, destination and issues of measurement. International Migration, 46(1), 103122.

McKenzie, D., \& Sasin, M. J. (2007). Migration, remittances, poverty, and human capital: conceptual and empirical challenges. World Bank Policy Research Working Paper No. 4272. Washington D.C.: World Bank Publications.

Mohamoud, A. A. (2006). African diaspora and post-conflict reconstruction in Africa. Copenhagen: Danish Institute for International Studies.

Musahara, H., \& Huggins, C. (2005). Land reform, land scarcity and post-conflict reconstruction: A case study of Rwanda. In From the Ground up: Land Rights, Conflict and Peace in Sub-Saharan Africa (269-346). Pretoria: Institute for Security Studies.

Narayan, D., \& Pritchett, L. (1999). Cents and sociability: Household income and social capital in rural Tanzania. Economic Development and Cultural Change, 47(4), 871-897.

Newland, K., \& Patrick, E. (2004). Beyond remittances: The role of diaspora in poverty reduction in their countries of origin. Washington D.C.: Migration Policy Institute.

Ngaruko, F., \& Nkurunziza, J. (2000). An economic interpretation of conflict in Burundi. Journal of African Economies, 9(3), 370-409.

Ngaruko, F., \& Nkurunziza, J. (2005). Civil war and its duration in Burundi. In Understanding civil war: Africa. Washington D.C.: World Bank Publications.

Nyberg-Sørensen, N., Van Hear, N., \& Engberg-Pedersen, P. (2002). The migration development nexus. Evidence and policy options. State-of-the-art overview. International Migration, 40(5), 3-46.

OECD (2006). DAC guidelines and reference series applying strategic environmental assessment: Good practice guidance for development co-operation. Paris: OECD

OECD. (2014). Fragile states 2014: Domestic revenue mobilization in fragile states. Paris: OECD.

Orjuela, C. (2008). Distant warriors, distant peace workers? Multiple diaspora roles in Sri Lanka's violent conflict. Global Networks, 8(4), 436-452.

Özerdem, A., \& Sofizada, A. H. (2006). Sustainable reintegration to returning refugees in 
post-Taliban Afghanistan: land-related challenges: Analysis. Conflict, Security $\mathcal{E}$ Development, 6(1), 75-100.

Page, J., \& Plaza, S. (2006). Migration remittances and development: A review of global evidence. Journal of African Economies, 15(suppl 2), 245-336.

Pantuliano, S. (2009). Going home: Land, return and reintegration in Southern Sudan and the three areas. In Uncharted Territory: Land. Conflict and Humanitarian Action. Rugby: Practical Action.

Portes, A. (2000a). Social capital: Its origins and applications in modern sociology. In Knowledge and Social Capital (pp. 43-67). Boston: Butterworth-Heinemann.

Portes, A. (2000b). The two meanings of social capital. In Sociological forum, 15, 1-12.

Putnam, R. D. (1995). Bowling alone: America's declining social capital. Journal of Democracy, $6(1), 65-78$.

Putnam, R. D. (2000). Bowling alone: The collapse and revival of American community. New York: Simon \& Schuster.

Putnam, R. D. (2002). Democracies in flux: The evolution of social capital in contemporary society. Oxford: Oxford University Press.

Ratha, D., Mohapatra, S., Ozden, C., Plaza, S., Shaw, W., \& Shimeles, A. (2011). Leveraging migration for Africa: Remittances, skills and investments. Washington D.C.: World Bank Publications.

Rema Ministries. (2012). "Umenga ntituri abarundi" Rethinking reintegration in Burundi. Bujumbura: Rema Ministries.

Republic of Burundi. (2000). Arusha Peace and Reconciliation agreement for Burundi. Bujumbura: Republic of Burundi.

Republic of Burundi. (2011). Politique nationale de migration de la Republique du Burundi: Avant-projet. Bujumbura: Republic of Burundi.

Rogge, J. R. (1994). Repatriation of refugees: A not so simple "optimum" solution. In When refugees go home. Suffolk: James Currey Publishers.

Rosenbaum, P. R. (2002). Observational studies. New York: Springer.

Rosenbaum, P. R., \& Rubin, D. B. (1983). The central role of the propensity score in observational studies for causal effects. Biometrika, 70(1), 41-55.

Rosenbaum, P. R., \& Rubin, D. B. (1985). The bias due to incomplete matching. Biometrics, 103-116.

Sahn, D. E., \& Stifel, D. (2003). Exploring alternative measures of welfare in the absence of expenditure data. Review of Income and Wealth, 49(4), 463-489.

Sianesi, B. (2004). An evaluation of the Swedish system of active labor market programs in the 1990s. Review of Economics and Statistics, 86(1), 133-155.

Skeldon, R. (2008). International migration as a tool in development policy: a passing phase? Population and Development Review, 34(1), 1-18. 
Sommers, M. (2001). Young, male and pentecostal: Urban refugees in Dar es Salaam, Tanzania. Journal of Refugee Studies, 14(4), 347-370.

Spaan, E., \& Van Moppes, D. (2006). African exodus? Trends and patterns of international migration in sub-Saharan Africa. Working Papers Migration and Development Series No. 4. Nijmegen: Research Group Migration and Development, Radboud University Nijmegen.

Stark, O. (1980). On the Role of Urban-to-Rural Remittances in Rural Development. Journal of Development Studies, 16(3), 369-374.

Stark, O., \& Bloom, D. E. (1985). The new economics of labor migration. The American Economic Review, 173-178.

Stark, O., \& Taylor, J. E. (1989). Relative deprivation and international migration. Demography, 26(1), 1-14.

Stigter, E. (2006). Livelihoods upon return: Afghan migratory strategies-An assessment of repatriation and sustainable return in response to the Convention Plus. Refugee Survey Quarterly, 25(2), 109-122.

Task Force on Remittance Flows to Post-Conflict States. (2013). Remittance flows to post conflict states: Perspectives on human security and development. Boston: Boston University.

Taylor, E. J. (1999). The new economics of labour migration and the role of remittances in the migration process. International Migration, 37(1), 63-88.

Taylor, E. J., \& Wyatt, T. J. (1996). The shadow value of migrant remittances, income and inequality in a household-farm economy. The Journal of Development Studies, 32(6), 899-912.

Terra-P Group. (2008). Impact evaluation of PRM humanitarian assistance to the repatriation and reintegration of Burundi refugees (2003-08). Bujumbura: Terra-P Group.

Theisen, O. M. (2008). Blood and soil? Resource scarcity and internal armed conflict revisited. Journal of Peace Research, 45(6), 801-818.

Thomson, J. (2009). Durable solutions for Burundian refugees in Tanzania. Forced Migration Review, 33, 35-37.

Trouwborst, A. A. (1973). Two types of partial networks in Burundi. In Network Analysis: Studies in Human Interaction (pp. 111-125). The Hague: Mouton \& Co.

Turner, S. (2008a). Cyberwars of words: Expressing the unspeakable in Burundi's diaspora. Journal of Ethnic and Migration Studies, 34(7), 1161-1180.

Turner, S. (2008b). The waxing and waning of the political field in Burundi and its diaspora. Ethnic and Racial Studies, 31(4), 742-765.

Turner, S., \& Bronden, B. M. (2011). From watch-dogs to nation-builders: The dilemmas of diaspora engagement in post-conflict Burundi. DIIS Working paper No. 10.

Copenhagen: Danish Institute for International Studies. 
UNDP. (2011). Human Development Report 2011. New York: UNDP.

UNHCR. (1997). Reintegration in the transition from war to peace. Geneva: UNHCR.

UNHCR. (2002). Statistiques demographiques du rapatriement. Bujumbura: UNHCR.

UNHCR. (2008a). A community-based apporach in UNHCR operations. Geneva: UNHCR.

UNHCR. (2008b). UNHCR's role in support of the return and reintegration of displaced populations: Policy framework and implementation strategy. Geneva: UNHCR.

UNHCR. (2011). Statistiques demographiques du rapatriement. Bujumbura: UNHCR.

UNHCR. (2012). Country operations profile - Burundi. Statistical snapshot as of January 2012. Geneva: UNHCR.

UNHCR. (2014c). UNHCR Global trends 2013. Geneva: UNHCR.

UNHCR. (2014b). UNHCR country operations profile - Afghanistan. Geneva: UNHCR.

UNHCR. (2014c). Statistiques demographiques du rapatriement. Bujumbura: UNHCR.

UNOCHA. (2000). UN consolidated inter-agency ppeal for Burundi 2001. Geneva: UN Office for the Coordination of Humanitarian Affairs (UNOCHA).

Unruh, J. D. (1998). Land tenure and identity change in postwar Mozambique. GeoJournal, 46(2), 89-99.

Unruh, J. D. (2003). Land tenure and legal pluralism in the peace process. Peace $\mathcal{E}$ Change, 28(3), 352-377.

Unruh, J. D. (2009). Land rights in postwar Liberia: the volatile part of the peace process. Land Use Policy, 26(2), 425-433.

Uphoff, N. (2000). Understanding social capital: Learning from the analysis and experience of participation. In Social capital: A multifaceted perspective (pp. 215-249). Washington D.C.: World Bank Publications.

Urdal, H. (2005). People vs. Malthus: Population pressure, environmental degradation, and armed conflict revisited. Journal of Peace Research, 42(4), 417-434.

USCRI. (2000). U.S. Committee for Refugees World Refugee Survey 2000 - Burundi. Virginia: United States Committee for Refugees and Immigrants (USCRI).

Uvin, P. (1999). Ethnicity and power in Burundi and Rwanda: Different paths to mass violence. Comparative Politics, 253-271.

Uvin, P. (2009). Life after violence: a people's story of Burundi. Zed books London.

Van Hear, N. (2002). Sustaining societies under strain: Remittances as a form of transnational exchange in Sri Lanka and Ghana. In New approaches to migration: Transnational communities and the transformation of home (pp. 202-223). London: Routledge.

Van Hear, N. (2004). "I went as far as my money would take me": Conflict, forced migration and class. COMPAS Working Paper No. 6. Oxford: Centre on Migration, Policy and Society (COMPAS).

Van Leeuwen, M. (2010). Crisis or continuity? framing land disputes and local conflict 
resolution in Burundi. Land Use Policy, 27(3), 753-762.

Varshney, A. (2001). Ethnic conflict and civil society. World Politics, 53(3), 362-398.

Verpoorten, M. (2012). Leave none to claim the land A Malthusian catastrophe in Rwanda? Journal of Peace Research, 49(4), 547-563.

Vervisch, T., Titeca, K., Vlassenroot, K., \& Braeckman, J. (2013). Social capital and post conflict reconstruction in Burundi: The limits of community-based reconstruction. Development and Change, 44(1), 147-174.

Vervisch, T., Vlassenroot, K., \& Braeckman, J. (2013). Livelihoods, power, and food insecurity: adaptation of social capital portfolios in protracted crises - case study Burundi. Disasters, 37(2), 267-292.

Watt, N. (2008). Burundi: Biography of small African country. London: Hurst \& Company.

Weiss Fagen, P., \& Bump, M. (2006). Remittances in conflict and crises: How remittances sustain livelihoods in war, crises and transitions to peace. New York: International Peace Academy.

Wessendorf, S. (2007). "Roots migrants": transnationalism and "return" among second generation Italians in Switzerland. Journal of Ethnic and Migration Studies, 33(7), 1083-1102.

Williams, R. C. (2006). The significance of property restitution to sustainable return in Bosnia and Herzegovina. International Migration, 44(3), 40-61.

Woolcock, M., \& Narayan, D. (2000). Social capital: Implications for development theory, research, and policy. The World Bank Research Observer, 15(2), 225-249.

World Bank. (2009). Country brief: Burundi. Washington D.C.: World Bank Publications.

World Bank. (2011a). World Development Report 2011: Conflict, security and development. Washington D.C.: World Bank Publications.

World Bank. (2011b). World development indicators. Washington D.C.: World Bank Publications.

World Bank. (2011c). Migration and remittances factbook 2011. Washington D.C.: World Bank Publications.

World Bank. (2014). Migration and Development Brief 22. Washington D.C.: World Bank Publications.

Wu, D. M. (1974). Alternative tests of independence between stochastic regressors and disturbances. Econometrica, 42, 529-546. 

Appendices 

Figure A.1a. Number of organization memberships per household

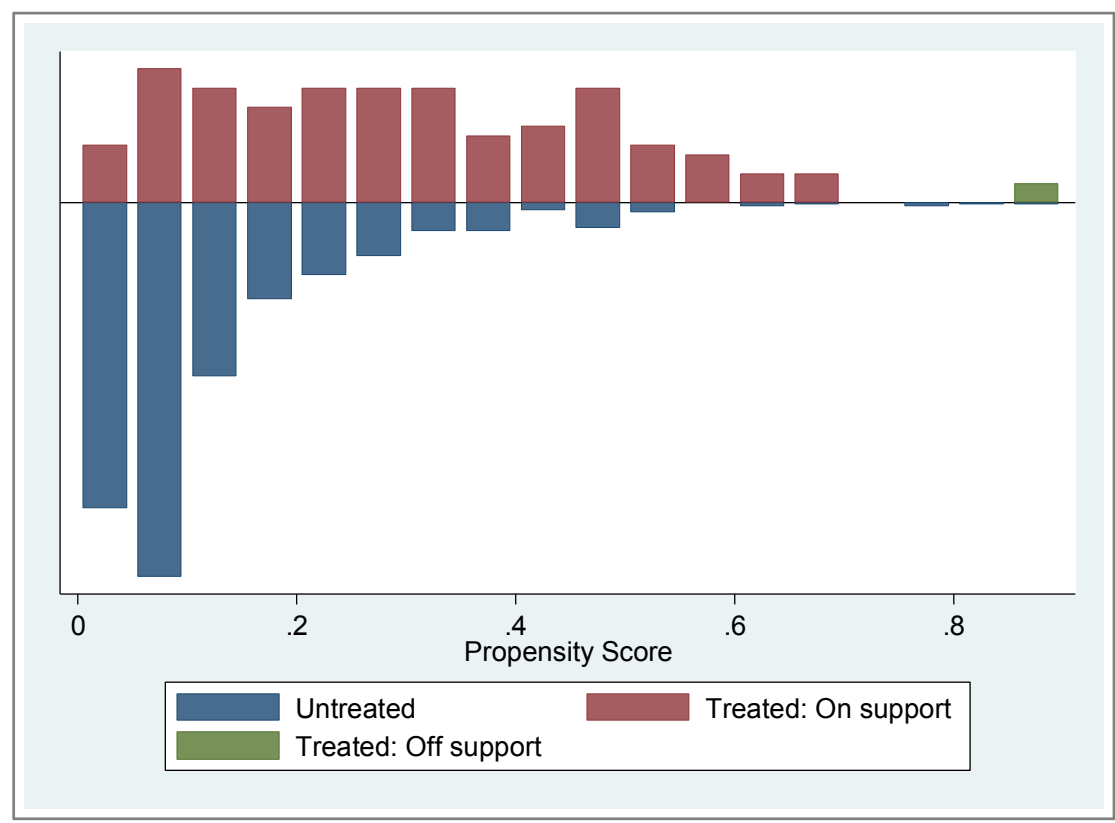

Figure A.1b. Expenditures on religious organisations (USD)

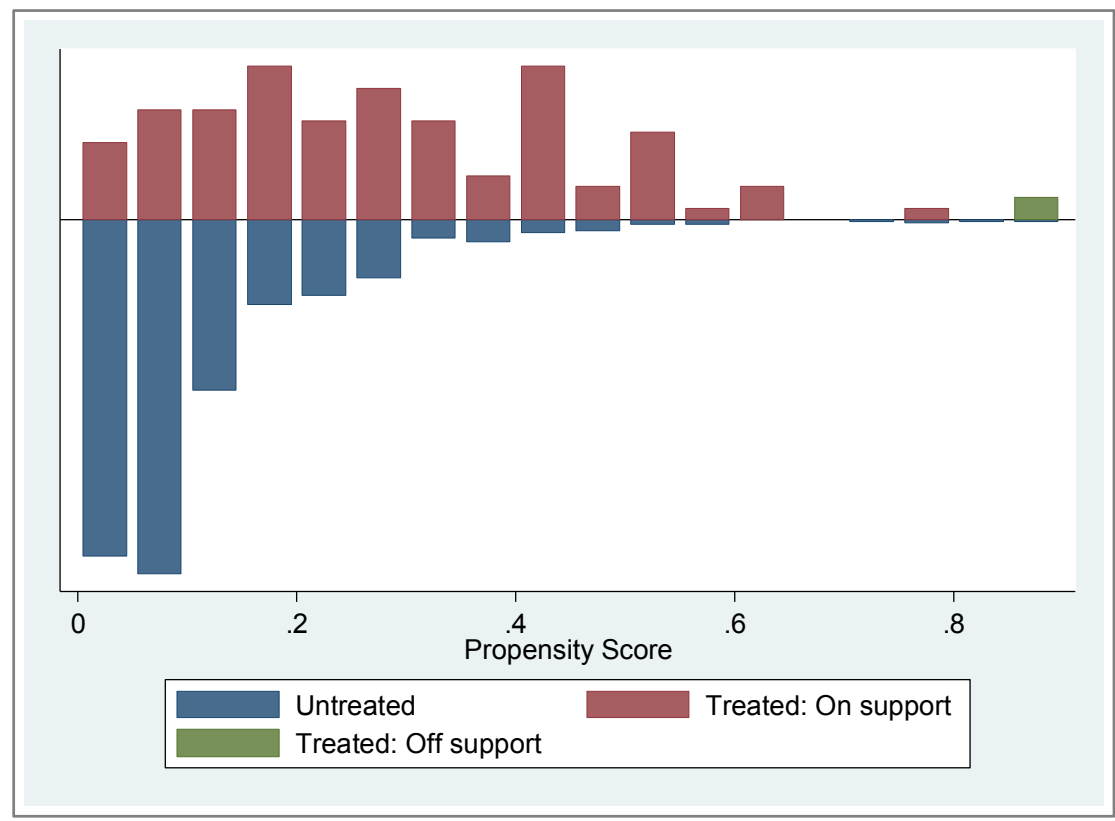


Figure A.1c. Expenditures on gifts to family and friends (USD)

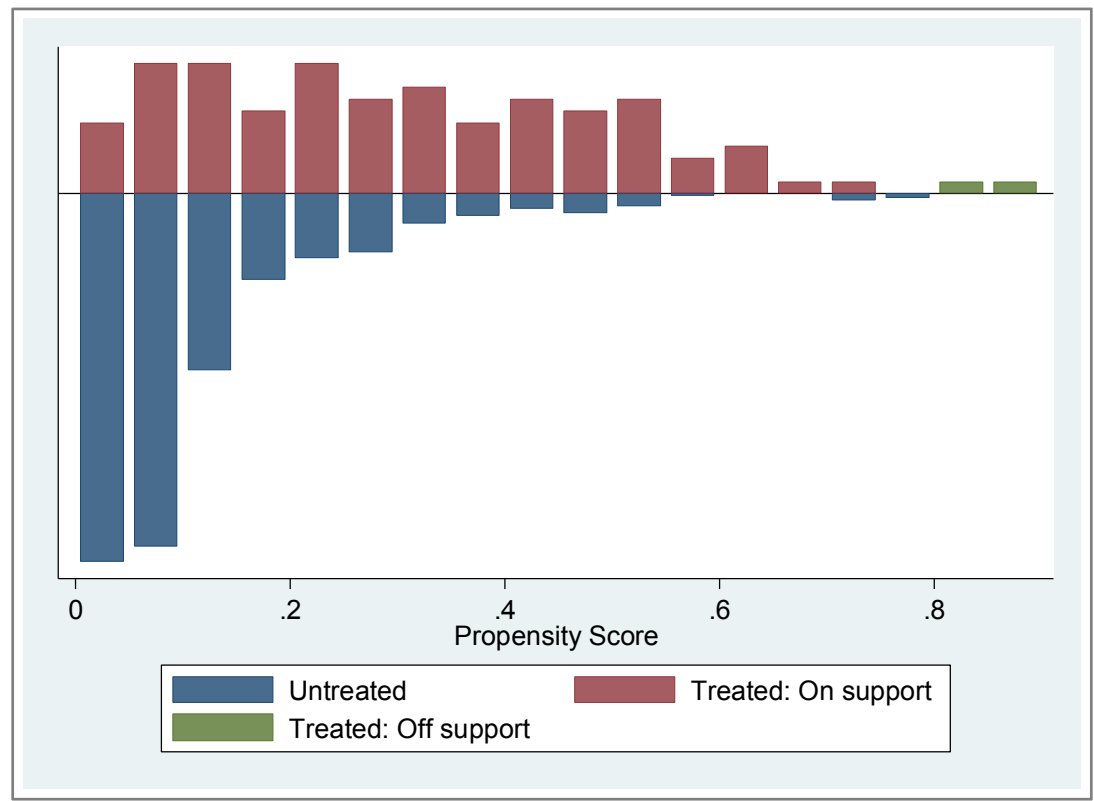

Figure A.1d. Urban-rural remittance sending $(1=$ yes $)$

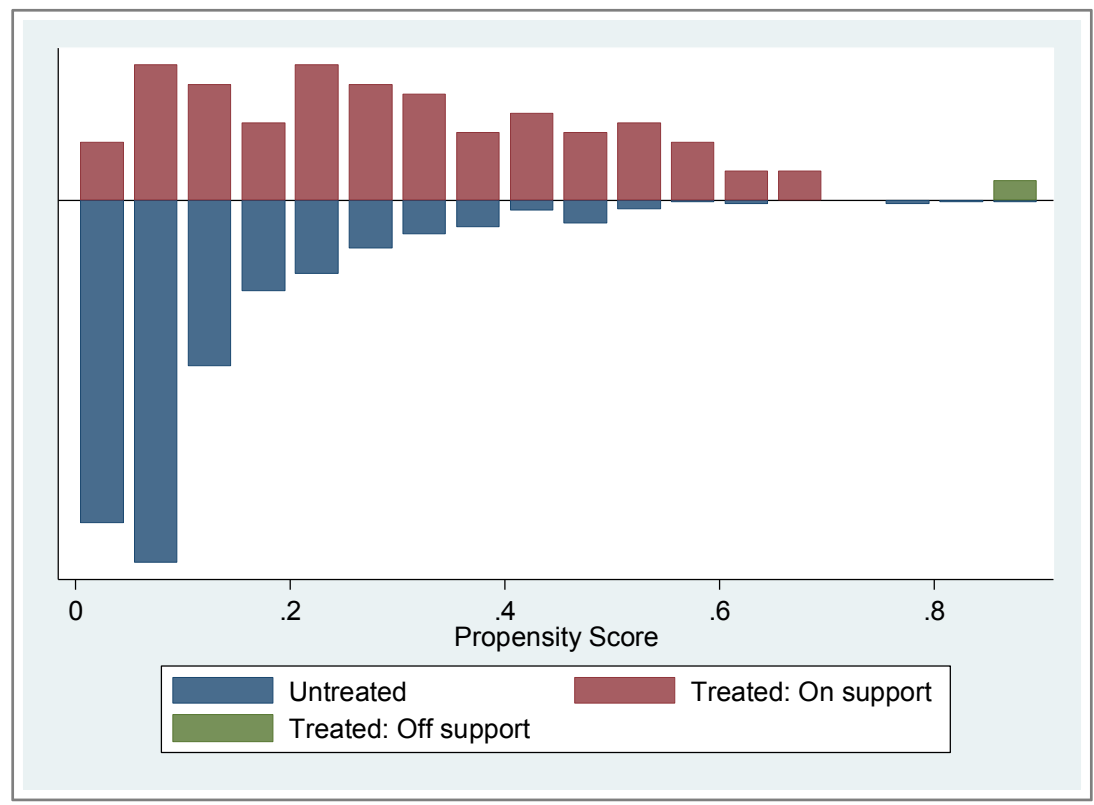


Figure A.1e. Value of urban-rural remittances (USD)

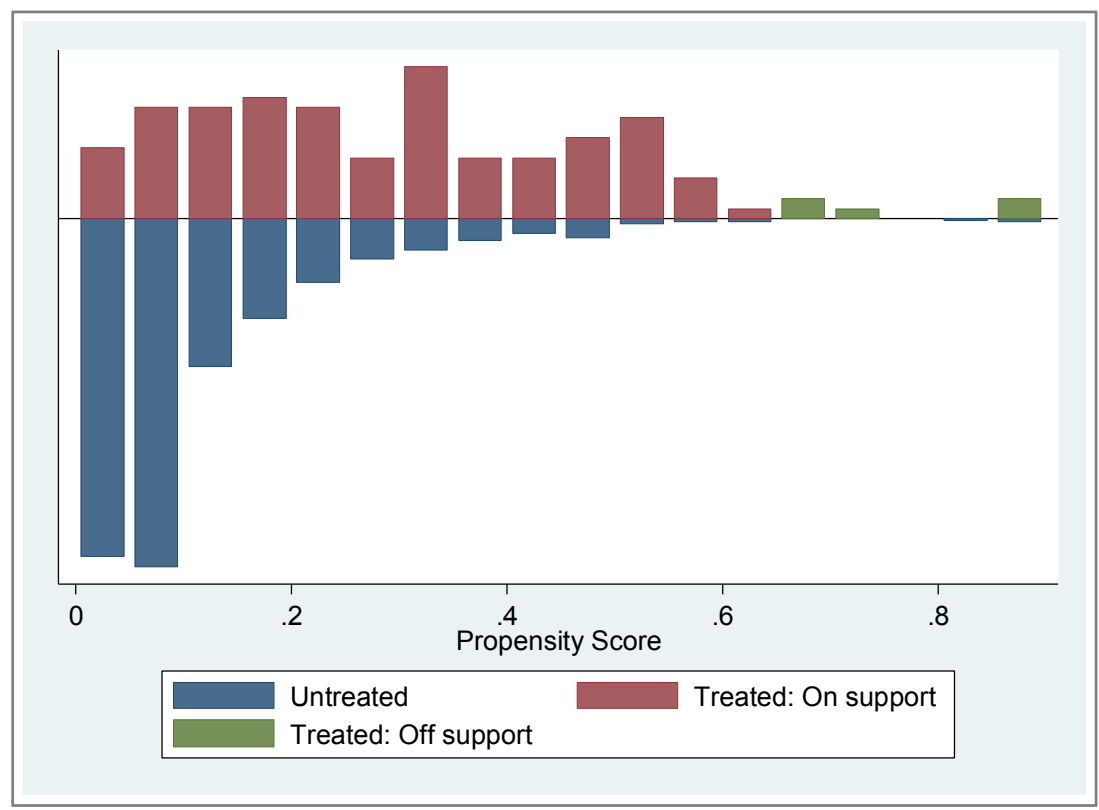


Map A.1. Geographic location of Burundi

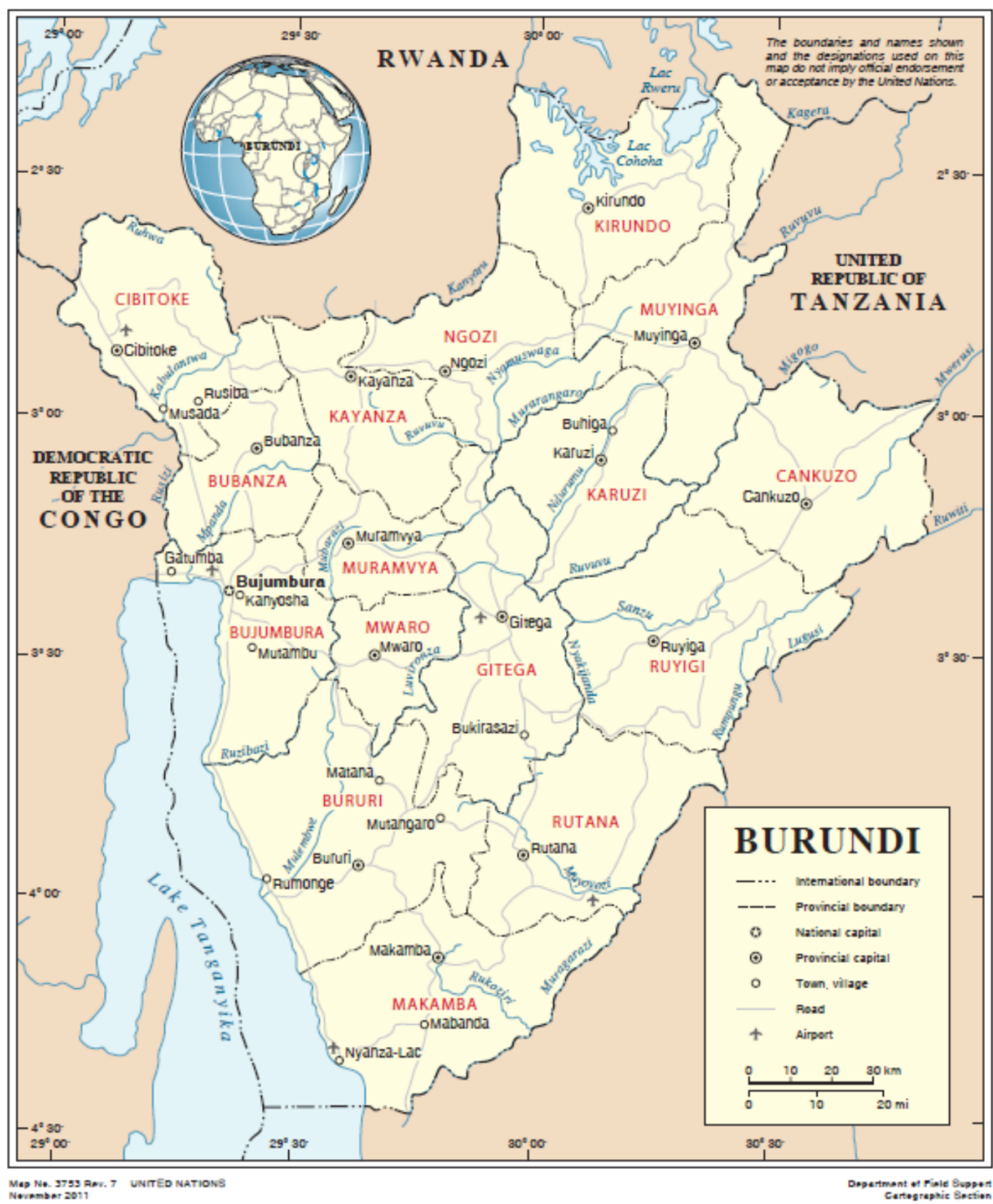

Source: United Nations Cartographic Section, 2011 
Map A.2. Returnees per province: March 2002-June 2011

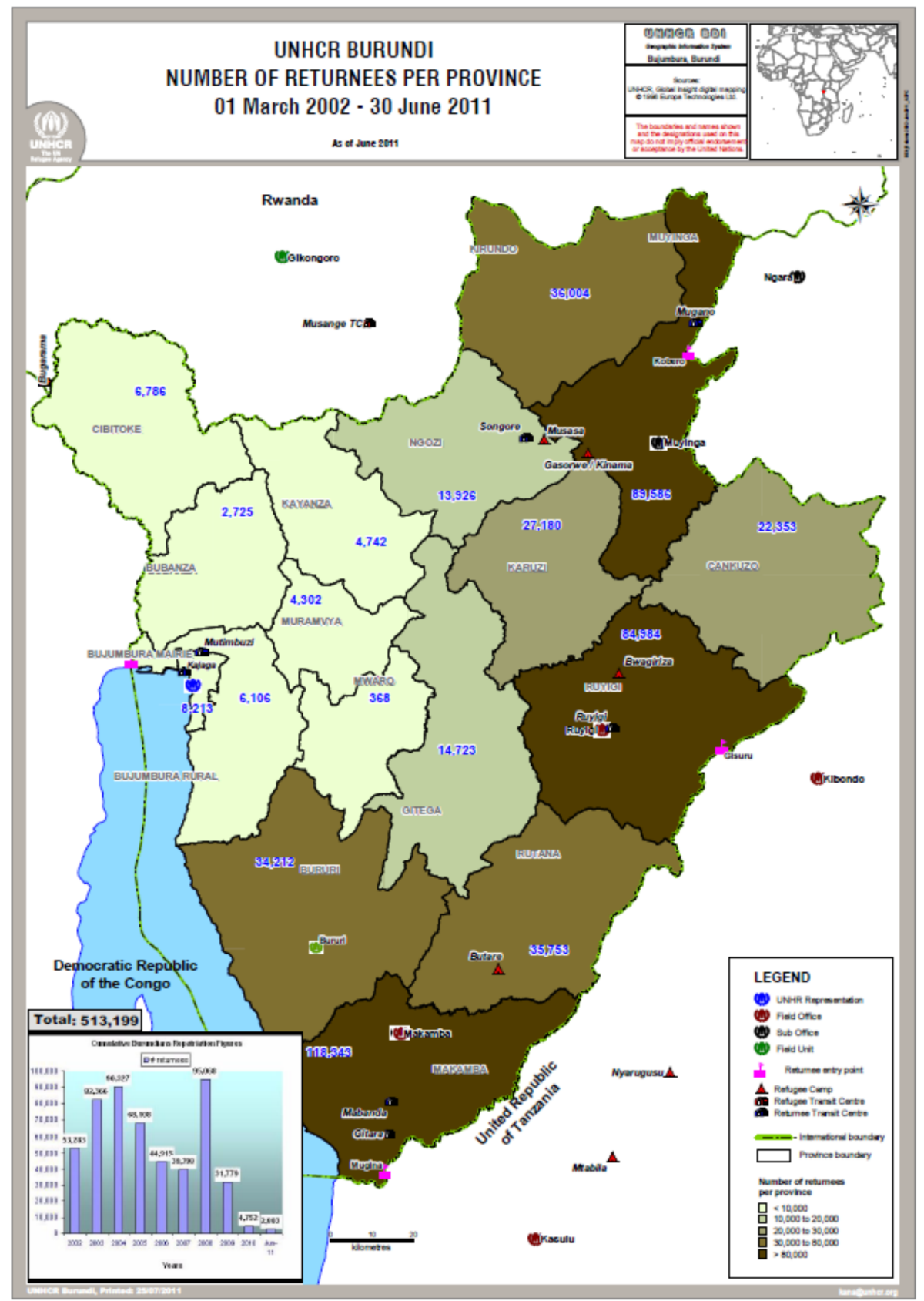

Source: UNHCR, 2011 


\section{Valorization addendum}

As described in this dissertation, migration has been increasingly considered as a contributor to development in conflict-affected states. Many conflict-affected countries experience large return migrations during periods of relative stability and receive vast amounts of remittances that are considered beneficial to reconstruction and economic development. The development effects of return migration and remittances, however, remain underexplored. Most research on migration and development has taken place in countries that were not affected by conflict, yielding limiting knowledge on the importance of migration in conflictaffected states. This dissertation studied the impact of migration on development in a conflict-affected state, Burundi. Focus was on remittances and return migration as potential contributors to development. These migration-related phenomena have surfaced from the migration and development literature as being among the most important that may contribute to development in migrant-sending countries. The central research question of this dissertation was: What are the economic and social effects of remittances and return migration on households and communities in a conflict- affected context?

This research was part of a larger research project called Migration and Development: A World in Motion. This was a five-year research project, funded by the Dutch Ministry of Foreign Affairs, that investigated the effects of migration on four migrant-sending countries (Afghanistan, Burundi, Ethiopia, and Morocco) and one migrant-receiving country (the Netherlands). The aim of the project was to stimulate new approaches to development cooperation using the available knowledge on sustainable development and poverty reduction and to gather new evidence on migration and development that would lead to effective policies. Specifically, the Migration and Development: A World in Motion project aimed to strengthen the scientific foundation for policy making in the area of migration and development, to strengthen the policy relevance of research and to increase the knowledge about migration and development among the Dutch society, policy makers in other sectors, as well as policy makers in developing countries.

\section{Innovation}

This dissertation contributed to the migration and development debate in three ways. First, this dissertation studied the lives of households and communities that 
are recovering from civil conflict and the role that migration plays in their lives. As described in the dissertation, data from conflict-affected contexts are scarce, and there is little knowledge on migration as a livelihood or the coping strategies of households in these contexts. Second, this dissertation applied specific tenets of theoretical approaches that have often been used to study labour migration to a conflict-affected setting to study how the effects of migration on development may differ in a conflict-affected setting. Third, this dissertation studied how migration affects both economic and social aspects of a conflict-affected society. This multidimensional focus is especially relevant in a conflict-affected context, in which not only economic structures have to be rebuilt, but social relations are often damaged as well.

This research showed that in a conflict-affected country such as Burundi, migration does not have the anticipated development- boosting effect that comes forward from the policy and academic literature on migration and development. This is most likely due to the conflict-affected context. Conflict-affected states differ significantly from other developing country contexts that were not affected by conflict, because a) the causes and characteristics of migration flows are significantly different in conflict-affected contexts, and b) civil conflict has both direct and indirect effects on society and creates a situation of insecurity and instability that often persists long after the conflict has ended. These findings highlight the necessity of a basic level of development before migration can positively affect development. In the absence of investment opportunities for remittances or opportunities for returnees or returning households to establish their livelihoods, the development effects of remittances and return migration will be limited or, in the case of return migration, even negative. The multidimensional focus on development that this dissertation adopted, focusing on both the economic and the social effects of remittances and return migration, showed that migration affects not only the economic aspects of societies but also social ties between society members.

\section{Policy implications}

The research findings in this dissertation highlight the need for policies and programs that simultaneously address humanitarian needs and economic and social development in conflict-affected settings. Without a basic level of economic development, the contribution that remittances and return migration can make to 
development is most likely minimal. Local governments should therefore work in close collaboration with international organizations to deliver both humanitarian aid and implement programs and policies that stimulate development. For migrant-receiving countries, such as the Netherlands, it is important to invest in development aid. The finding that remittances are not received by those who 'need' it the most, for example, highlights that remittances cannot replace official state and international aid initiatives on development and poverty alleviation programmes, as is sometimes suggested by 'co-development' initiatives in which migrants are seen as a way to channel development aid.

The findings on remittances also showed that the potential of the diaspora is not yet fully recognized. A draft diaspora engagement policy has been designed in Burundi in 2011, but has not been implemented to date. Putting the issue of remittances on the policy agenda can lead to the design and implementation of policies that stimulate remittance inflows and enhance the effectiveness of remittances for development. The most important condition for remittances to increase and have substantial impacts on development in the country is, however, a stable political situation. Political stability will lead to more security, which will probably positively affect the economy and enhance the business climate in Burundi. A better financial climate will also enhance the possibilities for receivers to invest remittances in businesses and other productive assets, which will have a positive impact on the economy. The tensions that are rising in Burundi in the runup to the 2015 elections are therefore the largest threat to remittance inflows and their potential impacts on development.

The findings on return migration highlighted the importance of property restitution after conflict and the responsibility of local governments in providing restitution and compensation for the losses that people suffered. The issue of property restitution, which in this case mainly concerns agricultural land, came forward as a central driver of the differences between returnees and non-returnees. The unequal distribution of land raised concerns because of the importance of land for livelihoods in rural Burundi and should therefore be addressed. This research also showed that returnees are not a homogeneous group, which highlights the need that reintegration assistance is adapted to fit the needs of different types of returnees. Second-generation returnees, for example, were found to be less well off than first-generation return households. Land ownership among secondgeneration return households was found to be low and most such households 
experienced food insecurity on a weekly basis and reported low subjective wealth. Different types of returnees are therefore in need of different types of support.

In addition, return migration was found to affect not only the returning households but other community members in communities of return as well. This finding highlights the need for support programs that benefit not only the returnees or the returning households but their community members well. The community-based approach (CBA) to humanitarian aid that UNHCR adopted in the early 2000s is a good example of such a program. The CBA implies local cooperation for humanitarian support and a more 'bottom-up' working method. In practice, this means that operations are undertaken in cooperation with local governments and decisions are made while working with the community. This community involves not only the displaced or the people of concern but also the community's non-displaced. The restoration of social ties is an important part of the peace-building process and should therefore be incorporated into policies and programs that are implemented in conflict-affected settings such as Burundi.

\section{Knowledge sharing}

Throughout the research, we worked in close collaboration with key actors in the area of migration and development, including international organizations (e.g. UNHCR, UNDP, IOM), local and international non-governmental organizations (NGOs), local research institutes, and government representatives in both the Netherlands and Burundi. Before our data collection started, we went on scoping visits to Burundi. During these visits we would have meetings with international organizations and local and international NGOs that were working on the area of migration and/or development in Burundi. We interviewed them about the current situation in the country and involved them in our research design. Maintaining close links with these organizations ensured that our research findings would be relevant for them. The Burundi government was also informed about our research and we conducted several interviews with government officials to learn about the current situation in Burundi. The data collection took place in close collaboration with a local research institute (Development Through Expert Consultancy DevEC) and a local university, Université Sagesse d'Afrique.

Throughout the research have also maintained close ties with members of the Burundi diaspora and the different organizations that they were involved in in the Netherlands. These actors and diaspora members provided input into the 
research design and the implementation of the research to ensure that the focus of the project and the results that were obtained would be of interest for them. For example, before data collection we held consultation meetings with Burundi diaspora organizations at the Ministry of Foreign Affairs, where we introduced our research design and the questionnaire that we would use for data collection. During these meetings we would receive feedback from the diaspora members, which ensured that the questions that we asked during the fieldwork were relevant and culturally appropriate. After data collection, we shared our preliminary findings with the Dutch Ministry of Foreign Affairs and the Burundi diaspora organizations to disseminate the results quickly and to receive feedback on our findings.

The research results of this dissertation have been disseminated, and will continue to be disseminated in the future, through different means. First, the research results have been published, and will be published, in academic papers and policy briefs. The empirical chapters that form the body of this dissertation have all been either published or sent to academic journals for publication. In addition, two policy briefs have been published in the Maastricht Graduate School of Governance Migration and Development policy brief series. These policy briefs provided insights into the remittance market in Burundi and the diaspora engagement policy that is currently being developed. Second, we have shared our research results through workshops and conferences that were attended by academics, policy makers, diaspora members, and representatives of international organizations. In the years to come, we will continue to share our research results through these types of events. Third, the data that were collected for the Migration and Development: A World in Motion project will become publicly available online in the near future. The publication of our survey data will offer other scholars and practitioners the opportunity to work with the data and to gain further insights into the linkages between migration and development. 


\section{About the author}

Sonja Fransen (Rotterdam, 1981) completed a Master degree in Clinical Health Psychology at Tilburg University in 2007, a pre-master year of Development Studies at Radboud University in 2007, and a Research Master in Social Cultural Sciences at Radboud University in 2009. For her Master theses in Clinical Health Psychology and Social Cultural Sciences she conducted fieldwork in South Africa and Rwanda, respectively. In September 2009 Sonja joined the migration research group at Maastricht Graduate School of Governance, Maastricht University, to do her PhD research. Her PhD research was part of the Migration and Development: A World in Motion project, funded by the Dutch Ministry of Foreign Affairs. Sonja is currently working as a postdoctoral researcher on the Labour Market Impacts of Forced Migration (LAMFOR) project, which is a two-year research conducted by the Centre for Migration, Policy and Society (COMPAS), University of Oxford, and the Maastricht Graduate School of Governance, Maastricht University. The project is funded by the German Institute for the Study of Labour (IZA) and the UK Department for International Development (DFID). Sonja's research interests include (forced) migration, return migration, (post-conflict) development, and remittances. 



\title{
MGSoG Dissertation Series
}

\author{
Ibrahim Khalil Conteh
}

The Impact of Floods on Primary School Education in Zambia

MGSoG Dissertation Series, nr 55 (2015)

Richard Bluhm

Growth Dynamics and Development

Essays in Applied Econometrics and Political Economy

MGSoG Dissertation Series, nr 54 (2015)

Nevena P. Zhelyazkova

Work-Family Reconciliation and Use of Parental Leave in Luxembourg

Empirical Analysis of Administrative Records

MGSoG Dissertation Series, nr 53 (2015)

Sachin Kumar Badkas

Metachoice and Metadata

Innovating with Environmental Policy Analysis in Europe

MGSoG Dissertation Series, nr 52 (2014)

Irina S. Burlacu

An Evaluation of Tax-Benefit Systems Impact on the Welfare of Frontier Workers

The Case of Luxembourg and Belgium

MGSoG Dissertation Series, nr 51 (2014)

Özge Bilgili

Simultaneity in Transnational Migration Research:

Links Between Migrants' Host and Home Country Orientation

MGSoG Dissertation Series, nr 50 (2014) 
Yulia Privalova Krieger

Reshaping the Big Agenda: Transnational Politics and Domestic Resistance

Financial crisis and social protection reform in Bosnia and Herzegovina

MGSoG Dissertation Series, nr 49 (2014)

Marieke van Houte

Moving Back or Moving Forward?

Return migration after conflict

MGSoG Dissertation Series, nr 48 (2014)

Oxana Slobozhan

Global Governance in the Management of Natural Resources

The Case of the Extractive Industries Transparency Initiative (EITI)

MGSoG Dissertation Series, nr 47 (2014)

Luis Bernardo Mejia Guinand

The Changing Role of the Central Planning Offices in Latin America:

A Comparative Historical Analysis Perspective (1950-2013)

MGSoG Dissertation Series, nr 46 (2014)

Cheng Boon Ong

Ethnic Segregation in Housing, Schools and Neighbourhoods in the Netherlands

MGSoG Dissertation Series, nr 45 (2014)

Luciana V. Cingolani

Bureaucracies for Development: Oxymoron or Reality?

Studies on State Capacity in Challenging Governance Contexts

MGSoG Dissertation Series, nr 44 (2014)

Carlos Cadena Gaitán

Green Politics in Latin American Cities - Sustainable Transport Agendas

MGSoG Dissertation Series, nr 43 (2014) 
Katie Kuschminder

Female Return Migration and Reintegration Strategies in Ethiopia

MGSoG Dissertation Series, nr 42 (2014)

Metka Hercog

Highly-Skilled Migration and New Destination Countries

MGSoG Dissertation Series, nr 41 (2014)

Margaret Agaba Rugadya

Can Remittances Influence the Tenure and Quality of Housing in Uganda?

MGSoG Dissertation Series, nr 40 (2014)

Ilire Agimi

New Governance Under Limited Statehood

The Case of Local Government Reform in Kosovo

MGSoG Dissertation Series, nr 39 (2014)

Kristine Farla

Empirical Studies on Institutions, Policies and Economic Development

MGSoG Dissertation Series, nr 38 (2013)

Marina Petrovic

Social Assistance and Activation in the Pursuit of Happiness:

Shedding New Light on Old Policy Solutions to Social Exclusion

MGSoG Dissertation Series, nr 37 (2013)

Laura Torvinen

Assessing Governance Assessments; The Case of Mozambique

Governance Assessments in the Context of Aid Effectiveness Discourse

MGSoG Dissertation Series, nr 36 (2013)

Biniam Egu Bedasso

Institutional Change in the Long Shadow of Elites

Essays on Institutions, Human Capital and Ethnicity in Developing Countries

MGSoG Dissertation Series, nr 35 (2013) 
Sepideh Yousefzadeh Faal Deghati

Childhoods Embargoed

Constructing and Reconstructing Multidimensional Child Poverty in Iran 1984-2009

MGSoG Dissertation Series, nr 34 (2013)

Robert Bauchmüller

Investing in Early Childhood Care and Education:

The Impact of Quality on Inequality

MGSoG Dissertation Series, nr 33 (2013)

Martin Rehm

Unified Yet Separated

Empirical Study on the Impact of Hierarchical Positions within Communities of Learning MGSoG Dissertation Series, nr 32 (2013)

Dorcas Mbuvi

Utility Reforms and Performance of the Urban Water Sector in Africa

MGSoG Dissertation Series, nr 31 (2012)

Lina Salanauskaite

Distributional Impacts of Public Policies:

Essays in Ex-Ante and Ex-Post Evaluation

MGSoG Dissertation Series, nr 30 (2012)

Esther Schüring

To Condition or not - is that the Question?

An Analysis of the Effectiveness of Ex-Ante and Ex-Post Conditionality in Social Cash

Transfer Programs

MGSoG Dissertation Series, nr 29 (2012)

Joe Abah

Strong Organisations in Weak States

Atypical Public Sector Performance in Dysfunctional Environments

MGSoG Dissertation Series, nr 28 (2012) 
Zina Samih Nimeh

Social Citizenship Rights: Inequality and Exclusion

MGSoG Dissertation Series, nr 27 (2012)

Lenka Eisenhamerová

Legitimacy of 'Humanitarian Military Intervention'

MGSoG Dissertation Series, nr 26 (2011)

Sonila Tomini

Informal Payments for Health Care Services in Albania

MGSoG Dissertation Series, nr 25 (2011)

Jinjing Li

Dynamic Microsimulation in Public Policy Evaluation

MGSoG Dissertation Series, nr 24 (2011)

Aziz Atamanov

Rural Nonfarm Employment and International Migration as Alternatives to Agricultural

Employment:

The Case of Kyrgyzstan

MGSoG Dissertation Series, nr 23 (2011)

Frieda Vandeninden

Poverty Alleviation: Aid and Social Pensions

MGSoG Dissertation Series, nr 22 (2011)

Juliana Nyasha Tirivayi

The Welfare Effects of Integrating AIDS Treatment with Food Transfers:

Evidence from Zambia

MGSoG Dissertation Series, nr 21 (2011)

Agnieska Ewa Sowa

Who's Left Behind? Social Dimensions of Health Transition and Utilization of Medical

Care in Poland

MGSoG Dissertation Series, nr 20 (2011) 


\section{Emmanaouil Sfakianakis}

The Role of Private Actors in the Provision of Public Goods with Applications to Infrastructure and Financial Stability

MGSoG Dissertation Series, nr 19 (2011)

\section{Siu Hing Lo}

White Collars Green Sleeves

An Interonganizational Comparison of Determinants of Energy-Related Behaviors among Office Workers

MGSoG Dissertation Series, nr 18 (2011)

\section{Treena $\mathrm{Wu}$}

Constraints to Human Capital Investment in Developing Countries:

Using the Asian Financial Crisis in Indonesia as a Natural Experiment

MGSoG Dissertation Series, nr 17 (2011)

\section{Henry Espinoza Peña}

Impact Evaluation of a Job-Training Programme for Disadvantaged Youths:

The Case of Projoven

MGSoG Dissertation Series, nr 16 (2011)

\section{Florian Tomini}

Between Family and Friends

Understanding the Interdependency of Private Transfers

MGSoG Dissertation Series, nr 15 (2010)

\section{Michał Polalowski}

The Institutional Transformation of Social Policy in East Central Europe:

Poland and Hungary in comparative and historical perspective

MGSoG Dissertation Series, nr 14 (2010)

\section{Maha Ahmed}

Defining, Measuring and Addressing Vulnerability:

The Case of Post Conflict Environments

MGSoG Dissertation Series, nr 13 (2010) 
Pascal Beckers

Local Space and Economic Success

The role of spatial segregation of migrants in the Netherlands

MGSoG Dissertation Series, nr 12 (2010)

Victor Cebotari

Conplicting Demands in Ethnically Diverse Societies

Ethnopolitical Contention and Identity Values in Europe

MGSoG Dissertation Series, nr 11 (2010)

Dennis Gyllensporre

Competing and Complementary Perspectives on the EU as a Crisis Management Actor: An Examination of the Common Security and Defence Policy through the Lenses of Idealism and Realism

MGSoG Dissertation Series, nr 10 (2010)

Judit Vall Castello

Business Cycle and Policy Effects on Labour Market Transitions of Older and Disabled Workers in Spain

MGSoG Dissertation Series, nr. 9 (2010)

Keetie Roelen

False Positives or Hidden Dimensions: the definition and measurement of child poverty MGSoG Dissertation Series, nr. 8 (2010)

Denisa Maria Sologon

Earning Dynamics in Europe

MGSoG Dissertation Series, nr. 7 (2010)

Melissa Siegel

Money and Mobility: Migration and Remittances

MGSoG Dissertation Series, nr. 6 (2010) 
Jessica S. Hagen-Zanker

Modest Expectations: Causes and effects of migration on migrant households in source countries

MGSoG Dissertation Series, nr. 5 (2010)

Mirtha R. Muniz Castillo

Human Development and Autonomy in Project Aid: Experiences from four

bilateral projects in Nicaragua and El Salvador

MGSoG Dissertation Series, nr. 4 (2009)

Christiane Arndt

Governance Indicators

MGSoG Dissertation Series, nr. 3 (2009)

Britta Augsburg

Microfinance - Greater Good or Lesser Evil?

MGSoG Dissertation Series, nr. 2 (2009)

Geranda Notten

Measuring and Managing Poverty Risks

MGSoG Dissertation Series, nr. 1 (2008) 